\title{
2011 Wildland Urban Interface Amarillo Fires Report \#2 - Assessment of Fire Behavior and WUI Measurement Science
}

Alexander Maranghides

Derek McNamara

http://dx.doi.org/10.6028/NIST.TN.1909

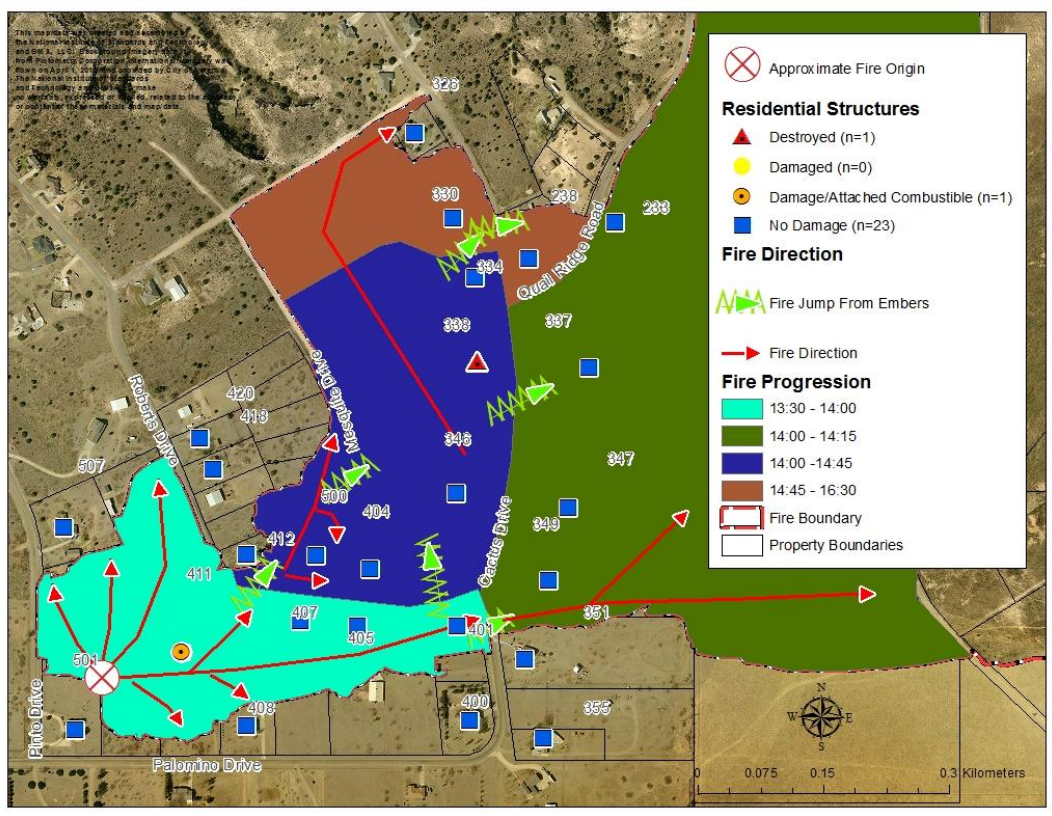

National Institute of Standards and Technology • U.S. Department of Commerce 


\section{Wildland Urban Interface Amarillo Fires Report \#2 - Assessment of Fire Behavior and WUI Measurement Science}

Alexander Maranghides

Fire Research Division

Engineering Laboratory

Derek McNamara

Geospatial Measurement Solutions, LLC

Hood River, OR

This publication is available free of charge from:

http://dx.doi.org/10.6028/NIST.TN.1909

February 2016

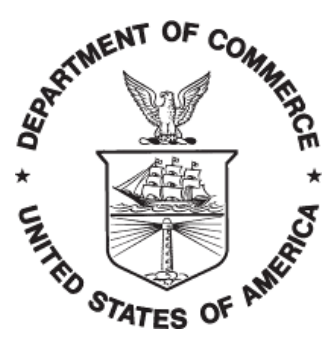

U.S. Department of Commerce Penny Pritzker, Secretary

National Institute of Standards and Technology

Willie May, Under Secretary of Commerce for Standards and Technology and Director 
Certain commercial entities, equipment, or materials may be identified in this document in order to describe an experimental procedure or concept adequately. Such

identification is not intended to imply recommendation or endorsement by the National Institute of Standards and Technology, nor is it intended to imply that the entities, materials, or equipment are necessarily the best available for the purpose.

In accordance with the Metric Conversion Act of 1975 as amended by Section 5164 of the Omnibus Trade and Competitiveness Act of 1988 and as required by related provisions of the Code of Federal Regulations, the National Institute of Standards and Technology (NIST) uses the modern metric system of measurement units (International System of Units; abbreviation: SI) in all publications. When the field of application or the special needs of users of NIST publications require the use of non-SI units, the values of quantities are first stated in SI units and the corresponding values expressed in non-SI units follow in parentheses.

National Institute of Standards and Technology Technical Note 1909 Natl. Inst. Stand. Technol. Technical Note 1909, 153 pages (February 2016) Coden: NTNOEF

This publication is available free of charge from: http://dx.doi.org/10.6028/NIST.ITN.1909
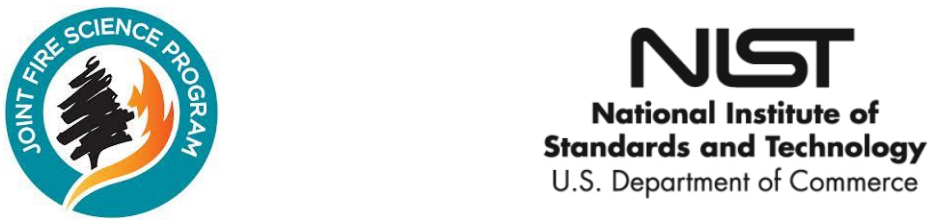

Cover Page Figure: Fire direction, fire road crossings, and general fire progression in Timber Creek Canyon. Prevailing wind direction at time of fire was from the Southwest 


\section{Table of Contents}

Table of Contents .........................................................................................................

List of Tables .......................................................................................................................................... iv

List of Figures............................................................................................................................... vi

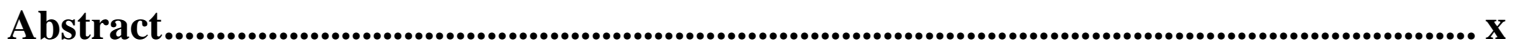

Executive Summary ..................................................................................................................... xi

1.0 Introduction .......................................................................................................................... 1

2.0 Report Objectives, Goals \& Organization........................................................................ 4

3.0 Materials and Methods........................................................................................ 5

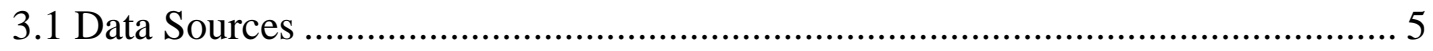

3.2 Field Data Enhancement and Local Data Integration .......................................... 6

3.3 Fire Witness Accounts, Images and Radio Logs ………................................... 8

3.4 Fire Timeline Development .......................................................................... 10

3.5 Topography and Radar.................................................................................. 11

4.0 Study Area, Weather and Event Overview .................................................................... 12

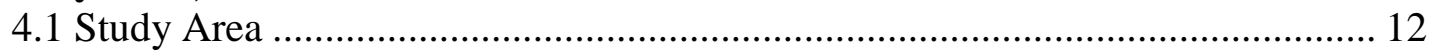

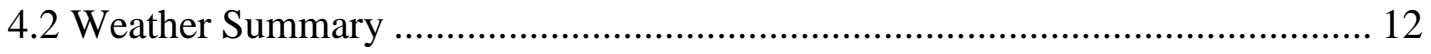

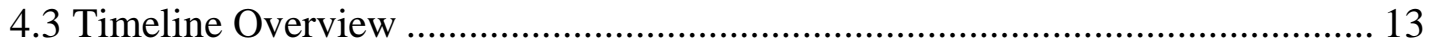

5.0 Timber Creek Canyon Community ................................................................................... 17

5.1 Damage Assessment, Fire Direction, Fire Timeline and Burned Vegetation..... 17

5.2 Defensive Action Categorizations ................................................................... 19

5.3 Topographic Information .......................................................................... 19

5.4 Structural Element Ignition Mechanisms......................................................... 20

5.5 Vegetative Element Ignition Mechanisms ...................................................... 28

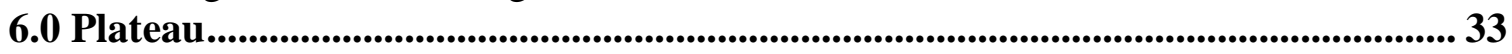

6.1 Damage Assessment, Fire Direction and Fire Timeline ..................................... 33

6.2 Defensive Action Categorizations ...................................................................... 34

6.3 Topographic Information .............................................................................. 34

6.4 Vegetation Element Ignition Mechanisms ......................................................... 34

7.0 Palisades South ............................................................................................................................ 42

7.1 Damage Assessment, Fire Direction and Fire Timeline ..................................... 42

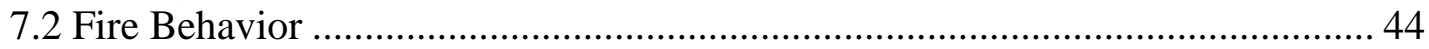

7.3 Defensive Action Categorizations ...................................................................... 45

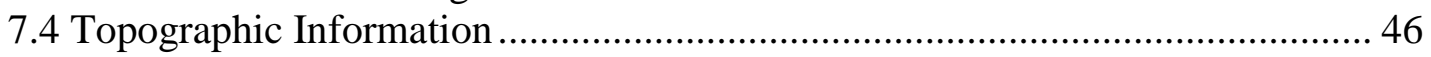

7.5 Structural Element Ignition Mechanisms.......................................................... 46

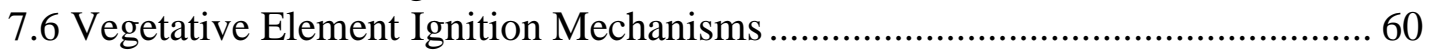

8.0 Palisades North and Tangle Aire...................................................................................... 61

8.1 Damage Assessment, Fire Direction and Fire Timeline ...................................... 61

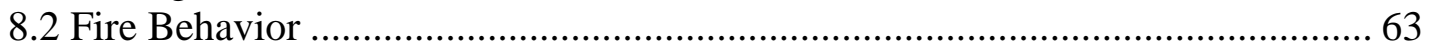

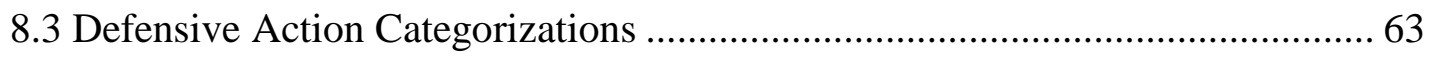

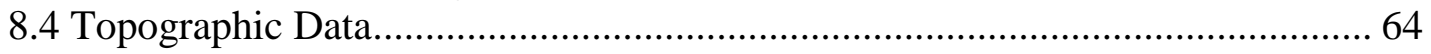

8.5 Structural Element Ignition Mechanisms.......................................................... 64

8.6 Vegetative Element Ignition Mechanisms ........................................................ 72

9.0 North Lake Tanglewood............................................................................................................ 72

9.1 Damage Assessment, Fire Direction and Fire Timeline ...................................... 73

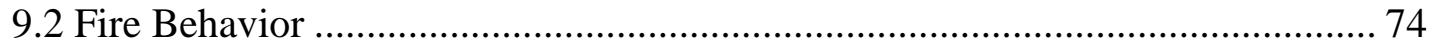


9.3 Defensive Action Categorizations ................................................................. 74

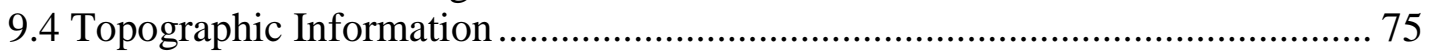

9.5 Structural Element Ignition Mechanisms....................................................... 83

9.6 Vegetative Element Ignition Mechanisms ......................................................... 84

10.0 South Lake Tanglewood ........................................................................................................ 86

10.1 Damage Assessment, Fire Direction and Fire Timeline ................................... 86

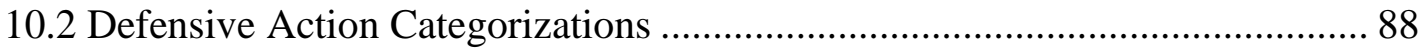

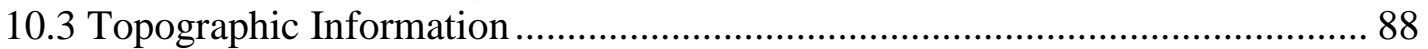

10.4 Structural and Vegetative Element Ignition Mechanisms ................................. 89

11.0 Southeast Lake Tanglewood ...........................................................................................95

11.1 Damage Assessment, Fire Direction and Fire Timeline .................................. 95

11.2 Defensive Action Categorization ................................................................... 95

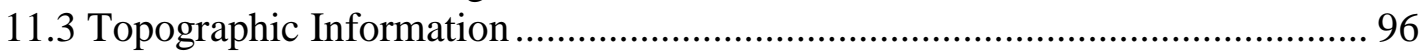

11.4 Structural and Vegetative Element Ignition Mechanisms. ............................... 96

12.0 WUI Assessment Methodology and Science ................................................................ 102

12.1 Pre-fire Hazard Mitigation Guidance and Assessment ................................... 102

12.2 Pre-Fire and Post-Fire Landscaping Characteristics....................................... 103

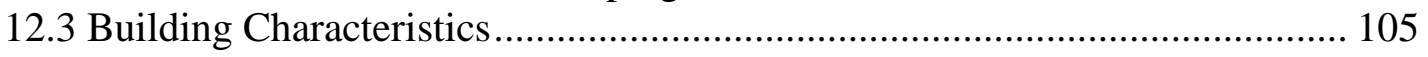

12.4 Topographic Characteristics ...................................................................... 106

12.5 Defensive Actions and Fire Behavior ............................................................ 107

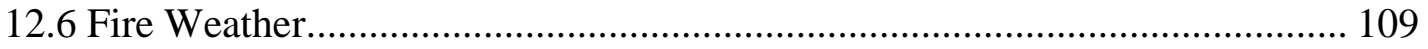

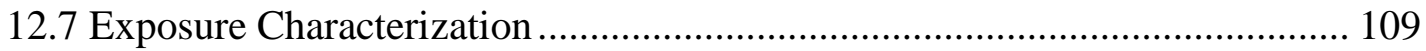

13.0 Technical Findings Summary ....................................................................................... 110

14.0 Recommendations ......................................................................................................... 113

15.0 Conclusions .............................................................................................................. 114

16.0 Acknowledgments ....................................................................................................... 114

Appendix A NIST TN1708 Preliminary Findings ............................................................. 115

Appendix B Unassessed Building Characteristics ....................................................... 117

Appendix C Unconfirmed Defensive Actions...................................................................... 120

Appendix D Suggested Improvements to the NIST WUI Assessment Defensive

Action Methodology ................................................................................................................ 122

Appendix E Aspect Transformations....................................................................................... 124

Appendix F Tabulation of Incident Data and Discussion ............................................. 126

Appendix G Recommendations for Improvements to WUI 2 Data Collection System

Appendix H Example of Pre-Fire WUI Mitigation Advice Form Implemented in Areas Affected by the Tanglewood Fire................................................................................ 138

17.0 References ...................................................................................................................... 143 


\section{List of Tables}

Table 1 Imagery used for post-fire assessment.......................................................... 7

Table 2 Ancillary electronic data sources used in analysis............................................ 8

Table 3 First responder discussions by departments along with known resources allocated

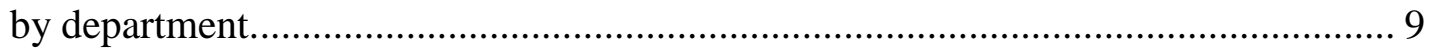

Table 4 KAMA Weather Data Summary …………………………………………...... 13

Table 5 KVII TV Lake Tanglewood Weather Data Summary......................................... 14

Table 6 Damage and destruction to detached combustibles in Timber Creek Canyon... 18

Table 7 Damage and destruction to linear features in Timber Creek Canyon.................. 18

Table 8 Damage and destruction to features in Timber Creek Canyon by defensive

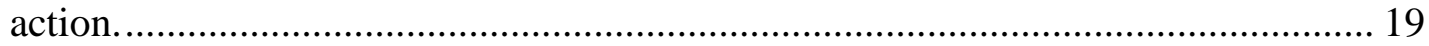

Table 9 Damage and destruction to detached combustibles in Plateau Community....... 34

Table 10 Damage and destruction to linear features in Plateau Community................... 34

Table 11 Damage and destruction to detached combustibles in Palisades South and selected portions of South Lake Tanglewood Community...................................... 42

Table 12 Damage and destruction to linear features in Palisades South and selected portions of Lake Tanglewood Community............................................................. 43

Table 13 Damage and destruction to features in Southern Palisades and selected portions of North Lake Tanglewood categorized by identified defensive actions. ................. 46

Table 14 Damage and destruction to detached combustibles in Palisades North, Tangle Aire and selected portions of North Lake Tanglewood Communities. ..................... 62

Table 15 Damage and destruction to linear features in Palisades North, Tangle Aire and selected portions of North Lake Tanglewood Communities.

Table 16 Damage and destruction to features in Northern Palisades, Tangle Aire and selected portions of North Lake Tanglewood categorized by identified defensive actions.

Table 17 Damage and destruction to detached combustibles in North Lake Tanglewood Community.

Table 18 Damage and destruction to detached linear features in North Lake Tanglewood Community.

Table 19 Damage and destruction to features in North Lake Tanglewood Community categorized by identified defensive actions.......................................................... 75

Table 20 Damage and destruction to detached combustibles in South Lake Tanglewood Community.

Table 21 Damage and destruction to linear features in South Lake Tanglewood Community. 88

Table 22 Damage and destruction to features in South Lake Tanglewood Community categorized by identified defensive actions.

Table 23 Damage and destruction to detached combustibles in Southeast Lake Tanglewood.

Table 24 Damage and destruction to linear features in Southeast Lake Tanglewood Community.

Table 25 Damage and destruction to features in Southeast Lake Tanglewood Community categorized by identified defensive actions..........................................................96

Table 26 Damaged structures with damage status and defensive action........................ 107

Table 27 Eave Material across Residential Structures. 118 
Table 28 Eave Type across Residential Structures ................................................... 118

Table 29 Gutter Material across Residential Structures .............................................. 118

Table 30 Roof and Gutter Debris across Residential Structures.................................... 119

Table 31 Shutter Material across Residential Structures ............................................... 119

Table 32 Window Frame Type across Residential Structures ...................................... 119

Table 33 Window Pane Type across Residential Structures ......................................... 119

Table 34 Anecdotal Defensive Actions ....................................................................... 121

Table 35 Issues and possible corrections with defensive action data collection

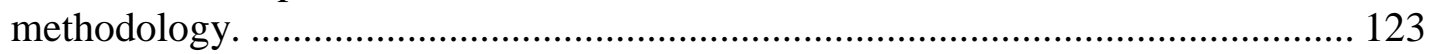

Table 36 Damage status of residential structures by structure type.............................. 128

Table 37 Damage status of residential structures by exterior type................................ 128

Table 38 Damage status of residential structures by roof type...................................... 129

Table 39 Damage status of residential structures by foundation type (NIST/TFS)....... 129

Table 40 Damage status of residential structures by foundation type (Potter-Randall

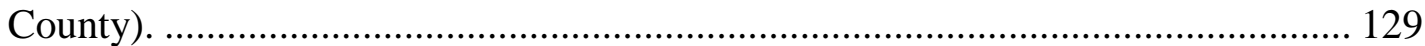

Table 41 Damage status of residential structures by chimney presence........................ 129

Table 42 Damage status of residential structures by mean aspect $(5 \mathrm{~m}((16.4 \mathrm{ft}))$ radar derived) within $9.1 \mathrm{~m}(30 \mathrm{ft})$ around the structure .............................................. 130

Table 43 Damage status of residential structures by mean aspect $(5 \mathrm{~m}((16.4 \mathrm{ft}))$ radar derived) within $30.5 \mathrm{~m}(100 \mathrm{ft})$ around the structure........................................... 130

Table 44 Damage status of residential structures by mean aspect $(5 \mathrm{~m}((16.4 \mathrm{ft}))$ radar derived) within $61.0 \mathrm{~m}(200 \mathrm{ft})$ around the structure.......................................... 130

Table 45 Damage status of residential structures by mean aspect $(5 \mathrm{~m}((16.4 \mathrm{ft}))$ radar derived) within $91.4 \mathrm{~m}(300 \mathrm{ft})$ around the structure............................................ 131

Table 46 Damage status of residential structures by mean slope $(5 \mathrm{~m}((16.4 \mathrm{ft}))$ radar derived) within $9.1 \mathrm{~m}(30 \mathrm{ft})$ around the structure............................................... 131

Table 47 Damage status of residential structures by mean slope $(5 \mathrm{~m}((16.4 \mathrm{ft}))$ radar derived) within $30.5 \mathrm{~m}(100 \mathrm{ft})$ around the structure............................................ 131

Table 48 Damage status of residential structures by mean slope $(5 \mathrm{~m}((16.4 \mathrm{ft}))$ radar derived) within $61.0 \mathrm{~m}(200 \mathrm{ft})$ around the structure.

Table 49 Damage status of residential structures by mean slope $(5 \mathrm{~m}((16.4 \mathrm{ft}))$ radar derived) within $91.4 \mathrm{~m}(300 \mathrm{ft})$ around the structure.............................................. 132 


\section{List of Figures}

Figure 1 Overview of WUI Assessment Methodology used here. ................................... 3

Figure 2 General procedures used in this report on the Tanglewood Fire. Pre-season training and property level data collection methods are described in NIST TN 1708.

Figure 3 Fire affected communities showing number of structures and percent destroyed by community. 15

Figure 4 General Timeline and fire direction observations generalized from radio logs, fire images, and post-fire data collection.

Figure 5 Damage to structural elements in Timber Creek Canyon. ................................ 21 Figure 6 Fire direction, fire road crossings, and general fire progression in Timber Creek

Canyon. Prevailing wind direction at time of fire was from the Southwest. ........... 22

Figure 7 Specific time observations and general fire behavior in Timber Creek Canyon.23 Figure 8 Defensive action areas and primary structure categorizations in Timber Creek Canyon. Larger structures shown in imagery and not categorized to a defensive action status are secondary buildings and not residential. ....................................... 24

Figure 9 Radar derived percent slope in Timber Creek Canyon. .................................... 25

Figure 10 Radar derived aspect in Timber Creek Canyon............................................ 26

Figure 11 Ignition mechanisms in and around 411 Roberts Drive, close to the fire origin.

Structure was defended

Figure 12 Ignition mechanisms around non-damaged or non-destroyed residential structures in Timber Creek Canyon, NIST photos................................................ 30

Figure 13 Structural element ignition mechanisms at 338 Cactus Drive. Structural elements portrayed are known or suspected to be ignited prior to residential structure ignition. Fire direction was from southeast to northwest and the attached fence was on the north of the destroyed home, NIST photos.

Figure 14 Pre-fire and post-fire imagery showing how vegetation treatments or landuse might have effected fire behavior. Approximate fire line is shown in red on image to the right.

Figure 15 Damage to structural elements in the Plateau Community. ............................ 35

Figure 16 Fire direction and fire timeline in Plateau Community. All times are on $2 / 27 / 2011$

Figure 17 Plateau area defensive action locations and primary structure categorizations in

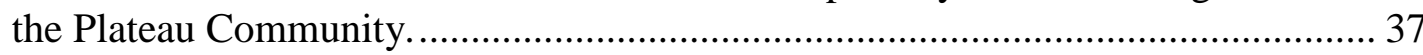

Figure 18 Radar derived percent slope in Plateau area.............................................. 38

Figure 19 Radar derived aspect in Plateau Community............................................... 39

Figure 20 Treated vegetation around 209 Quail Ridge Road that might have helped to stop fire from contacting house. Exact contributions of defensive actions are unknown.

Figure 21 Two distinct vegetation ignitions adjacent to structure at 209 Quail Ridge

Road. Red feature is $15 \mathrm{~cm}$ (6 in) long ballpoint pen, NIST photos.

Figure 22 Damage to structural elements in the southern Palisades Community and selected portions of the South Lake Tanglewood Community.....

Figure 23 Fire direction in Southern Palisades and South Lake Tanglewood Community. The main fire front moved through area between 14:30 and 15:30 on 2/27/2011 .. 48 
Figure 24 Palisades South and portions of South Lake Tanglewood with specific time observations on $2 / 27 / 2011$.

Figure 25 General fire behavior observations and location of retardant drop in southern Palisades community and portions of South Lake Tanglewood. 50

Figure 26 Post-fire south facing oblique imagery showing results of higher intensity fire on the southeastern side (northeast facing) of the canyon .................................. 51

Figure 27 Post-fire south facing oblique imagery showing results of fire behavior in the upper portion of the middle canyon area of Southern Palisades Community........... 52

Figure 28 Post-fire east facing oblique imagery showing results of fire behavior in the bottom of the middle canyon area of Southern Palisades Community.................... 53

Figure 29 Post-fire south facing oblique imagery showing results of fire behavior in the eastern most canyon area of the Southern Palisades and South Lake Tanglewood Communities.

Figure 30 Defensive action locations and primary structure categorizations in Southern Palisades and selected areas of South Lake Tanglewood Communities.

Figure 31 Radar derived percent slope in Palisades South and selected portions of South Lake Tanglewood Communities....................................................................... 56

Figure 32 Radar derived aspect in Palisades South and selected portions of South Lake Tanglewood Communities.

Figure 33 Burned hay bales leading from destroyed secondary structure to primary structure causing scorching on the brick siding. Categorization of defensive actions is unknown, NIST photo.

Figure 34 Unidentified burned features adjacent to the northern side of the residential structure at 102 Gary Drive. These features are believed to be ignited by the burning mobile home to the north of the brick residential structure, NIST photo.

Figure 35 A: Stand replacing fire in the canyon to the west of 102 Gary Drive. B: Vegetation and building features with minimal damage at the top of the canyon, indicating topographically influenced fire behavior. Image taken from the south side of 102 Gary Drive looking north, NIST photos.

Figure 36 Portions of the fire perimeter overlaid on pre-fire (2009) color-infrared imagery. Fire did not travel into redder residential grass areas. This could be due to exposure conditions, defensive actions, pre-fire vegetation treatment or a combination of these factors.

Figure 37 Damage to structural elements in the northern Palisades, Tangle Aire and selected portions of North Lake Tanglewood Communities.

Figure 38 Fire direction and fire timeline in north Palisades, Tangle Aire and selected portions North Lake Tanglewood Communities. The main fire front moved through this area between 15:00 and 15:30 on 2/27/2011. A wind shift occurred later on $2 / 27 / 2011$ that caused flare-ups and fire direction from the north. The second fire front, portrayed as an orange arrow above, was observed as one fire direction indicator in the field observed through radiant heat damage and confirmed through eyewitness observations.

Figure 39 Palisades North, Tangle Aire and portions of North Lake Tanglewood specific time observations on 2/27/2011 from radio logs and images. 114 Palisades Boulevard was destroyed late in the night of 2/27/2011 or in the early morning hours of $2 / 28 / 2011$ after a wind shift from the north occurred. It is believed all other destroyed structures burned before 17:00 on 2/27/2011. 
Figure 40 Fire behavior observations in Palisades North, Tangle Aire and portions of Lake Tanglewood North communities.

Figure 41 Defensive action locations and primary structure categorizations in Northern Palisades, Tangle Aire and selected areas of North Lake Tanglewood Communities.

Figure 42 Radar derived percent slope in Northern Palisades, Tangle Aire and selected areas of North Lake Tanglewood Communities. ................................................... 70

Figure 43 Radar derived aspect in Northern Palisades, Tangle Aire and selected areas of

North Lake Tanglewood Communities................................................................. 71

Figure 44 Ignited deck, which was extinguished by homeowners, NIST photo. ............ 72

Figure 45 Fully involved residential structure at 128 Exmoor Road igniting residential structure at 130 Exmoor Road, Photo Gordon Ivy, used by permission................... 72

Figure 46 Field delineated burned vegetation around Tangle Aire Point overlayed on a false color composite pre-fire image. Red areas show healthy photosynthetically

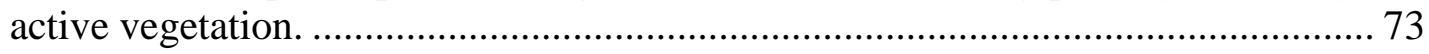

Figure 47 Damage to structural elements in the North Lake Tanglewood Community... 76 Figure 48 Fire direction and fire timeline in North Lake Tanglewood Community. The main fire front moved through the area between $15: 00$ and 18:30 on 2/27/2011 .... 77

Figure 49 North Lake Tanglewood specific time observations on 2/27/2011 from radio logs and images................................................................................. 78

Figure 50 Fire behavior changes coincident with topography. Side directly exposed to wind (left) saw limited scorching and no torching of trees in post-fire imagery, and a low intensity ground fire during Amarillo Sheriff Helicopter flight. Side not facing wind (right) exhibited scorching and torching of trees in post-fire imagery, and a high intensity crown fire during helicopter flight was observed.

Figure 51 Defensive action locations and primary structure categorizations in North Lake

Tanglewood Community. 80

Figure 52 Radar derived percent slope in North Lake Tanglewood Community............. 81

Figure 53 Radar derived aspect in North Lake Tanglewood Community. ...................... 82

Figure 54 Partially destroyed fence at 100 Camino Alto, NIST photo............................ 83

Figure 55 Defended firewood pile at 100 Camino Alto, NIST photo. ............................ 83

Figure 56 Damaged wooden bench and burned and unburned vegetation on west side of

100 Camino Alto, NIST photo.

Figure 57 Partially destroyed wood fence, which caused scorching to brick siding and melting of vinyl soffit, NIST photo.

Figure 58 Burnt hedgerow and Buffalo grass that facilitated fire spread to destroyed secondary structure at 105 Port-O-Call Drive, NIST photo.

Figure 59 Pre-fire false color imagery showing redder areas that did not burn along with brown to black areas that did burn. In some locations the fire perimeter ended where these red, photosynthetically active, areas began and interior, red, photosynthetically active areas did not burn. 86

Figure 60 Damaged pergola roof ignited by embers, NIST photo. ............................... 89 Figure 61 Damage to structural elements in the South Lake Tanglewood Community... 90 Figure 62 Fire direction and fire timeline in South Lake Tanglewood Community. ...... 91 Figure 63 Defensive action locations and primary structure categorizations in South Lake Tanglewood Community. ................................................................................. 92

Figure 64 Radar derived percent slope in South Lake Tanglewood Community............ 93 
Figure 65 Radar derived aspect in South Lake Tanglewood Community. 94

Figure 66 Damage to structural elements in the Southeast Lake Tanglewood Community.

Figure 67 Fire direction in Southeast Lake Tanglewood Community. The main fire front moved through area by 18:21 on 2/27/2011 based on Amarillo Sheriff Helicopter flight. 98

Figure 68 Southeast Lake Tanglewood Community defensive action locations and primary structure categorizations 99

Figure 69 Radar derived percent slope in Southeast Lake Tanglewood Community..... 100 Figure 70 Radar derived aspect in Southeast Lake Tanglewood Community................ 101 Figure $71 \mathrm{~A}$ : Image of burned vegetation right after the main fire front moved through the

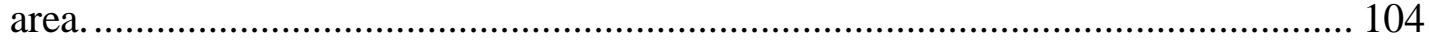

Figure 72 Residential structures by appraised building values and by damage status. .. 127 Figure 73 Residential structures by effective year built and by damage status............ 128

Figure 74 Erroneous field collected burn vegetation boundary ................................. 136 


\section{Abstract}

On February 27, 2011, three fires began in the outskirts of Amarillo, Texas, two of which destroyed or damaged buildings in multiple housing developments. The National Institute of Standards and Technology (NIST), as part of its Disaster and Failure Studies Program, began gathering electronic data for the incident within 6 hours of the Tanglewood fire front moving through the Palisades Community in Lake Tanglewood. NIST and the Texas Forest Service (TFS) integrated a field data collection team into the Incident Command System (ICS) within 48 hours to conduct a post-fire assessment. Initially, both the Willow Creek South Complex and Tanglewood Complex fires were assessed. Within 72 hours after ICS integration, the Tanglewood Fire became the focus of the deployment. The deployment also supported local and state damage assessment efforts.

This assessment represented the first deployment of the NIST Wildland Urban Interface (WUI) 2 field data collection method where logistics and standard operating procedures (SOPs) were integrated into the ICS. Information was collected in the field related to residential structures, combustible features, non-combustible features, fire direction, fire timeline, burned vegetation and defensive actions. Documentation included over 29000 ground photographs, 2330 geolocated man-made features, 281 distinct records of burned vegetation, and discussions with 48 first responders and homeowners. Pre-fire and postfire aerial imagery as well as radar data were acquired for the study area. All of the data collected was entered into a Geographic Information System (GIS) database, which is being prepared for public dissemination.

This report represents the second report for the Tanglewood Complex Fire. The first report, NIST Technical Note 1708, provided information on all three fires and provided an overview of possible technical factors affecting the damage, failure, and/or successful performance of buildings and/or infrastructure in the aftermath of the fire. The first summary report addressed the particulars of the deployment. Additionally, the first report provided a summary of the primary structures lost.

This second report provides the event timeline reconstruction and general fire behavior observations. Additionally, a general assessment of defensive actions is presented to show the spatial extent of these actions and identify potential structure and parcel level ignition mechanisms. Topographic characteristics within the affected communities are discussed. This report also details structural and vegetative element ignition mechanisms throughout the communities affected by the Tanglewood Fire. A discussion of current WUI mitigation information is conducted in the context of applicable hazard mitigation for the affected communities and an assessment of WUI fire measurement science is presented.

KEY WORDS: Amarillo fires, community fires, fire data collection, fire behavior, Tanglewood Fire, Wildland Urban Interface, WUI, WUI data collection 


\section{Executive Summary}

On February 27, 2011, three fires - the Willow Creek Complex, the Tanglewood Complex, and the Country Club - began on the outskirts of Amarillo, Texas. The Tanglewood Complex fire was the main focus of this case study. Out of the 183 buildings exposed, 35 structures were destroyed and 13 were damaged in multiple housing developments. The National Institute of Standards and Technology (NIST), as part of its Disaster and Failure Studies Program, began gathering data for the incident within 6 hours of the Tanglewood fire front moving through the Palisades Community in Lake Tanglewood. NIST and the Texas Forest Service (TFS) integrated a field data collection team into the Incident Command System (ICS) within 48 hours to conduct a post-fire assessment. Initially, both the Willow Creek South Complex and Tanglewood Complex fires were assessed. Within 72 hours after ICS integration, due to resource limitations, the Tanglewood Fire became the focus of the deployment. The deployment also supported local and state damage assessment efforts.

NIST has developed a two tiered approach, documented in NIST Technical Note 1708, to enable the collection of reliable Wildland Urban Interface (WUI) fire data. The first tier, called WUI 1, was used to collect general data across the entire perimeter of the Tanglewood Complex fire, while the second tier, WUI 2, was used to collect in-depth fire behavior, timeline, defensive action and structural performance data.

This assessment was the first deployment of the NIST WUI 2 field data collection method where logistics and standard operating procedures (SOPs) were integrated into the ICS. Information was collected in the field related to residential structures, combustible features, non-combustible features, fire direction, fire timeline, burned vegetation and defensive actions. Documentation included over 29000 ground photographs, 2330 geolocated man-made features, 281 distinct records of burned vegetation and discussions with 48 first responders and homeowners. Pre-fire and postfire aerial imagery as well as radar data were acquired for the study area. All of the data collected was entered into a Geographic Information System (GIS) database, which is being prepared for public dissemination.

This is the second report about the Tanglewood Complex Fire. The first report provided information on all three fires and provided an overview of possible technical factors affecting the damage, failure, and/or successful performance of buildings and/or infrastructure in the aftermath of the fire. The first summary report, NIST TN 1708, provided a summary of the primary structures lost.

This second report provides the event timeline reconstruction and general fire behavior observations. Additionally, a general assessment of defensive actions is presented to show the spatial extent of these actions and identify potential ignition mechanisms. Out of the 183 structures in the study domain 82 (45\%) were identified as having been defended during the fire.

Topographic characteristics within the affected communities are discussed. This report also details structural and vegetative element ignition mechanisms throughout the communities affected by the Tanglewood Fire. A discussion of current WUI mitigation information is conducted in the context of applicable hazard mitigation for the affected communities and an assessment of WUI measurement science is presented. 
It has been found that the lack of evidence of a defensive action around a particular structure or feature does not mean that a defensive action did not occur on that feature. Additionally defended damaged structures, in many cases, did not show direct signs of defensive actions. Without the evidence and comprehensive documentation of defensive actions, the field observations can be wrongly interpreted as self-extinguishment.

Relatively recent technologies like automated vehicle location (AVL) systems, mobile phones, global positioning systems (GPS) and imaging technologies like GoPro ${ }^{\mathrm{TM}}$ allow recording of real time fire information to better understand fire timeline information.

Many features including fences and railroad ties (landscaping timbers) were recorded as being defended multiple times by different first responders highlighting the features' long lasting potential to generate flames and embers, therefore increasing the hazard to nearby unburned structures.

In examining the ignition of residential structures, it was found that secondary structures if ignited can, expose primary residences under certain conditions to increased hazardous conditions. Secondary structures are frequently not addressed in hazard mitigation guidance. It was also found that embers and fire generating combustibles, both detached and attached, included fences, decks, railroad ties (used as landscaping timbers), mulch beds, attached stairs and piles of firewood. Detached combustibles, in numerous cases, ignited prior to the primary structure and resulted in the ignition of the primary structure. In numerous cases, defensive actions prevented structure ignition of primary and secondary structures.

The post-fire scene represents the final product of the interactions among exposure, defensive actions and the response of fuels (vegetative or urban) to the actual received exposure. The exposure itself is a function of fuels, topography and the local weather. It was found that the exposure, defensive action and weather can vary with time. There can be numerous fire fronts, wind shifts and multiple defensive actions all taking place at different times. The exposure from a fire burning up to or near a structure varied significantly throughout the incident. In some cases, a very low intensity fire reached the structure walls while in other cases very severe exposure was experienced by the structure without fuel reaching all the way to the structure walls. In numerous locations, steep slopes or cliffs appeared to stop fire spread in both the upward and downward direction. It should be noted that fire direction observations from the field should not be interpreted without utilizing a detailed event timeline, as multiple fire fronts or changes in wind direction can occur during the fire incident.

A number of technical findings were identified with respect to data collection and analysis. The complexities of collecting field data with sufficient temporal and spatial resolution make the quantification of exposure in the post-fire environment extremely difficult to complete. There can be, however, great value in a qualitative assessment of exposure as this information can be used, in first order, to determine how the event developed and which homes were exposed to significant fire and embers, and which homes were not. This report shows that the information collected from detailed post-fire case studies is more useful for assessing hazard mitigation technology failures than for quantifying successes. 
The timely collection of aerial imagery was identified as a significant data collection issue, with data being lost with time. Additionally, it was determined that wildlands and residential vegetation data is critical to characterizing fire behavior through the WUI community.

It was also determined that remote sensing data collection combined with field assessments presents the best means to obtain pre-fire and post-fire vegetation information. It should be noted that, even if aerial imagery is collected early, ground based imagery still has to be collected. This is necessary as aerial imagery lacks the ability to identify understory conditions for both pre-fire and post-fire conditions, and even Light Detection and Ranging (LiDAR) data will vary in its ability to identify understory conditions.

In looking at specific building attributes (such as siding type or eaves construction), it was confirmed that analysis of structural treatments is possible only when reliable prefire information exists. The availability of pre-fire data is very incident/community specific and affects what can be investigated at each incident. This was also identified at the Witch/Guejito case study. Additionally, it was determined that many structure

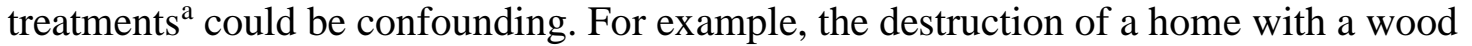
roof does not mean the wood roof was the cause of the destruction. Without eyewitness accounts of the exposure and subsequent destruction it is impossible to determine the ignition sequence.

The Tanglewood Complex post-fire data collection and analysis resulted in a number of technical findings, including seven on structure ignition and hazard mitigation, five on defensive actions, eight on exposure and fire behavior, and fourteen on data collection and analysis methodologies. The technical findings identified in this case study are applicable at the interface of wildland and urban areas. The data collection and analysis findings will also apply at the Wildland Urban Intermix ${ }^{\mathrm{b}}$.

The five primary findings are listed here:

1. Information collected from detailed post-fire case studies is more useful for assessing hazard mitigation technology failures than for quantifying successes (data collection and analysis methodologies).

2. Damaged structures provided more useful information compared to destroyed structures, as building materials and ignition location were more reliably identified (structure ignition and hazard mitigation).

3. Damaged structures, which were defended, in many cases did not show direct signs of defensive actions. Without the collection of defensive action data, the effectiveness of hazard treatments can be wrongly interpreted (defensive actions).

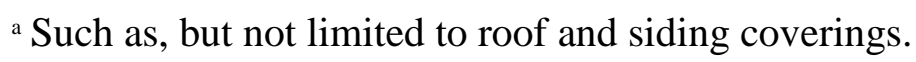

b The term wildland-urban intermix refers to a specific type of wildland-urban interface in which the homes or other structures are intermixed with wildland fuels, as opposed to a distinct area of wildland fuel adjacent to a developed area. 
4. Remote sensing combined with field assessments presents the best means to obtain pre-fire and post-fire vegetation information (data collection and analysis methodologies).

5. Mapping of existing hazards in WUI communities without the use of weighted attributes ${ }^{\mathrm{c}}$ provides a means for identification of existing hazards (manmade and natural). This will provide potential for removal of hazards by homeowners and land managers, and recognition by first responders during fires (structure ignition and hazard mitigation).

The specific findings on structure ignition and hazard mitigation areas include:

1. Out of the 183 structures documented in this case study, 35 homes were destroyed, and 13 were damaged.

2. Secondary structures such as sheds, garages, etc., when ignited, generated a significant amount of embers, exposing primary residences under certain conditions to increased hazardous conditions.

3. Mapping of existing hazards in WUI communities without the use of weighted attributes provides a means of identification of existing hazards (manmade and natural), thereby providing potential for removal of hazards by homeowners and land managers, and recognition by first responders during fires.

4. Ember and fire generating combustibles, both detached and attached to residential structures, include fences, decks, railroad ties, mulch beds, attached stairs and piles of firewood.

5. Detached combustibles, in numerous cases, ignited prior to the primary structure and were then responsible for the ignition of the structure.

6. Damaged structures, which were defended, in many cases did not show direct signs of defensive actions. Without evidence and documentation of defensive action data, the effectiveness of hazard treatments can be wrongly interpreted.

7. The exposure from a fire burning up to or near a structure varied significantly across the incident. In some cases, a very low intensity fire reached the structure walls, while in other cases very severe fire exposure was experienced by the structure even without fuel reaching all the way to the structure walls.

The findings on defensive actions include:

8. Out of the 183 structures in the study, 82 (45\%) were identified through technical discussions as having been defended during the fire.

9. The lack of evidence of a defensive action around a particular structure or feature does not mean that a defensive action did not occur on that feature. This implies that due diligence in collecting data from first responders is necessary.

10. Same as technical finding \#6 (above).

11. Many features including fences and railroad ties were recorded as being defended multiple times by different first responders. This is consistent with the features' long

${ }^{\mathrm{c}}$ Current WUI Fire hazard rating systems rely on very limited technical information to develop weighted ratings. Due to this limited technical information such weighed systems can provide erroneous assessments of actual hazards. 
lasting potential to generate flames and embers. These items increased the hazard to nearby unburned structures.

12. Relatively recent technologies such as AVL systems, mobile phones, GPS and imaging technologies allow for recording of real time fire information that could help better understand fire timeline information.

The findings on exposure and fire behavior include:

13. Fire moved from the fire origin, in the vicinity of 501 Pinto Drive, and crossed Cactus Road into the wildlands to the east of Timber Creek Canyon (a linear distance of approximately $500 \mathrm{~m}(1640 \mathrm{ft}$.)) in about $30 \mathrm{~min}$ or less.

14. The post-fire scene represents the final product of the interactions between exposure, defensive actions and the response of fuels (vegetative or urban) to the actual received exposure. This was also identified in the Witch/Guejito case study.

15. Fire and ember exposure onto a target was a complex function of fuels, topography and the local weather. The interaction between topography and weather significantly affected local exposure conductions. Parcel aspect in combination with local prevailing winds sometimes had a significant impact on local exposure conditions.

16. The exposure, defensive actions, and weather vary with time. There were numerous fire fronts, wind shifts and multiple defensive actions all taking place at different times.

17. Fire burned more intensely along the leeward side of canyons and drainages.

18. Topographic features that significantly affected fire behavior were in many cases less than $40 \mathrm{~m}(130 \mathrm{ft})$ in length, such as terracing around a structure.

19. In numerous locations, steep slopes or cliffs appeared to stop fire spread in both the upward and downward directions.

20. Fire direction observations from the field were misleading without utilizing a detailed event timeline, as multiple fire fronts or changes in wind direction occurred during the fire incident.

The findings on data collection and analysis methodologies include:

21. Electronic data collection systems are essential in capturing the multidimensional data and interactions between topography, fuels, weather and defensive actions associated with WUI fires.

22. Same as technical finding \#14 (above).

23. Complexities of collecting field data with sufficient temporal and spatial resolution make the quantification of exposure in the post-fire environment difficult. There is, however, great value in a qualitative assessment of exposure as this information can be used, in first order, to determine how the event developed and which homes were exposed to significant fire and embers and which homes were not.

24. Information collected from detailed post-fire case studies is more useful for assessing hazard mitigation technology failures than for quantifying successes.

25 . There is a lack of clear guidance provided to first responders for documenting incidents in real time, as well as collecting, sorting and storing incident images and video.

26. Data collected on vegetation both for the wildlands and in the community were important to understand the fire behavior. 
27. There is currently no established post-fire data collection methodology to estimate vegetative fuel consumption.

28. Remote sensing combined with field assessments presents the best means to obtain pre-fire and post-fire vegetation information, as aerial imagery and LiDAR lacks the ability to identify understory conditions for both pre-fire and post-fire conditions.

29. Post fire data loss based on aerial imagery increased with time of acquisition after the fire.

30. Analysis of the effectiveness of structure treatments requires pre-fire data for comparison. This was also identified during the Witch/Guejito case study, NIST TN 1635.

31. Many structure treatments could confound the analysis/interpretation of structure performance during a WUI fire. For example, the destruction of a home with a wood roof does not mean the wood roof was the cause of the destruction. Without eyewitness accounts of the destruction, it is impossible to determine the ignition sequence.

32. Damaged structures provided more useful information compared to destroyed structures, as building materials and ignition location were more reliably identified.

33. There are no case studies similar to this one at the Wildland Urban Intermix, resulting in very limited understanding of how to effectively implement mitigation techniques in that environment.

34. Currently, there is a no validated physics based fire model capable of providing a better understanding of appropriate scales for assessing and analyzing WUI environments.

As a result of this study, the following are the five primary technical recommendations:

1. Adequate technologies need to be developed and deployed to document the event including first responder actions. - Technical finding \#12.

2. The coupling of wind and fire behavior needs to be better characterized, including the quantification of wind flow through topographically complex communities. This is necessary in order to quantify fire behavior at the WUI - Technical finding \#15.

3. Standardized electronic data collection systems need to be implemented to capture post-fire data - Technical finding \#21.

4. Clear guidance need to be developed for first responders to document incidents in real time, as well as collect, sort and store incident images and video - Technical finding \#25.

5. Pre-fire WUI mitigation advice needs to involve vegetative sampling of wildlands in close proximity to residential structures using standardized plot based techniques Technical finding \#26.

Additionally there are three recommendations that will improve community resilience to WUI fires by conducting specific research activities as well as data collection. These are:

1. Heat fluxes and ember fluxes from wildland and urban interface fuels need to be quantified in both wildfire and controlled environments - Technical finding \#3.

2. A methodology needs be developed to estimate vegetative fuel consumption in a postfire environment. Collection of this information should not be limited to residential areas and should continue into the wildlands - Technical finding \#27. 
3. Case studies similar to this one need be conducted at the Wildland Urban Intermix Technical finding \#33. 


\subsection{Introduction}

On February 27, 2011, three fires began on the outskirts of Amarillo, Texas, two of which destroyed or damaged buildings in multiple housing developments. The National Institute of Standards and Technology (NIST), as part of its Disaster and Failure Studies Program, began gathering electronic data for the incident within 6 hours of the Tanglewood fire front moving through the Palisades Community in Lake Tanglewood. NIST and the Texas Forest Service (TFS) integrated a field data collection team into the Incident Command System (ICS) within 48 hours to conduct a post-fire assessment. Initially, both the Willow Creek South Complex and Tanglewood Complex fires were assessed. Within 72 hours after ICS integration, due to resource limitations, the Tanglewood Fire became the focus of the deployment. The deployment also supported local and state damage assessment efforts.

NIST has an active program to study the risk to buildings and communities from wildland fires. The areas at risk are termed the wildland-urban interface (WUI). NIST has statutory authority to deploy teams of technical experts to conduct disaster studies under the NIST Organic Act as amended by the America Competes Act of 2010 and the Fire Prevention and Control Act of 1974. Findings derived from WUI studies are being developed to improve building and landscaping standards, codes, and practices as well as improving measurement science associated with the WUI.

Current information regarding the WUI is based on anecdotal information and limited assessment of post-fire conditions in the context of the entire fire disturbance continuum. ${ }^{1}$ Frequently, a structure and its response is only evaluated by looking at the post-fire environment without context of fire and ember exposure, local weather, and the potential impact of defensive actions. Geographic data sets portraying the basic geographic distribution of WUI destruction are limited to coarse scale assessments ${ }^{2,3}$ with no significant spatial-temporal database of WUI destruction at the parcel level existing. Efforts to categorize wildland fire behavior are in their infancy. ${ }^{4}$ Categorization of fire behavior in the WUI is even less developed with only a basic framework currently presented on how to proceed with categorization of fire behavior in the wildland and WUI. ${ }^{5}$

The lack of rigorous WUI fire studies is a reflection of the current state of technology required for complete assessment of the WUI. The emerging technology is just beginning to reach a level of sophistication that is commensurate with the complexities of the event. Technology systems that are still being developed and refined for WUI applications include remote sensing, heat and ember flux measurements, vegetation characterization, unmanned aerial systems, geographical linked information systems (GIS), and automated vehicle location systems.

The result has been studies that only examine partial populations, ${ }^{6}$ do not assess exposure conditions ${ }^{7}$ or do not present details on how exposure conditions and fire timelines were determined, but still give recommendations on WUI mitigation advice. ${ }^{8}$ Maranghides et al. ${ }^{9}$ categorized the fire timeline, defensive actions and exposure conditions and identified a limited number of structure and parcel-level fire vulnerabilities for a community affected by the 2007 Witch and Guejito fires. 
Without comprehensive WUI data, extensive post-fire analyses, and science-based understanding of the WUI fire phenomena, current WUI mitigation guidance is based on anecdotal experience of first responders. First responders provide valuable expert knowledge. It is not, however, the responsibility of first responders to scientifically assess fire behavior at WUI incidents nor the response of structures to the fire. Therefore, and due to the limited perspective any individual first responder can have at one incident, development of WUI mitigation guidance based on expert opinion of those defending incidents is at best limited and possibly dangerous. As an example, an observation may be made that a structure survived the fire assault, with limited knowledge of previously conducted defensive actions.

WUI building codes and standards are also limited by the same lack of data, analyses, and science. Current WUI codes and test standards have adapted and extended existing design and material performance standards from urban structure-based codes, but the testing conditions do not adequately reflect WUI fire conditions. For example, in WUI codes and standards such as NFPA $1144,{ }^{10}$ specific separation distances, such as $30 \mathrm{~m}$ $(98 \mathrm{ft})$ are required to prevent ignition by wildfires. Separation distances or buffer zones may be effective in preventing ignition by thermal radiation, but are not effective against firebrands, which have been documented to travel $200 \mathrm{~m}$ to $300 \mathrm{~m}(656 \mathrm{ft}$ to $984 \mathrm{ft}){ }^{\mathrm{d}}$ More effective codes and standards will require better understanding of the underlying science of WUI fire phenomena.

There is a need for post-fire assessments to categorize all aspects of the fire incident, from pre-fire conditions, through ignition and fire spread, to suppression and post-fire recovery (Fire Disturbance Continuum). ${ }^{1}$ NIST has been developing a WUI Assessment Methodology to address this need. Through the development of this methodology, NIST is identifying the measurement science required to categorize all aspects of the fire disturbance continuum by attempting to gather data on the following key items:

1. Pre-Fire conditions of the entire WUI environment being studied.

2. Defensive actions that occurred during the fire.

3. Documented evidence of incident time of burning features (e.g. from images during the fire and local weather conditions).

4. Post-fire assessment of the entire area, focusing on documentation of the entire extent of damage and destruction to the wildland and built environments being studied and exposed undamaged features being assessed.

In theory, the above data would be used to categorize defensive actions, develop the timeline of fire damage and destruction, and quantify fire and ember exposure. Collection of the above type of data to divide the respective WUI area into pertinent populations of exposure is believed to be an essential step in evaluation of the WUI fire. The data is needed to answer questions such as "What structures were exposed to thermal flux, flame contact, and firebrands, and when were these populations of structures exposed." This idealized data analysis methodology is presented in Figure 1.

\footnotetext{
${ }^{\mathrm{d}}$ While embers have been documented to travel many kilometers, the majority of both vegetative and structural embers is causing ignitions in the first 200 to 300 meters ahead of the wildland fire front or burning building. Waldo case study report in progress.
} 


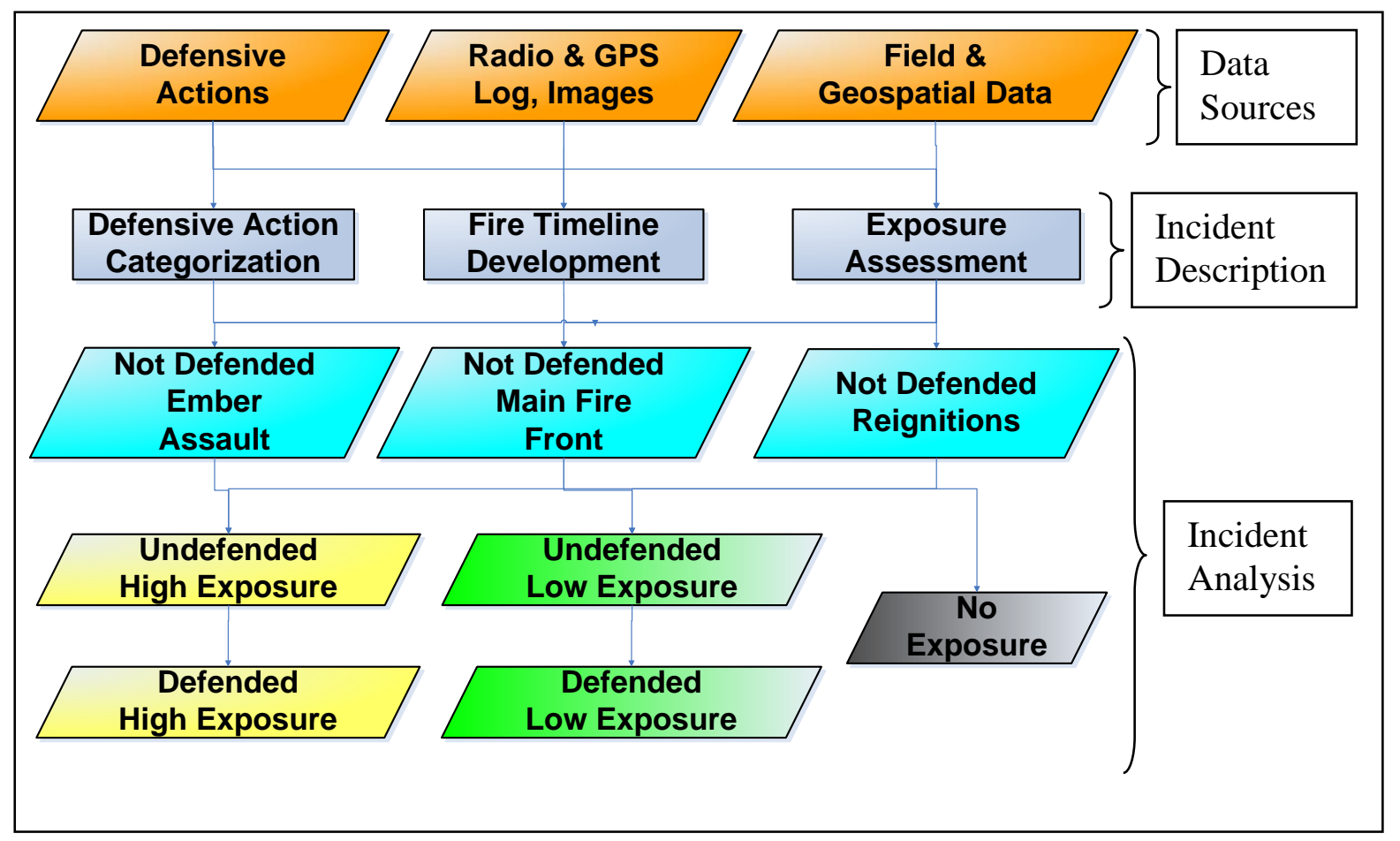

Figure 1 Overview of WUI Assessment Methodology used here.

The NIST WUI Assessment Methodology also has the advantage of providing a framework for guiding conclusions that can be drawn from any WUI assessment. For example, the extent to which WUI communities can be subdivided into appropriate populations as shown in Figure 1 illustrates the depth and breadth of analyses that can be conducted and the conclusions that can be drawn about the respective WUI incident. The data available to characterize the fire disturbance continuum will determine the ability to partition the respective WUI populations for appropriate analysis, which in turn will guide possible analyses that might be conducted; thereby guiding the conclusions that can be drawn from any one WUI incident or area.

It would not, for example, be appropriate to discuss the merits of building retrofit techniques when only examining the structures that were not destroyed by the respective fire and the characteristics of those non-destroyed (damaged and un-damaged) buildings. It would also not be appropriate to study the merits of building retrofitting techniques for these same buildings if defensive actions could not be quantified. Finally, assessment of building retrofitting techniques for these same buildings would require understanding the timeline of fire behavior for the respective incident along with proper, as yet to be determined, categorization of wind, fuels and topography as well as a method to integrate this data to assess exposure conditions.

Consequently, NIST is assessing measurement science techniques to determine if collection of the above described items is possible in a WUI environment and the conditions under which the required data can be collected. This assessment is being accomplished through the following activities in post-fire WUI environments: 
1. Implementing a broad and detailed field data collection system as described in NIST Technical Note $1708 .^{11}$

2. Integrating field data with remote sensing data (ground and aerial) to identify fire timeline defensive actions, as practical. This activity is performed in a Geographic Information System (GIS) environment.

The above activities will also help to identify shortcomings in current measurement science techniques; thereby allowing for the potential development of new and improved technologies and techniques for assessment of WUI fires.

The first attempt in assessment and development of the NIST WUI Methodology was at the 2007 California Witch Fire as detailed in Maranghides and Mell ${ }^{12}$ and Maranghides et al. ${ }^{9}$ The NIST deployment to the 2011 Texas Tanglewood Fire Complex was summarized in Maranghides et $\mathrm{a}^{11}$. The Tanglewood Fire Complex deployment conducted a more complete implementation and assessment of the NIST WUI Methodology compared to what was conducted for the 2007 California Witch/Guejito Fire.

Maranghides et al. ${ }^{11}$ detailed deployment procedures, integration of the data collection team into the ICS and scope of the data collected for the Tanglewood Fire Complex. There were 35 residential structures ${ }^{\mathrm{e}}$ destroyed and 13 damaged residential structures found within the perimeter of the Tanglewood Fire. Numerous other secondary structures and other combustible features were also damaged or destroyed in the fire. Appendix A contains the preliminary findings as identified in Maranghides et al. ${ }^{11}$

\subsection{Report Objectives, Goals \& Organization}

This second technical note on the Tanglewood Fire Complex focuses only on the Lake Tanglewood Fire. Specifically, this technical note has the goal of assessing current WUI post-fire assessment measurement science while providing information to guide laboratory experiments and fire model testing and development. Through this assessment, we hope to provide a better understanding of fire behavior in the WUI and identify potential ignition vulnerabilities. The above goals will be achieved through completion of the following objectives related to the 2011 Tanglewood Fire:

1) Development of the fire event timeline.

2) Documentation of general fire behavior observations.

3) Documentation of defensive actions.

4) Identification of ignition vulnerabilities.

All of the above items will be assessed to determine limitations of these items, in terms of methods and technologies utilized, regarding achievement of the above described objectives.

\footnotetext{
${ }^{\mathrm{e}}$ Residential structures are those used for residential occupation. This includes guest houses or secondary residential structures found on property lots including mobile homes.
} 
This fire was selected for a detailed case study after an initial reconnaissance was conducted in the first days following the fire. Texas Forest Service had been trained to collect WUI data using the NIST methodology, and equipment had been forward deployed to Texas in anticipation of a WUI fire. Technically, the Tanglewood Fire presented a scenario where the impact of topography on fire behavior and structural survivability could be analyzed. Additionally, the incident size enabled data collection to be conducted for the entire incident, something that was not possible for the 2007 Witch fire case study of the Trails community.

The report is organized beginning with the materials and methods presented in Section 3. A general overview of the study area and fire timeline is presented in Section 4. In sections 5 through 11, the fire area is broken into communities and more detailed fire behavior, fire timeline, and ignition mechanisms are detailed. WUI Assessment Methodology and Science is discussed in Section 12. Section 13 contains the summary of the technical findings. Section 14 contains recommendations and section 15 contains the report conclusions. Appendices A through H contain: Preliminary Findings from the NIST TN 1708, building materials not assessed, unconfirmed defensive actions, suggested data collection defensive action methodology improvements, aspect transformations (topographical calculations), tabulation of incident data and discussion, recommendations for improving the data collection methodology and an example of prefire mitigation advice form implemented in areas affected by the Tanglewood Fire.

\subsection{Materials and Methods}

Maranghides et al. ${ }^{11}$ detailed the procedures required and outcomes expected for the assessment of a WUI fire event. Maranghides et al ${ }^{11}$ also describes the methods used for property level data collection. This property level field data collection occurred on all properties in and around the Tanglewood Fire perimeter in February and March of 2011. These same procedures were followed for a small number of additional properties assessed in a subsequent three day field deployment in August of 2011 in order to complete the assessment of all potentially affected properties. Figure 2 portrays the training, the property level data collection and additional procedures required to complete an assessment of this event.

This section describes the materials and methods used for fire witness data collection and office data production. The data sources used for the analysis conducted in this report are also detailed. Methods to incorporate these data sources to enhance field collected data and create new data are discussed. Finally, the data analysis methods utilized are described.

\subsection{Data Sources}

Table 1 describes aerial imagery used in this analysis. Other ancillary GIS and electronic data sources were used for this analysis as shown in Table 2. These electronic data sources included images taken during the fire from homeowners and first responders. Additionally, sources for weather station information are shown in Table 2. 


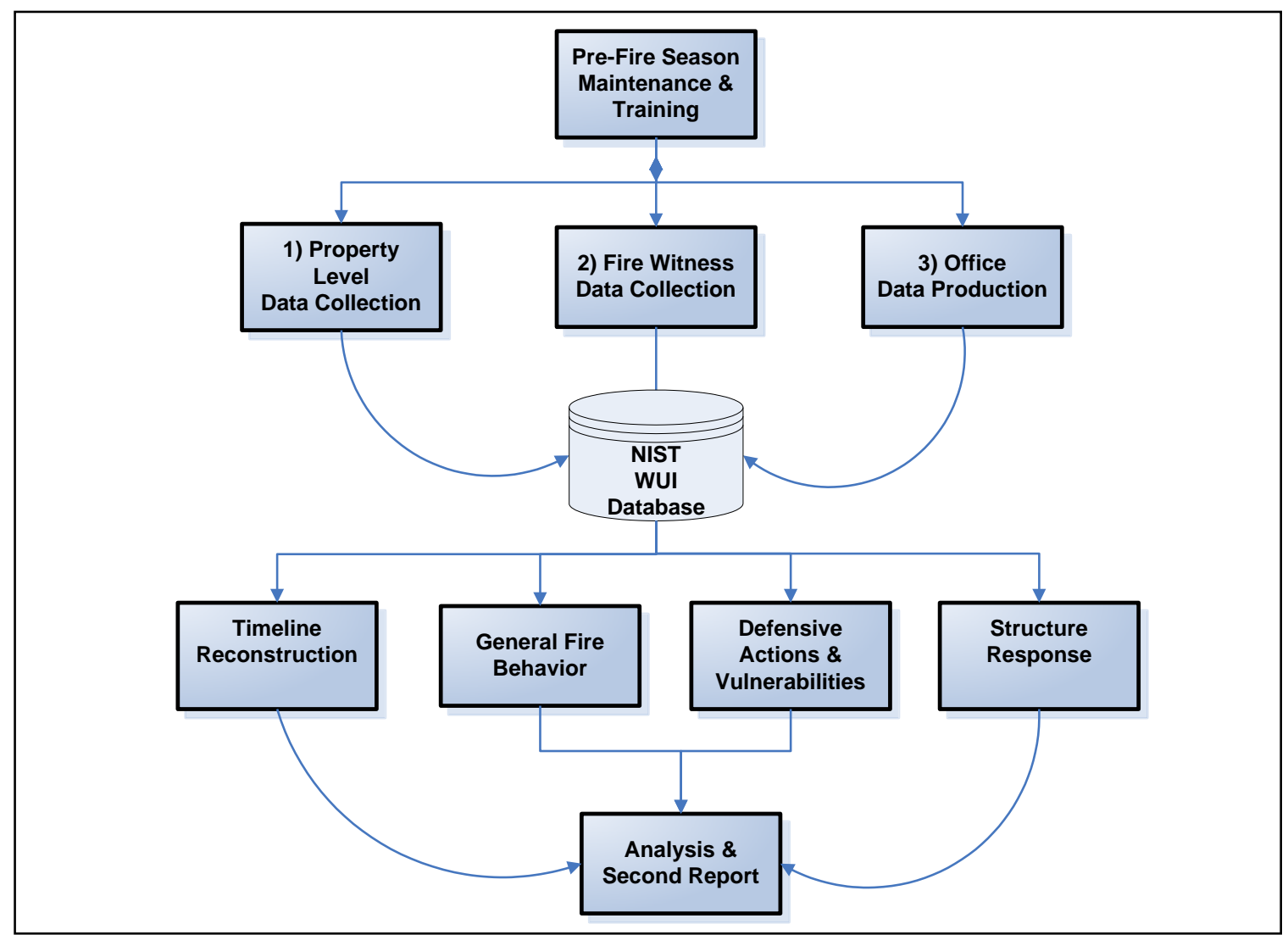

Figure 2 General procedures used in this report on the Tanglewood Fire. Pre-season training and property level data collection methods are described in NIST TN 1708.

\subsection{Field Data Enhancement and Local Data Integration}

Geographic Information Systems (GIS) were used for the collection of field data and the integration of all data sources. It was determined that electronic data collection systems are essential in documenting WUI fires. This is associated with the multidimensionality of the data both in space and time, as interactions between topography, fuels, weather and defensive actions associated with WUI fires can only be captured in a GIS. The PotterRandall County 911 imagery was used as the base layer from which features were recorded in the field in combination with an internal tablet global positioning system (GPS), for the majority of the field days. On April 1, 2011 oblique and nadir images were acquired by Pictometry, Inc. for the City of Amarillo. The orthorectified imagery was used as a new base map from which to more precisely geolocate field collected data in the office in order to ensure proper alignment among the different features. This step was required due to imprecision in the GPS and improper/erroneous geolocation by data collectors. This imagery remained as the base map for all subsequent work.

Many features in burnt environments were difficult to determine in the field. Pre-fire oblique and nadir imagery were compared to post-fire imagery to ascertain changes. Footprints of structures were digitized from the post-fire nadir images. Building and property characteristics as recorded by the Randall County Assessor web page and shown in Table 2 were also entered into the GIS. Nonetheless, in heavily canopied areas certain features might have been missed. 
Most of the building characteristics recorded in a WUI 2 assessment could not be determined for the majority of destroyed homes. Appendix B shows tabulations of these building characteristics by residential structure response. There is a disproportionate amount of missing values for destroyed homes compared to damaged or undamaged homes. This makes further analysis of these building attributes difficult and questionable. Consequently, these building treatment values are not assessed further in this report.

Other building characteristics could be obtained for destroyed homes using local tax assessor information ${ }^{13}$. These include exterior siding material, roofing material, flooring, roof edge protection and the presence of a chimney. These materials are assessed as practical. It was determined that remote sensing combined with field assessments presents the best means to obtain pre-fire and post-fire vegetation information.

Table 1 Imagery used for post-fire assessment.

\begin{tabular}{|c|c|c|c|}
\hline $\begin{array}{l}\text { Imagery } \\
\text { Source }\end{array}$ & Characteristics & $\begin{array}{l}\text { Acquisition } \\
\text { Time }\end{array}$ & Purpose \\
\hline $\begin{array}{l}2008-2009 \text { Texas } \\
\text { Orthoimagery } \\
\text { Program }\end{array}$ & $\begin{array}{l}0.5 \mathrm{~m}(1.6 \mathrm{ft}) \text { spatial } \\
\text { resolution; two } 3 \text {-band datasets } \\
\text { (natural and color infrared). }\end{array}$ & $\begin{array}{l}2008 \text { Leaf On } \\
\text { Conditions }\end{array}$ & $\begin{array}{l}\text { - Natural color imagery used for first } 3 \\
\text { days of field data collection } \\
\text { - Color infrared used to identify, } \\
\text { healthy, well-watered vegetation. }\end{array}$ \\
\hline $\begin{array}{l}2010 \text { National } \\
\text { Agriculture } \\
\text { Imagery Program } \\
\text { (NAIP) }\end{array}$ & $\begin{array}{l}1 \mathrm{~m}(3.3 \mathrm{ft}) \text { spatial resolution } \\
\text { 3-band color infrared. }\end{array}$ & $\begin{array}{l}2010 \text { Leaf On } \\
\text { Conditions }\end{array}$ & $\begin{array}{l}\text { Color infrared used to visually } \\
\text { identify, healthy, well-watered } \\
\text { vegetation. }\end{array}$ \\
\hline $\begin{array}{l}\text { Potter-Randall } \\
\text { County } 911 \\
\text { Imagery }\end{array}$ & $\begin{array}{l}0.3 \mathrm{~m}(1 \mathrm{ft}) \text { spatial resolution } 3- \\
\text { band natural color. }\end{array}$ & $\begin{array}{l}2010 \text { Leaf On } \\
\text { Conditions }\end{array}$ & $\begin{array}{l}\text { Imagery used as base data for } \\
\text { remainder of the first and second } \\
\text { deployments. }\end{array}$ \\
\hline $\begin{array}{l}\text { Pre-Fire } \\
\text { Pictometry }\end{array}$ & $\begin{array}{l}0.15 \mathrm{~m}(0.5 \mathrm{ft}) \text { oblique and } \\
\text { NADIR 3-band natural color } \\
\text { imagery. }\end{array}$ & $\begin{array}{l}\text { Pre-Fire } \\
\text { (Exact Date } \\
\text { Unknown) }\end{array}$ & $\begin{array}{l}\text { - Verification and identification of pre- } \\
\text { fire conditions. }\end{array}$ \\
\hline $\begin{array}{l}\text { Post-Fire } \\
\text { Pictometry }\end{array}$ & $\begin{array}{l}0.15 \mathrm{~m}(0.5 \mathrm{ft}) \text { oblique and } \\
\text { NADIR 3-band natural color } \\
\text { imagery. }\end{array}$ & April 1, 2011 & $\begin{array}{l}\text { - Verification and identification of } \\
\text { post-fire conditions. }\end{array}$ \\
\hline $\begin{array}{l}\text { Post-Fire } \\
\text { Helicopter Video }\end{array}$ & Color video. & $\begin{array}{c}2 / 27 / 2011 \\
18: 00-19: 00\end{array}$ & $\begin{array}{l}\text { - Fire timeline reconstruction, fire } \\
\text { behavior and defensive action } \\
\text { identification. }\end{array}$ \\
\hline $\begin{array}{l}\text { Post-Fire Aerial } \\
\text { Images }\end{array}$ & Oblique Color Images. & $2 / 28 / 2012$ & $\begin{array}{l}\text { - Verification and identification of } \\
\text { post-fire conditions. }\end{array}$ \\
\hline $\begin{array}{l}\text { Nextmap }^{\mathrm{TM}} \text { Basic } \\
\text { Radar Products }\end{array}$ & $\begin{array}{l}\text { 1) Digital Terrain Model } \\
\text { (DTM) portraying elevation of } \\
\text { the surface of the bare earth. } \\
\text { 2) Digital Surface Model } \\
\text { (DSM) portraying elevations of } \\
\text { the surface features. }\end{array}$ & Unknown & $\begin{array}{l}\text { - Visual portrayal of topographic } \\
\text { characteristics. } \\
\text { - Derivation of slope and aspect. } \\
\text { - Derivation of surface height model. }\end{array}$ \\
\hline
\end{tabular}




\subsection{Fire Witness Accounts, Images and Radio Logs}

Technical discussions (TDs) with homeowners and first responders present during the Tanglewood Fire were conducted during two field deployments. Each TD was documented using hard copy notes, which were subsequently entered into electronic format. Locations of defensive actions were also recorded on hard copy maps and referenced in the notes.

Discussions with first responders and homeowners began with a qualitative assessment of the resources that were allocated to the Tanglewood Fire. After this assessment, it was decided to focus efforts on the fire departments listed in Table 3. Time did not allow for discussions with other responders or a quantification of the specific resources allocated.

Table 2 Ancillary electronic data sources used in analysis.

\begin{tabular}{|c|c|c|c|}
\hline $\begin{array}{c}\text { Data } \\
\text { Source }\end{array}$ & Characteristics & Time Period & Purpose \\
\hline $\begin{array}{l}42 \\
\text { discussions } \\
\text { with First } \\
\text { Responders }\end{array}$ & $\begin{array}{l}\text { Hard copy notes and maps } \\
\text { portraying details of discussions } \\
\text { with first responders. }\end{array}$ & $\begin{array}{l}\text { Occurred between } \\
\text { March 1, 2011 } \\
\text { and August 5, } \\
2011\end{array}$ & $\begin{array}{l}\text { - Identification of the } \\
\text { location and characteristics } \\
\text { of defensive actions. } \\
\text { - General fire chronology. }\end{array}$ \\
\hline $\begin{array}{l}6 \text { discussions } \\
\text { with } \\
\text { homeowners }\end{array}$ & $\begin{array}{l}\text { Hard copy notes and maps } \\
\text { portraying details of discussions } \\
\text { with homeowners. }\end{array}$ & $\begin{array}{c}\text { Occurred between } \\
\text { March 1, } 2011 \\
\text { and August 5, } \\
2011\end{array}$ & $\begin{array}{l}\text { - Identification of the } \\
\text { location and } \\
\text { characteristics of } \\
\text { defensive actions. }\end{array}$ \\
\hline $\begin{array}{l}\text { Assessor } \\
\text { Web Page }\end{array}$ & $\begin{array}{l}\text { Building characteristics for } \\
\text { properties in the study area. }\end{array}$ & $\begin{array}{l}\text { Time period of } \\
\text { data not known }\end{array}$ & $\begin{array}{l}\text { - Identification of building } \\
\text { characteristics for } \\
\text { destroyed structures. }\end{array}$ \\
\hline $\begin{array}{l}911 \text { Radio } \\
\text { Logs }\end{array}$ & $\begin{array}{l}\text { Printed description of radio } \\
\text { traffic during the Tanglewood } \\
\text { Fire. }\end{array}$ & $\begin{array}{c}02 / 27 / 201111: 57 \\
\text { to } \\
02 / 27 / 201113: 40\end{array}$ & - Fire timeline creation. \\
\hline $\begin{array}{l}\text { Gordon Ivy } \\
\text { Images - } \\
\text { reporter }\end{array}$ & $\begin{array}{l}\text { Ground images taken during the } \\
\text { Tanglewood Fire in the Northern } \\
\text { Palisades Community. }\end{array}$ & $\begin{array}{c}02 / 27 / 201116: 25 \\
\text { to } \\
02 / 27 / 201117: 42\end{array}$ & - Fire timeline creation. \\
\hline $\begin{array}{l}\text { Karen Slagle } \\
\text { Images - } \\
\text { resident }\end{array}$ & $\begin{array}{l}\text { Ground images taken during the } \\
\text { Tanglewood Fire in the Timber } \\
\text { Creek Community }\end{array}$ & $\begin{array}{c}02 / 27 / 201116: 25 \\
\text { to } \\
02 / 27 / 201117: 42\end{array}$ & - Fire timeline creation. \\
\hline $\begin{array}{l}\text { KKTV } \\
\text { Weather }\end{array}$ & $\begin{array}{l}\text { Weather information from } \\
\text { weather station located at } \\
\text { Tanglewood Drive, by the } \\
\text { entrance of Lake Tanglewood } \\
\text { community. }\end{array}$ & $\begin{array}{c}2 / 21 / 201100: 00 \\
\text { to } \\
2 / 28 / 201123: 00\end{array}$ & $\begin{array}{l}\text { - Weather information for } \\
\text { incident. }\end{array}$ \\
\hline $\begin{array}{l}\text { Airport } \\
\text { Weather }\end{array}$ & $\begin{array}{l}\text { Weather information from } \\
\text { weather station located at the } \\
\text { Amarillo Airport. }\end{array}$ & $\begin{array}{c}2 / 26 / 201101: 22 \\
\text { to } \\
2 / 28 / 201123: 53\end{array}$ & $\begin{array}{l}\text { - Weather information for } \\
\text { incident. }\end{array}$ \\
\hline
\end{tabular}

Additionally, discussions with seven homeowners encountered during various deployment activities took place. These discussions included the mayor of the Palisades Community and the president of the Lake Tanglewood Homeowners Association. Two of the discussions took place with homeowners who conducted their own defensive actions on various properties. There was substantial evidence of homeowners not 
evacuating (due to not being aware of the evacuation or the rapidity with which the fire spread) and defending their properties.

Defensive action information from first responder and homeowner hard copy data sheets was entered into a GIS database by associating the defensive action with a general location represented by a digitized polygon. Within this polygon, if a particular feature was identified in the discussion (e.g. railroad ties); this feature was then cross-referenced in the database. Defensive actions were recorded in the database; if it was feasible that a defensive action might have occurred in the area (e.g. there was fire behavior on or close to the location). Additionally, defensive actions evident in videos and images taken during the fire and listed in Table 2 were used to confirm defensive actions in certain locations.

Table 3 First responder discussions by departments along with known resources allocated by department.

\begin{tabular}{|c|c|c|}
\hline Fire Department & $\begin{array}{l}\text { Number of } \\
\text { Discussions }\end{array}$ & Known Resources Allocated \\
\hline $\begin{array}{l}\text { Lake Tanglewood } \\
\text { Fire Department }\end{array}$ & 5 First Responders & $\begin{array}{l}1 \text { Grass Truck } 1900 \text { liters ( } 500 \text { Gallons) of water; } \\
1 \text { Grass Truck } 7600 \text { liters ( } 2000 \text { Gallons) of water; } \\
1 \text { Grass Truck (unknown capacity); Unknown total } \\
\text { number of First Responders. }\end{array}$ \\
\hline $\begin{array}{l}\text { Randall County Fire } \\
\text { Department }\end{array}$ & 15 First Responders & $\begin{array}{l}1 \text { Tanker; } 2 \text { Engines } 6650 \text { liters ( } 1750 \text { Gallons; } 1 \\
\text { Unknown) of water; } 3 \text { Attack Trucks; } 1 \text { Brush } \\
\text { Truck } 19001 \text { liters ( } 500 \text { Gallons) of water; } 1 \text { Brush } \\
\text { Truck (unknown capacity); Vehicle Called } \\
\text { Command 2; Unknown total number of first } \\
\text { responders. }\end{array}$ \\
\hline $\begin{array}{c}\text { Timber Creek Fire } \\
\text { Department }\end{array}$ & 2 First Responders & 1 Brush Truck; 2 Engines; 7 First Responders. \\
\hline $\begin{array}{l}\text { Palisades Fire } \\
\text { Department }\end{array}$ & $\begin{array}{c}1 \text { First Responder (Fire } \\
\text { Chief) }\end{array}$ & Unknown resources. \\
\hline $\begin{array}{l}\text { Amarillo Fire } \\
\text { Department }\end{array}$ & 23 First Responders & $\begin{array}{l}\text { Engine } 41 \text { (5 First Responders); Training Engine } \\
50 \text { (4 First Responders); Service Engine } 40 \text { (4 First } \\
\text { Responders); Engine } 15 \text { (4 First Responders); } \\
\text { Engine } 5 \text { (4 First Responders); Unit } 956 \text { (1 First } \\
\text { Responder); Unit } 952 \text { (1 First Responder). }\end{array}$ \\
\hline $\begin{array}{l}\text { Happy Fire } \\
\text { Department }\end{array}$ & 1 First Responder & 4WD Rescue 11401 (300 Gallons) of water. \\
\hline Pantex Department & 1 First Responder & 2 Grass Trucks 38001 (1000 Gallons) of water. \\
\hline Texas Forest Service & 1 First Responder & $\begin{array}{l}\text { Unknown resources specific to Tanglewood (Total } \\
\text { resources are known for all three fires but not } \\
\text { broken down into specific fires). }\end{array}$ \\
\hline
\end{tabular}


Many defensive actions referenced precise addresses that were often locations where there was no fire or associated damage. However, the description often matched that of an adjacent or geographically close property and the damage assessed in the field on that property. These discrepancies were also noted when a first responder team member identified a similar action on a matching property. In these cases, the defensive action was associated with the feature that was believed to be defended based on field data and multiple anecdotal observations.

Often times there were multiple individuals conducting a defensive action, which was also recorded in the database as a single action or set of actions with multiple responders. First responders sometimes discussed defensive actions conducted by another first responder team. This information was also recorded in the database as the respective defensive action being confirmed by multiple observations. Some defensive actions could not be associated with a particular action and/or were anecdotal in nature and could not be confirmed $\mathrm{d}^{\mathrm{f}}$. These actions are listed in Appendix C.

Finally, this cross-referenced defensive action information was used to assign to each primary structure a defensive action category as follows:

- Protected: The structure was protected from flames, radiant heat or embers produced from fire that was a consequence of the respective wildland fire incident.

- Contained: The structure was fully involved or destroyed but the structural fire was suppressed to prevent further spread of flames, radiant heat and embers.

- Not Defended: The structure was not defended by any human action during the fire incident. Structures in this category would have been specifically identified as not defended.

- No Defensive Action identified: There was no defensive action identified on the respective structure.

Structures were categorized as described above in an attempt to subdivide or partition the study area population into sub-populations for further assessment. The focus of the postfire reconstruction was limited nominally to the first 12 hours after ignition. Defensive actions of flare-ups or general mop-up operations that may have occurred after the initial fire front were not captured in this data collection. Appendix D lists suggested improvements to the NIST Defensive Action Data Collection Methodology.

\subsection{Fire Timeline Development}

Information from first responder discussions was also used to re-create the fire timeline. Accuracy, however, of first responder time estimates varied greatly and it was often difficult to reconcile first responder time estimates with times portrayed in the radio log and images. This might have been likely due to the high stress situation that the first responders encountered during the incident and the fact that it was not their job to keep accurate account of their activities by time. Nonetheless, the first responder accounts did

\footnotetext{
${ }^{\mathrm{f}}$ Anecdotal defensive actions describing homeowner defensive actions are mapped in the sections below as potential locations of defensive actions.
} 
help to provide general chronologies of events that were not recorded with images or documented in the radio log.

Fire witness accounts also provide key information in interpretation of actual event timelines. For example, the fire in the Timber Creek Community flared up several times as was described in discussions by witnesses. Radio logs and images do not provide sufficient contextual information to help understand and resolve discrepancies in timelines.

The majority of the timeline reconstruction was conducted from the radio logs and fire images listed in Table 2. Radio logs provide information of varying accuracy and precision. In some cases, the radio log represented the location of the vehicle of the responder to the fire, who was actually at a nearby location. An example is the 13 records in the radio log referencing a conflagration at 415 Palomino Drive. This address was outside the fire perimeter but across the street from the fire origin; where many of the first responders to the incident parked their vehicles.

Additionally, many records in the radio log portray a first responder moving from one location to another and it was not always clear which of the respective locations, if any, had fire. Consequently, radio logs were interpreted in context of other existing data to identify what were believed to be reliable burn times. Correlation of these burn times with those from images allow for the creation of some aspects of the event timeline.

\subsection{Topography and Radar}

The area most affected by the Tanglewood Fire contained unique and distinctive topographic features. These features and other topographic characteristics might have had consequences for both the fire and ember exposures experienced by structures and other combustibles. This is evident at a coarse scale where 34 structures were destroyed in the canyon areas around Lake Tanglewood, while only 1 structure was destroyed on the plateau above the canyon. The interaction of topography, fuels and weather is complex and not well understood.

Digital elevation models (DEM) portraying elevations of the surface of the earth can be valuable in consistently identifying topographic features and characteristics. The required scale of topographic analysis, however, is not known for a WUI environment and depends on the specific purpose and, possibly, the scale of the features in relation to the fire. Initial studies, such as Maranghides et al. ${ }^{9}$, used high resolution data to map high hazard areas as a surrogate for exposure. This high resolution data does not exist freely for the Tanglewood study area, though other commercial products exist.

Freely available DEM data is provided by the United States Geologic Survey (USGS). This data has a $10 \mathrm{~m}(33 \mathrm{ft})$ horizontal resolution. Fire phenomena, particularly structure threatening/destroying fire behavior might be occurring on topographic features of finer scale than what can be discerned in a coarse scale DEM. This data would be too coarse for performing an analysis similar to that performed in Maranghides et $\mathrm{al}^{9}$.

Resources that were available for this reconstruction were not sufficient to allow for acquisition of high resolution DEM products. Radar data at $5 \mathrm{~m}(17 \mathrm{ft})$ horizontal spatial resolution was available within project resources from Nextmap ${ }^{\mathrm{TM}}$. Consequently, this report utilizes the radar DEM products to conduct a topographic assessment similar to 
that conducted in Maranghides et al. ${ }^{9}$ Field collected data identified significant changes in fire behavior and exposure occurring over distances much shorter than $5 \mathrm{~m}(17 \mathrm{ft})$.

Percent slope and aspect data sets for all the parcels within the fire perimeter were derived from the radar DEM using the ArcGISTM Spatial Analyst ${ }^{\mathrm{TM}}$ extension. These data sets were used to portray topography in the sections below describing the various affected communities. Additionally, the slope and transformed aspect data sets were also used to calculate average slopes and aspects within polygons portraying various buffers (areas) around residential buildings.

In order to average aspects within specified polygons, the aspect must be transformed to account for the measurement unit being in degrees. The procedures conducted on the ArcGIS derived aspect data set can be found in Appendix E.

\subsection{Study Area, Weather and Event Overview}

This section provides a brief description of weather at the study area. Additionally, a general portrayal of damage by community across the entire study area is presented. Finally, a general timeline for the incident is portrayed. Details of each community along with the fire timeline and other items are presented in sections below.

\subsection{Study Area}

This study is limited to the area around Lake Tanglewood affected by the fire that occurred on February 27, 2011 and continued through February 28. This area is comprised of different communities as shown in Figure 3. The Tangle Aire community is actually part of the city of Amarillo. The Lake Tanglewood study area has 77 homes, the Palisades study area has 71, the Tangle Aire study area has four, the Plateau study area has six and the Timber Creek study area has 25 homes.

These five community groupings provide a convenient method for analyzing different areas affected by the Tanglewood Fire. The fire did not stop at community boundaries, however, and destruction varied significantly among the different communities. As can be seen in Figure 3, Palisades had $77 \%$ (27 of 35), Lake Tanglewood had $20 \%$ (7 of 35) and Timber Creek Canyon had $3 \%$ (1 of 35) of the residential structure destructions that occurred during the incident.

\subsection{Weather Summary}

The data provided in this section came from two different sources, the KAMA weather station at the Amarillo airport, $21.5 \mathrm{~km}$ (13.3 miles) from the fire origin, and the KVIITV weather station, $4.2 \mathrm{~km}$ (2.6 miles) in Tanglewood. ${ }^{\mathrm{g}}$ Weather information is summarized in Table 4 for the KAMA data and Table 5 for the KVII data. Both weather stations recorded very similar weather patterns. There is a $9 \mathrm{~m}(30 \mathrm{ft})$ difference in elevation between the stations. The KAMA station is surrounded by flat ground and is at $1099 \mathrm{~m} \mathrm{(3607} \mathrm{ft)} \mathrm{above} \mathrm{sea} \mathrm{level.} \mathrm{The} \mathrm{Tanglewood} \mathrm{station} \mathrm{is} 78 \mathrm{~m} \mathrm{(255} \mathrm{ft)} \mathrm{above} \mathrm{the}$

\footnotetext{
g KVII TV Lake Tanglewood Weather Station- 35:04:20 N, 101:47:35 $1090 \mathrm{~m}$ (3 $576 \mathrm{ft}$ ) elevation

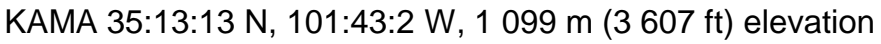


lake. There were no weather stations down in the canyon and around Lake Tanglewood (1021 m (3352 ft) elevation), so the potential effects of the topography on the local weather cannot be quantified.

Both weather stations provided similar regional weather data. The stations, however, did not provide any local weather in the canyons where the Tanglewood Fire burned most structures. There was no weather information available within the canyons. Fire behavior was observed and field indicators were used to infer wind direction at certain locations, however, field data was not available to provide wind speed information.

\subsection{Timeline Overview}

The Tanglewood Complex fire ignited in the vicinity of the western intersection of Palomino Dr. and Pinto Dr. According to the Randle County Sheriff's Department, the source of ignition remained indeterminate as of April 19, 2011. The Potter-Randal County 911 dispatch for the incident was received at 13:44 on February 27, 2011; TFS dispatch was contacted at 17:56 ${ }^{\mathrm{i}}$. Fire suppression activities continued through February 28.

Figure 4 portrays key time points for the main fire front of the Tanglewood Fire across the entire incident. There were numerous flare up and fire direction changes that occurred after the fire reached its most northeast extent, where it was extinguished by first responders. Wind shifts occurred after the main fire front was extinguished causing previously unaffected areas within the fire perimeter to experience fire. Additionally, some features within the fire perimeter ignited after the main fire front moved through.

Table 4 KAMA Weather Data Summary.

\begin{tabular}{|c|c|}
\hline $\begin{array}{l}\text { Date/ Time } \\
\text { (mm/dd/yyyy hhmm-hhmm) }\end{array}$ & Weather Observation \\
\hline 02/27/2011 0800-1300 & $\begin{array}{l}\text { - Wind increased from } 15 \text { to } 66 \mathrm{~km} / \mathrm{hr} \text { (9 to } 41 \mathrm{mph}) \\
\text { - } \mathrm{RH} \text { dropped from } 25 \text { to } 8 \%\end{array}$ \\
\hline $02 / 27 / 2011 \quad 1300-1500$ & $\begin{array}{l}\text { - Sustained wind speed between } 57 \text { and } 78 \mathrm{~km} / \mathrm{hr}(35 \text { and } 48 \mathrm{mph}) \\
\text { - Wind gusting from } 83 \text { to } 112 \mathrm{~km} / \mathrm{hr}(51 \text { to } 69 \mathrm{mph}) \\
\text { - RH between } 6 \% \text { and } 8 \%\end{array}$ \\
\hline $02 / 27 / 2011 \quad 1330-2200$ & - Wind from $220^{\circ}$ (southwest) and $240^{\circ}$ (west southwest) \\
\hline $02 / 27 / 2011 \quad 2300-2330$ & $\begin{array}{ll}\text { - } & \text { Arrival of weather front } \\
\text { - } & \text { Wind veered to } 350^{\circ} \text { (north northwest) } \\
\text { - } & \text { Wind increased from } 28 \text { to } 41 \mathrm{~km} / \mathrm{hr} \text { (17 to } 25 \mathrm{mph} \text { ) } \\
\text { - } & \text { RH climbed from } 35 \% \text { to } 65 \% \\
\end{array}$ \\
\hline $02 / 28 / 2012 \quad 0500$ & - $\quad$ Wind dropped under $32 \mathrm{~km} / \mathrm{hr}(20 \mathrm{mph})$ \\
\hline
\end{tabular}

\footnotetext{
${ }^{\mathrm{h}}$ Radio Log, Randall County Sheriff Department

'Texas Forest Service Dispatch
} 
Table 5 KVII TV Lake Tanglewood Weather Data Summary.

\begin{tabular}{|c|c|}
\hline $\begin{array}{l}\text { Date/ Time } \\
\text { (mm/dd/yyyy hhmm-hhmm) }\end{array}$ & Weather Observation \\
\hline $02 / 27 / 2011 \quad 0800-1300$ & $\begin{array}{ll}\text { - } & \text { Wind increased from } 1.6 \text { to } 44 \mathrm{~km} / \mathrm{hr}(1 \text { to } 27 \mathrm{mph}) \\
\text { - } & \text { RH dropped from } 31 \% \text { to } 6 \%\end{array}$ \\
\hline $02 / 27 / 2011 \quad 1300-1500$ & $\begin{array}{ll}\text { - } & \text { Sustained wind speed between } 34 \text { and } 44 \mathrm{~km} / \mathrm{hr}(21 \text { and } 27 \mathrm{mph}) \\
\text { - } & \text { Wind gusting from } 60 \text { to } 70 \mathrm{~km} / \mathrm{hr}(37 \text { to } 43 \mathrm{mph}) \\
\text { - } & \text { RH between } 6 \% \text { and } 10 \%\end{array}$ \\
\hline $02 / 27 / 2011 \quad 1330-2200$ & - Wind from $225^{\circ}$ (southwest) and $245^{\circ}$ (west southwest) \\
\hline $02 / 27 / 2011 \quad 2300-2400$ & $\begin{array}{ll}\text { - } & \text { Arrival of weather front } \\
\text { - } & \text { Wind veered to } 0^{\circ} \text { (north) } \\
\text { - } & \text { Wind increased from } 20 \text { to } 40 \mathrm{~km} / \mathrm{hr}(12 \text { to } 24 \mathrm{mph}) \\
\text { - } & \text { RH climbed from } 36 \% \text { to } 68 \%\end{array}$ \\
\hline $02 / 28 / 20120400$ & - $\quad$ Wind dropped under $32 \mathrm{~km} / \mathrm{hr}(20 \mathrm{mph})$ \\
\hline
\end{tabular}




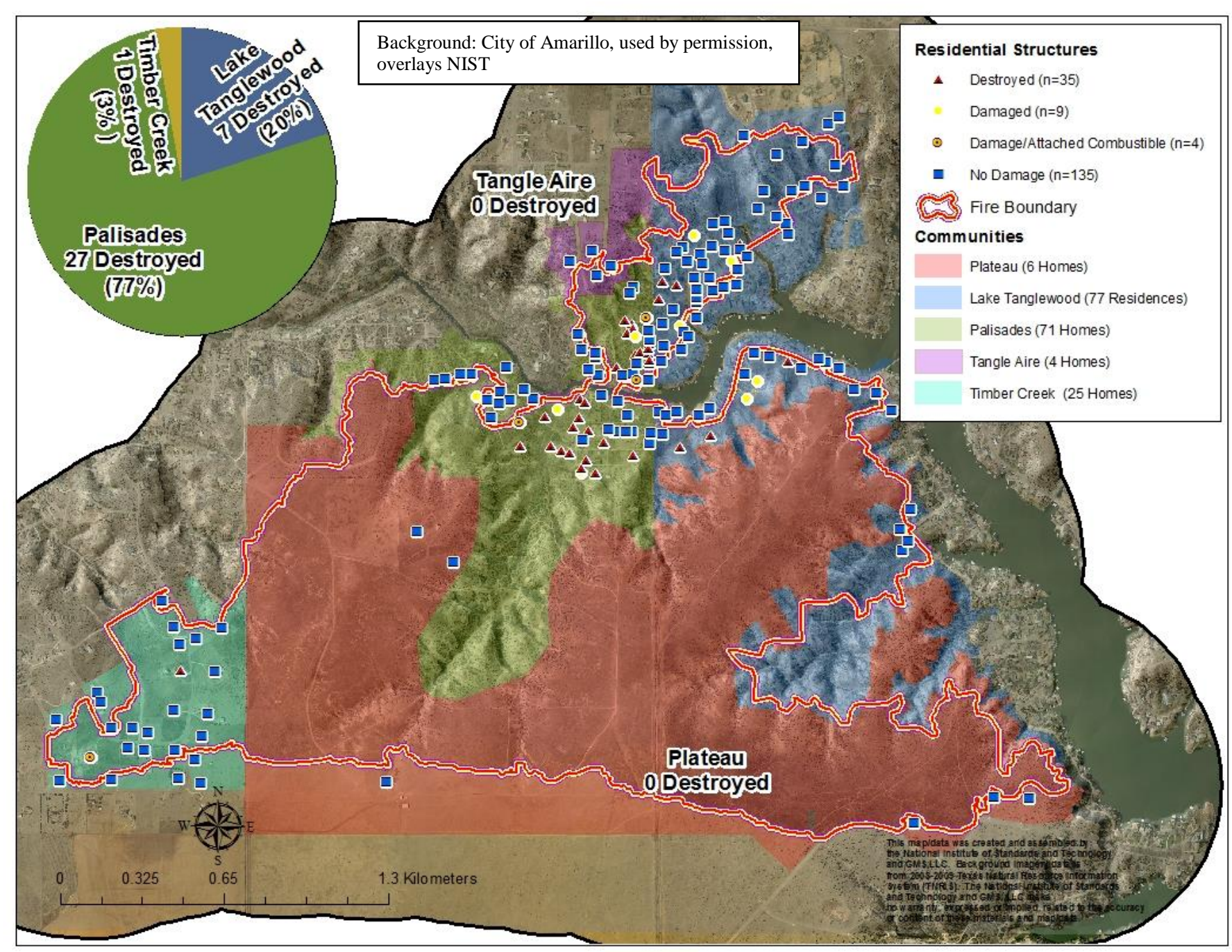

Figure 3 Fire affected communities showing number of structures and percent destroyed by community. 


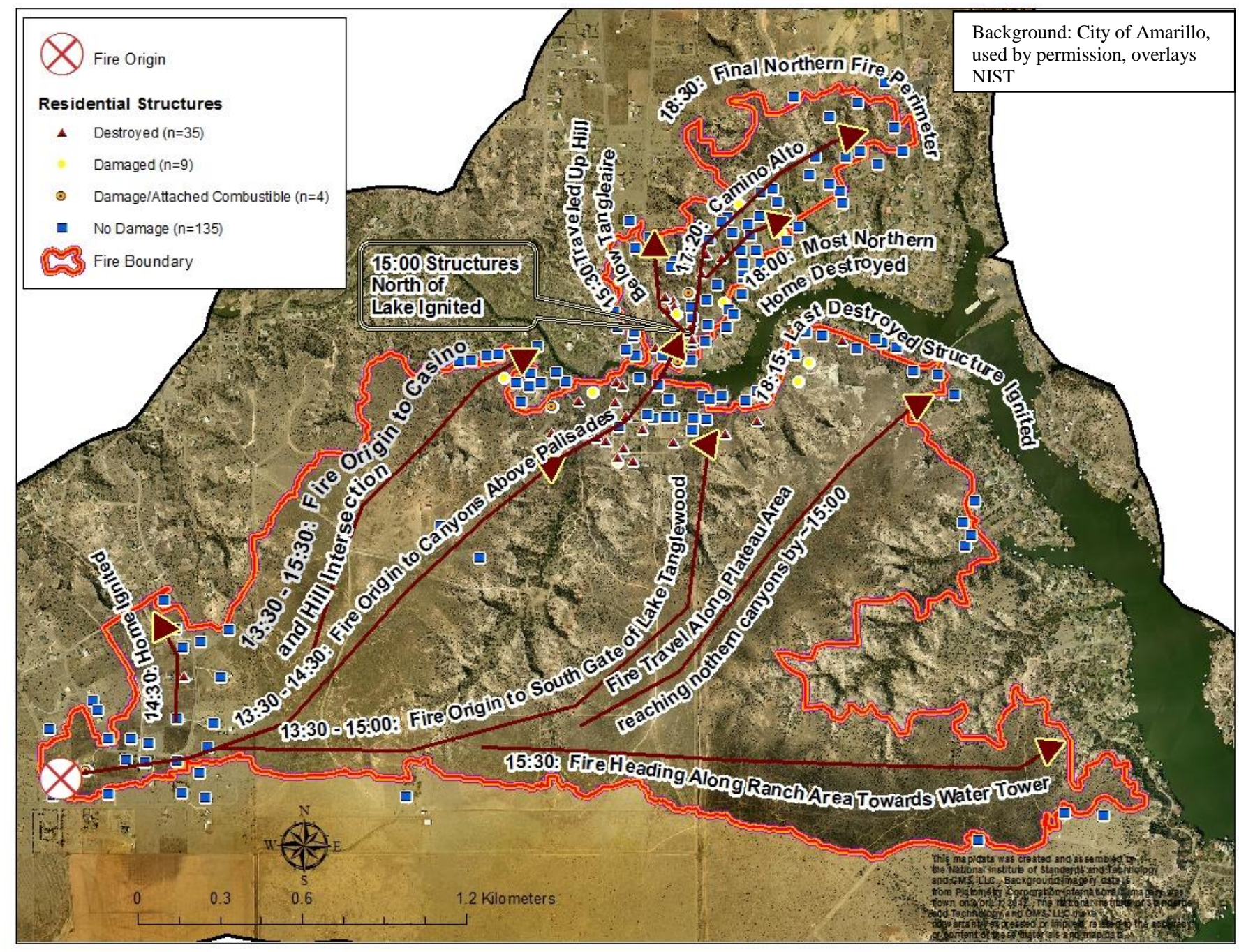

Figure 4 General Timeline and fire direction observations generalized from radio logs, fire images, and post-fire data collection. 


\subsection{Timber Creek Canyon Community}

This section begins with a tabulation of the damage and destruction to structural elements in the Timber Creek Canyon Community. Fire timeline, flame heights and fire direction information described in this section are derived or estimated from images taken by Karen Slagle, radio logs, eyewitness discussions and/or field assessments.

Additionally, areas where defensive actions were conducted in the community are detailed. Topographic characteristics are mapped and discussed. Primary structure categorizations to defensive action type are also presented. Finally, a qualitative examination of structural and vegetative ignition mechanisms in this community is presented.

\subsection{Damage Assessment, Fire Direction, Fire Timeline and Burned Vegetation}

Figure 5 shows damage to structural elements from the Tanglewood Fire within the Timber Creek Canyon Community. As can be seen in Figure 5, there was one primary structure with damage to an attached combustible (i.e., wood deck) and one primary structure that was completely destroyed, 411 Roberts Road and 338 Cactus Drive, respectively. There were 23 primary structures receiving no damage from the fire. Damaged combustibles and linear features are, for the most part, concentrated around the damaged and destroyed primary structures.

A breakdown of damage to detached combustible features in Timber Creek Canyon is shown in Table 6. Damage and destruction to linear features by length is shown in Table 7. There is a large length for damaged linear features that is the result of the two long fenced areas shown in Figure 5 that could have contributed to ember production and possible fire spread. These metal fences with wood posts received minimal damage and were not a significant source of radiant heat or embers; one was possibly defended.

Figure 6 shows fire direction and fire progression in Timber Creek Canyon. There were six locations where the fire was recorded as crossing a road over seven meters wide based on post-fire ground assessments ${ }^{10}$. The fire also jumped a dirt road (Mesquite Drive) that was somewhat narrower than the paved roads. The fire might have jumped more than one location in the general area around each fire jump shown in Figure 6.

Fire moved from the origin and crossed Cactus Road into the wildlands to the east of Timber Creek Canyon (a linear distance of approximately $500 \mathrm{~m}(1640 \mathrm{ft})$ ) in about 30 minutes or less. North/northwest flanking fires continued to the east of Roberts Drive and in the wildlands between Mesquite Drive and Cactus Drive. There was also a flanking fire to the west of Roberts Drive.

The majority of structural element destruction or damaging fire appears to have occurred between 13:44 and 16:00 on February 27, 2011. Figure 7 shows specific time observations from images and radio logs in Timber Creek Canyon. Additionally, general fire behavior is shown in Figure 7. The area around the origin appears to have flared-up

\footnotetext{
${ }^{10}$ It is not known if the fire crossed through direct flame contact, radiant heating and/or embers.
} 
at least twice after the initial ignition. Additionally, there were flare-ups on the eastern side of Timber Creek Canyon on the morning of February, 28, 2011.

Grass areas are reported by first responders to have had flame heights of about $0.1 \mathrm{~m}$ $(0.3 \mathrm{ft})$ Areas with shrubs such as mesquite and juniper experienced some torching with maximum flame heights of $3 \mathrm{~m}(10 \mathrm{ft})$ to $5 \mathrm{~m}(16 \mathrm{ft})$ observed in images. Higher flame heights might have occurred.

Table 6 Damage and destruction to detached combustibles in Timber Creek Canyon.

\begin{tabular}{|l|c|c|}
\hline \multicolumn{1}{|c|}{ Combustible Feature } & Number Damaged & Number Destroyed \\
\hline Deck & 0 & 1 \\
\hline Playground Equipment & 1 & 0 \\
\hline Secondary Structures & 4 & 3 \\
\hline Vehicles & 4 & 5 \\
\hline RV/Camper & 0 & 1 \\
\hline Trailers & 2 & 3 \\
\hline Planters & 5 & 0 \\
\hline Lawn Mowers & 2 & 0 \\
\hline Lawn Furniture & 1 & 0 \\
\hline Firewood Piles & 0 & 2 \\
\hline Trash/Stock Feed Piles & 0 & 5 \\
\hline Small Cluster of Railroad Ties & 0 & 1 \\
\hline
\end{tabular}

Table 7 Damage and destruction to linear features in Timber Creek Canyon.

\begin{tabular}{|l|c|c|}
\hline \multicolumn{1}{|c|}{ Combustible Feature } & Meters Damaged & Meters Destroyed \\
\hline Landscaping Borders & $45(147 \mathrm{ft})$ & $246(807 \mathrm{ft})$ \\
\hline Fences & $929(3049 \mathrm{ft})$ & $149(489 \mathrm{ft})$ \\
\hline Retaining Walls & $80(261 \mathrm{ft})$ & $29.5(97 \mathrm{ft})$ \\
\hline
\end{tabular}

As shown in Figure 7, the one destroyed structure in Timber Creek Canyon was determined to be burning for 41 minutes between the first signs of flames on the eastern roof and the last image of the structure when it was almost completely destroyed. The total burn time, while unknown, would have been greater than 41 minutes from ignition to the last flames on the structure. Field observations have shown that a destroyed structure, even if the structure has burned to the ground, can potentially continue to be a source of embers and continue posing a fire spread risk for hours after the structural collapse. One destroyed shed was also photographed by Karen Slagle and was shown to be burning for at least 15 minutes between the times of full involvement to complete destruction. Again, the total burn time, while unknown, would have been greater than 15 minutes. The fire timeline contains information from different sources. The uncertainty associated with the timeline is specific to the individual events. A specific observation that was photographically documented may be very precisely located in time and space, while a set of confirmed observations that took place between two well defined/timeresolved activities may have larger associated temporal uncertainty. 


\subsection{Defensive Action Categorizations}

Figure 8 shows areas identified as being defended and the subsequent categorizations of primary structures as to a defensive action category. The one destroyed residential structure at 338 Cactus Drive did not show any evidence of defensive actions once the primary structure was ignited. Defensive actions on this residential structure and combustibles around it contained the fire only after ignition and full involvement occurred. The one residential structure that had damage to an attached combustible at 411 Roberts Drive had extensive defensive actions identified, including a defensive action on the attached damaged deck.

Three structures as indicated in Figure 8 were categorized as defended because of observations made by field crews during field data collection or discussions field crews had with homeowners indicating the respective homeowner stayed and defended. All known flare-ups have been documented as being suppressed by first responders. Figure 8 also shows areas where no defensive actions were identified. All of these had burn patterns that suggest the possibility of suppression, although these patterns could be due to pre-fire treatment, micro-scale topographic features such as a ditch (see Section 5.3), and/or other factors.

Table 8 shows a count of damaged and destroyed linear features such as fences or railroad ties used for landscaping, and damaged and destroyed detached combustible features, along with the number of features with identified defensive actions. Figure 8 and Table 8 highlight the main shortcoming with the defensive action identification method utilized. This shortcoming, the lack of identification of a defensive action around a particular structure or feature, does not mean that a defensive action did not occur on that feature.

Table 8 Damage and destruction to features in Timber Creek Canyon by defensive action.

\begin{tabular}{|l|c|c|}
\hline \multicolumn{1}{|c|}{ Feature } & $\begin{array}{c}\text { Number } \\
\text { Damaged/Destroyed }\end{array}$ & Number Defended \\
\hline Linear Features & 23 & 8 \\
\hline Detached Combustible Features & 32 & 4 \\
\hline
\end{tabular}

\subsection{Topographic Information}

Figure 9 displays radar derived slope for the Timber Creek Canyon Community. Figure 10 portrays radar derived aspect information. The flanking fire in the canyon going southeast to northwest was concentrated on south to north facing slopes. Additionally, the destroyed structure did lie in a small depression in this canyon, which might have influenced fire behavior.

The destroyed structure was closest to this canyon feature when compared to all the structures in Timber Creek Canyon. This destroyed structure was also on a Northwest aspect, providing direct exposure from the flanking fire. Slopes were relatively minor in the Timber Creek Canyon Community. Furthermore, small scale features such as drainage ditches did appear to influence fire behavior where it could be seen in images taken by Karen Slagle that the fire traveled faster up these ditches compared to 
neighboring areas. The radar data did not appear to capture these fine scale features, which appeared to have consequences for fire behavior.

\subsection{Structural Element Ignition Mechanisms}

This section provides detailed accounts of damage and destruction on built properties in Timber Creek Canyon, as known. This type of information provides indications of ignition mechanisms. Additionally, this information will aid in the initial data segmentation into high and low exposure areas at a coarse scale.

The damage to structural elements found on 411 Roberts Drive, near the origin, indicate the structure would have been destroyed without these defensive actions. These actions, consequently, provide significant clues to the ignition mechanism at this location. Figure 11 shows destroyed combustibles around 411 Roberts Drive. 


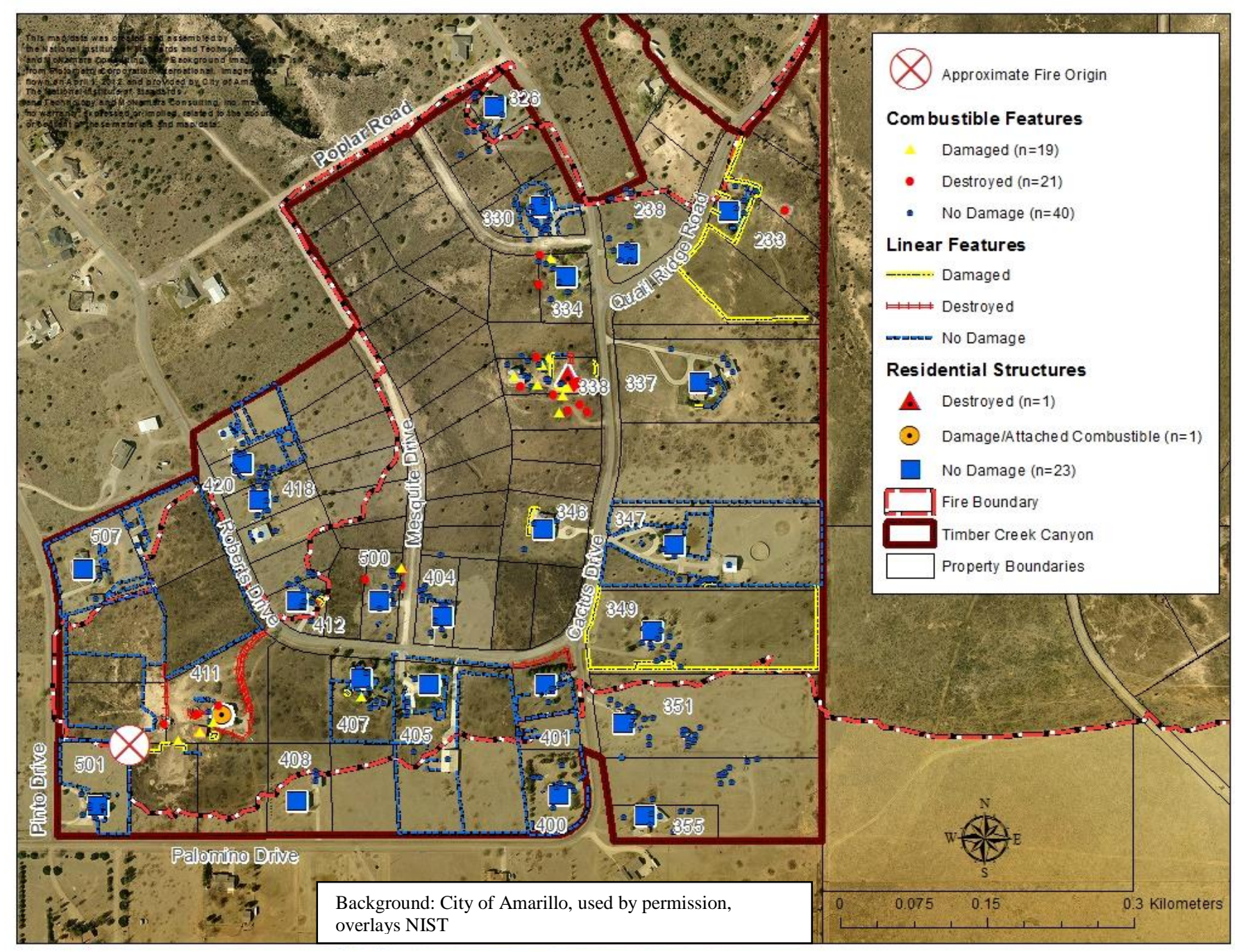

Figure 5 Damage to structural elements in Timber Creek Canyon. 


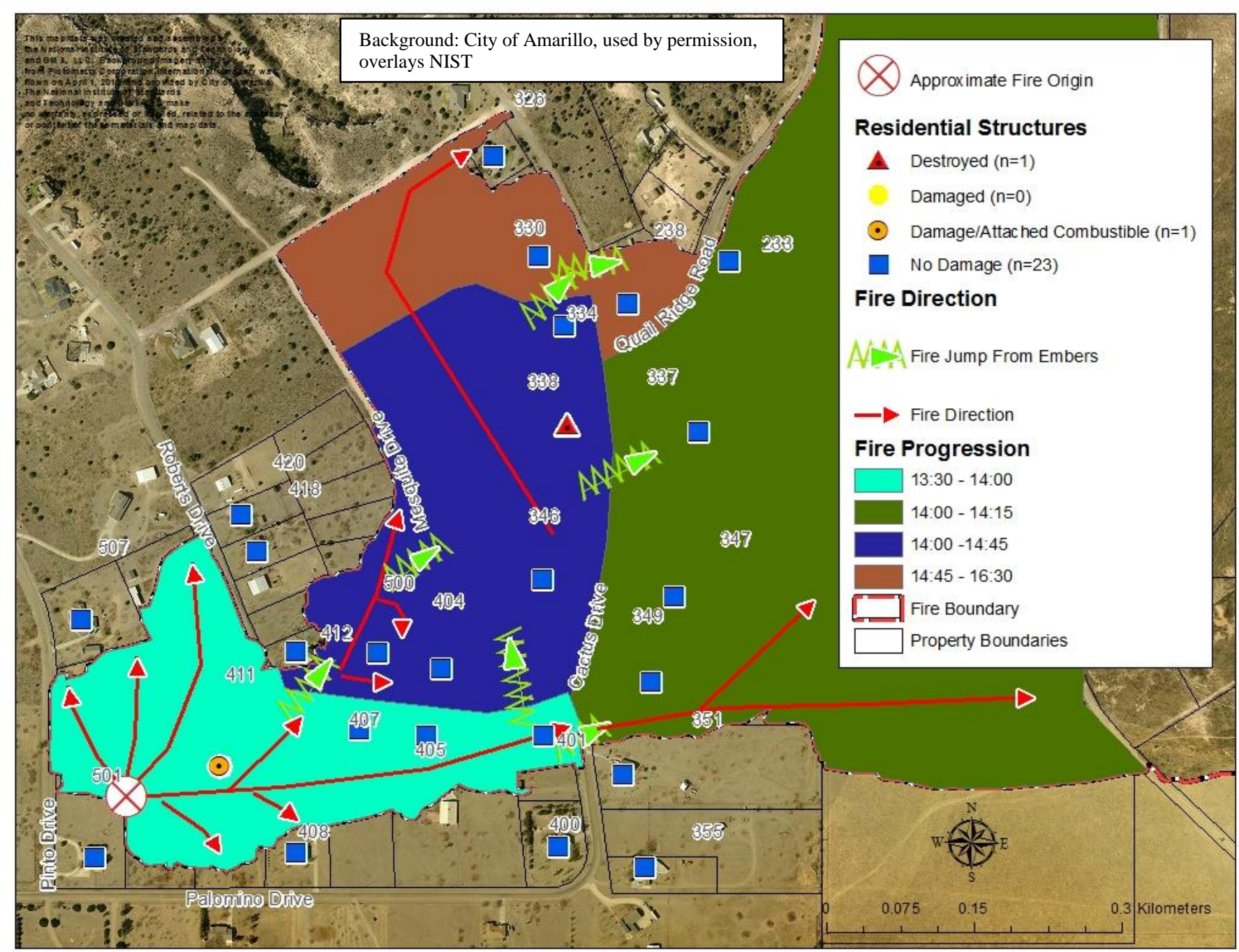

Figure 6 Fire direction, fire road crossings, and general fire progression in Timber Creek Canyon. Prevailing wind direction at time of fire was from the Southwest. 


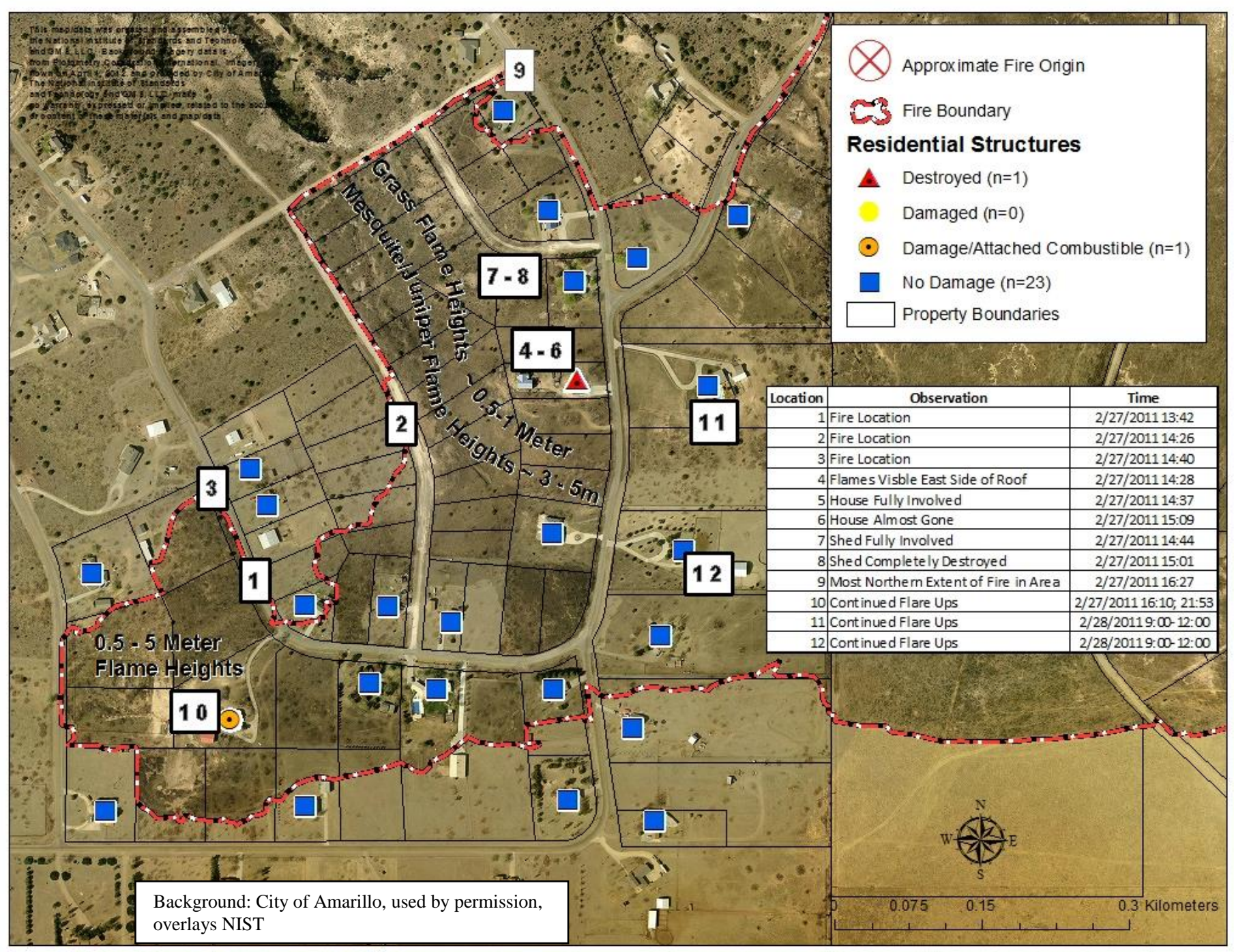

Figure 7 Specific time observations and general fire behavior in Timber Creek Canyon. 


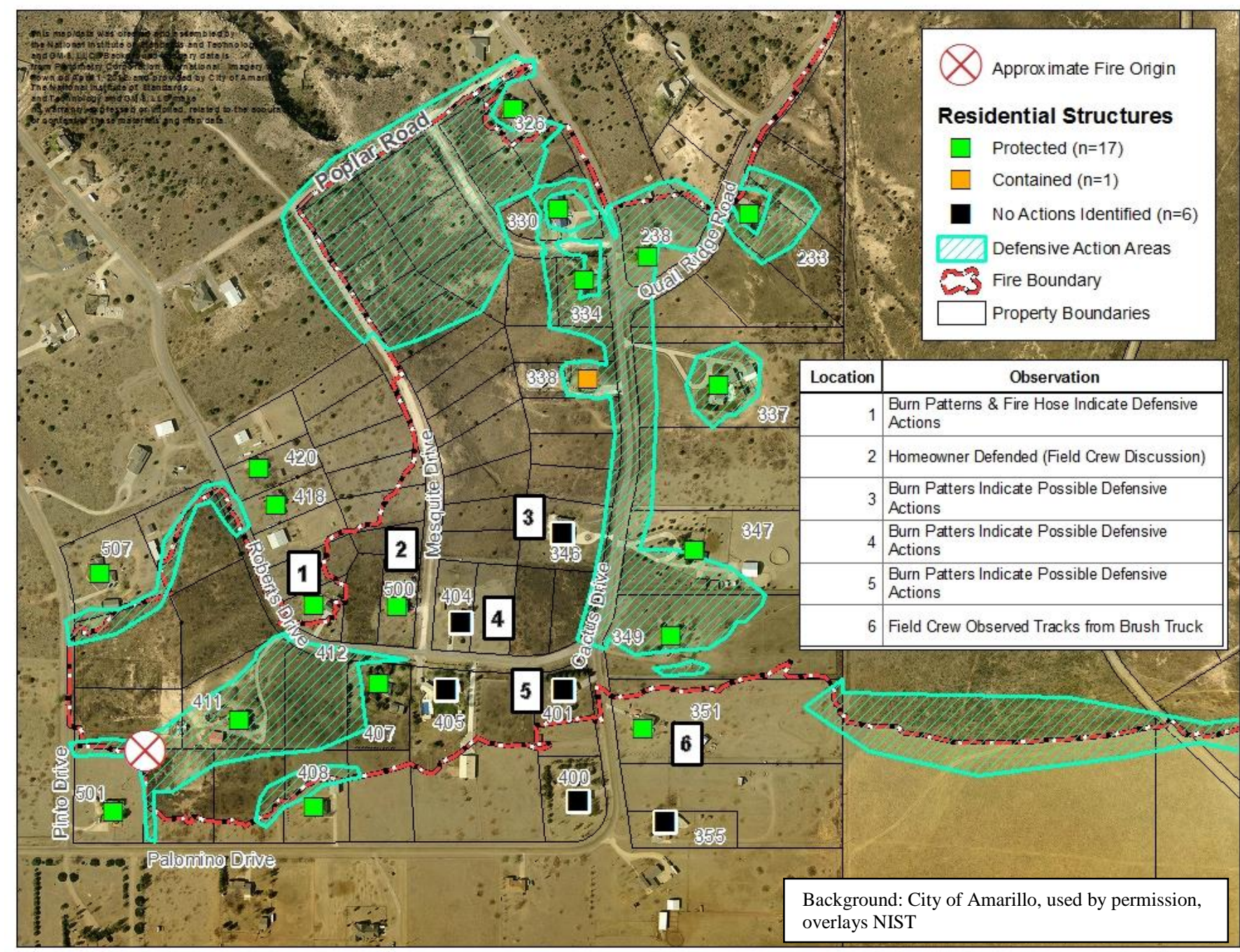

Figure 8 Defensive action areas and primary structure categorizations in Timber Creek Canyon. Larger structures shown in imagery and not categorized to a defensive action status are secondary buildings and not residential. 


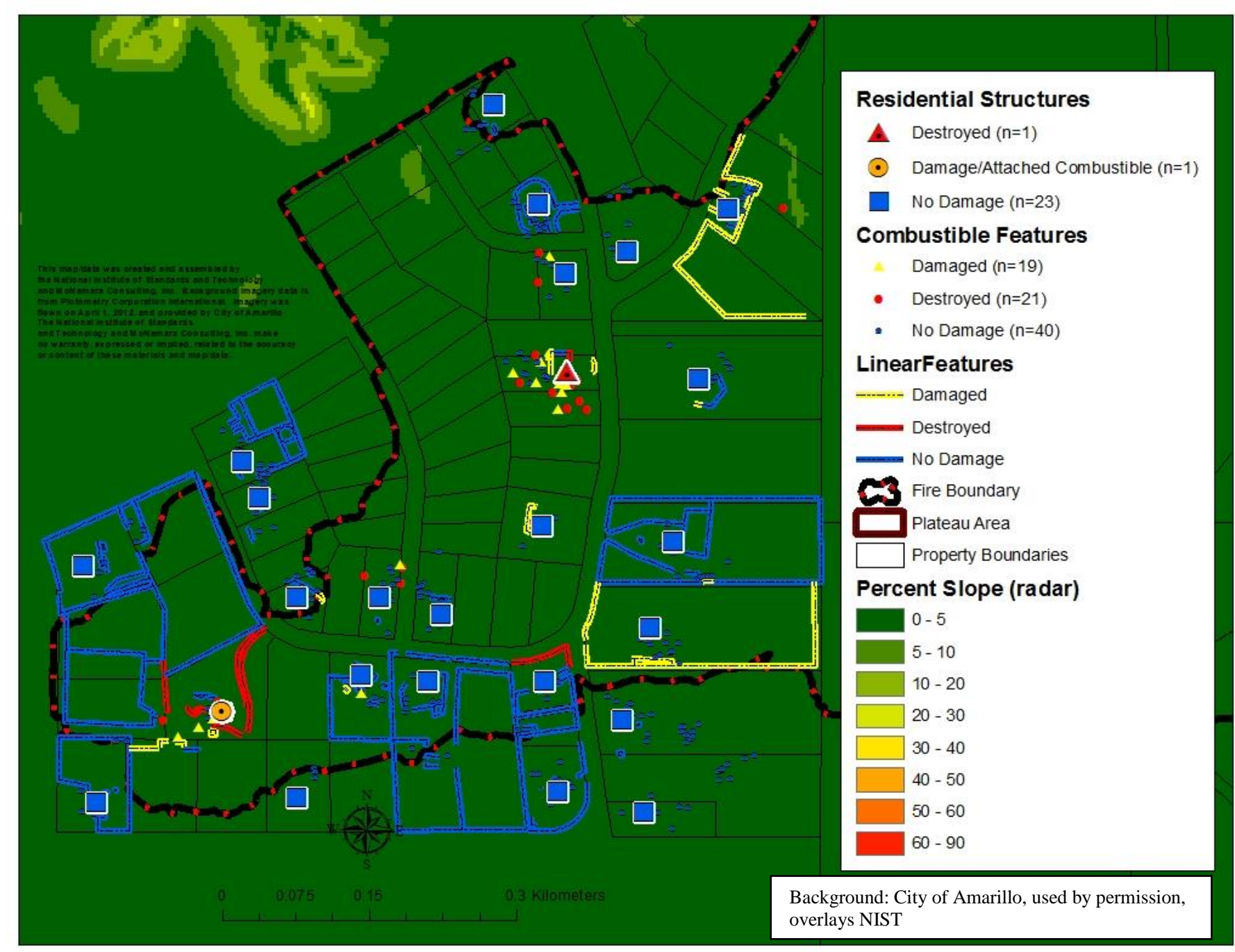

Figure 9 Radar derived percent slope in Timber Creek Canyon. 


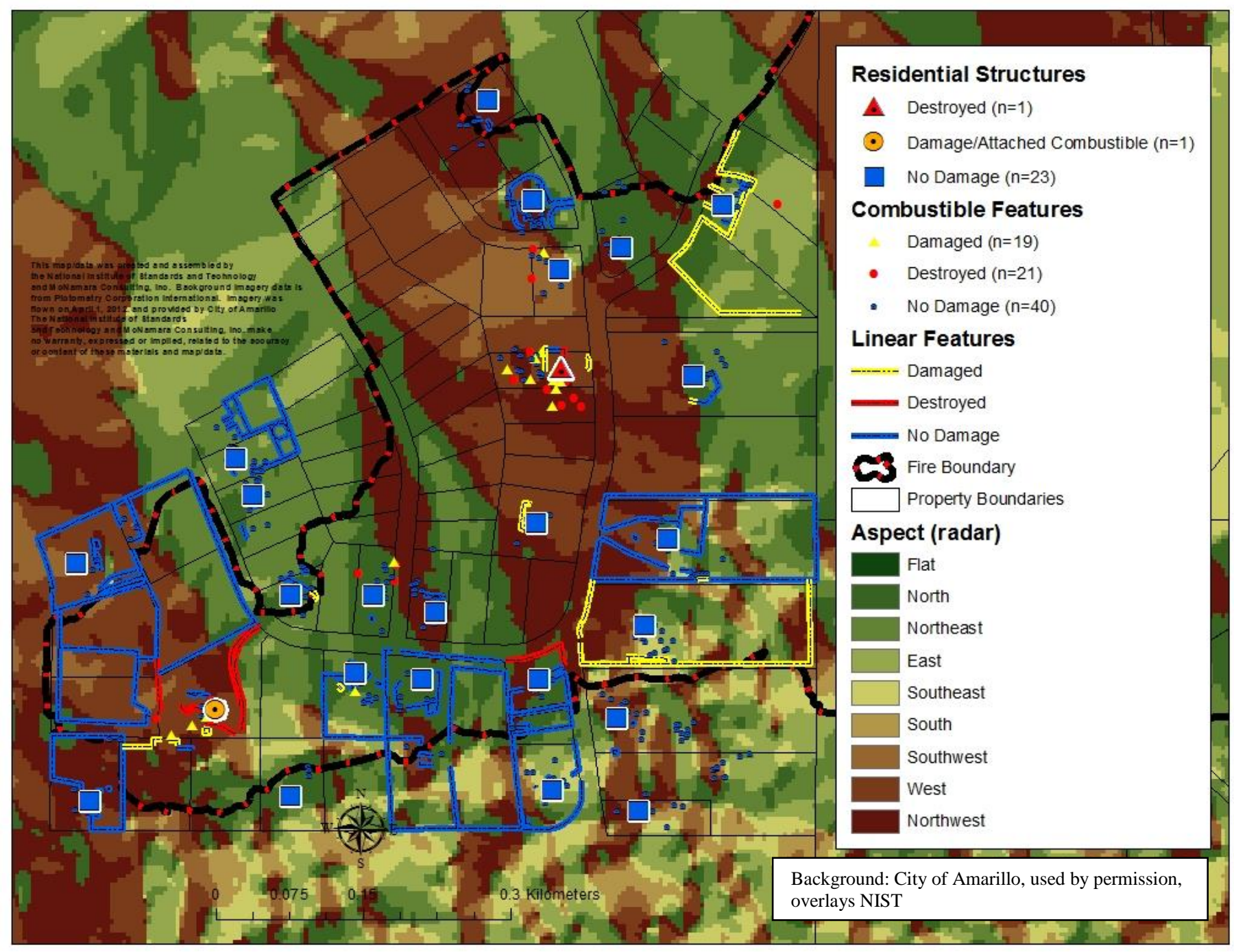

Figure 10 Radar derived aspect in Timber Creek Canyon. 
It is believed the barn ignited first from fire in the directly adjacent wildlands. Embers from the burning barn then ignited vegetation, a deck and retaining walls near the residential structure at 411 Roberts Drive, in some unknown order. The combustible

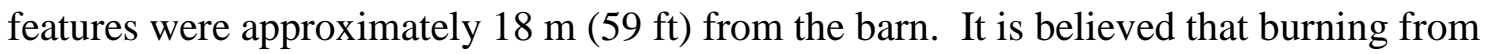
these features caused embers that accumulated in an exterior house corner and caused burning of a wall and elevated deck. There was also extensive destruction to burning railroad ties along the driveway, which were defended. Finally, the home had a wood roof. From discussions with first responders, there was no indication of roof ignition or defensive action on the roof. Additionally, there was no indication of any roof ignition in the field collected images.

The destruction to larger structural elements found on other properties with no destroyed residential structures is portrayed in finer detail in Figure 12. The shed destroyed at 334 Cactus Drive was known to be contained by first responders. This destroyed shed is believed to have caused damage to a larger shed $3 \mathrm{~m}(10 \mathrm{ft})$ away. The damage to the shed led to the assumption it was defended. This damaged shed was a significant fuel source, $7 \mathrm{~m}(23 \mathrm{ft})$ from the primary structure.

The barn at 233 Quail Ridge Road was a large fuel source located over $40 \mathrm{~m}(131 \mathrm{ft})$ from the primary structure. It was known to be contained at some level. The two destroyed fence portions at 337 and 347 Cactus Drive were also known to be defended. The fence at 337 Cactus Drive was attached to the residential structure, and the fence at 347 Cactus Drive was attached to a large secondary structure.

There is anecdotal evidence that defensive actions occurred at 500 Mesquite Drive. Additionally, the firewood pile was only partially consumed implying that it was most likely defended. The destroyed recreational vehicle/camper was $19 \mathrm{~m}(62 \mathrm{ft})$ from the main structure. The damaged railroad tie retaining wall at 346 Cactus Drive was not recorded as defended. The image shows some mechanical alteration of the feature. This alteration might have occurred after the fire. Although it cannot be determined if the feature was extinguished on its own or through human intervention, there is evidence that railroad ties can smolder or burn for extended periods. As stated earlier, the focus of the post-fire reconstruction was limited nominally to the first 12 hours after ignition. Mop-up or flare-ups that may have occurred after the initial fire front are not captured in this data collection.

The main fire front was photographed approximately $50 \mathrm{~m}(164 \mathrm{ft})$ from the one destroyed home at 338 Cactus Drive at 15:10. At 15:20 pm, the fire front had moved approximately $20 \mathrm{~m}$ (66 ft) past the most western non-destroyed secondary structure on the property of 338 Cactus Drive. The first visible sign of smoke coming from the roof of 338 Cactus Drive occured at 15:28 pm.

There were numerous combustibles found around the one destroyed home at 338 Cactus Drive. Figure 13 shows those structural elements that were known or suspected to have ignited prior to the ignition of the residential structure. There is a pile of unknown material greater than $30 \mathrm{~m}(98 \mathrm{ft})$ from the destroyed residential structure that ignited before flames or smoke are evident from the residential structure, but this was on the opposite side of the structure where flames first appeared. A vehicle $25 \mathrm{~m}(82 \mathrm{ft})$ from 
the residential structure is also shown to have ignited before the residential structure, again on the opposite side of the initial ignition seen in the images.

First responders observed a vehicle and fence on fire at the same time smoke was observed coming from the roof assembly of the residential structure. There were three destroyed vehicles in front of and to the southern side of the destroyed residential structure. First responder statements and images of flames coming from the roof indicate the ignition might have been through the eaves or an attic vent or space. The vehicle and/or fence were possible ignition sources as are other unidentified combustibles and/or vegetation.

Other combustibles destroyed on 338 Cactus Drive are believed to be the result of the structure ignition and backing fires as the flanking fire spread north. First responder discussions indicate the fire on the property was contained after the residential structure ignition. Damaged and undamaged combustibles were concentrated on the interior part of the property, away from the initial flanking and backing fires that occurred after the main flanking fire moved through. Combustibles in the wildlands adjacent to the property on the south might have been significant sources of flames, radiant heat and embers.

\subsection{Vegetative Element Ignition Mechanisms}

The elements that are believed to have ignited and produced the initial flames of the Tanglewood Fire are shrub and grass wildlands in and around the origin, shown in Figure 5. The ignition of these vegetative elements led to the ignition of some part of the combustibles discussed previously, as well as treated vegetation, such as Buffalo grass (Buchloe Dactyloides (Nutt.) Engelm), found around residential structures. Untreated areas appeared to burn completely, and experienced the highest flame heights, aside from large man-made combustibles.

Figure 14 portrays how vegetation treatment might affected burning. In some cases, such as the grazing, and possibly irrigation (shown in Figure 14), there is a clear line of demarcation between burning that occurred in areas that were known to be grazed and areas not grazed. Areas that appeared to be irrigated based on green vegetation were also able to stop the fire spread, as shown in Figure 14. The fire, however, burned right through some residential grasses, while others did not ignite from adjacent burning.

Vegetation treatment, though not studied in this report, might have had consequences for vegetation burning. However, what is not clear is the exact contribution of vegetation treatment and defensive actions in reducing or preventing the burning of certain residential grass and grazing areas. Many treated vegetated areas appeared to be undergoing senescence due to the time of the year. It was consequently difficult to evaluate treatment levels.

Additionally, it is quite possible that the fire might have stopped as a result of unidentified defensive actions. It seems likely that fire perimeter locations representing flanking and backing fire behavior (i.e. undefended areas along the fire perimeter to the north, south and west) areas shown as undefended in Figure 8, were defended to some extent. This scenario is likely due to the large number of first responders present in the area. Also, micro-scale topographic changes, coupled with the wind direction during the fire, might have affected fire behavior and vegetation burn patterns. 


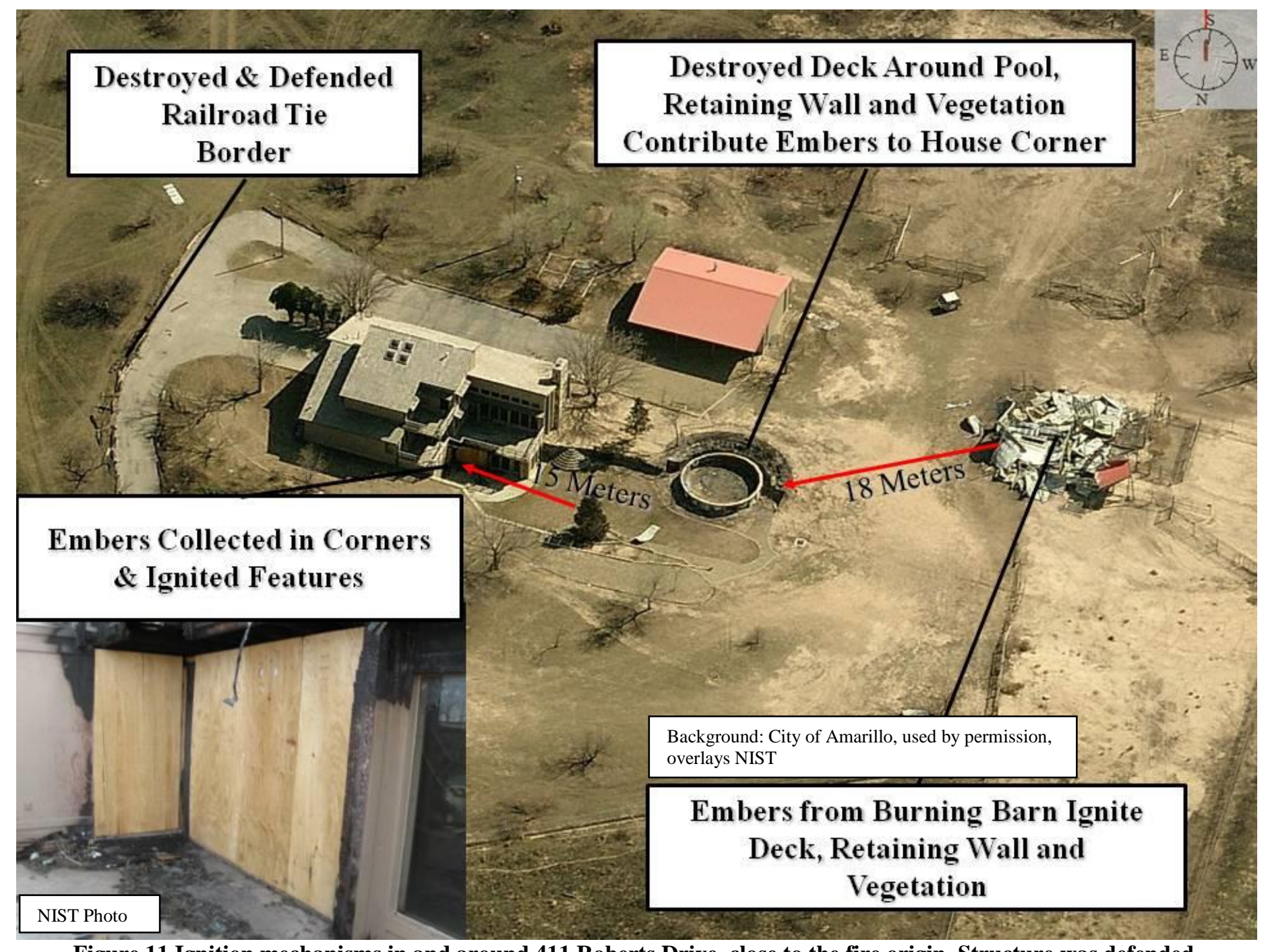

Figure 11 Ignition mechanisms in and around 411 Roberts Drive, close to the fire origin. Structure was defended. 


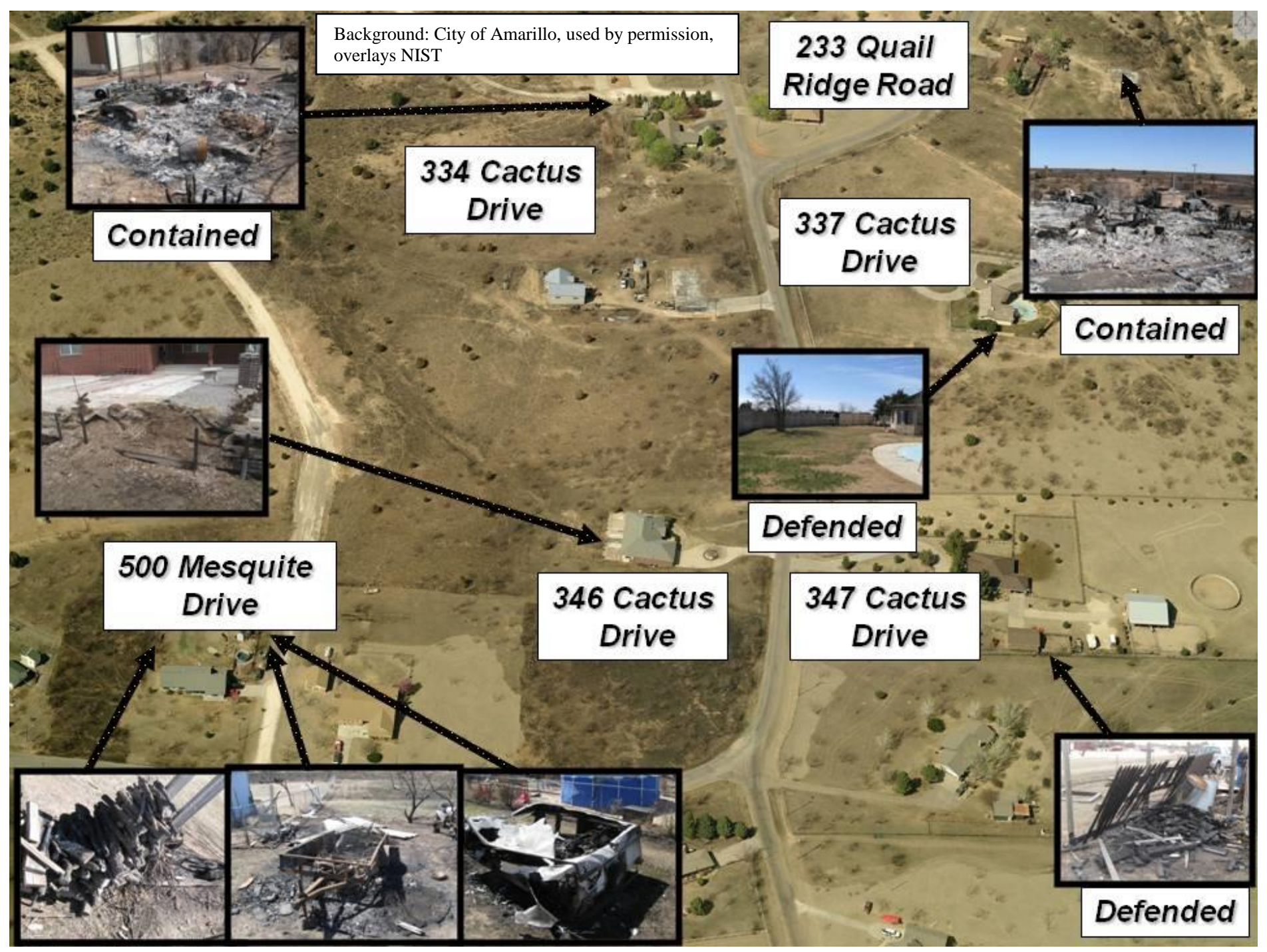

Figure 12 Ignition mechanisms around non-damaged or non-destroyed residential structures in Timber Creek Canyon, NIST photos. 


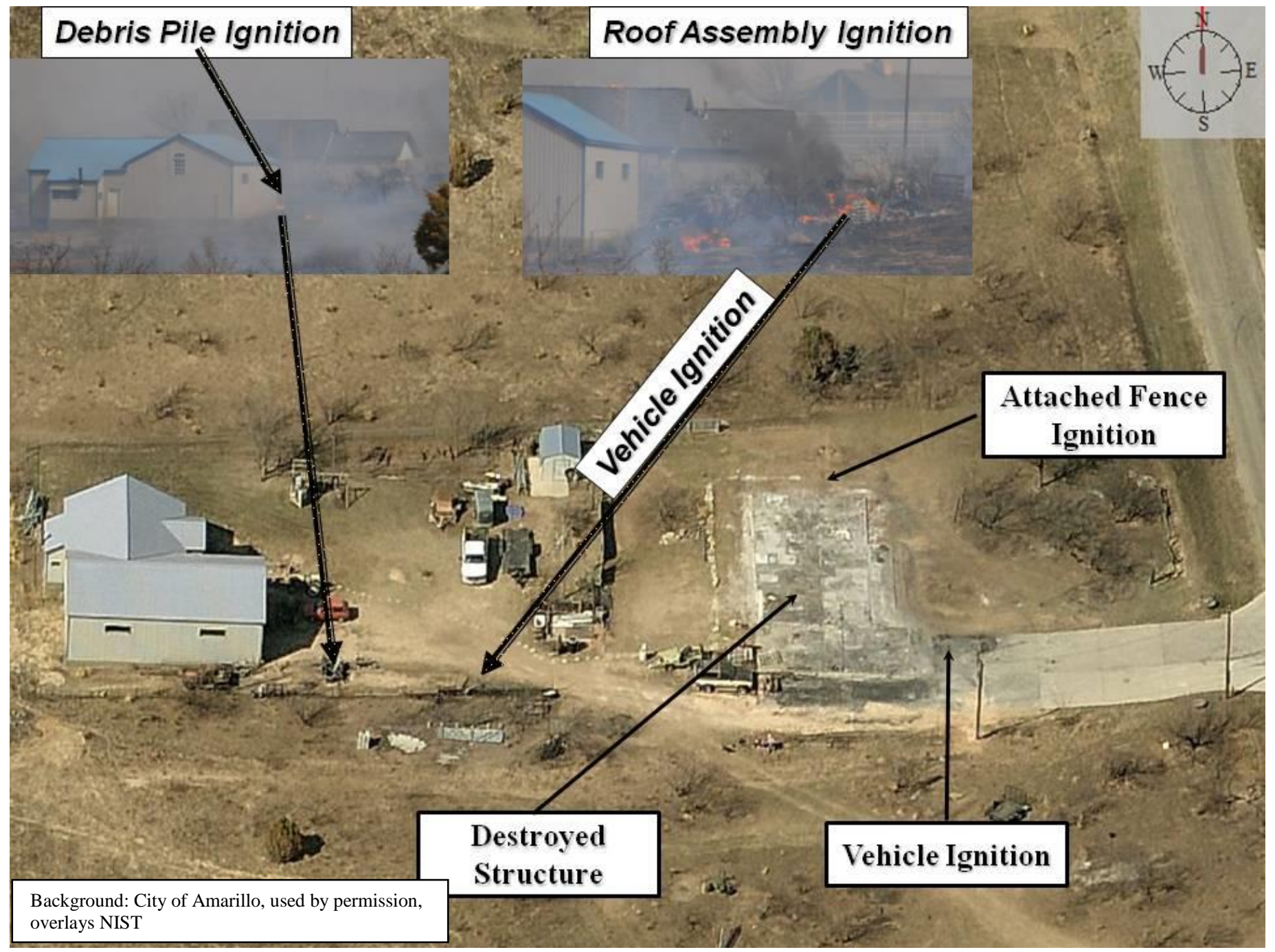

Figure 13 Structural element ignition mechanisms at 338 Cactus Drive. Structural elements portrayed are known or suspected to be ignited prior to residential structure ignition. Fire direction was from southeast to northwest and the attached fence was on the north of the destroyed home, NIST photos. 


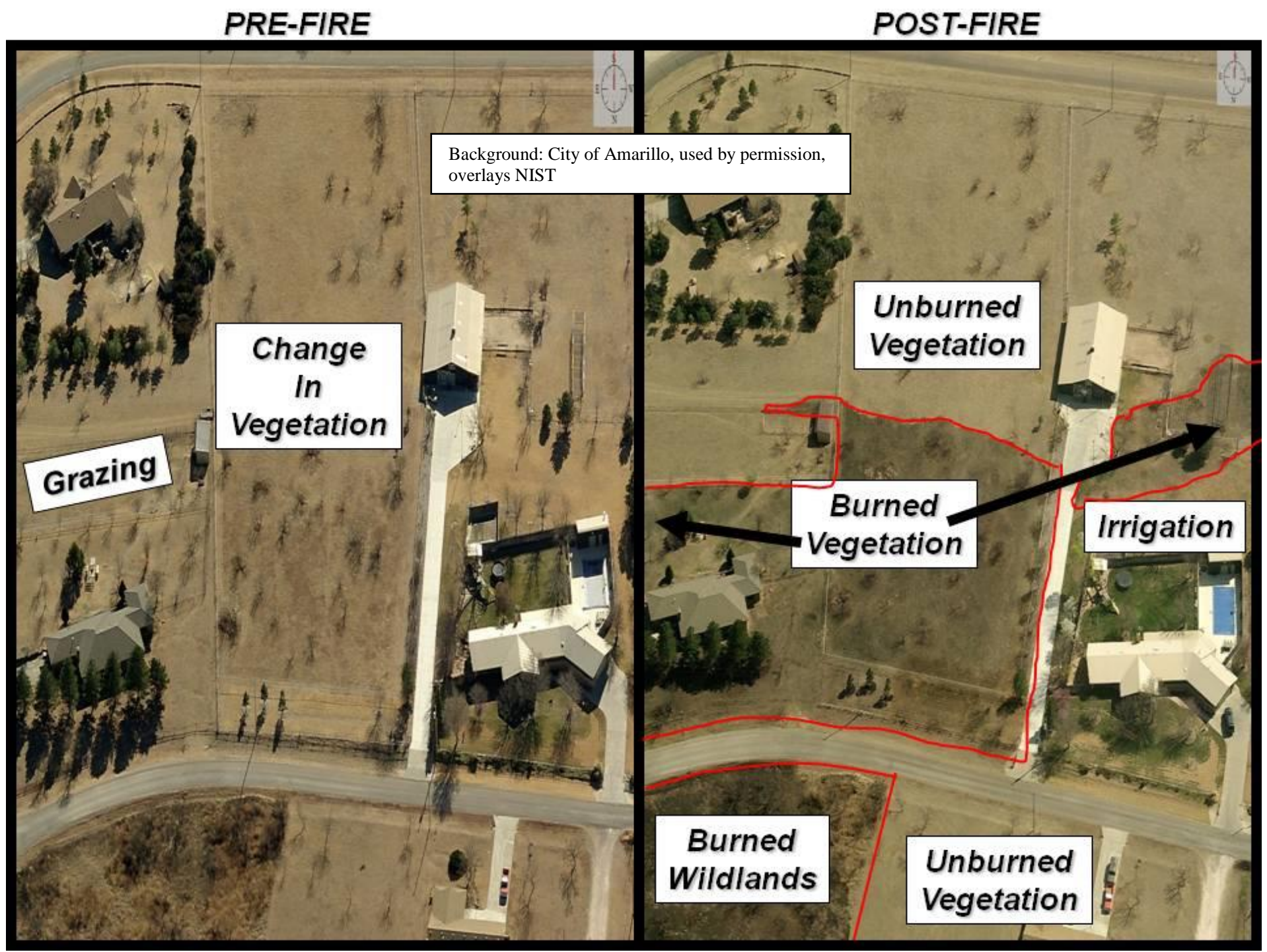

Figure 14 Pre-fire and post-fire imagery showing how vegetation treatments or landuse might have effected fire behavior. Approximate fire line is shown in red on image to the right. 


\subsection{Plateau}

The Plateau area is comprised of residential structures in different communities, including one structure in Timber Creek Canyon. These structures are termed the Plateau Community in this report and are grouped to help portray fire behavior over the study area. This section begins with a tabulation of the damage and destruction to structural elements in the Plateau Community. Generalized fire direction is presented and flame height estimates are portrayed. Fire timeline, flame heights and fire direction information are derived from radio logs, eyewitness discussions and field assessments.

Areas where defensive actions were conducted in the community are detailed.

Topographic characteristics are mapped and discussed. Primary structure categorizations to defensive action type are also portrayed. Finally, a qualitative examination of ignition mechanisms in this community is presented.

\subsection{Damage Assessment, Fire Direction and Fire Timeline}

Figure 15 shows damage to structural elements from the Tanglewood Fire within the Plateau Community. As can be seen in Figure 15, residential structures were sparsely distributed. The residential structures to the south were outside the final fire perimeter. Residential structures inside the fire perimeter in this area saw no damage from the fire but there was damage to other combustible elements.

A breakdown of damage to detached combustible features is shown in Table 9 . Table 10 shows damage to linear features. The extent of exposed but unburned combustible features is not listed as field data collection indicated that determining exposure in this complex topographic environment with varying winds has very large associated uncertainties. The destroyed secondary structures were small sheds, each over $20 \mathrm{~m}$ (66 ft) from the residential structure. The damaged fence was a metal fence with scorched wooden posts near 207 Quail Ridge Road.

Figure 16 shows fire direction and fire progression across the Plateau Community. There were some narrow dirt roads that the fire crossed but these areas were not assessed in the field, so exact fire cross locations are not known. There was, however, one statement by a first responder of the fire crossing Quail Ridge Road to the east of 215 Quail Ridge Road. There were no images obtained in this study of burning in the Plateau Community so timelines are more generalized. Figure 16 shows the main fire front burn times.

First responder discussions described the fire around 207 and 209 Quail Ridge Road as a flanking fire that was trying to push north. Erratic fire behavior was described in the Plateau Community, south of the Palisades Community. There was burning up to the ridge, torching of shrubs and winds described as greater than $32 \mathrm{kph}$ (20 mph).

Topographic features such as cliffs and rock outcrops might have influenced when and how the fire traveled into the canyon areas.

The fire line was described by first responders as creeping south to the east of 215 Quail Ridge Road. Flame lengths around 215 Quail Ridge Road were described by first responders as being $0.3 \mathrm{~m}$ to $0.6 \mathrm{~m}$ high ( $1 \mathrm{ft}$ to $2 \mathrm{ft}$ ) in 2.5 centimeter ( 1 in) tall grass. Burning yucca plants were described as producing embers in this area. 
Table 9 Damage and destruction to detached combustibles in Plateau Community.

\begin{tabular}{|l|c|c|}
\hline \multicolumn{1}{|c|}{ Combustible Feature } & Number Damaged & Number Destroyed \\
\hline Playground Equipment & 2 & 0 \\
\hline Secondary Structures & 0 & 2 \\
\hline
\end{tabular}

Table 10 Damage and destruction to linear features in Plateau Community.

\begin{tabular}{|c|c|c|}
\hline Combustible Feature & Meters Damaged & Meters Destroyed \\
\hline Fences & $195(639 \mathrm{ft})$ & 0 \\
\hline
\end{tabular}

\subsection{Defensive Action Categorizations}

Figure 17 shows areas identified as being defended and the subsequent categorizations of primary structures as to a defensive action category. All structures were identified as being defended except one. First responders anecdotally described 209 Quail Ridge Road as being defended by homeowners. Also, field crews observed a garden hose that might have been used to defend the property. The entire southern flank of the fire in the Plateau Community was identified as being defended.

Damage or destruction to other structural elements found in the area was not specifically identified as being defended. The two destroyed secondary structures appeared to have been burned to the ground with no containment. The two damaged playground features were in low fuel areas. One was a trampoline with no signs of defensive actions. The second was a play structure with scorching and some burned features that might indicate defensive actions. The fence was a metal fence with wood posts that received scorching and possibly other destruction.

\subsection{Topographic Information}

Figure 18 shows radar derived percent slope across the Plateau Community. Figure 19 shows radar derived aspect across the Plateau Community. The Plateau is relatively flat as can be seen in Figure 18. As shown in Figure 19, there are two plateau areas that are oriented towards the canyon area from southwest to northeast. The fire entered the canyon communities around these areas.

\subsection{Vegetation Element Ignition Mechanisms}

The majority of structural element ignition mechanisms for the Plateau Community are described above and no further information is known in this regard. Again, though not studied specifically in this paper, vegetation treatment did appear to have consequences on fire behavior. For example, Figure 20 shows green grass around 209 Quail Ridge Road and the lack of fire in this area. While none were documented, the exact contributions of defensive actions, if any, are not known.

However, field assessments at 209 Quail Ridge Road identified small areas of vegetation burning adjacent to noncombustible sections of the house as shown in Figure 21. It is not known if these areas were extinguished through manual intervention or if they extinguished independently. These burned areas were in the direction of the fire front and might have ignited due to ember accumulation against the wall possibly combined with the non-mowed grass directly adjacent to the house. 


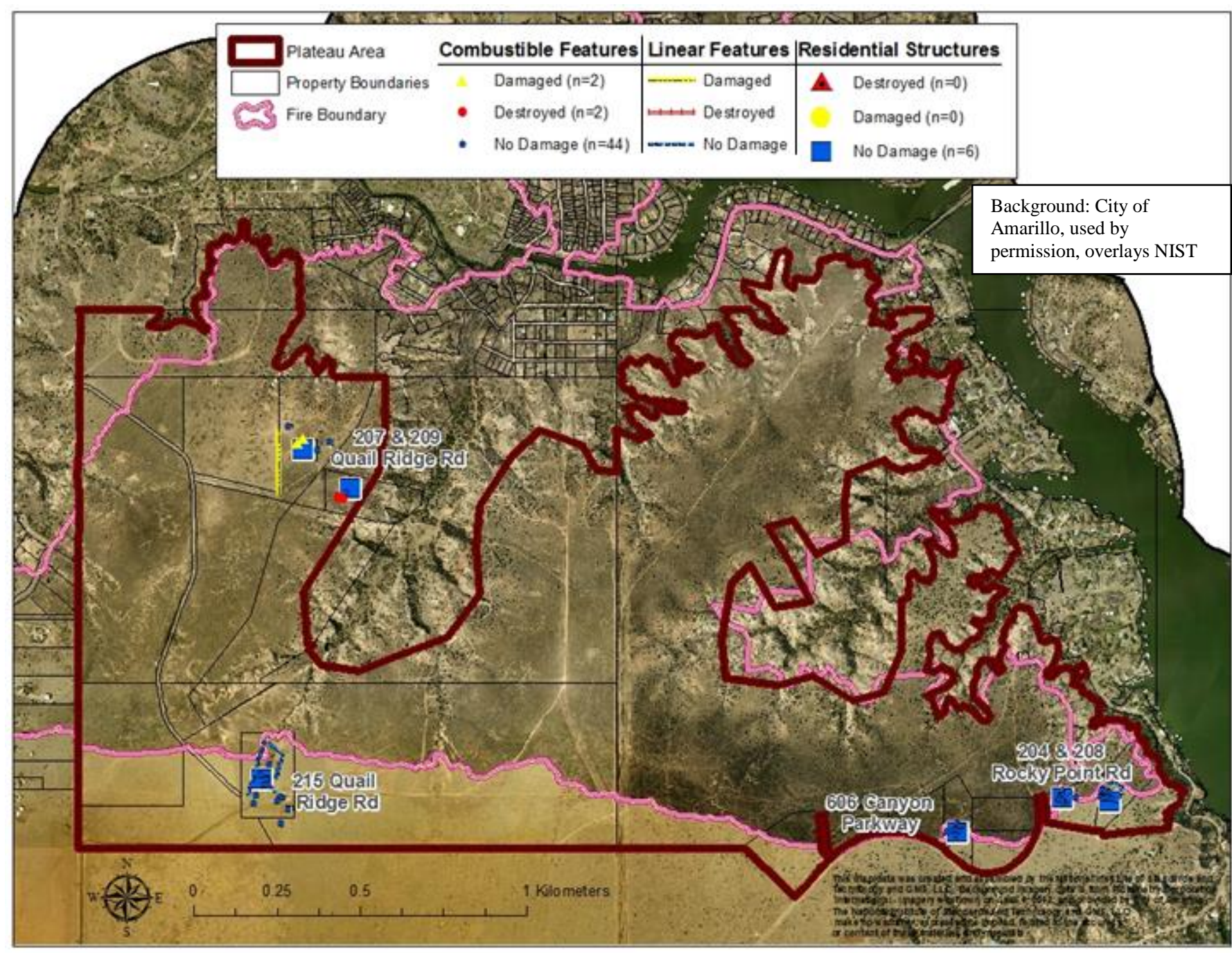

Figure 15 Damage to structural elements in the Plateau Community. 


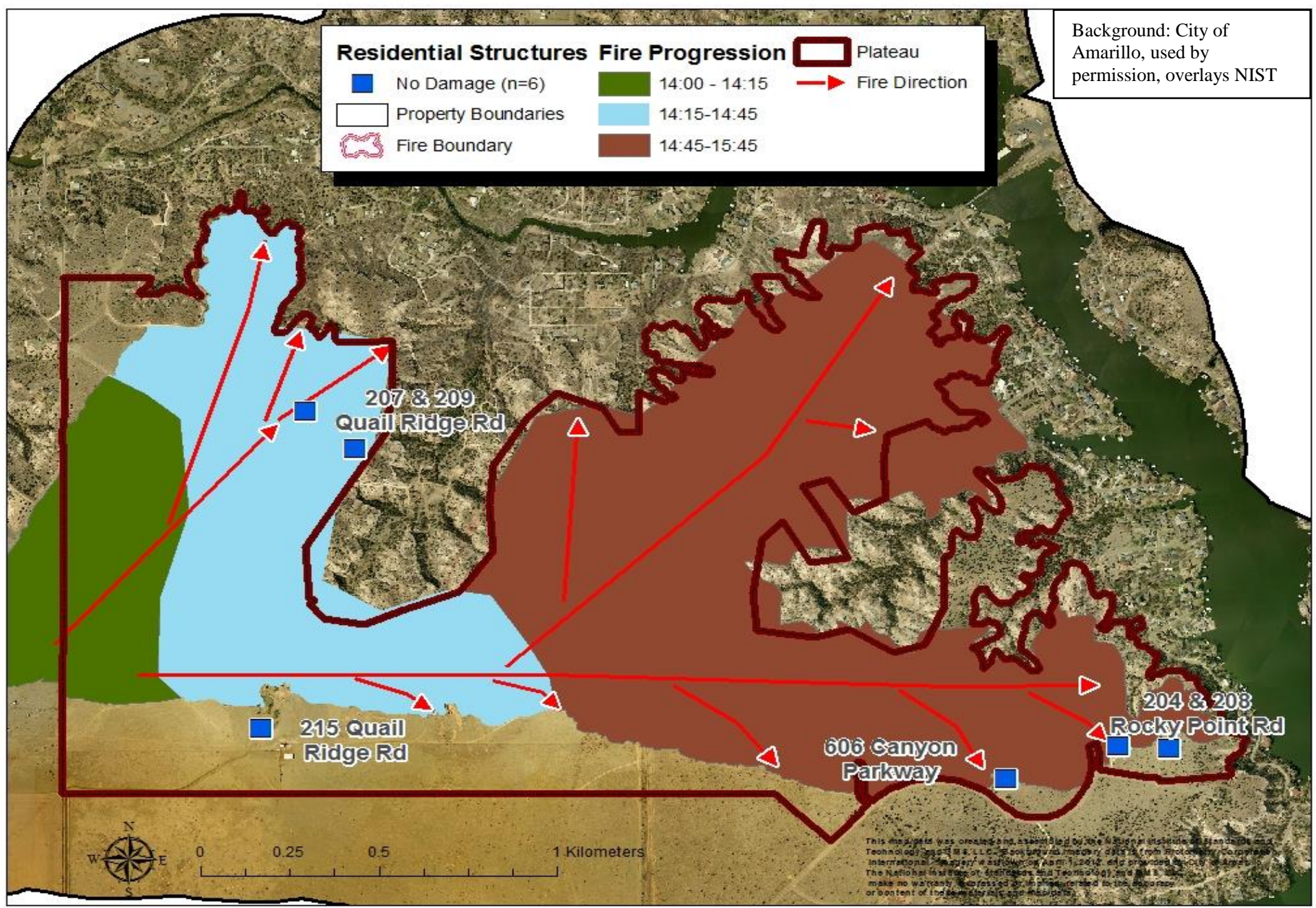

Figure 16 Fire direction and fire timeline in Plateau Community. All times are on 2/27/2011. 


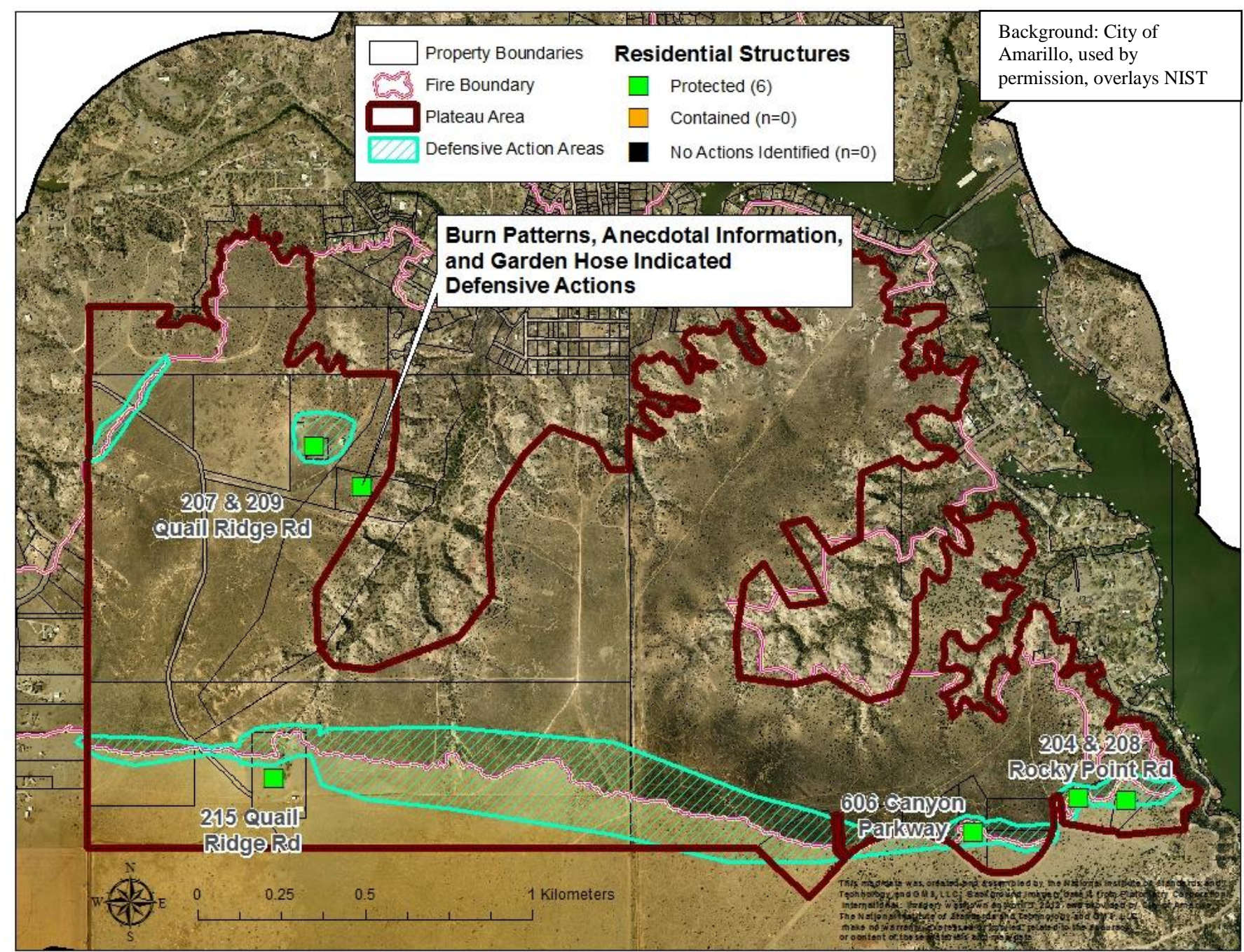

Figure 17 Plateau area defensive action locations and primary structure categorizations in the Plateau Community. 


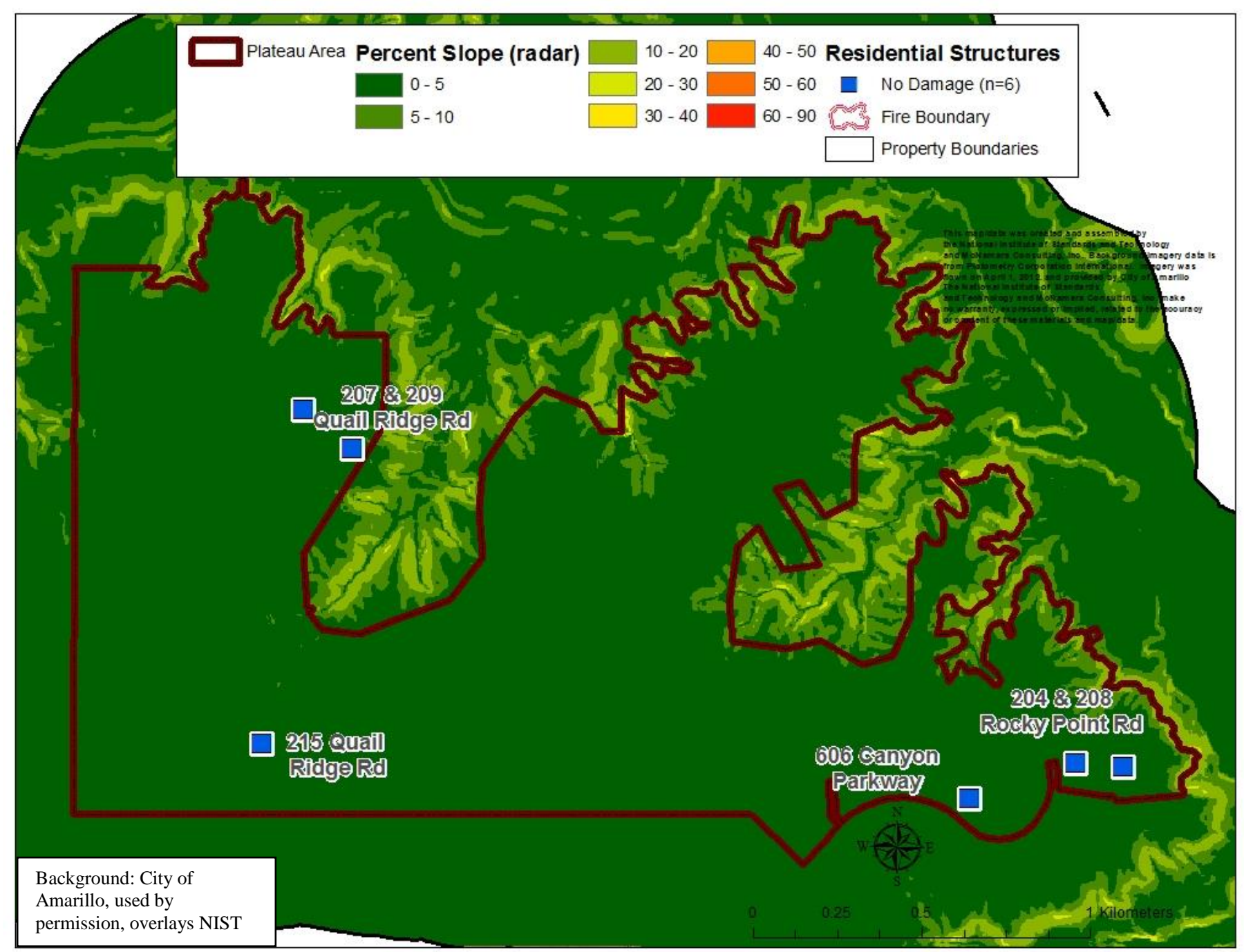

Figure 18 Radar derived percent slope in Plateau area. 


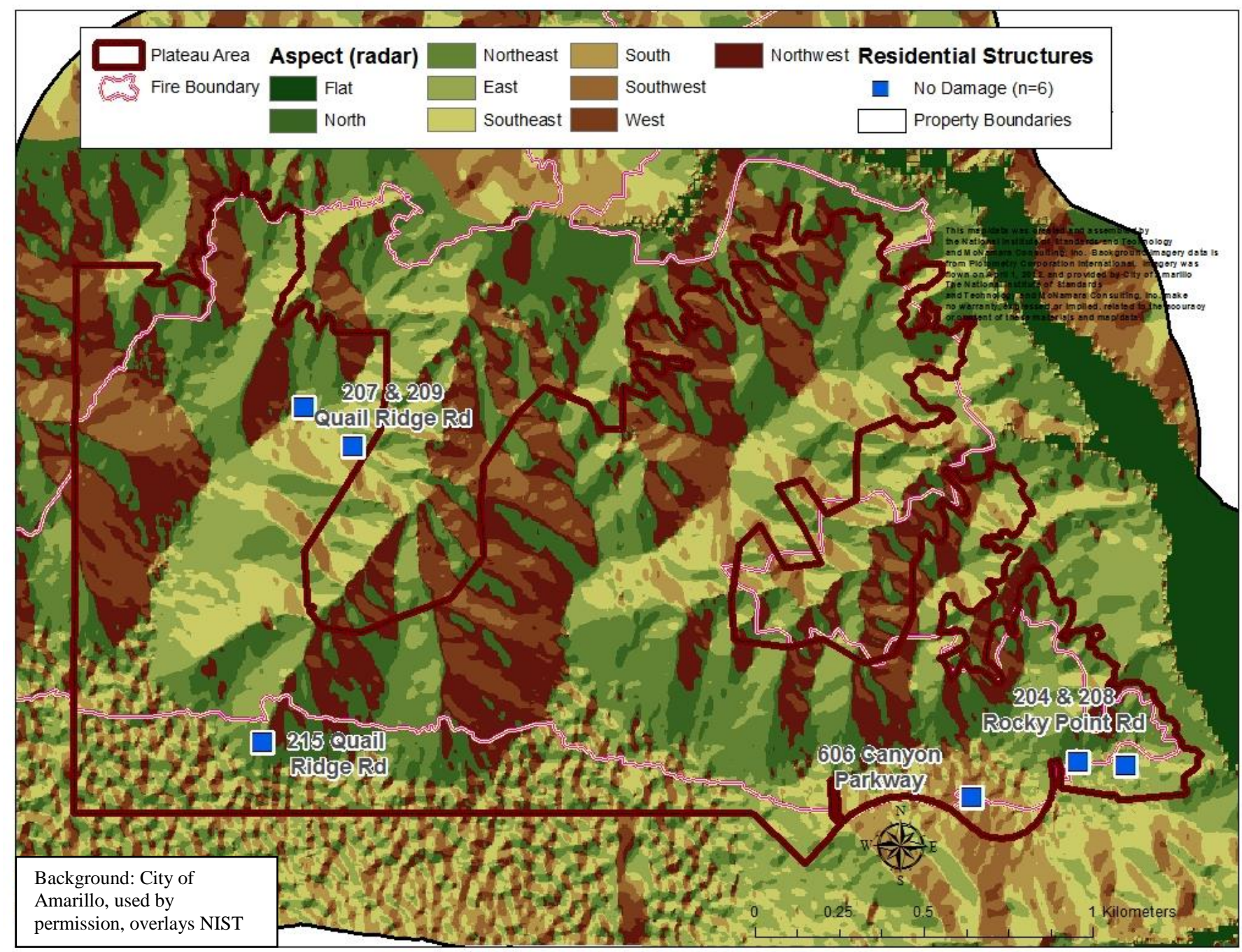

Figure 19 Radar derived aspect in Plateau Community. 


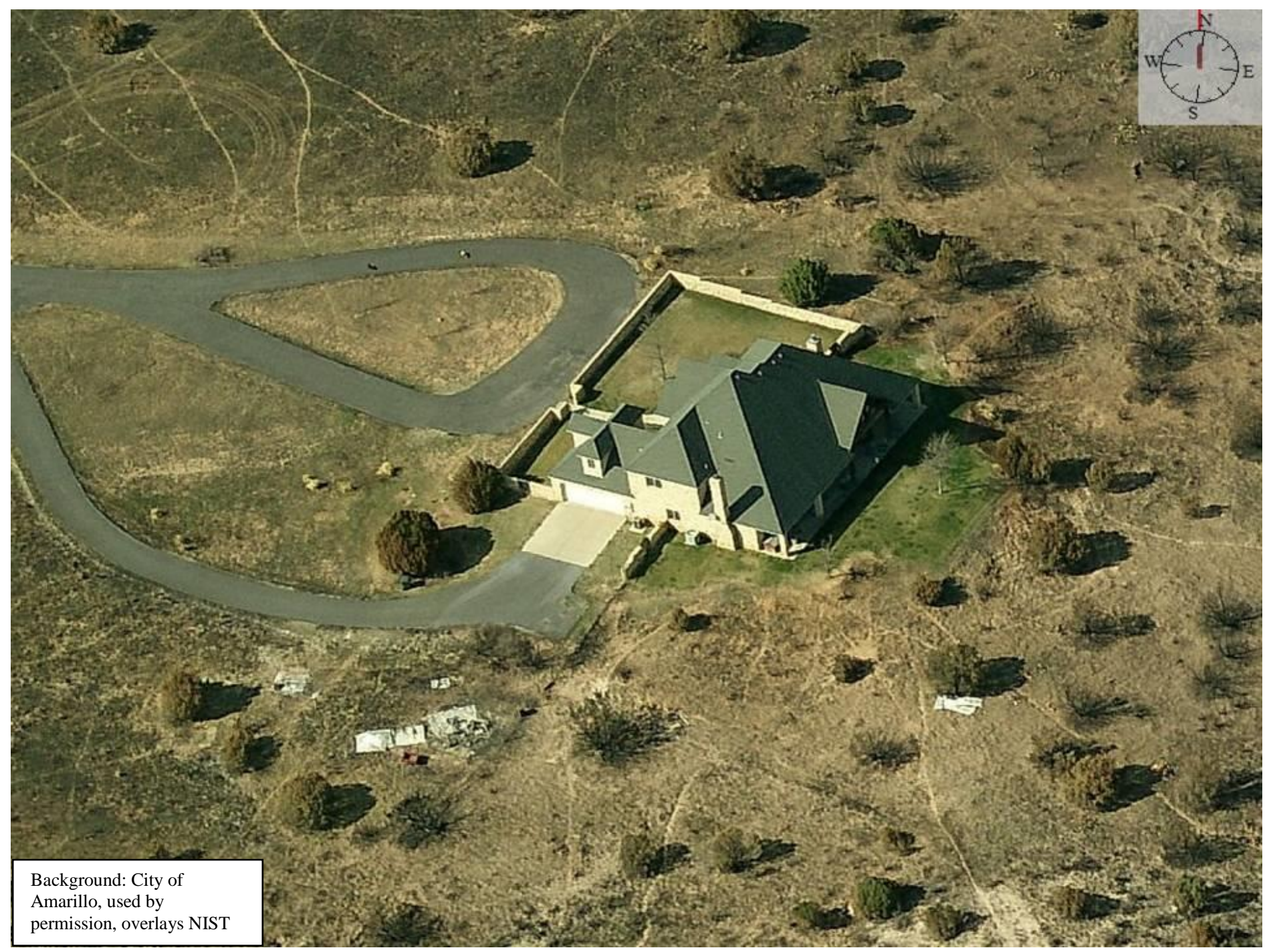

Figure 20 Treated vegetation around 209 Quail Ridge Road that might have helped to stop fire from contacting house. Exact contributions of defensive actions are unknown. 


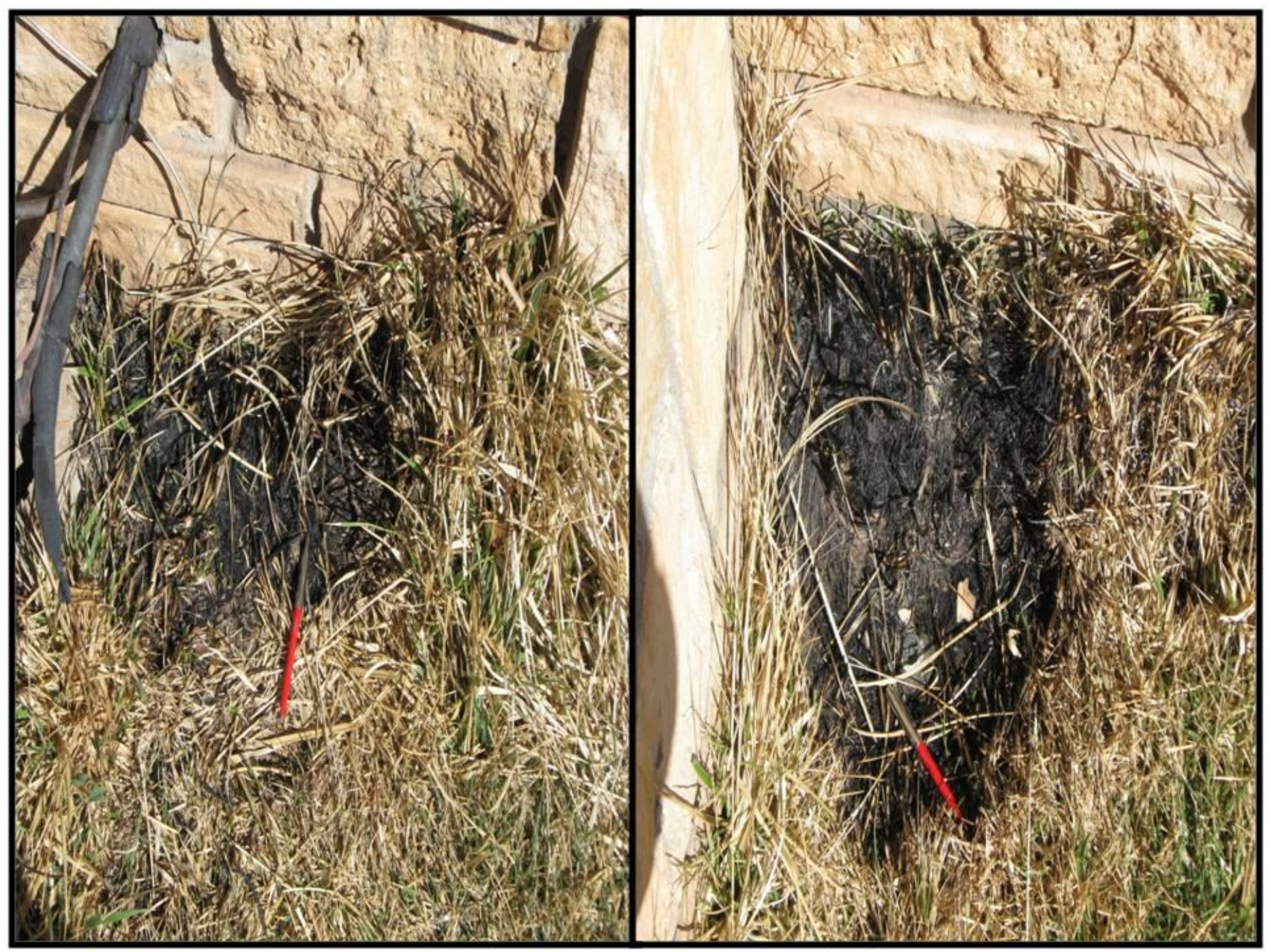

Figure 21 Two distinct vegetation ignitions adjacent to structure at 209 Quail Ridge Road. Red feature is $15 \mathrm{~cm}(6 \mathrm{in})$ long ballpoint pen, NIST photos. 


\subsection{Palisades South}

This section begins with a tabulation of the damage and destruction to structural elements in the Palisades Community south of Lake Tanglewood. Also included in this section is a small area of the Lake Tanglewood Community south of the lake. Additionally, fire direction generalized from field observations of directional scorching are presented. Fire timeline information portrayed is derived primarily from radio logs. The fire behavior in this area is portrayed. Defensive actions conducted in the community along with defensive action categorizations of structures are also described. Topographic characteristics are mapped and discussed. Finally, identified structural and vegetative element ignition mechanisms are detailed.

\subsection{Damage Assessment, Fire Direction and Fire Timeline}

Figure 22 shows damage to structural elements from the Tanglewood Fire within the southern portion of the Palisades Community and a small selected portion of the Lake Tanglewood Community. As can be seen in Figure 22, there were three damaged residential structures, 17 destroyed residential structures and one residential structure with damage to an attached combustible deck. There was numerous damage and destruction to combustible and linear features. A breakdown of damage to detached combustible features is shown in Table 11. Damage and destruction to linear features by length is shown in Table 12.

Table 11 Damage and destruction to detached combustibles in Palisades South and selected portions of South Lake Tanglewood Community.

\begin{tabular}{|c|c|c|}
\hline Combustible Feature & Number Damaged & Number Destroyed \\
\hline Deck & 0 & 2 \\
\hline Playground Equipment & 13 & 0 \\
\hline Car Ports & 0 & 2 \\
\hline Secondary Structures & 7 & 35 \\
\hline Dock & 0 & 1 \\
\hline Vehicles & 5 & 15 \\
\hline RV/Camper & 0 & 1 \\
\hline Boats & 2 & 0 \\
\hline Trailers & 6 & 6 \\
\hline Lawn Mowers & 2 & 0 \\
\hline Firewood Piles & 1 & 0 \\
\hline Corrals & 2 & 0 \\
\hline $\begin{array}{l}\text { Other Items (Building Material, Stock } \\
\text { Feed, Small Railroad Ties and } \\
\text { Retaining Walls, Trash/Brush Piles, } \\
\text { Machinery, Grills, Propane Tanks, } \\
\text { Stairs, Lawn Furniture, Tires, Wagons } \\
\text { and Other Small Features) }\end{array}$ & 20 & 58 \\
\hline
\end{tabular}

Figure 23 shows fire direction in the Southern Palisades and Lake Tanglewood portion of the study area. The fire directions shown in Figure 23 appeared to have been driven by weather, topographic features and available fuels. Fire traveled up and down canyons both in the direction of the wind as well as perpendicular to the main wind direction when topographic configurations aligned in this manner. Additionally, eyewitness observations 
described swirling fire behavior in Southern Palisades, which was verified in post-fire field observations of directional scorching recorded near 450 Casino Drive.

There were 9 locations where the fire was recorded as crossing roads. It is possible the fire crossed multiple locations along these roads. It is also possible that some of these fire crossings might have been a consequence of flames or radiant heat and not embers. For instance, there was a residential structure (mobile home) that was destroyed at 102 Gary Drive. Flames or radiant heat from this large combustible feature might have ignited vegetation or the destroyed structure at 111 Gary Drive to the northeast.

Table 12 Damage and destruction to linear features in Palisades South and selected portions of Lake Tanglewood Community.

\begin{tabular}{|l|c|c|}
\hline \multicolumn{1}{|c|}{ Linear Feature } & Meters Damaged & Meters Destroyed \\
\hline Landscaping Border & $37(121 \mathrm{ft})$ & $263(863 \mathrm{ft})$ \\
\hline Fence & $2026(6647 \mathrm{ft})$ & $375(1230 \mathrm{ft})$ \\
\hline Retaining Wall & $1014(3327 \mathrm{ft})$ & $563(1847 \mathrm{ft})$ \\
\hline
\end{tabular}

Additionally, there were two locations where the fire was recorded as jumping across Lake Tanglewood, a distance of approximately $23 \mathrm{~m}(75 \mathrm{ft})$. The most western location shown in Figure 23 was apparent in the field due to a large tree that experienced scorching on the southern side of the lake and burn patterns on the northern side of the lake in the direction of the fire. There was also one location where radiant heat was identified in the field as spreading the fire across a road, or possibly multiple roads, near Janet and Gary Drive.

Some specific time observations are shown in Figure 24. These observations all came from radio logs or the brief and not geographically complete flight by the Amarillo sheriff helicopter. In addition to the specific time observations shown in Figure 24, there was an additional radio log report of numerous structures being on fire at 15:37 in Palisades. It is not clear if this refers to southern or northern Palisades or both.

However, it can be seen in the helicopter fly over that 113 Janet Drive, while completely destroyed, still had smoke and flames present at 18:18. This indicates the possibility that the structure was ignited later, after the main fire front. The structure at 120 Russell Drive was completely destroyed with no flames or smoke emission visible at the same time. Additionally, some white smoke could be seen coming from the direction of 507 Casino Drive, which was also identified by two first responders as burning later (i.e., around 17:00).

First responders specifically described flames or destruction from 465 and 519 Casino Drive occurring early in the fire (e.g. around 15:00). The burning in the yards of 401 Myrtle Drive and 401 Casino Drive were also described as occurring early in the fire (e.g. around 15:00). Flare-ups of combustibles and vegetation occurred into the morning of February 28th in the southern Palisades area. Significant flare-ups occurred later (e.g. after dark) and were all identified as being defended. These included a burning retaining wall that broke windows and possibly ignited soffits at 102 Gary Drive. The mobile home at 102 Gary Drive was also identified as being destroyed at this time (e.g. after dark around 23:45). Additionally, damaged combustibles along Hill Drive ignited later, while vegetation ignited earlier (around 14:45). Finally, some of the combustibles, including a large Box Car used for storage, on the south side of Jamie Lane across the street from 55 
Jamie Lane were identified as burning late in the night of February $27^{\text {th }}$ into the morning of February $28^{\text {th }}$.

\subsection{Fire Behavior}

Figure 25 shows some general fire behavior observations inferred from post-fire ground and aerial imagery. As can be seen in Figure 25, there are three primary canyons that the fire traveled through. The fire did not, however, travel through all areas within each of these three canyons and appeared to be very topographically oriented in relation to the wind. Each of these canyons contained smaller sub-canyons and other topographic features. It is thought, though not confirmed, that the main fire front moved down each canyon at relatively the same time (i.e., somewhere between 14:30 to 15:00). A generally south facing oblique aerial image of the western most canyon in the southern Palisades Community is shown in

Figure 26. The fire might have entered this canyon from the plateau area in several different locations. These fire entrances, however, into this canyon appeared to be limited to topographic lows or drainage locations along the canyon rim where there were continuous fuels between the changes in geology types and less steep slopes.

Conversely, cliffs, rocky outcrops and defensive actions (retardant drops) might have prevented the fire from entering the canyon in some locations. Fire behavior in this western canyon was more intense on the southeastern side of the canyon as can be seen in Figure 26, where scorching of shrubs was prominent on the southeastern side and less so on the northeastern side. The divide of this change in fire intensity was along the dry drainage channel of the canyon. However, burning did occur in ground and structural fuels on the northeastern side of the canyon and into the properties on this side of the canyon. The middle canyon is portrayed in south and east facing oblique images shown in Figure 27 and Figure 28. Entry into this canyon was confined to an area on the western side of the canyon located to the northeast of 209 Quail Ridge Road. This area was characterized by a narrow area of rock outcrops with vegetation allowing fire to travel into the canyon. Additionally, there were fewer cliffs in this area of the canyon. As shown in Figure 28, when the fire reached the bottom of the canyon, crowning fire occurred.

Stand replacing fires occurred on the southern side of Casino Drive in the middle canyon but only in certain sections on the northern side. Fire behavior in the wildlands to the west of 519, 513 and 507 Casino Drive was generally spotty and again topographically oriented. For example, 475 Casino Drive, the damaged home, was sheltered from fire behavior coming from the south to southwest due to topographic features.

As shown in Figure 27, fire then traveled up the canyon located to the south of Jamie Lane. Fire, however, did not enter the southern portion of the canyon. At least one fire retardant drop was delivered in that location and the contribution was unknown. Fire behavior consistently appeared to be more intense on what might be called the leeward side of topographic features compared to the windward side. In this area of the Tanglewood Fire, portrayed in Figure 278, the leeward side of the slopes was generally facing northeast. This is shown in Figure 27, where stand replacing fires occurred on the leeward side, while shrubs on the windward side were not consumed. This in part could be due to higher fuel loads or possibly an eddy effect of the wind/fire on these windward sides of topographic features. The video from the sheriff helicopter flight shows how fire 
behavior changed with topographic positions in the northern Lake Tanglewood Community as described in section 9. A similar effect could have occurred in this Southern Palisades area. Figure 29 shows fire behavior in the eastern most canyon area of the Southern Palisades and Lake Tanglewood Communities. The same behavior is noticed in this canyon and adjacent areas where stand replacing or high intensity fires occurred on the leeward side of topographic features. Additionally, fire behavior was focused on the canyon bottom and somewhat into the southeastern side of the canyon with little or no fire behavior seen on the northwestern side of the canyon (north to northeast facing slopes).

\subsection{Defensive Action Categorizations}

Figure 30 shows locations of identified defensive actions along with the resulting categorization of structures as to a defended category. As shown in Figure 30, a power line was down during the incident preventing first responders from entering into the eastern side of the Southern Palisades Community until after the main fire front had passed. The homeowner at 537 Casino Drive, however, was described as being present for the entire incident.

Almost all homes on the western side of the downed power line were shown to have been protected. Homes at 365 and 375 Casino Drive and 450 Myrtle Drives did not have defensive actions identified. Defensive actions, however, along Casino Drive likely prevented fire from entering these properties as no burned features were identified. The sprinklers left on at 401 Casino Drive appeared to coincide with the final fire perimeter on this property. It is not, however, known if it was the sprinkler being on during the time of fire, continued historic use of the sprinkler to treat the lawn in the specified area, or a combination of both that ultimately stopped the fire.

The defensive action that occurred at 102 Gary Drive occurred later in the incident, after the adjacent structure was destroyed. The burning residential structure at 507 Casino Drive was contained (i.e. fire was prevented from spreading beyond that structure) and it is believed this is one of the last homes to burn in this southern Palisades area. This containment along with containment of a destroyed large secondary building at 100 Janet Drive resulted in 100 Janet Drive being categorized as protected.

The residential structure at 475 Casino Drive had no specific defensive actions identified but there was evidence of mechanical alteration of burned straw bales adjacent to the home. Consequently, the structure was classified as protected. The residential structure at 450 Casino Drive had a carport destroyed next to the home but no specific defensive actions were identified. Interior homes along Janet Drive did not have defensive actions identified but there was also limited fire behavior in this area.

Table 113 shows a count of damaged and destroyed linear features, and damaged and destroyed detached combustible features, along with the number of features with identified defensive actions. Again, Table 13 highlights the main shortcoming with the defensive action identification method utilized. This shortcoming, the lack of identification of a defensive action around a particular structure or feature, does not mean that a defensive action did not occur. 
Table 13 Damage and destruction to features in Southern Palisades and selected portions of North Lake Tanglewood categorized by identified defensive actions.

\begin{tabular}{|l|c|c|}
\hline \multicolumn{1}{|c|}{ Feature } & $\begin{array}{c}\text { Number } \\
\text { Damaged/Destroyed }\end{array}$ & $\begin{array}{c}\text { Number Identified as } \\
\text { Defended }\end{array}$ \\
\hline Linear Feature & 32 & 3 \\
\hline $\begin{array}{l}\text { Detached Combustible } \\
\text { Features }\end{array}$ & 138 & 4 \\
\hline
\end{tabular}

\subsection{Topographic Information}

Figure 31 portrays percent slope for Palisades South and selected portions of Lake Tanglewood Communities. As mentioned above, topography appeared to play an important role in fire behavior in the Palisades South and selected portions of Lake Tanglewood Communities. The steepest slopes were found along the rim of the canyon and these steep slopes or cliffs appeared to prevent fire spread from the plateau into the communities. The fire appeared to enter the canyons in areas of more moderate slopes along the canyon rim. Microscale steep slopes found along the canyon bottoms might also have played a role in fire behavior in this portion of the study area.

As can be seen in Figure 32, damage and destruction was more prevalent on one side of a particular canyon compared to the other side. The side facing the wind appeared to have more damage. There is damage and destruction into the interior of the Southern Palisades Community. As discussed below, some of this might have been due to structure to structure fire spread.

\subsection{Structural Element Ignition Mechanisms}

Structures located along Hill Drive and portions of Casino Drive (the western canyon described in section 7.2 above) exhibited some damage and destruction to structural elements. Many first responders were in this area and some of the damaged features were specifically identified as defended. As described above, in Section 7.2, structures on Hill Drive received less exposure to the fire compared to those on the opposite side of the Canyon on Casino Drive. Even within specific canyon sides, different exposures were experienced based on other topographic features present.

The primary damage close to homes found in this area was to a storage shed located on 110 Hill Drive and railroad tie retaining walls and borders located on the parcels at 110 and 120 Hill Drive and 401 and 430 Casino Drive. These damaged features were close to or directly adjacent to wildlands. The damaged storage shed was over $19 \mathrm{~m}(62 \mathrm{ft})$ from the closest primary structure. Damaged railroad tie retaining walls were $9 \mathrm{~m}(29 \mathrm{ft})$ away from the residential structure located at 110 Hill Drive and about $19 \mathrm{~m}(62 \mathrm{ft})$ away from the residential structure located at 120 Hill Drive.

The primary structure at 400 Casino Drive was also damaged. This was due to a pile of trash bags with unknown debris that burned and melted a vinyl soffit. The radiant heat or flames appeared to be sufficient to melt the vinyl soffit but no scorching to the underlying enclosed wood soffit was document by field observers. The brick siding was scorched. 


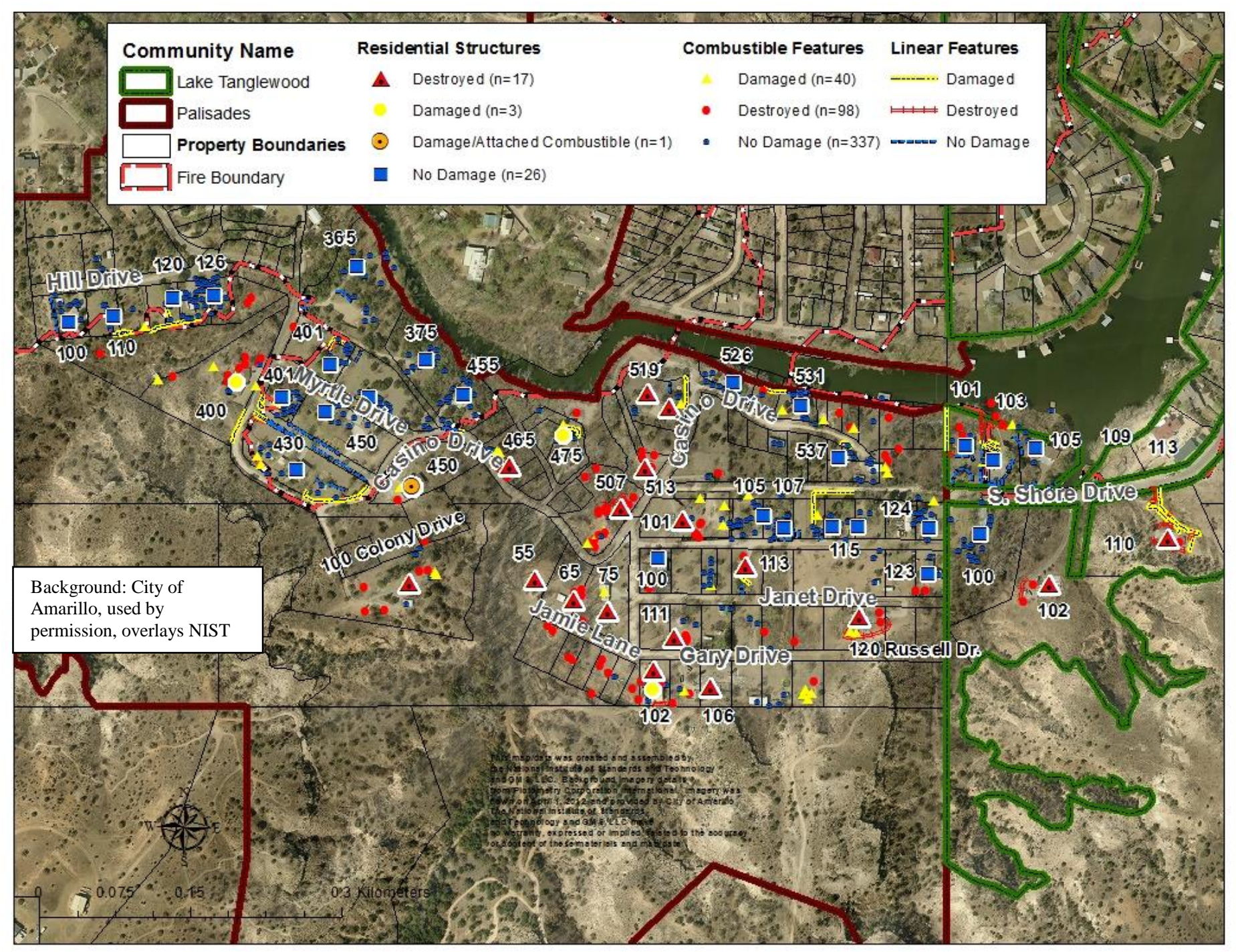

Figure 22 Damage to structural elements in the southern Palisades Community and selected portions of the South Lake Tanglewood Community. 


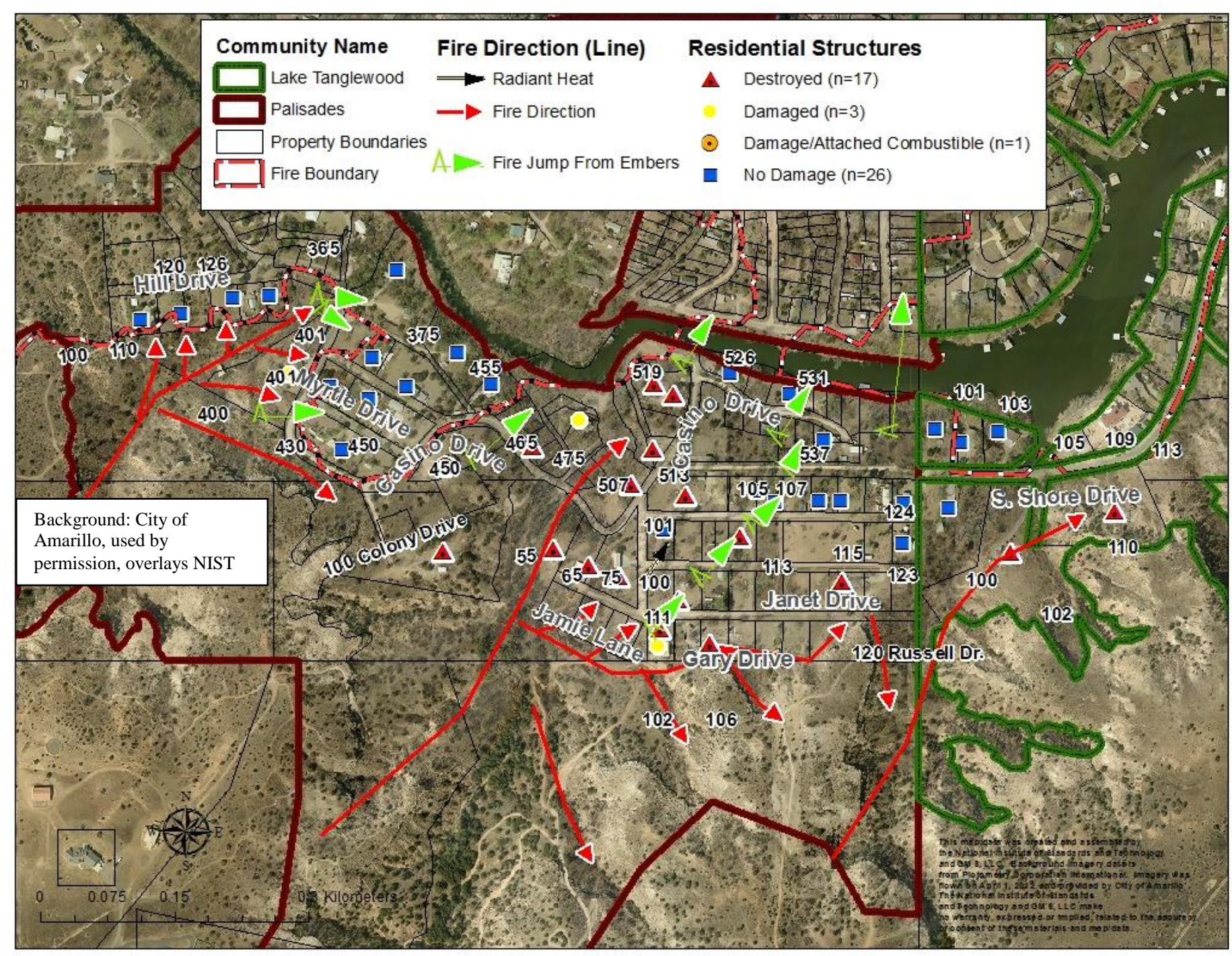

Figure 23 Fire direction in Southern Palisades and South Lake Tanglewood Community. The main fire front moved through area between 14:30 and 15:30 on 2/27/2011. 


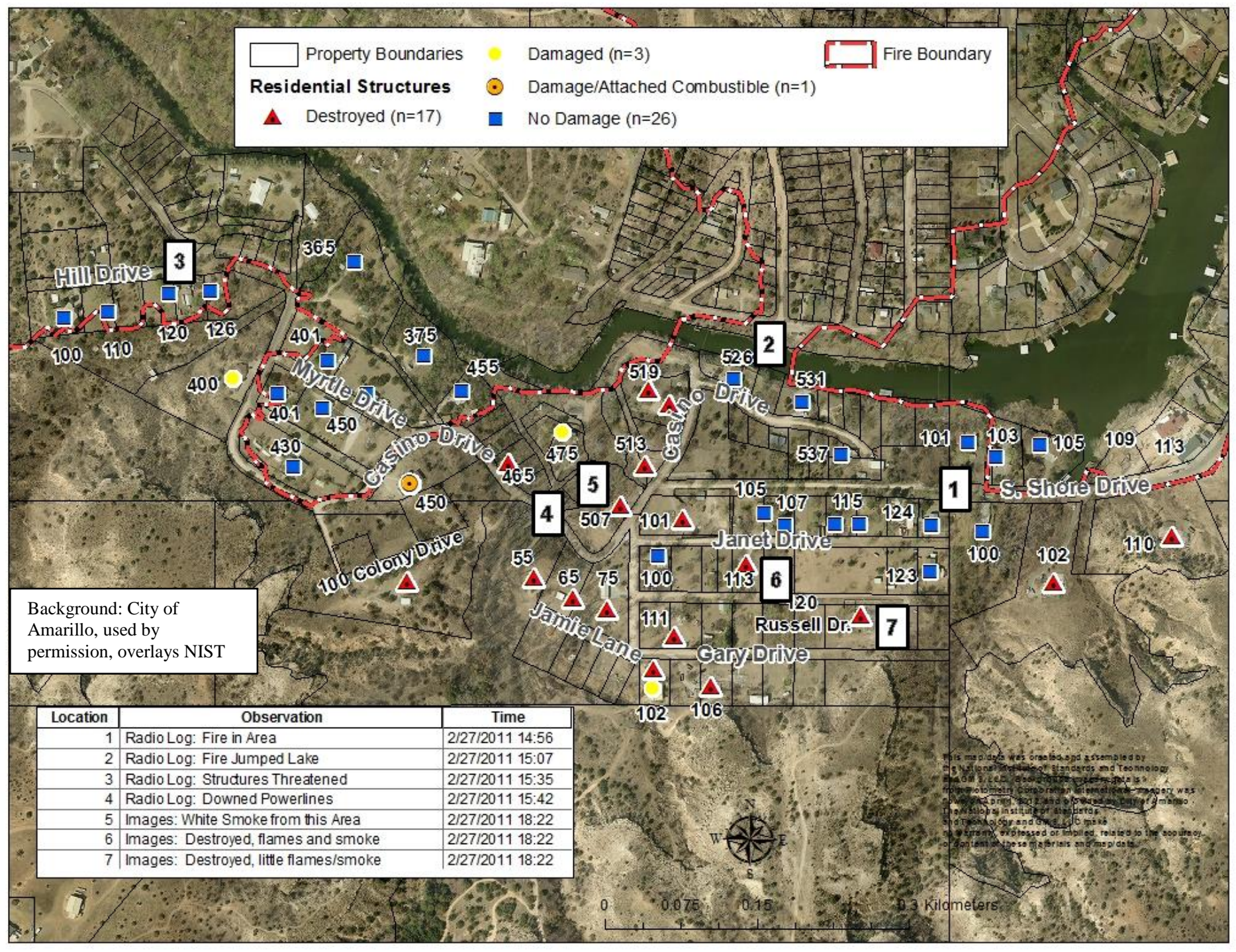

Figure 24 Palisades South and portions of South Lake Tanglewood with specific time observations on 2/27/2011. 


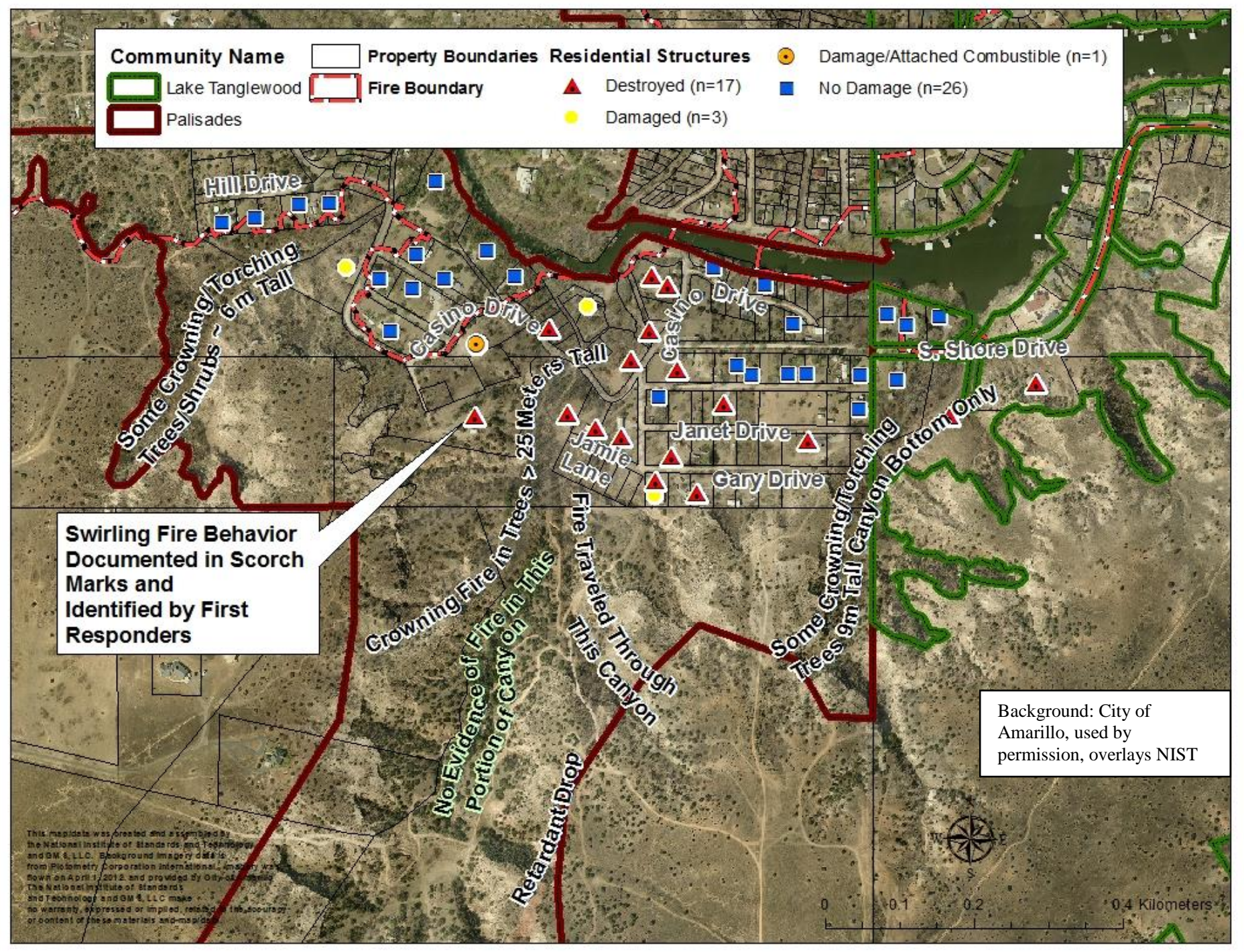

Figure 25 General fire behavior observations and location of retardant drop in southern Palisades community and portions of South Lake Tanglewood. 


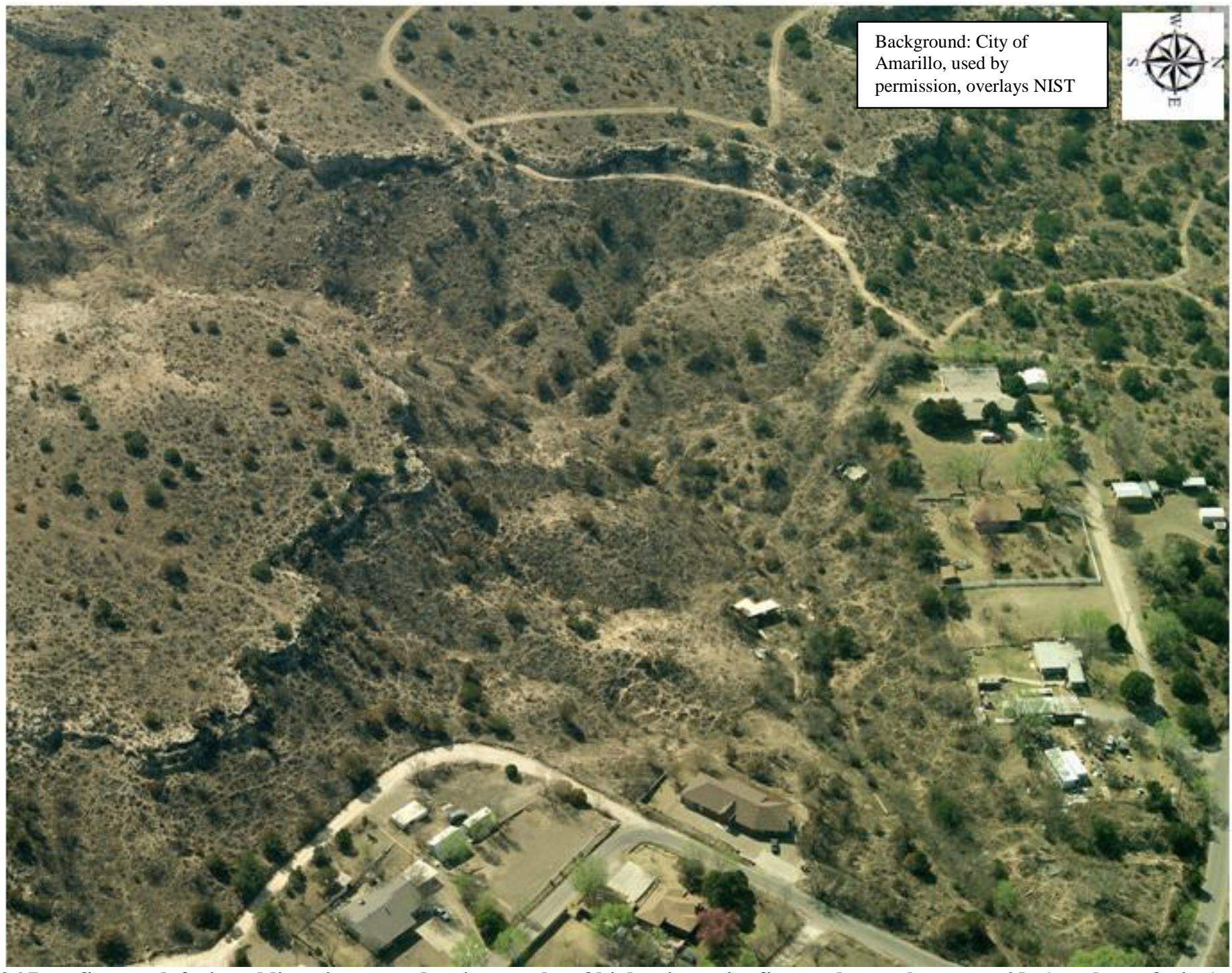

Figure 26 Post-fire south facing oblique imagery showing results of higher intensity fire on the southeastern side (northeast facing) of the canyon compared to the northwestern side. 


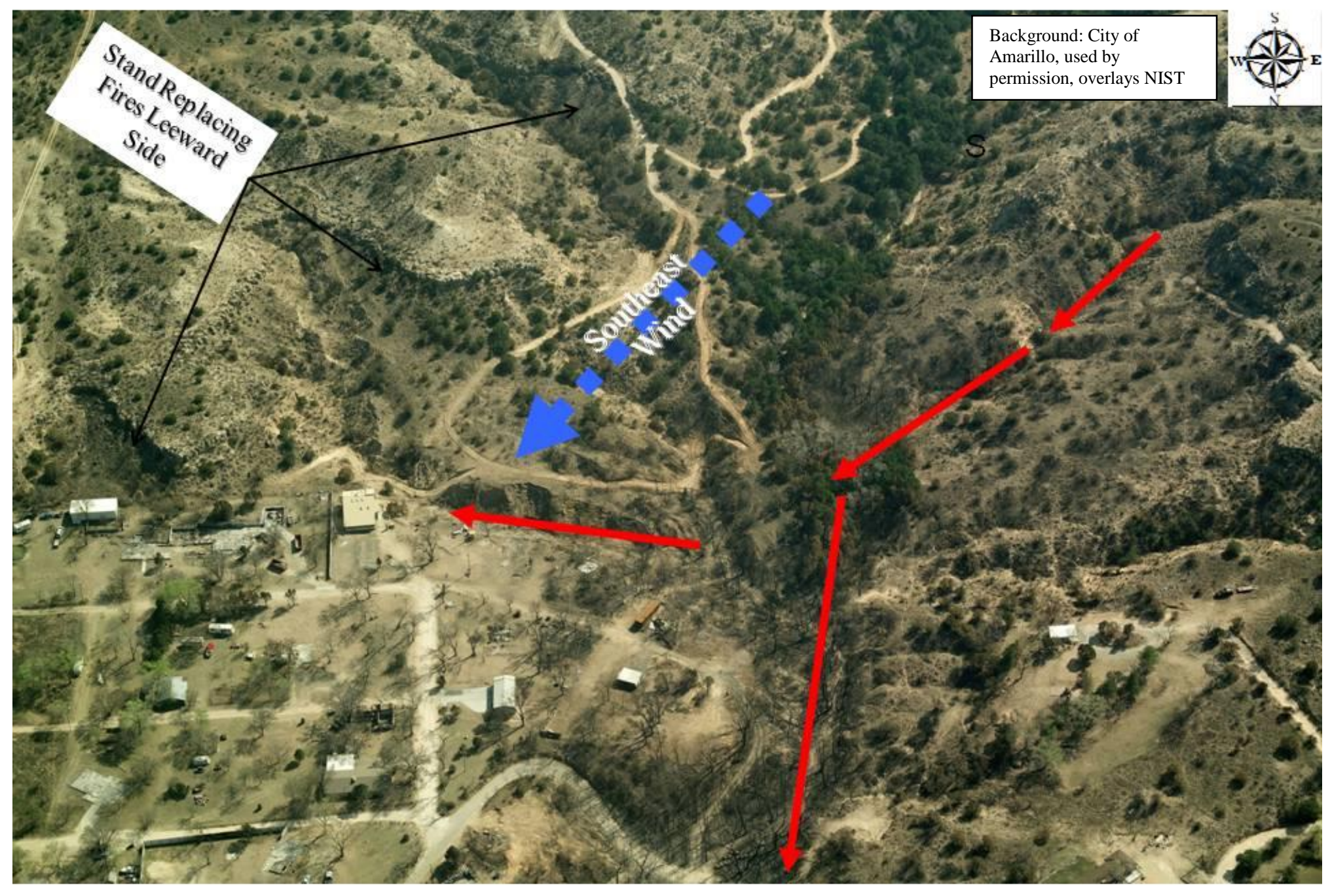

Figure 27 Post-fire south facing oblique imagery showing results of fire behavior in the upper portion of the middle canyon area of Southern Palisades Community. 


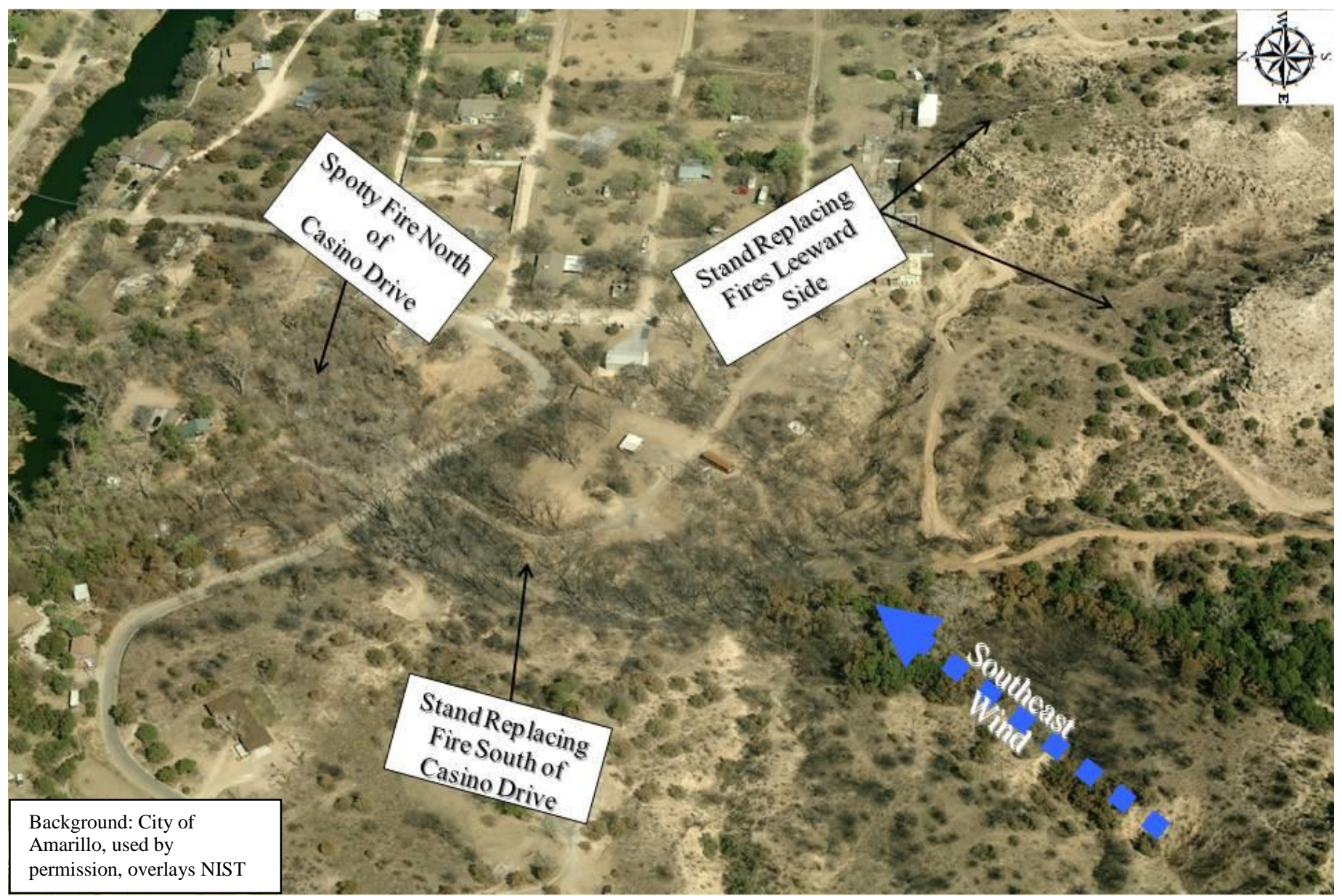

Figure 28 Post-fire east facing oblique imagery showing results of fire behavior in the bottom of the middle canyon area of Southern Palisades Community. 


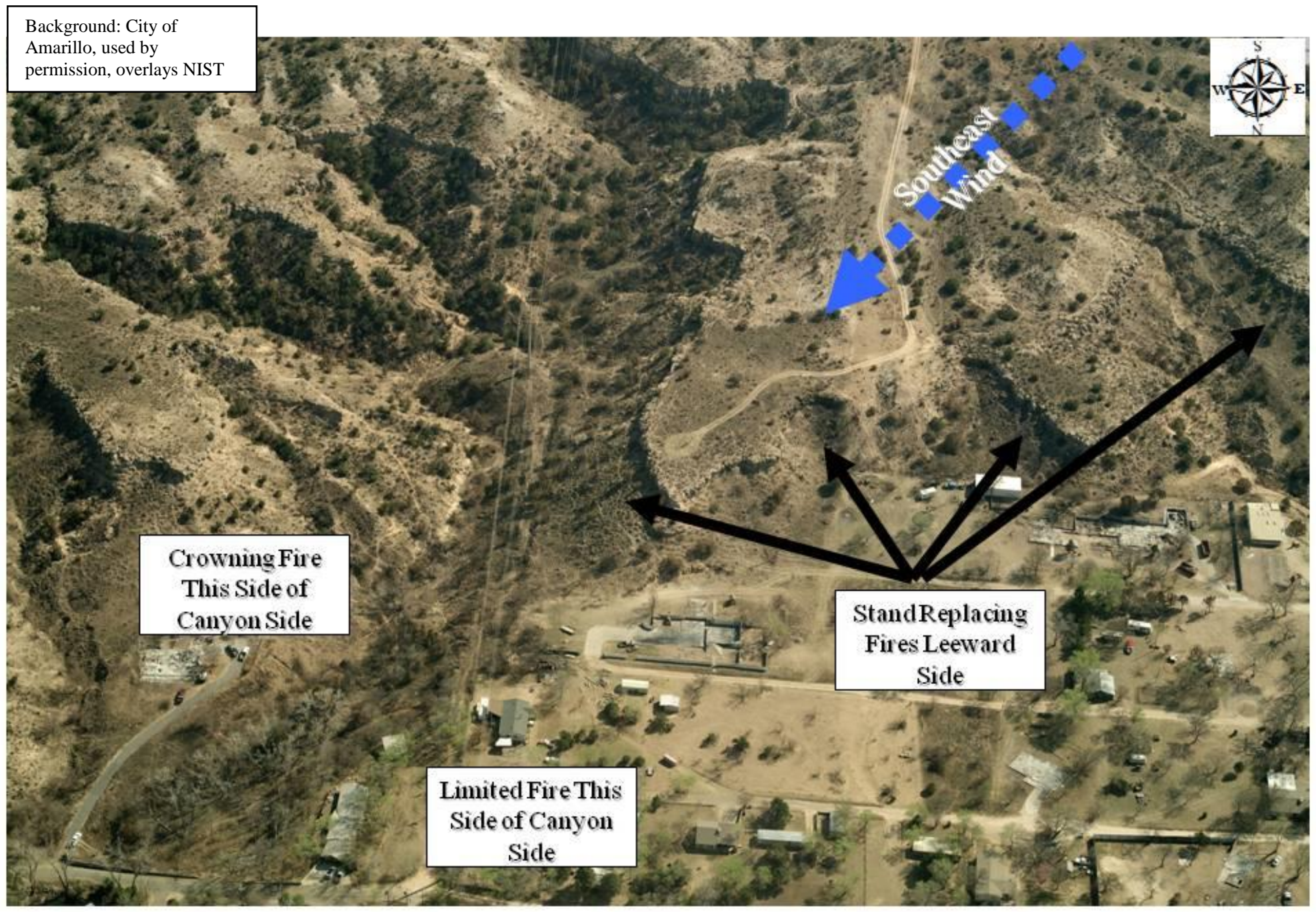

Figure 29 Post-fire south facing oblique imagery showing results of fire behavior in the eastern most canyon area of the Southern Palisades and South Lake Tanglewood Communities. 


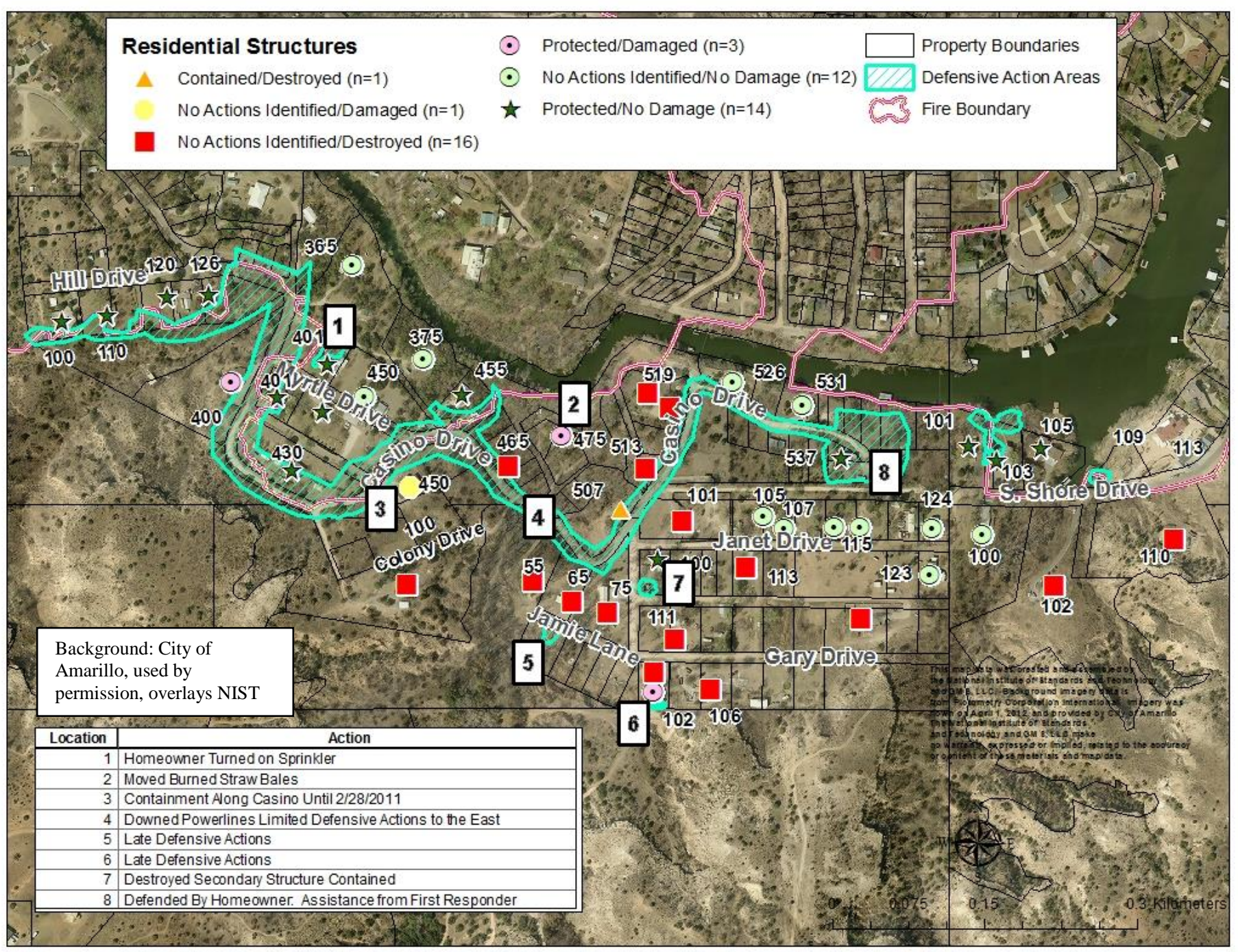

Figure 30 Defensive action locations and primary structure categorizations in Southern Palisades and selected areas of South Lake Tanglewood Communities. 


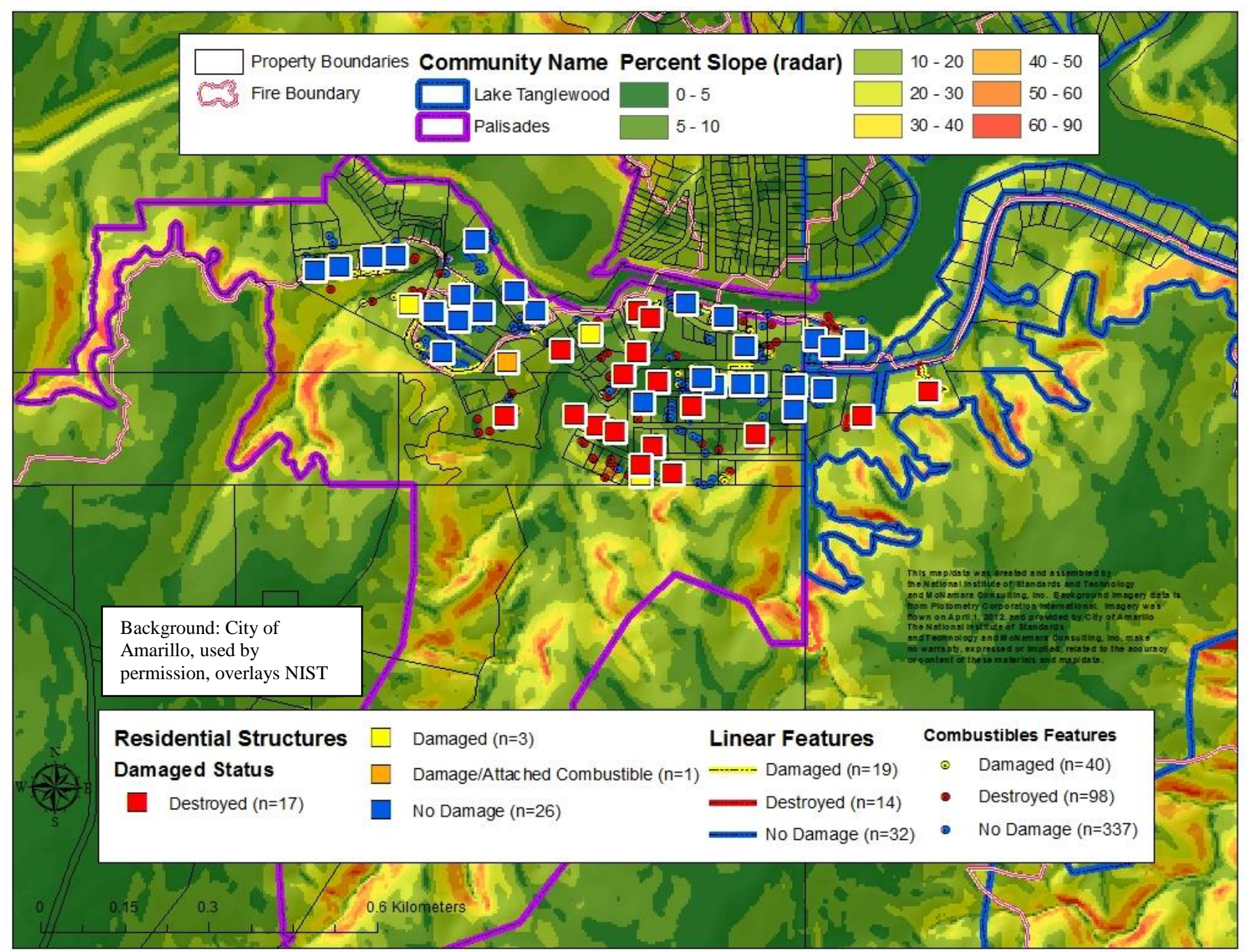

Figure 31 Radar derived percent slope in Palisades South and selected portions of South Lake Tanglewood Communities. 


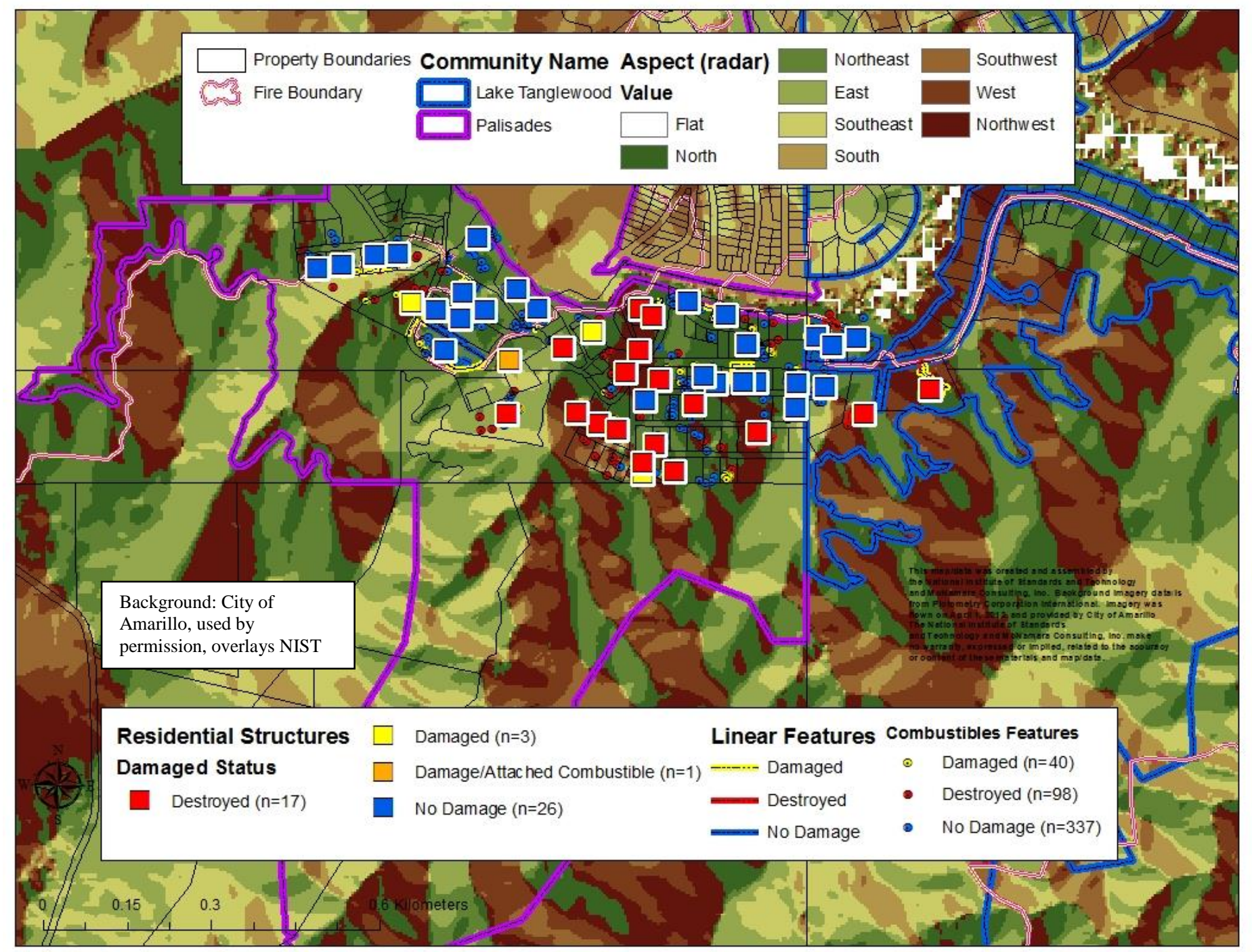

Figure 32 Radar derived aspect in Palisades South and selected portions of South Lake Tanglewood Communities. 
This feature was not specifically recorded as defended and the burned feature appeared to be completely consumed.

Other damage found around 400 Casino Drive was to railroad tie borders, stairs, and retaining walls. Additionally, a bird feeder, plastic trash cans and a partially melted grill cover were damaged or destroyed from ember exposure. All but the grill cover and the trash pile described above were directly adjacent to wildlands.

The structure on 400 Casino Drive was on a terraced platform that might have helped direct fire and embers away from this house. The lack of damage and scorching to other features located around the house provide evidence for a lack of exposure. The destroyed trash piles were located closest to the adjacent wildlands. Additionally, the damage to the grill cover was minor, with ember damage absent on other parts of the cover or other features (e.g. clothed lawn furniture) located adjacent to the grill.

Furthermore, damage to lawns and structural elements on the opposite side of Casino Drive from 400 Casino Drive occurred in topographic locations across from the canyon or areas with topographic configuration that might have helped influence fire behavior. However, the exact contribution of defensive actions and exposure conditions are not known. For example, the terracing might have provided first responders a means to defend the property.

Damage or destruction to structural elements along Casino Drive in the middle canyon area described above was universal among all primary structures found adjacent to this canyon. There were, however, three homes that received varying degrees of damage and were not destroyed. These were 450 and 475 Casino Drive and 102 Gary Drive.

450 Casino Drive is the most western home adjacent to the middle canyon. An attached car port to the structure was destroyed. The attachment appeared to be metal to brick siding. There were numerous first responders in the area but it is not known if this particular home was defended or if the brick siding and other structural features prevented the residential structure from igniting. The volume of fuels this car port contained is not known. Fire burned directly up to this house in low grasses and no damage or scorching was observed on the brick siding.

475 Casino Drive also had damage to various structural elements attached and adjacent to the house as well as destruction of a large secondary building. Wildland vegetation burning was spotty around 475 Casino Drive with localized intense burning. Numerous features were damaged including hay bales leading from

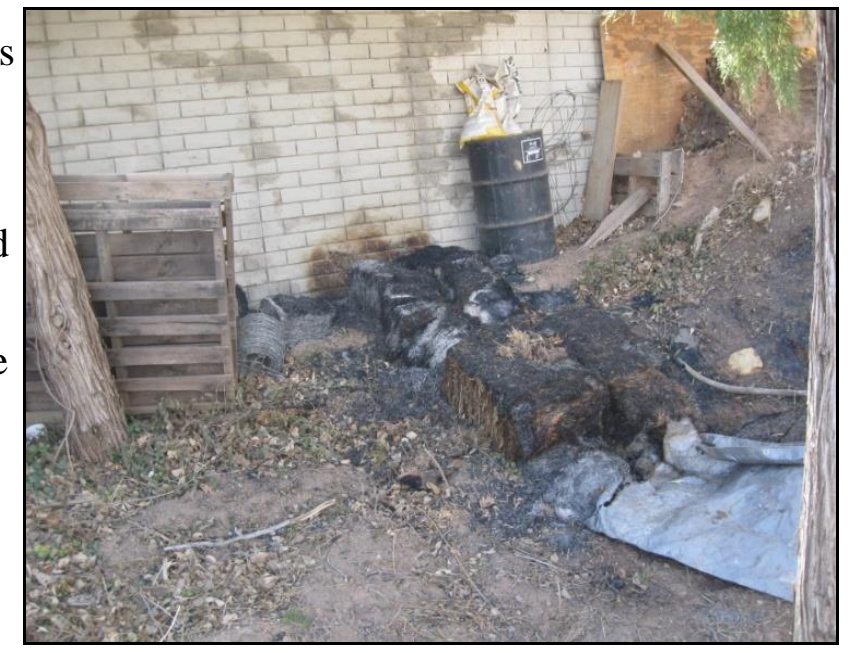

Figure 33 Burned hay bales leading from destroyed secondary structure to primary structure causing scorching on the brick siding. Categorization of defensive actions is unknown, NIST photo. 
the destroyed structure to the residential structure as shown in Figure 33. The defensive action categorization is not known. However, there were other partially burned items and cut burned trees (time of cutting not known), which could indicate defensive actions.

102 Gary Drive is the other non-destroyed home in this middle canyon area. This home

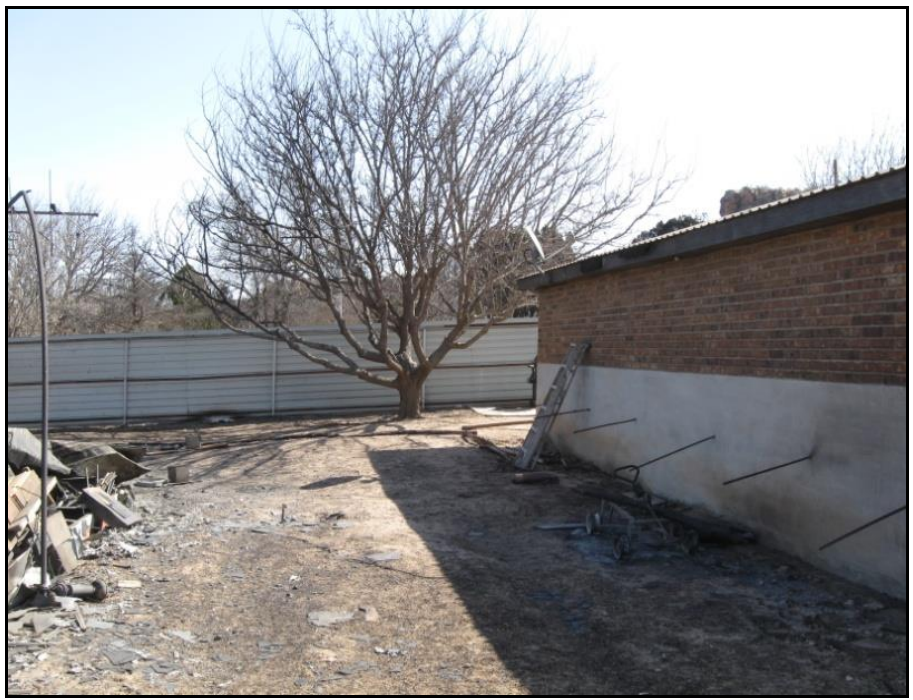

Figure 34 Unidentified burned features adjacent to the northern side of the residential structure at 102 Gary Drive. These features are believed to be ignited by the burning mobile home to the north of the brick residential structure, NIST photo. was damaged but the damage appeared to be from reignitions of vegetation and rail road ties adjacent to the home. These items were identified as being defended after 17:00 on February $27^{\text {th }}$. There was also destruction of some unidentified attached feature as shown in Figure 34, which appeared to be caused by burning of the adjacent mobile home. This unidentified feature was not identified as being defended and the brick likely protected the home from the burning of these unidentified objects. The burning of these objects, however, did not appear to produce flames of significant

height as is evident in Figure 34, which resulted in damage to the wood eaves found in one location above the unidentified features.

While the brick and metal siding likely helped to protect the non-destroyed residential structure at 102 Gary Drive, there was also evidence the structure was protected by a specific topographic configuration. There was a canyon to the west of 102 Gary Drive that saw a stand replacing fire as shown in Figure 35A. This canyon might have helped direct fire away from the home as is evident in Figure 35B, where a juniper bush, yucca plants, and rail road ties had minimal scorching and no burning, while vegetation and features to both the north and south of this area saw extreme fire behavior.

It should also be noted that structure to structure fire spread might have occurred in the Southern Palisades Community. The secondary structure at 475 Casino Drive appeared to have helped spread the fire directly to the residential structure at this address.

Secondary structures at 75 Jamie Lane and 465 Casino Drive might also have ignited the residential structures on these properties. As mentioned above, structure to structure fire spread might have occurred from the mobile home at 102 Gary Drive to the residential structure at 111 Gary Drive. The burning of Gary Drive might also have resulted in the ignition of 113 Janet Drive. Other structure to structure fire spread might also have occurred. 


\subsection{Vegetative Element Ignition Mechanisms}

As shown in Figure 36, fire also spread into the yards of some properties along Hill Drive

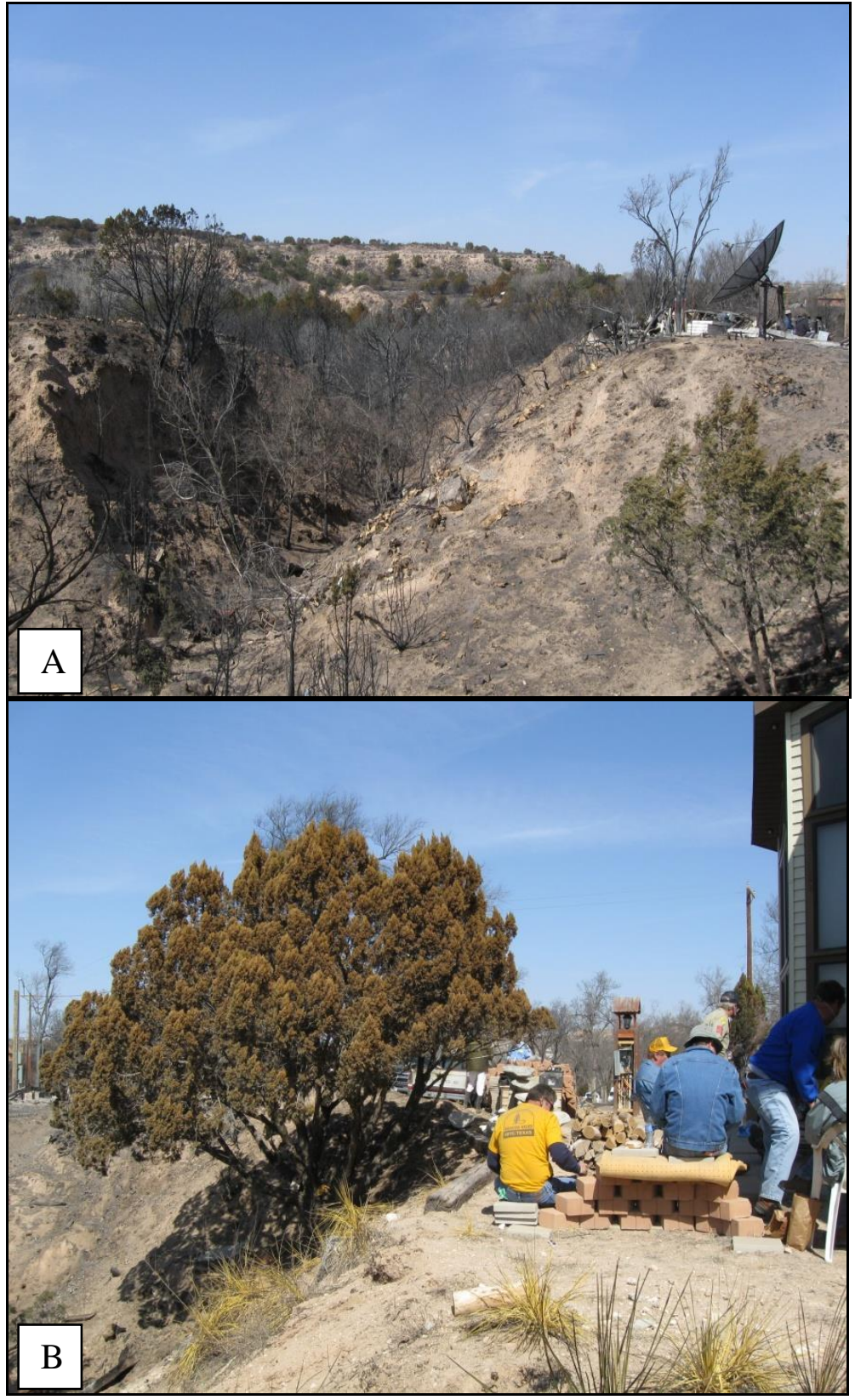

Figure 35 A: Stand replacing fire in the canyon to the west of 102 Gary Drive. B: Vegetation and building features with minimal damage at the top of the canyon, indicating topographically influenced fire behavior. Image taken from the south side of $\mathbf{1 0 2}$ Gary Drive looking north, NIST photos. as well as on Casino Drive, burning into the residential grass areas. It is assumed that the fire was suppressed in these yards. However, as shown in Figure 36, the fire did not travel into the grass on some properties. These properties can be shown to exhibit a higher degree of redness as shown in the pre-fire false color display shown in Figure 36. Red areas in color-infrared imagery displayed as a false-color composite portray areas that have photosynthetically active vegetation. This imagery, however, was flown two years prior to the incident and might not reflect pertinent ground conditions.

Nonetheless, the grass areas that are redder might have had more treatment (i.e., water and possibly nutrition) that could have helped prevent fire spread on these properties. It is also possible that first responders suppressed

the fire and treatments, either those present or lack thereof, on the yards did not affect fire behavior. Also, the properties on Hill Drive appeared to be located on a less exposed area due to topography and wind. Other areas along Janet Drive and Gary Drive also showed burn patterns that corresponded to possible vegetation treatment in pre-fire imagery. 


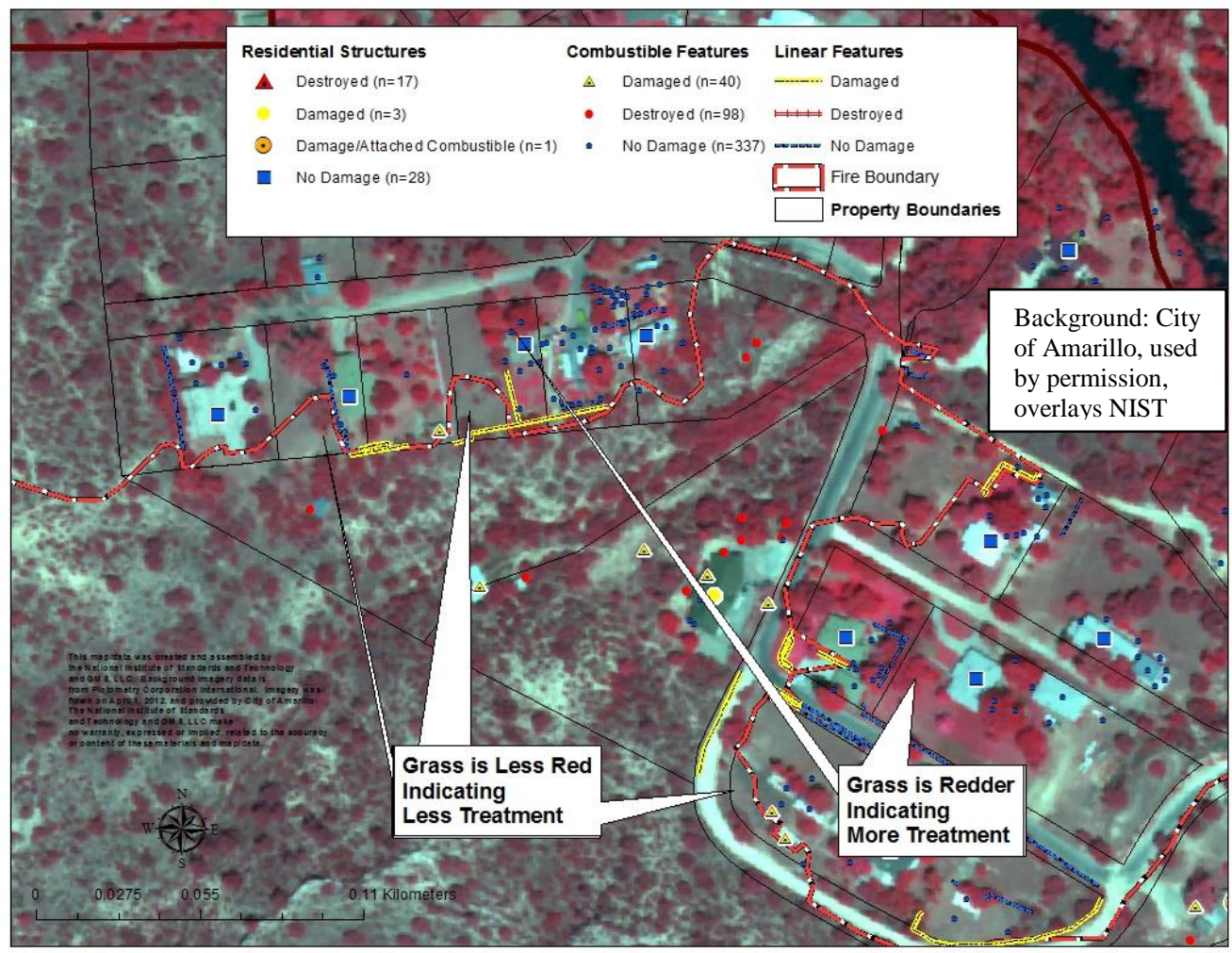

Figure 36 Portions of the fire perimeter overlaid on pre-fire (2009) color-infrared imagery.

Fire did not travel into redder residential grass areas. This could be due to exposure conditions, defensive actions, pre-fire vegetation treatment or a combination of these factors.

\subsection{Palisades North and Tangle Aire}

This section begins with a tabulation of the damage and destruction to structural elements in the Palisades Community North of Lake Tanglewood. Also included in this section is a small area of the Lake Tanglewood Community North of the lake and the Tangle Aire Community. Additionally, fire direction generalized from field observations of directional scorching are presented. Fire timeline information is derived from radio logs and some images.

This section also discusses fire behavior in the Palisades North, sections of South Lake Tanglewood and Tangle Aire Communities. Defensive actions conducted in the community along with defensive action categorizations of structures are also described. Topographic characteristics are mapped and discussed. Finally, identified structural and vegetative element ignition mechanisms are detailed.

\subsection{Damage Assessment, Fire Direction and Fire Timeline}

Figure 37 shows damage to structural elements from the Tanglewood Fire within the Palisades North, Tangle Aire and portions of North Lake Tanglewood Communities. There were two damaged residential structures, 15 destroyed residential structures, two residential structures with damage to attached combustibles and 27 residential structures with no damage. There was numerous damage and destruction to detached combustible 
and linear features. A breakdown of damage to detached combustible features is shown in Table 14. Damage and destruction to linear features by length is shown in Table 15.

Table 14 Damage and destruction to detached combustibles in Palisades North, Tangle Aire and selected portions of North Lake Tanglewood Communities.

\begin{tabular}{|l|c|c|}
\hline \multicolumn{1}{|c|}{ Combustible Feature } & \multicolumn{1}{|c|}{$\begin{array}{c}\text { Number } \\
\text { Damaged }\end{array}$} & $\begin{array}{c}\text { Number } \\
\text { Destroyed }\end{array}$ \\
\hline $\begin{array}{l}\text { Short Linear Features (Fence, Retaining Walls, } \\
\text { Railroad Ties) }\end{array}$ & 7 & 4 \\
\hline Playground Equipment & 3 & 1 \\
\hline Car Ports & 0 & 1 \\
\hline Secondary Structures & 2 & 4 \\
\hline Machinery & 1 & 2 \\
\hline Vehicles & 3 & 1 \\
\hline RV/Camper & 0 & 2 \\
\hline Boats & 1 & 2 \\
\hline Trailers & 2 & 0 \\
\hline Lawn Mowers & 0 & 5 \\
\hline Firewood Piles & 2 & 3 \\
\hline Building Material Piles & 3 & 3 \\
\hline Trash Piles & 0 & 12 \\
\hline Grills & 1 & \\
\hline $\begin{array}{l}\text { Other Items (Propane Tanks, Stairs, Hot Tub, } \\
\text { Lawn Furniture, Tires, Work Bench, Planters, Gas } \\
\text { Can, Lawn Art, Wheelbarrow, Burn Barrel and } \\
\text { Other Small Features) }\end{array}$ & 8 & \\
\hline
\end{tabular}

Figure 38 shows fire direction in the North Palisades, Tangle Aire and South Lake Tanglewood portion of the study area. As with other areas, weather, topographic features and available fuels appeared to be the main drivers for fire behavior. It should also be noted that wind shifts that occurred late in the evening of February $27^{\text {th }}$ caused flare-ups that burned in a southern direction. In fact, 114 Palisades Boulevard survived the main fire front moving through the area around 15:00, but was destroyed later from these flareups and change in fire direction.

Table 15 Damage and destruction to linear features in Palisades North, Tangle Aire and selected portions of North Lake Tanglewood Communities.

\begin{tabular}{|l|c|c|}
\hline \multicolumn{1}{|c|}{ Linear Feature } & Meters Damaged & Meters Destroyed \\
\hline Fence & $66(216 \mathrm{ft})$ & $81(266 \mathrm{ft})$ \\
\hline Retaining Wall & $102(335 \mathrm{ft})$ & $25(82 \mathrm{ft})$ \\
\hline
\end{tabular}

There were three locations along Canyon Creek Drive where the fire jumped the road. It is, however, not known if the embers came from the southern side of the lake or from burning wildlands along the northern edge of the lake. The fire jump at 555 Canyon Creek Drive resulted in the fire traveling north through the wildlands along Palisades Boulevard and jumping over to the wildlands between Palisades Boulevard and Saint Andrews Road. The fire jumped Saint Andrews Road and ignited the most southern destroyed homes between Saint Andrews Road and Exmoor Road. The fire continued to travel north to northeast, jumping Bayshore Road in three locations and jumping Tangle Aire Point in one location as noted in Figure 38. 
Figure 39 shows specific burning time observations from radio logs and images taken of the area. The main fire front was estimated to have moved through the area shown in Figure 38 between 15:00 to 15:30. Initial structure ignitions occurred shortly after or during this time frame, four hours after the initial fire ignition. It is estimated that all residential structures in the area shown in Figure 39 were destroyed by 17:00 with the exception of 114 Palisades Boulevard, which survived the main fire front and was destroyed later on the evening of the $27^{\text {th }}$ or the early morning hours of the $28^{\text {th }}$ when the wind was coming from the north.

\subsection{Fire Behavior}

Figure 40 portrays some general fire behavior observations inferred from post-fire ground and aerial imagery. As mentioned above, the fire jumped Lake Tanglewood in some specific locations. Ember spread did not appear to be ubiquitous in the southern portion of the Northern Palisades community as many man-made and natural combustibles did not burn in this area.

The fire traveled up the west side of Palisades Boulevard. There was crowning fire behavior in the wildlands between Palisades Boulevard and Saint Andrews Road. This crowning fire behavior continued up the canyon to the Tangle Aire Community where torching of trees was observed by first responders and in images taken in the area. The canyon to the south of 155 Saint Andrews Road also experienced crowning fire behavior that was very topographically oriented and was a function of local winds.

The fire jumped from wildlands to the south of Tangle Aire Point into Buffalo grass found on the property of 13800 Tangle Aire Point. Additionally, the fire jumped from either burning structures or wildlands on Exmoor Road into Buffalo grass found on 136 Bayshore Drive. As mentioned above, there was a change in wind direction in the night of February $27^{\text {th }}$ which caused fire spread from the north (due a north wind) and resulted in areas that were not burned from the initial fire front movement, which burned later.

\subsection{Defensive Action Categorizations}

Figure 41 shows locations of identified defensive actions along with the categorization of structures as to a defended category. As shown in Figure 41, most homes that were destroyed had no specific defensive actions identified during passage of the first main fire front. There were containment actions on 143 Bayshore Drive as well as on some unidentified structures along Exmoor Road, but these containment actions appeared to be after most of the residential structures were fully involved. The mobile home at 130 Exmoor Road also had the front porch pulled off but the fire had spread underneath the home and the action was not successful. The residential structure at 114 Palisades Boulevard was protected during passage of the second main fire front when winds changed. The structure had already ignited, however, and was ultimately destroyed.

The residential structure at 144 Exmoor Road had a very small ember ignition on the deck extinguished by homeowners. The homeowner at 124 Saint Andrews Road watered down the residential structure during the time 131 Exmoor Road was burning. This action was taken, according to the homeowner, to prevent ember ignitions from the burning of this structure. The home on 140 Bayshore Drive had an attached wood fence extinguished by first responders. The homes on 13844 Tangle Aire Point and 120 Glen 
Eagle Trail had detached wood fences extinguished by homeowners. A detached wood fence on 125 Bayshore Drive was also extinguished by first responders. The home on 585 Canyon Creek Drive appeared to have had burning mulch and attached stairs extinguished early by a first responder. Table 16 identifies damaged and destroyed linear and detached combustible features by identified defensive actions.

Table 16 Damage and destruction to features in Northern Palisades, Tangle Aire and selected portions of North Lake Tanglewood categorized by identified defensive actions.

\begin{tabular}{|l|c|c|}
\hline \multicolumn{1}{|c|}{ Feature } & $\begin{array}{c}\text { Number } \\
\text { Damaged/Destroyed }\end{array}$ & $\begin{array}{c}\text { Number Identified } \\
\text { as Defended }\end{array}$ \\
\hline Linear Feature & 65 & 13 \\
\hline Detached Combustible Features & 95 & 8 \\
\hline
\end{tabular}

The residential structure at 155 Saint Andrews Road might have been protected by homeowners at least indirectly, through extinguishing burning vegetation to the north of 155 Saint Andrews. The one home on Exmoor Road identified as No Actions was a concrete abandoned building with fire not coming close to the building. Homes in the southwest corner of the community as shown in Figure 41 were outside any exposure from fire. Other mapped defensive actions areas around destroyed residential structures shown in Figure 41 display mop-up actions occurring after the homes were destroyed and burning was largely completed.

\subsection{Topographic Data}

Figure 42 shows radar derived slope for the Northern Palisades, Tangle Aire and selected areas of North Lake Tanglewood Communities. Slopes were relatively moderate in many of the areas receiving the majority of the damage and destruction from the fire. In certain northern areas, cliffs appeared to stop fire spread into the plateau area of Tangle Aire. The fire appeared to travel up canyons into Tangle Aire in areas where slopes were more moderate.

Radar derived aspect is shown in Figure 43. As can be seen in Figure 43, there is also complex topography found in this portion of the study area. Many destroyed residential structures appeared to be on or close to south and southwest slopes. Structure to structure fire spread might have resulted in additional damage and destruction to areas outside these south and southwest facing slopes.

\subsection{Structural Element Ignition Mechanisms}

Fences, rail road ties and secondary structures were ignition mechanisms in the Northern Palisades, Tangle Aire and selected portions of Lake Tanglewood communities. As shown in Table 16, there were several fences extinguished by first responders. Additionally, railroad ties were identified as being damaged or destroyed with some identified as being defended, though these could not be linked to a specific feature. Also, a deck was ignited at one location by minor ember accumulation at 144 Exmoor Road and extinguished by homeowners, as shown in Figure 44. Figure 44 demonstrates the need for discussions with first responders and homeowners to determine defensive actions as no signs of actions were present at this home. This also demonstrates that when structural items are damaged, researchers should assume a defensive action as opposed to assuming no defensive action occurred, as stated in Quarles et al ${ }^{6}$ and Foote et al. ${ }^{14}$ Fire underneath mobiles homes was also identified as an ignition mechanism. 


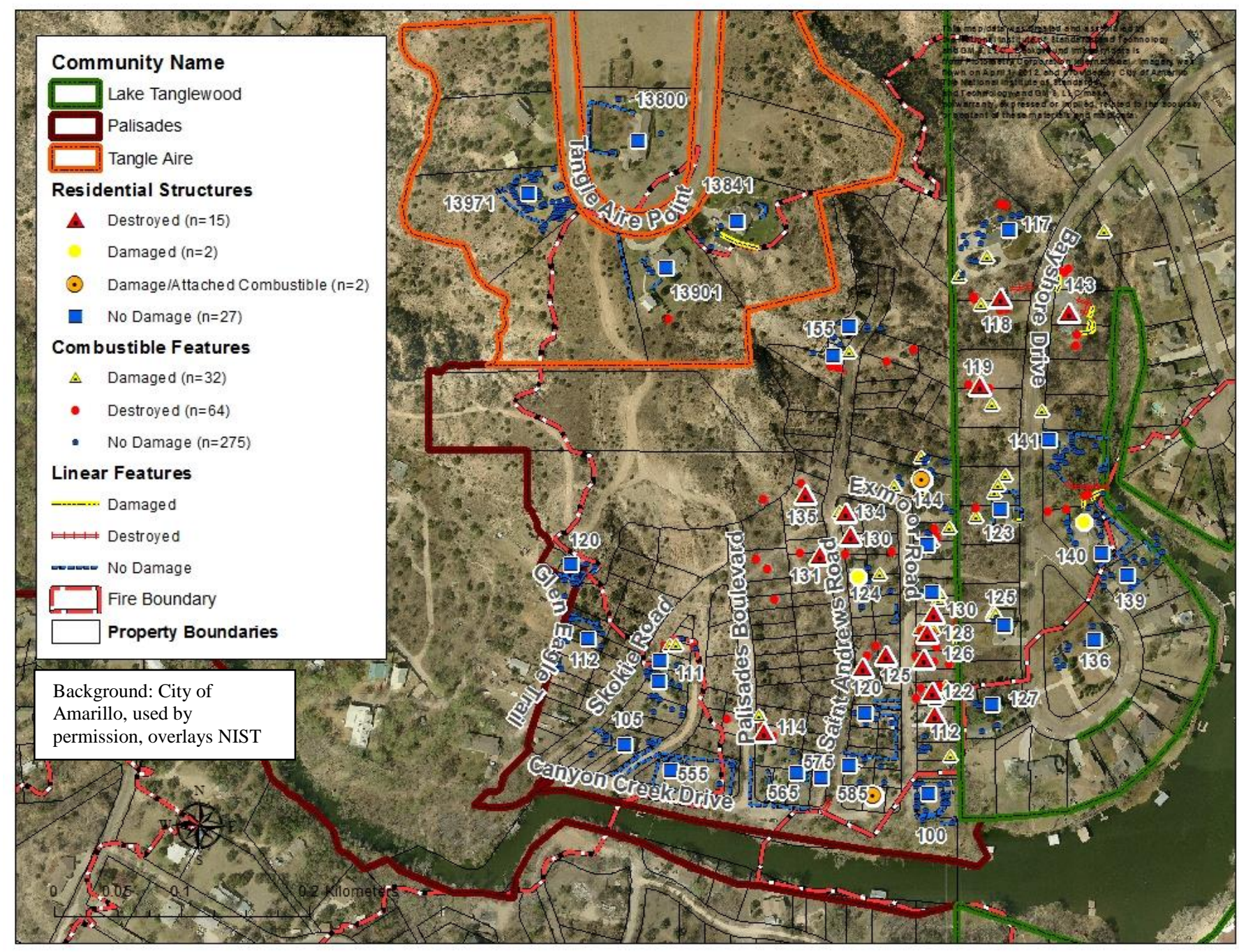

Figure 37 Damage to structural elements in the northern Palisades, Tangle Aire and selected portions of North Lake Tanglewood Communities. 


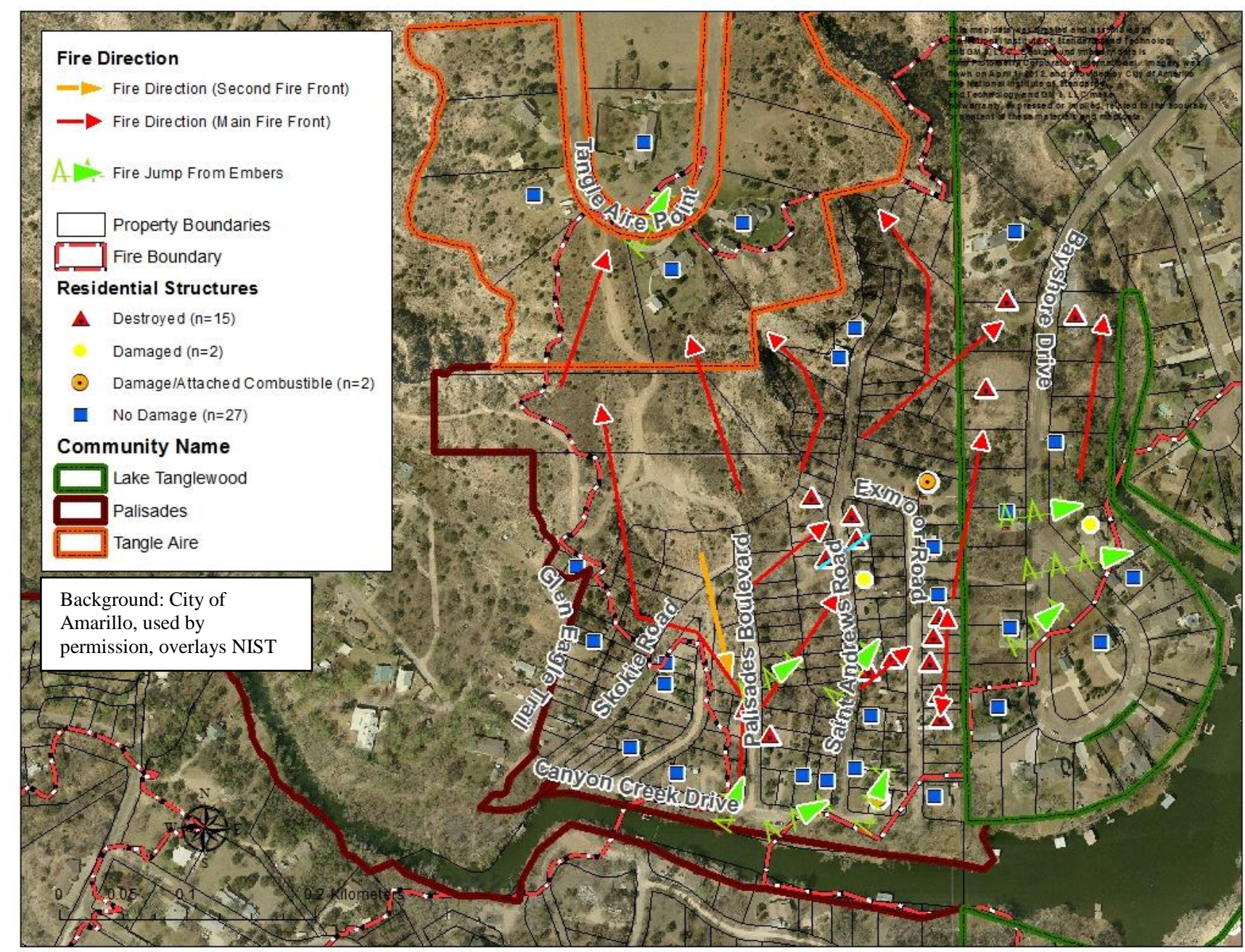

Figure 38 Fire direction and fire timeline in north Palisades, Tangle Aire and selected portions North Lake Tanglewood Communities. The main fire front moved through this area between 15:00 and 15:30 on 2/27/2011. A wind shift occurred later on 2/27/2011 that caused flare-ups and fire direction from the north. The second fire front, portrayed as an orange arrow above, was observed as one fire direction indicator in the field observed through radiant heat damage and confirmed through eyewitness observations. 


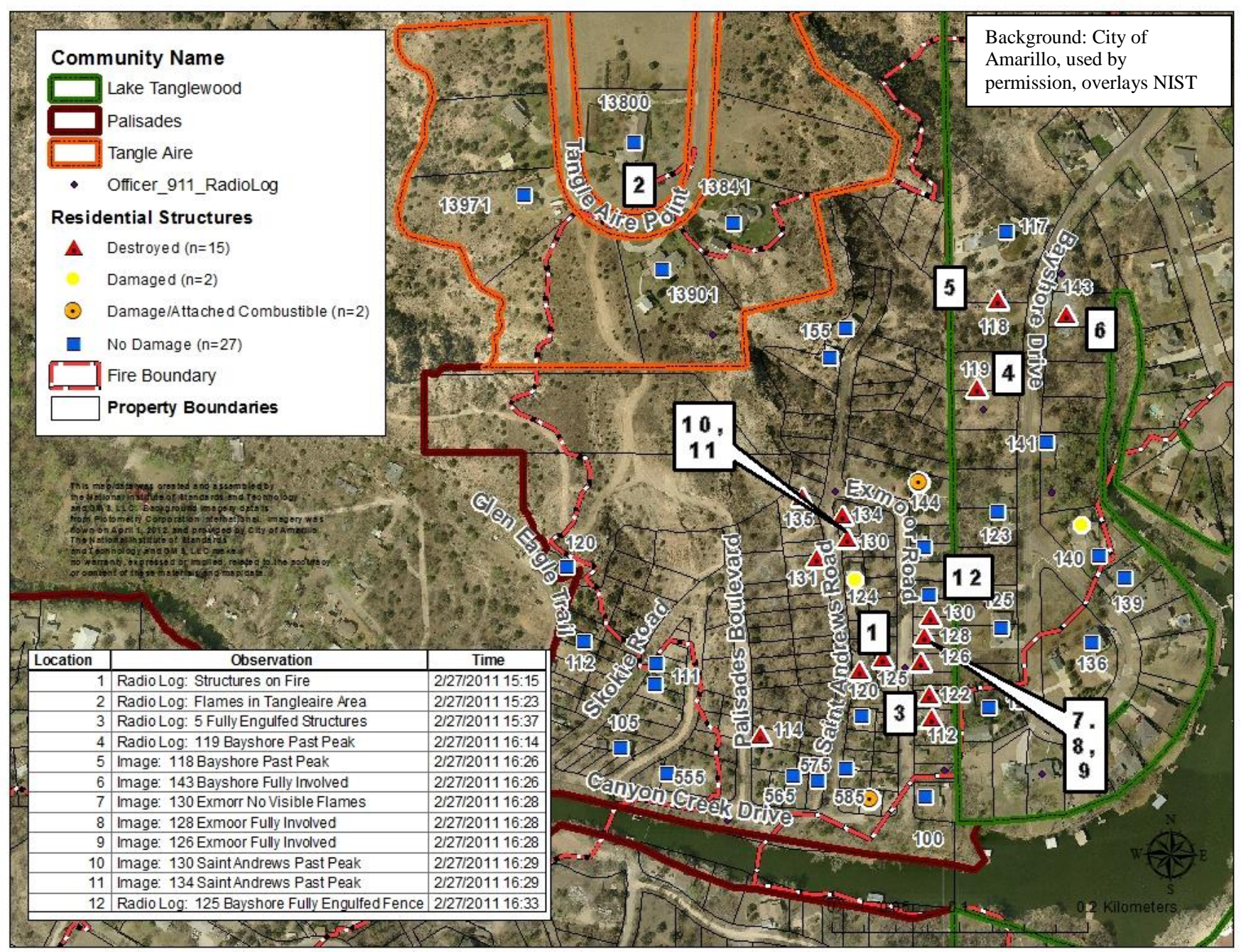

Figure 39 Palisades North, Tangle Aire and portions of North Lake Tanglewood specific time observations on 2/27/2011 from radio logs and images. 114 Palisades Boulevard was destroyed late in the night of 2/27/2011 or in the early morning hours of 2/28/2011 after a wind shift from the nor th occurred. It is believed all other destroyed structures burned before 17:00 on 2/27/2011. 


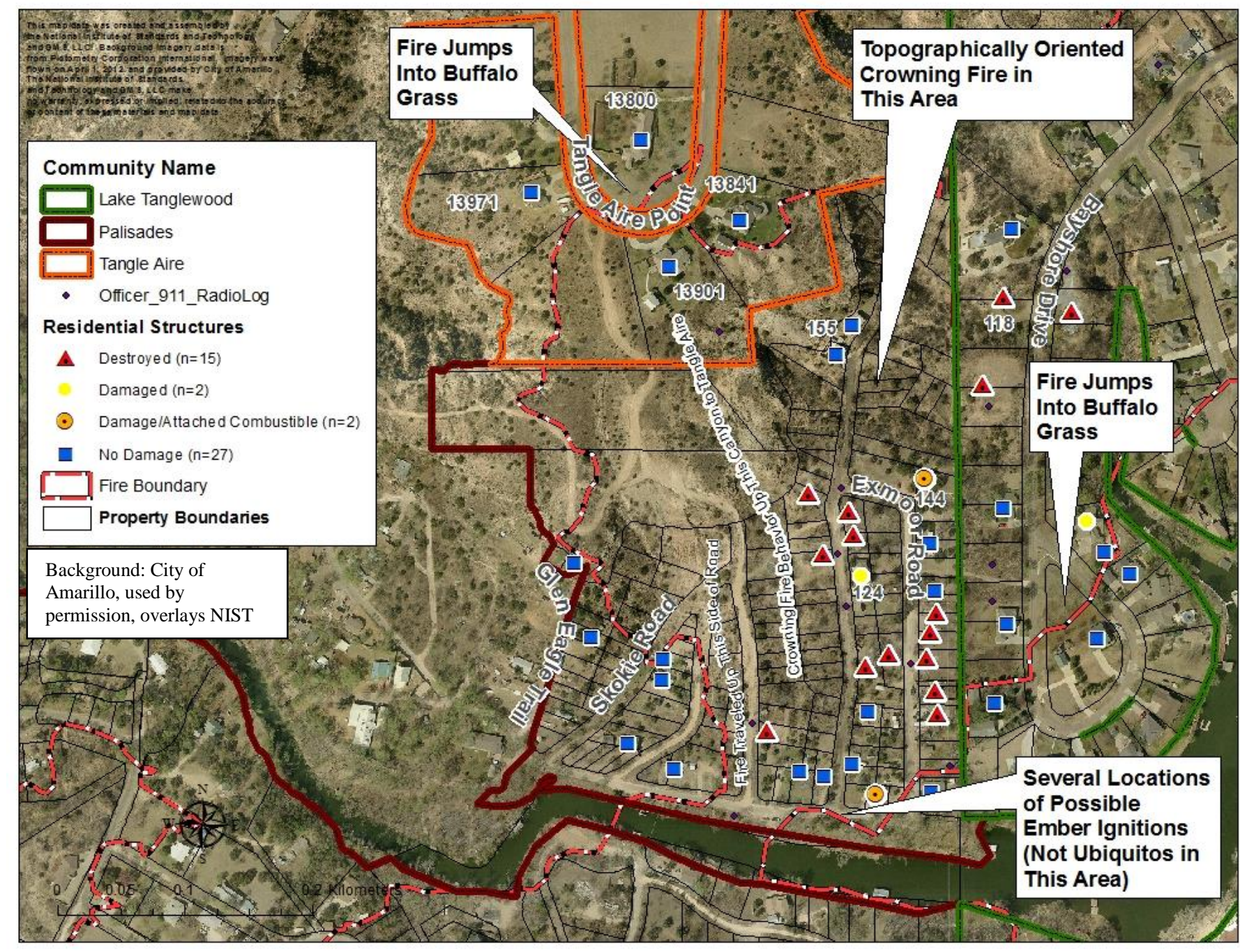

Figure 40 Fire behavior observations in Palisades North, Tangle Aire and portions of Lake Tanglewood North communities. 


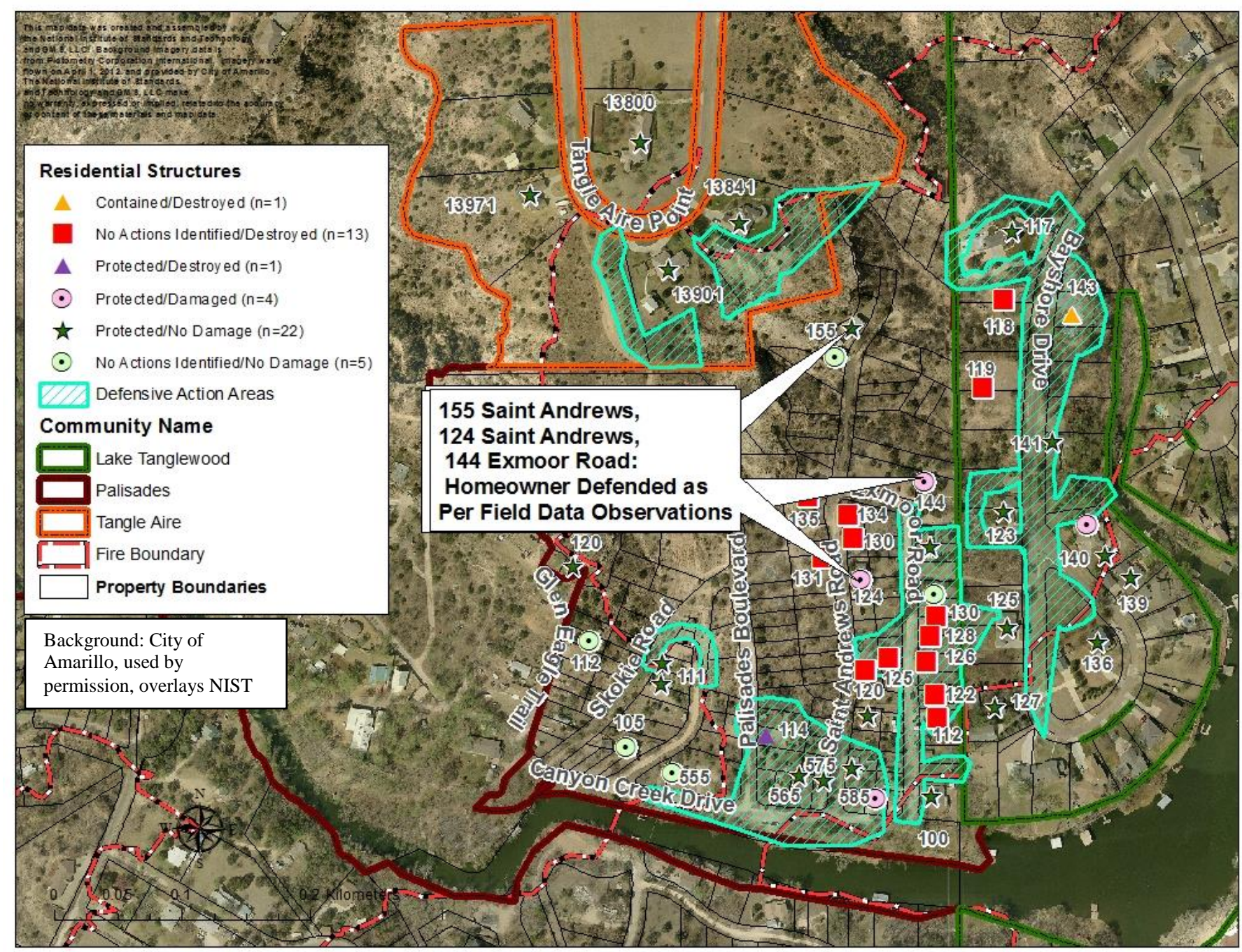

Figure 41 Defensive action locations and primary structure categorizations in Northern Palisades, Tangle Aire and selected areas of North Lake Tanglewood Communities. 


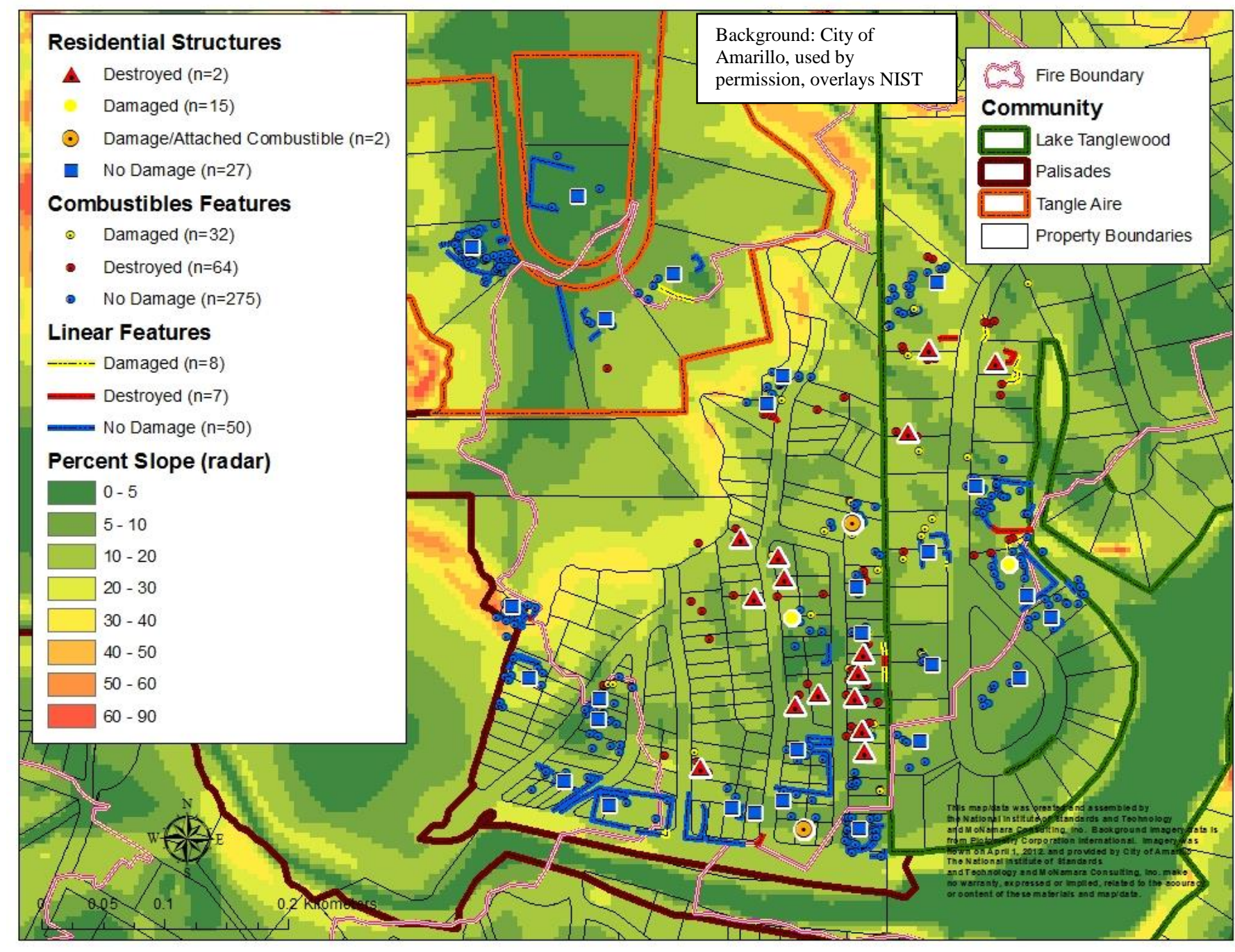

Figure 42 Radar derived percent slope in Northern Palisades, Tangle Aire and selected areas of North Lake Tanglewood Communities. 


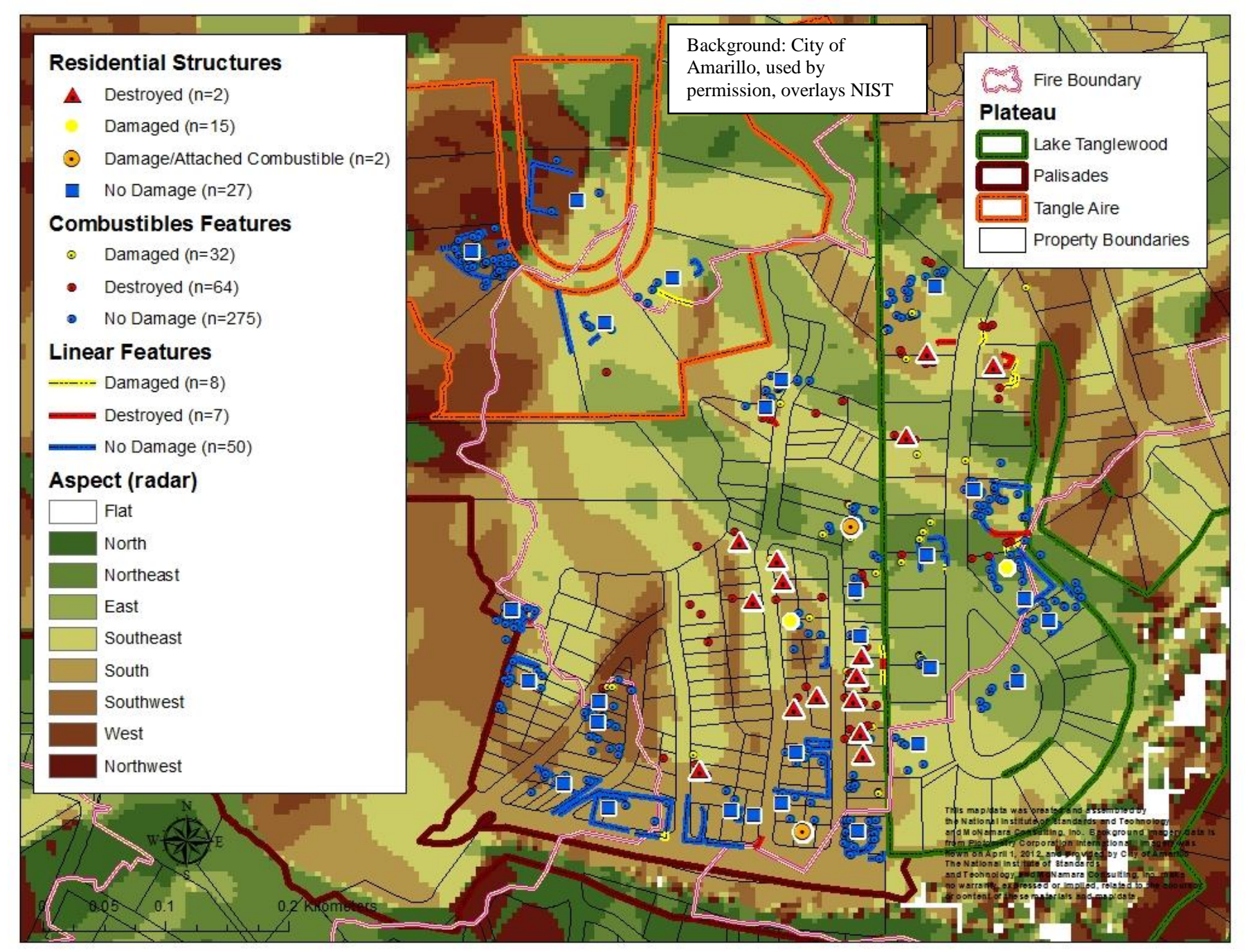

Figure 43 Radar derived aspect in Northern Palisades, Tangle Aire and selected areas of North Lake Tanglewood Communities. 


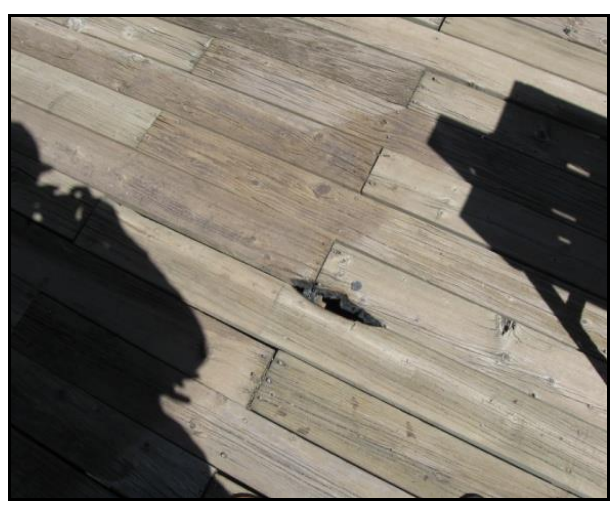

Figure 44 Ignited deck, which was extinguished by homeowners, NIST photo.

Structure to structure fire spread might have been prevalent in this portion of the study area. The homeowner at 124 Saint Andrews Road saw flames from 135 Exmoor Road spread to 134 and 130 Exmoor Road. Ember ignitions from these burning homes were extinguished by the homeowner at 124 Exmoor Road. It is possible that the numerous secondary structures to the east of 135 and 131 Exmoor Road ignited these residential structures. Additionally, there is one image of 128 Exmoor Road fully involved with 130 Exmoor Road beginning to be ignited as shown in Figure 45.

\subsection{Vegetative Element Ignition Mechanisms}

Vegetation treatment also appeared to have consequences for fire behavior. For example, Figure 46 shows field delineated burned vegetation around some homes in the Tangle Aire Point Community. Areas portrayed in bright red indicate healthy, photosynthetically active vegetation. As can be seen in Figure 46, the fire sometimes stopped where the treatment began, such as on the properties of 13901 and 13841 Tangle Aire Point. It is, however, not known if it was a combination of defensive actions

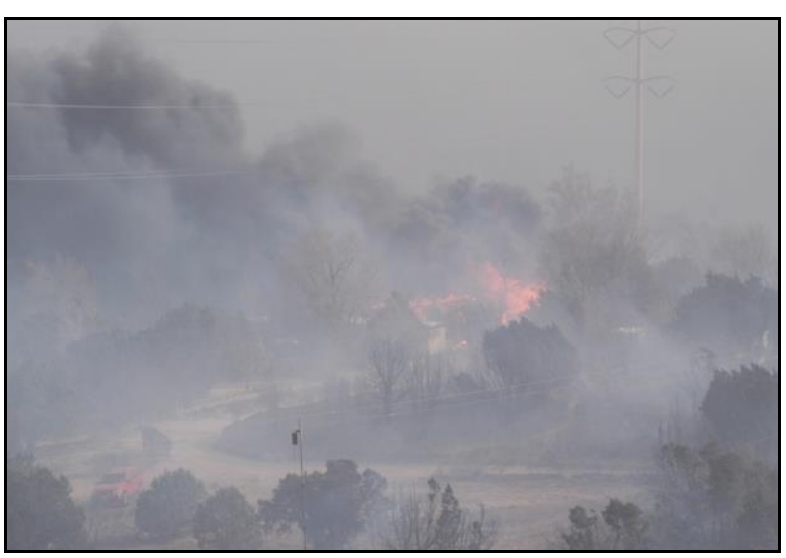

Figure 45 Fully involved residential structure at 128 Exmoor Road igniting residential structure at 130 Exmoor Road, Photo Gordon Ivy, used by permission. and vegetation treatment or treatment alone that resulted in the fire stopping in these locations. Other areas show similar patterns in this portion of the study area but again, it could not be determined if treatment alone stopped fire spread or a combination of treatment and defensive actions.

\subsection{North Lake Tanglewood}

This section begins with a tabulation of the damage and destruction to structural elements in the North Lake Tanglewood Community. Additionally, fire direction generalized from field observations of directional scorching are presented. Fire timeline information is derived from radio logs, and some images and video.

This section also discusses fire behavior in the North Lake Tanglewood Community. Defensive actions conducted in the community along with defensive action categorizations of structures are also described. Topographic characteristics are mapped and discussed. Finally, identified structural and vegetative element ignition mechanisms are detailed. 


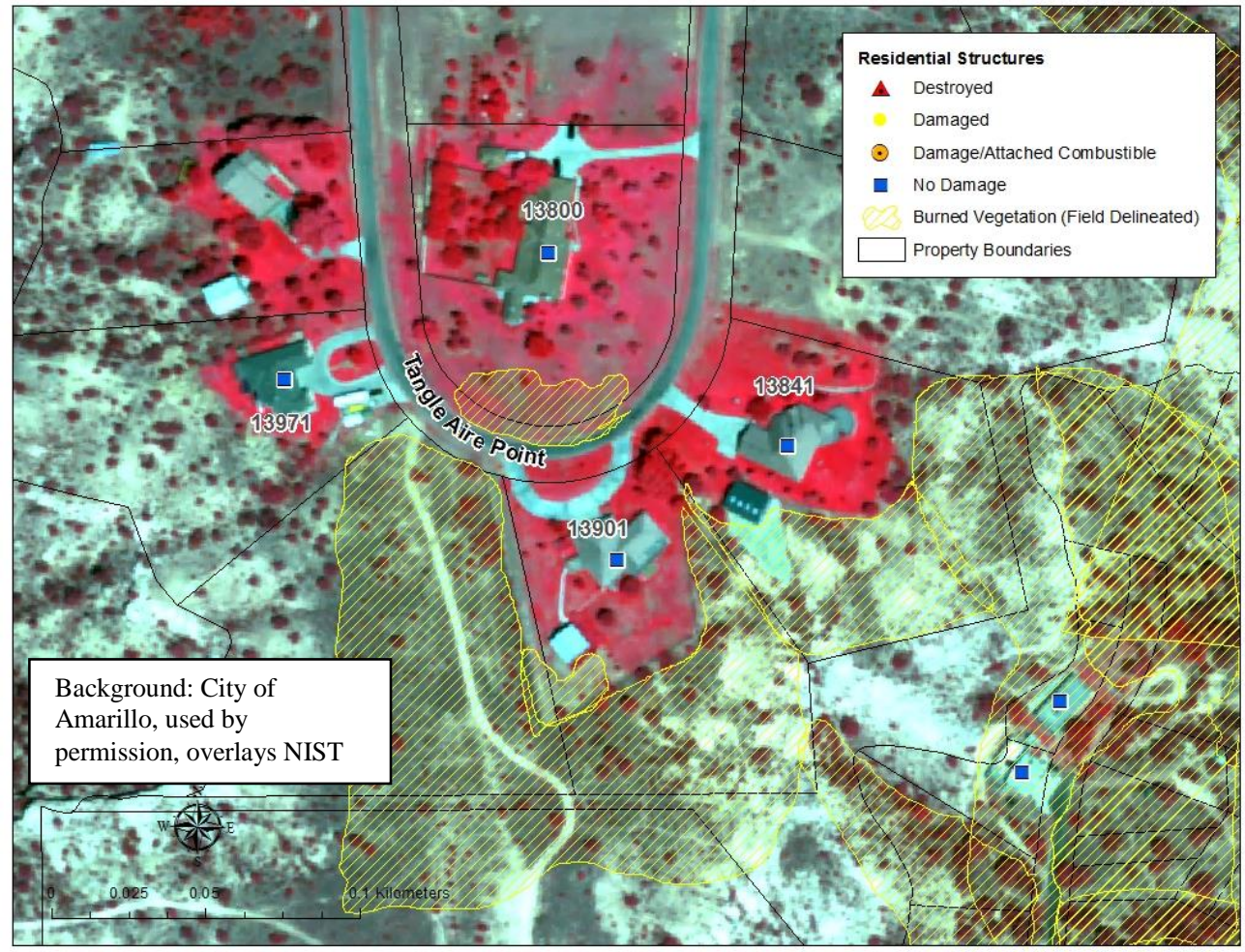

Figure 46 Field delineated burned vegetation around Tangle Aire Point overlayed on a false color composite pre-fire image. Red areas show healthy photosynthetically active vegetation.

\subsection{Damage Assessment, Fire Direction and Fire Timeline}

Figure 47 shows damage to structural elements from the Tanglewood Fire within the North Lake Tanglewood Community. There were two damaged residential structures, one destroyed residential structure, and 37 residential structures with no damage. There was numerous damage and destruction to combustible and linear features. A breakdown of damage to detached combustible features is shown in Table 17. Damage and destruction to linear features by length is shown in Table 18.

Table 17 Damage and destruction to detached combustibles in North Lake Tanglewood Community.

\begin{tabular}{|l|c|c|}
\hline \multicolumn{1}{|c|}{ Combustible Feature } & Number Damaged & Number Destroyed \\
\hline Railroad Tie Retaining Walls & 1 & 1 \\
\hline Decks & 1 & 2 \\
\hline Hot Tub & 0 & 1 \\
\hline Secondary Structures & 1 & 7 \\
\hline Stairs & 1 & 0 \\
\hline Building Material & 0 & 1 \\
\hline Firewood & 1 & 1 \\
\hline Lawn Furniture & 2 & 0 \\
\hline Trailers & 1 & 0 \\
\hline Lawn Mowers & 0 & 2 \\
\hline Door Mat & 0 & 1 \\
\hline Wagon & 1 & 0 \\
\hline
\end{tabular}

Figure 48 shows fire direction in the North Lake Tanglewood Communities. As with other areas, weather, topographic features and available fuels appeared to be the main drivers for the fire behavior. There were three locations along the west side of Port-OCall Drive where the fire jumped the road. The fire also jumped the road from burning 
structural elements on the east side of Port-O-Call drive to unknown features at 102 PortO-Call Drive. The fire jumped from some location on the west side of Bayshore Drive around 115 Bayshore Drive to 101 Bayshore Drive. The fire also jumped from the destroyed structure at 102 Port-O-Call Drive to grass on 113 Bay Rock Circle.

Table 18 Damage and destruction to detached linear features in North Lake Tanglewood Community.

\begin{tabular}{|l|c|c|}
\hline \multicolumn{1}{|c|}{ Linear Feature } & Meters Damaged & Meters Destroyed \\
\hline Landscaping Border & $110(361 \mathrm{ft})$ & 0 \\
\hline Fence & $457(1499 \mathrm{ft})$ & $4(13 \mathrm{ft})$ \\
\hline Retaining Wall & $219(719 \mathrm{ft})$ & $319(1047 \mathrm{ft})$ \\
\hline
\end{tabular}

Figure 49 portrays some specific time observations of burning features in the North Lake Tanglewood Community. It is difficult to precisely portray fire progression through vegetation in this area as the fire appeared to move rapidly through some areas and slowly through others. Fire was observed moving through flammable vegetation in the areas behind 119, 117, 103 and 105 Port-O-Call Drive. The detached garage at 103 PortO-Call Drive was fully involved at 16:33. At 17:17 there were high (taller than the residential structure) flame heights around 100 Camino Alto. The fire was described as moving rapidly towards the golf course north of Lago Vista Street at 17:28.

The one destroyed structure at 102 Port-O-Call Drive had the roof observed as fully involved at 16:55 with an image of full involvement also recorded at 17:48. At 18:11 the Amarillo Sheriff Helicopter flight showed the structure as a foundation. The final flames of the main fire front were observed through vegetation around the end of the mapped fire perimeter at approximately 18:18 by the Amarillo Sheriff Helicopter flight. Various flare-ups of vegetation and structural elements were observed in the North Lake Tanglewood Community into the morning of February $28^{\text {th }}$.

\subsection{Fire Behavior}

Fire behavior in the North Lake Tanglewood Community exhibited some similar topographically influenced fire behavior as described in the Southern Palisades Community. More intense fire behavior on the wind facing side of slopes was shown in the Amarillo Sheriff Helicopter flight in Figure 50, which also portrays the result of this fire behavior in the post-fire imagery. There is a complex interaction between fuels and topography, the exact components of which are identified but not studied in this paper. The burn patterns shown in Figure 50 and observed in other areas described in the Southern Palisades Community section above were also observed in other areas in the North Lake Tanglewood Community.

\subsection{Defensive Action Categorizations}

Figure 51 shows locations of identified defensive actions along with the resulting categorization of structures as a function of defensive actions. Defensive actions were extensive in the North Lake Tanglewood Community. They started with the arrival of the fire front and continued into the morning hours of February 28. Defensive actions were occurring at the time 102 Port-O-Call Drive was ignited and containment of this structure occurred. Numerous first responder teams stopped the high intensity fire shown in Figure 50 from spreading east across Tanglewood Drive. First responders stopped fire spread both to the north of Haddock Drive and along the southern fire perimeter north of 
Bayshore Drive. Suppression of fire spread by first responders also occurred in the occluded flammable vegetation area in the back yards of 101, 103, 105, 117, 119 and 121 Port-O-Call Drive. However, some fire spread might have been stopped by vegetation treatment described below.

Many features, including fences and railroad ties were recorded as being defended multiple times by different first responders using water. First responders also stopped fire spread in the wildland behind 142 to 154 Port-O-Call Drive and the fire spread at 113 Bay Rock Circle was also described as being extinguished by first responders. Only three homes in this area had no specific defensive actions identified namely 116, 115 and 110 Bayshore Drive. There was a small secondary structure and lawn mower destroyed at 116 Bayshore Drive with no specific containment actions determined for these features. Fences, borders and railroad tie retaining walls were damaged at 110 Bayshore Drive, indicating the possibility of defensive actions for these features; though these features were not specifically identified as defended. The property at 115 Bayshore Drive did not have any damaged or destroyed features identified. Table 19 numerates damaged and destroyed linear and combustible features by identified defensive actions.

Table 19 Damage and destruction to features in North Lake Tanglewood Community categorized by identified defensive actions.

\begin{tabular}{|l|c|c|}
\hline \multicolumn{1}{|c|}{ Feature } & Number Damaged/Destroyed & Number Defended \\
\hline Linear Feature & 27 & 16 \\
\hline $\begin{array}{l}\text { Detached Combustible } \\
\text { Features }\end{array}$ & 21 & 12 \\
\hline
\end{tabular}

\subsection{Topographic Information}

Figure 52 portrays radar derived percent slope for the North Lake Tanglewood Community. Figure 53 portrays radar derived aspect for the North Lake Tanglewood Community. As mentioned above, topography appeared to play an important role in fire behavior in the North Lake Tanglewood Community. The exact contribution of topography and fuels is not examined in this study. Nonetheless, the steepest slopes were found along the rim of the canyon and these steep slopes or cliffs appeared to prevent fire spread into the northern plateau area of the Lake Tanglewood Community. As with the fire entering the canyon area in the Southern Palisades Community, fire appeared to only enter the plateau area of the Lake Tanglewood Community in areas of moderate slopes.

In fact, cliffs to west of 100 Camino Alto appeared to cause the flames described by first responders as jumping over the top of the house resulting in radio logs incorrectly reporting the house on fire. Moderate slopes along the cliff to the west of 100 Camino Alto provided locations where the fire was directed away from the house and towards wood fences and retaining walls as described below. The home appeared to see low intensity fire behavior directly to the west and close to the home $(<8 \mathrm{~m}(26 \mathrm{ft}))$ where there was green vegetation as described below. Finally, topographic configurations along with fuels might have had consequence for structure ember spread from 102 Port-O-Call Drive to the Buffalo grass burned at 113 Bay Rock Circle. 


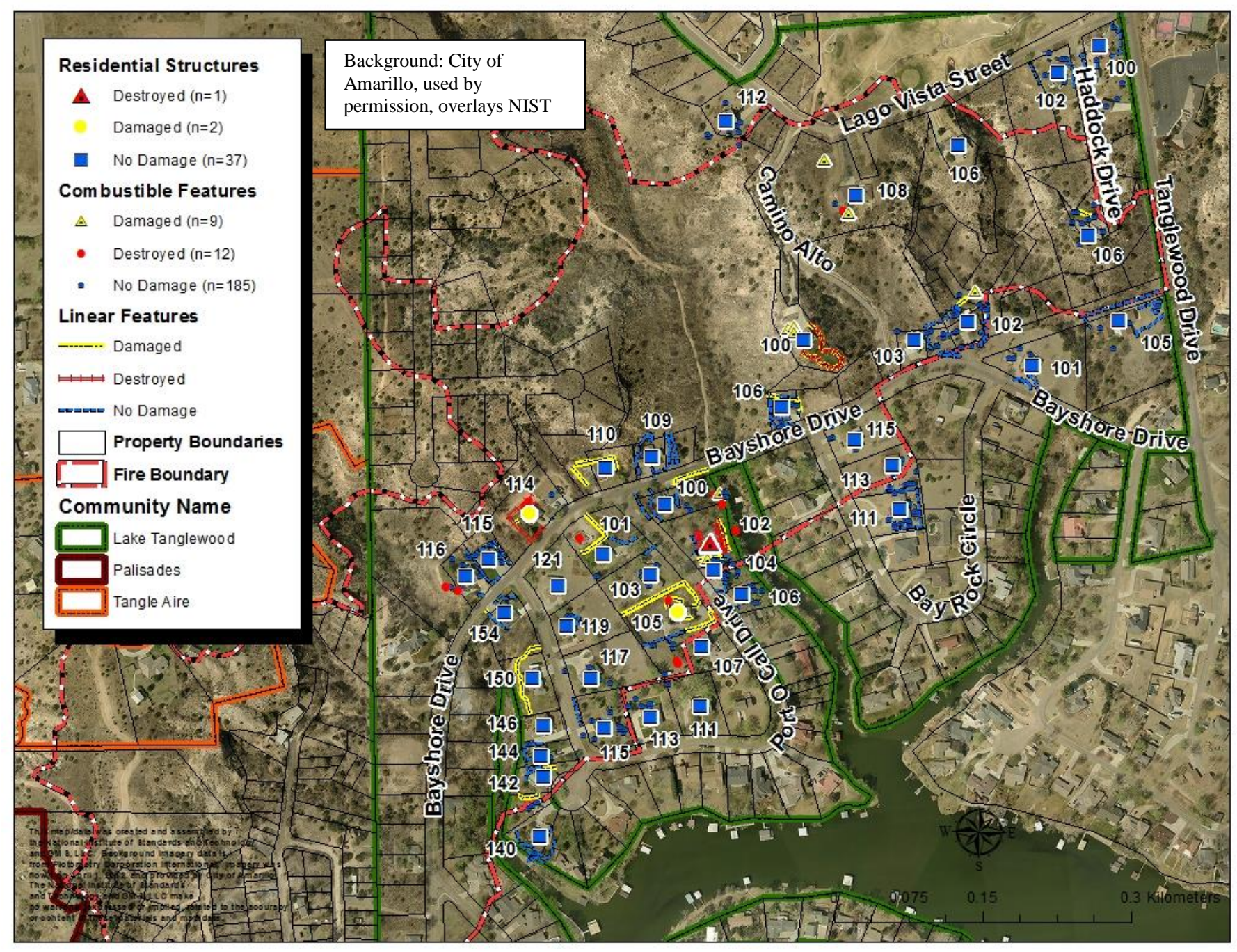

Figure 47 Damage to structural elements in the North Lake Tanglewood Community. 


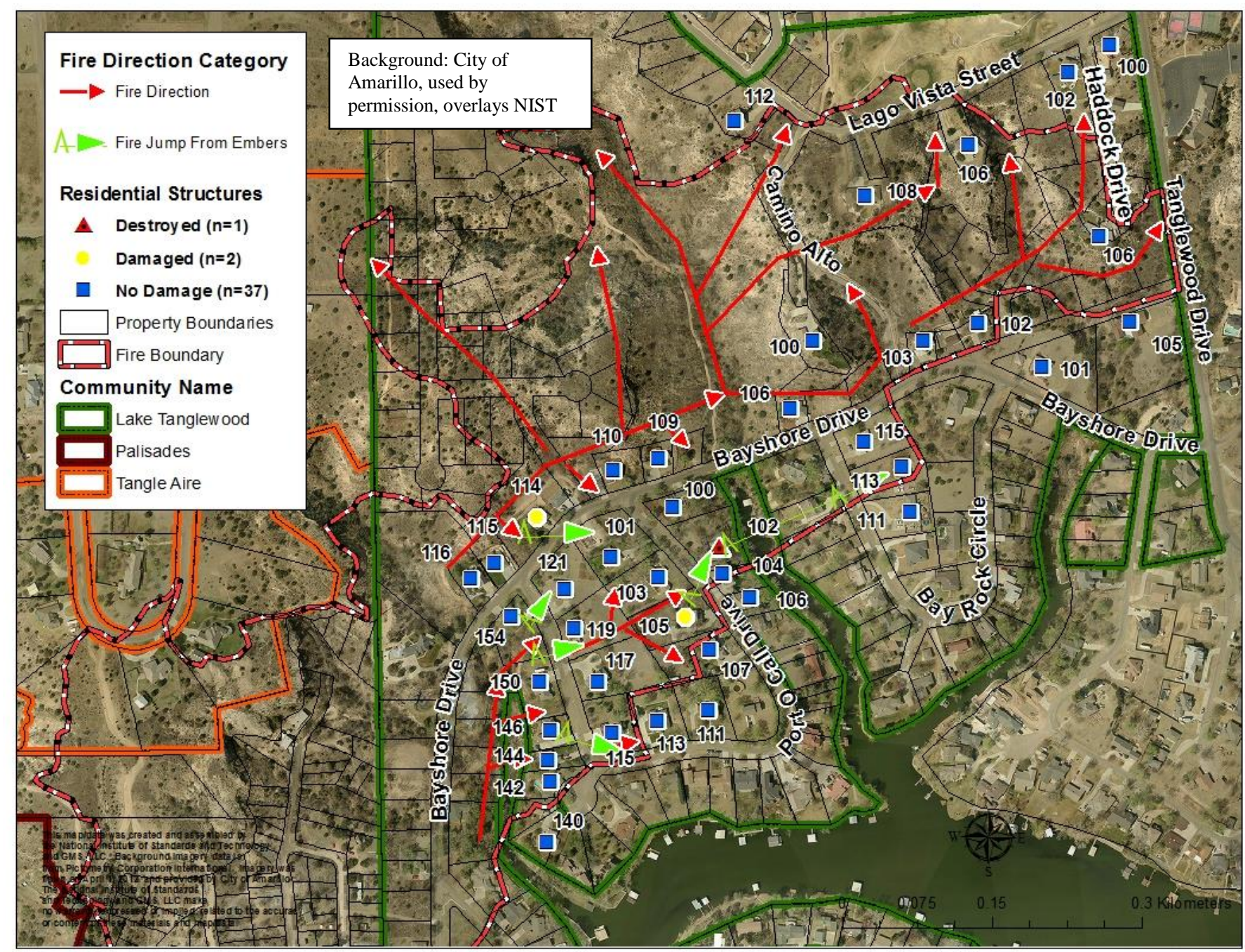

Figure 48 Fire direction and fire timeline in North Lake Tanglewood Community. The main fire front moved through the area between 15:00 and $18: 30$ on $2 / 27 / 2011$. 


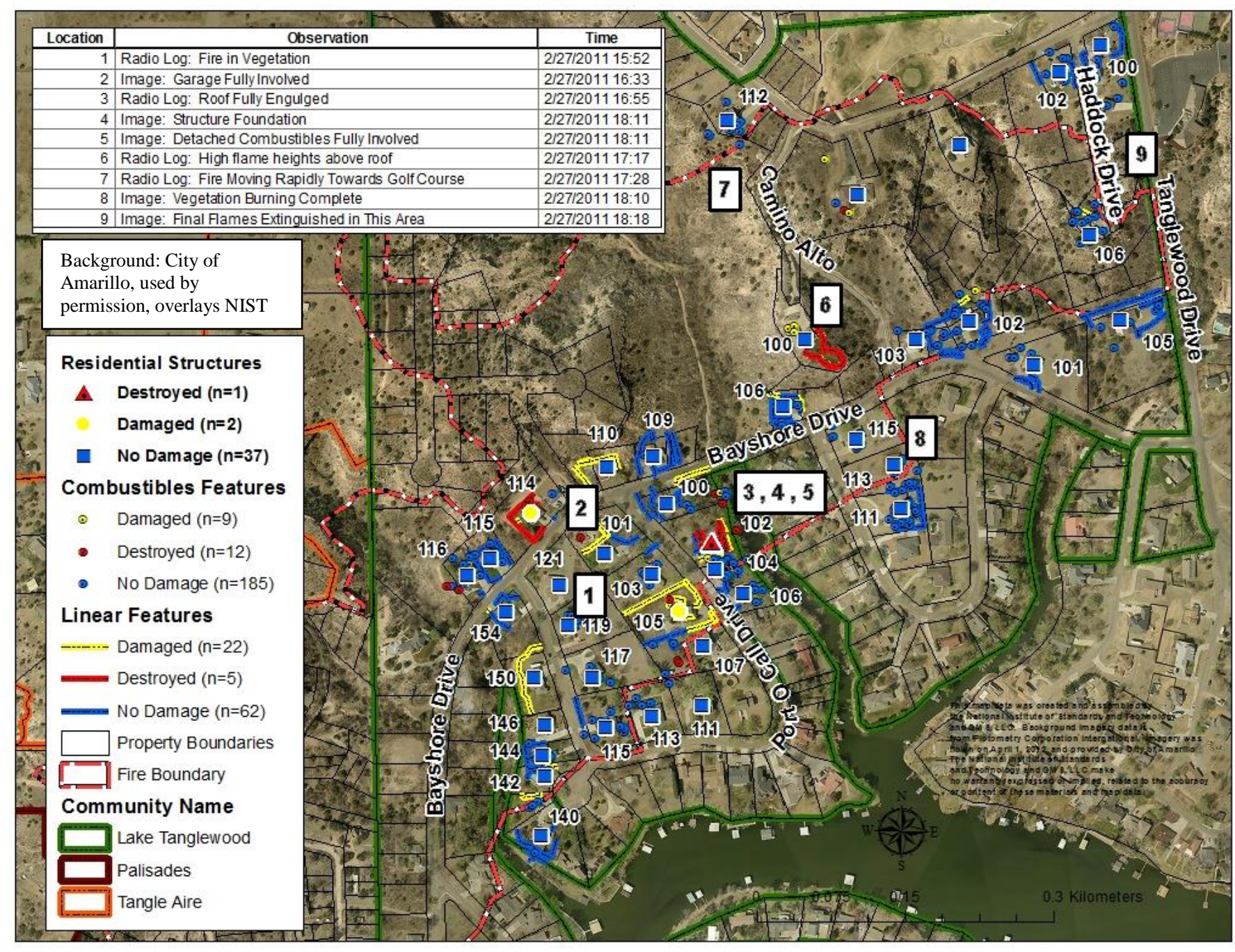

Figure 49 North Lake Tanglewood specific time observations on 2/27/2011 from radio logs and images. 


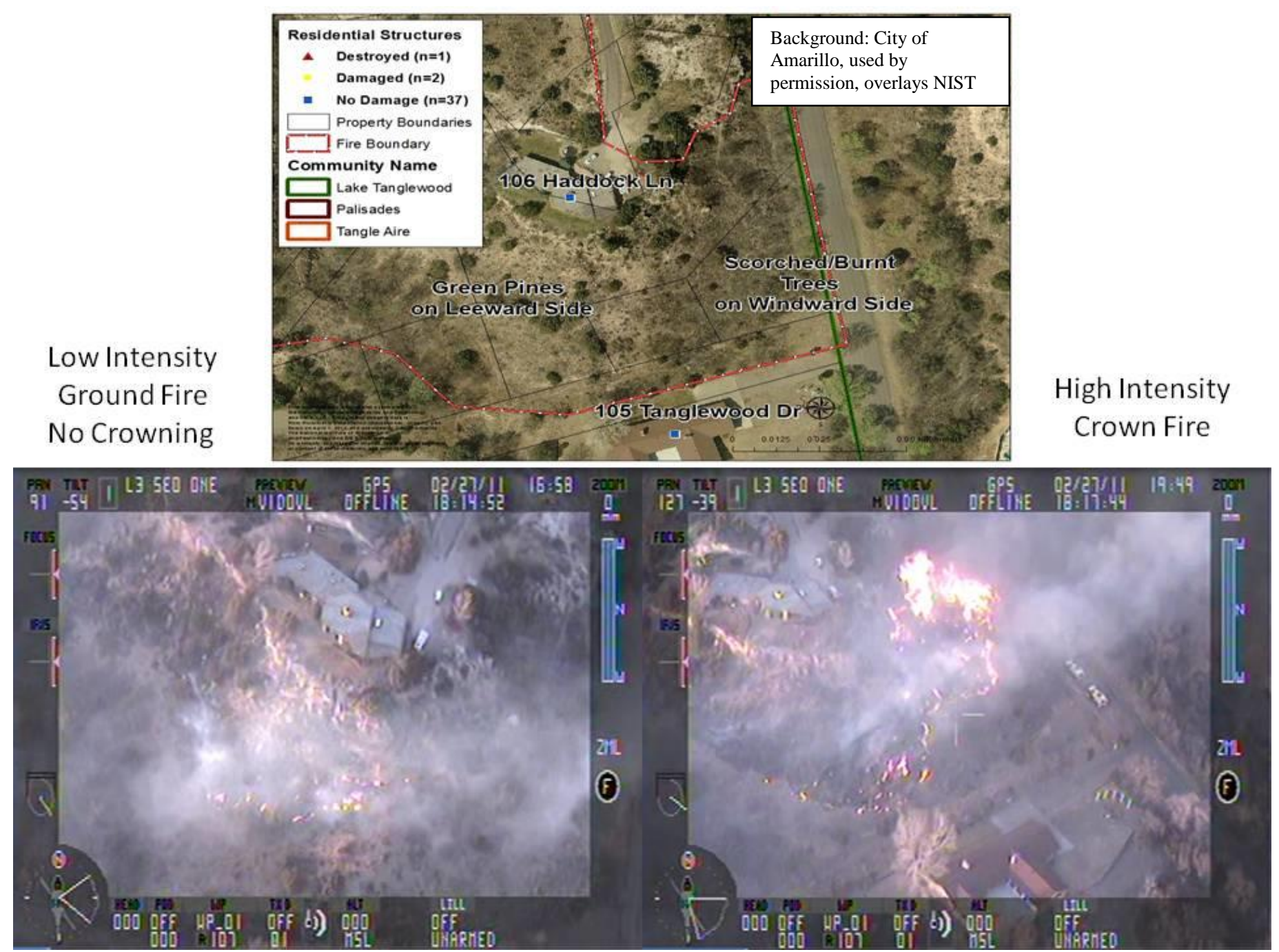

Figure 50 Fire behavior changes coincident with topography. Side directly exposed to wind (left) saw limited scorching and no torching of trees in post-fire imagery, and a low intensity ground fire during Amarillo Sheriff Helicopter flight. Side not facing wind (right) exhibited scorching and torching of trees in post-fire imagery, and a high intensity crown fire during helicopter flight was observed. 


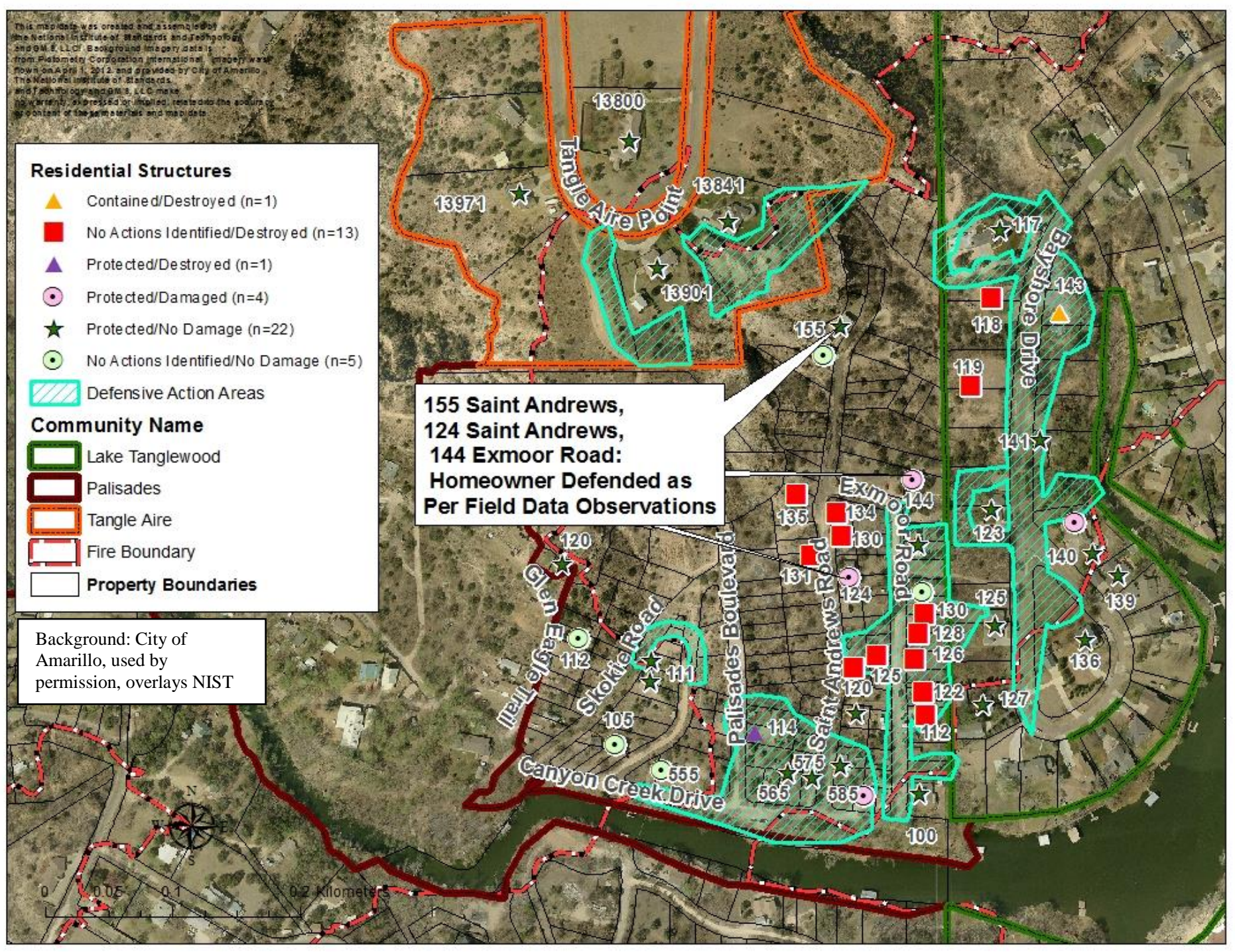

Figure 51 Defensive action locations and primary structure categorizations in North Lake Tanglewood Community. 


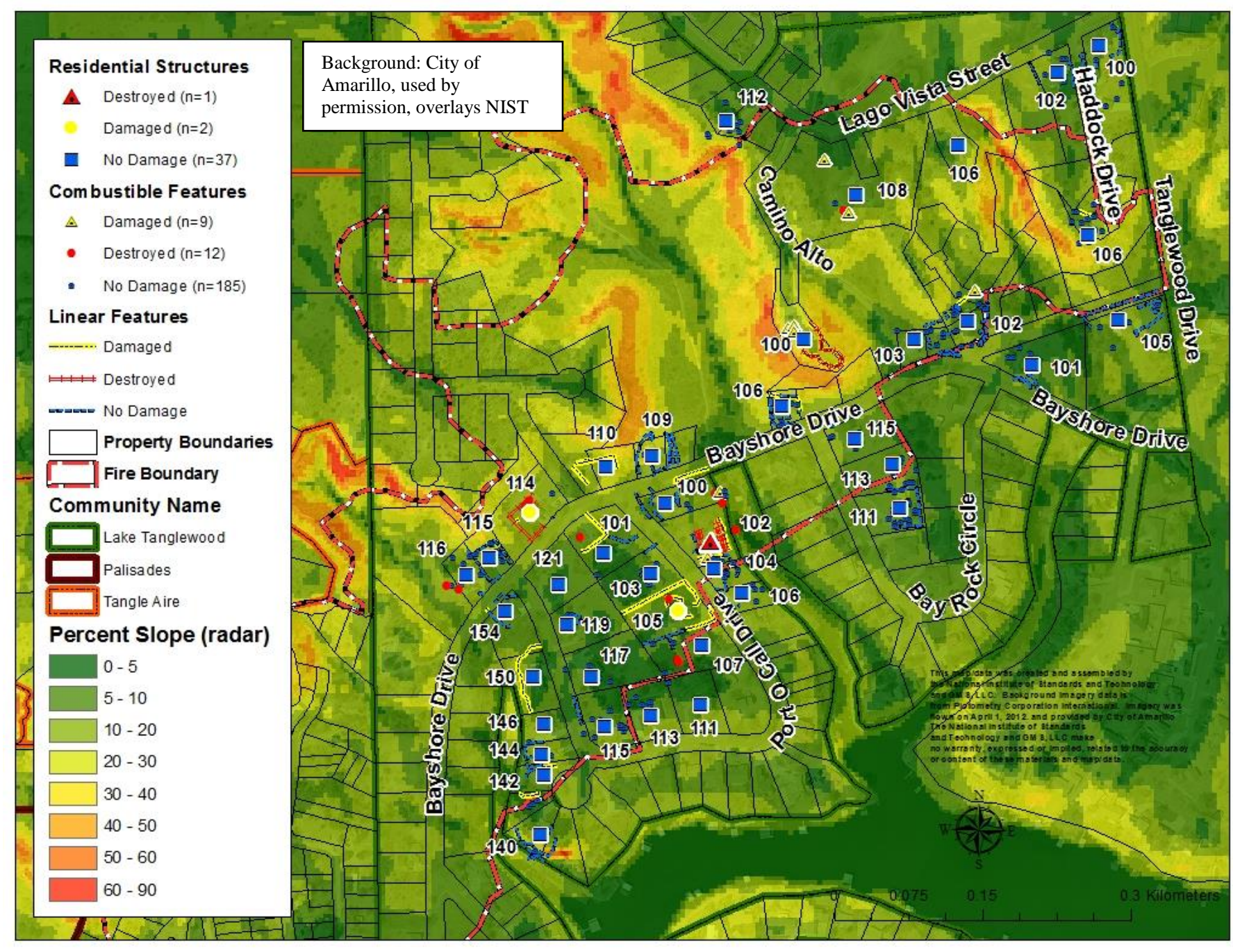

Figure 52 Radar derived percent slope in North Lake Tanglewood Community. 


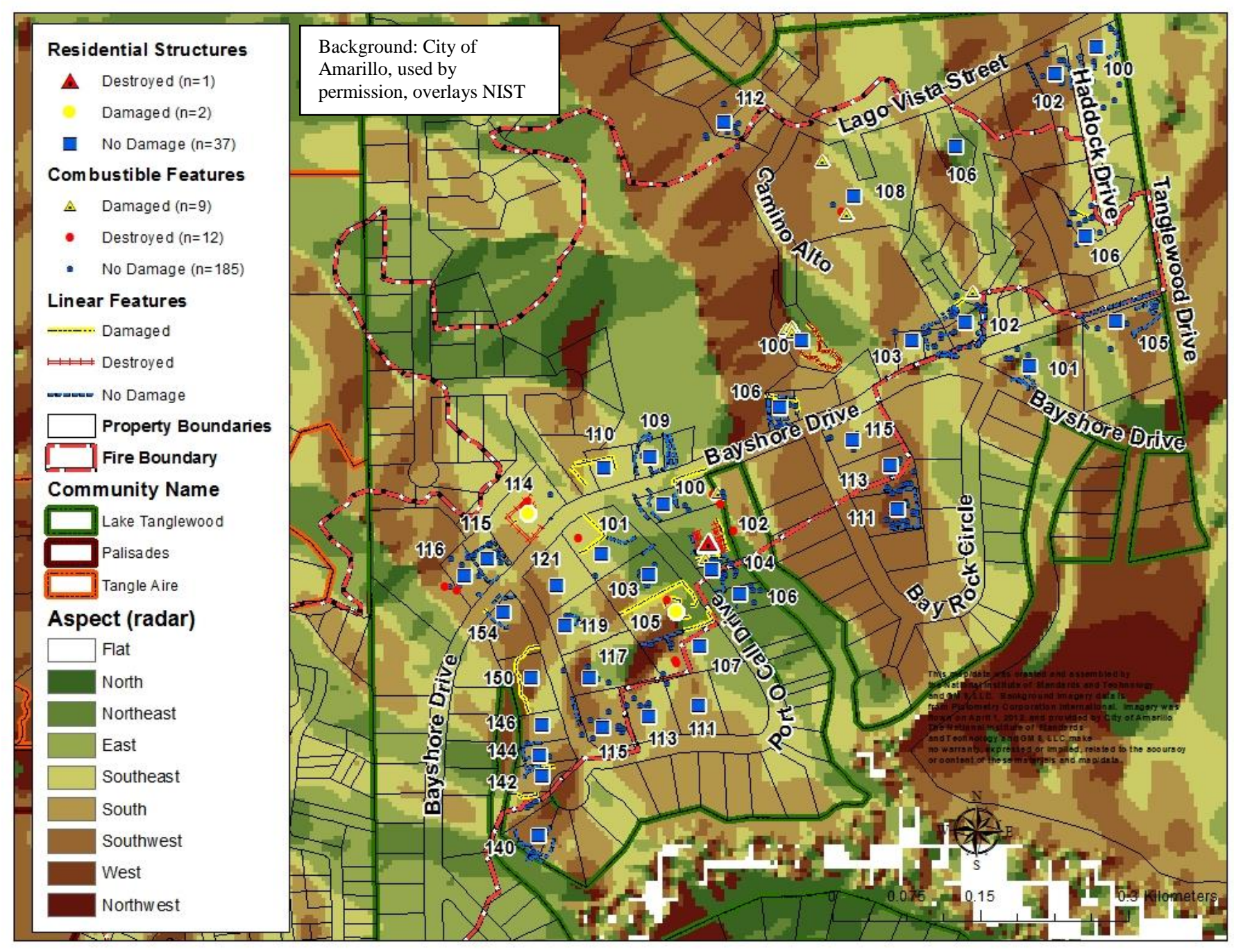

Figure 53 Radar derived aspect in North Lake Tanglewood Community. 


\subsection{Structural Element Ignition Mechanisms}

The fire in the North Lake Tanglewood Community damaged numerous fences, railroad tie retaining walls and landscaping borders. Additionally, detached decks, firewood piles and other features were also damaged and destroyed. A detached secondary structure was destroyed at 105 Port-O-Call Drive. Based on the timing of the destruction of this feature and the chronology of first responder actions in the area, it is possible that embers from this secondary structure ignited the wood roof at 102 Port-O-Call Drive.

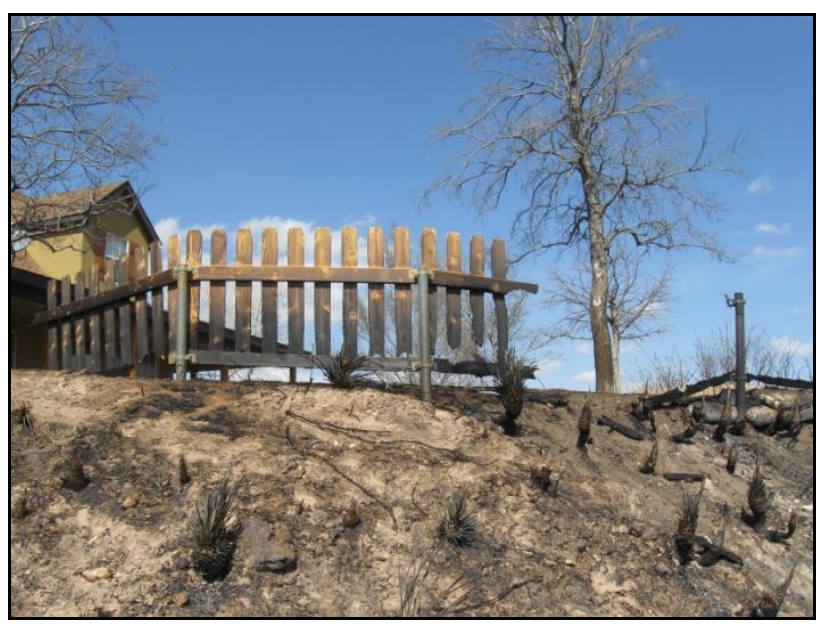

Figure 54 Partially destroyed fence at 100 Camino Alto, NIST photo.

Some fences in the North Lake Tanglewood Community were only partially burned. An example is shown in Figure 54 of a partially destroyed fence at 100 Camino Alto Drive. The destruction of the fence was predominantly in the direction of the wind and topographic configuration as discussed in section 9.4 above, with partial damage in the opposite direction of the wind and topographic configuration. It is unknown if the fence extinguished on its own or if it was extinguished by first responder intervention.

A firewood pile directly adjacent to the residential structure at 100 Camino Alto was also

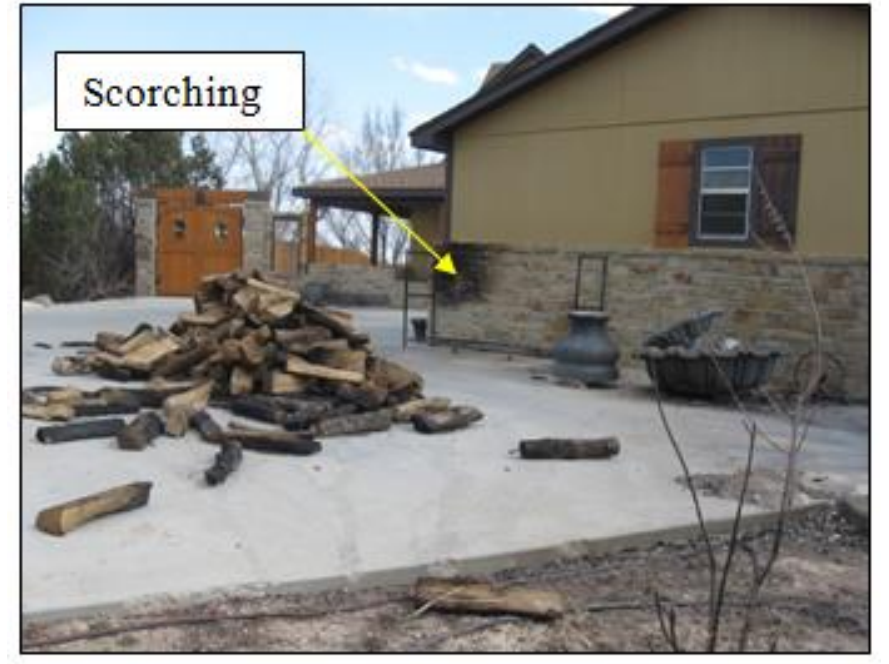

Figure 55 Defended firewood pile at 100 Camino Alto, NIST photo. ignited and specifically identified as being defended by first responders and moved away from the structure as shown in Figure 55. No damage other than scorching to the residential structure was identified. The brick siding as shown in Figure 55 , aided in protection of the structure from fire in the early stages of burning.

A wooden bench was also damaged on the west side of Camino Alto and not specifically identified as defended. As shown in Figure 56, the bench was burned from the bottom with

no associated scorching to the siding or the top of the bench. There was also green vegetation in the adjacent area as shown in Figure 56. This indicates there was relatively 


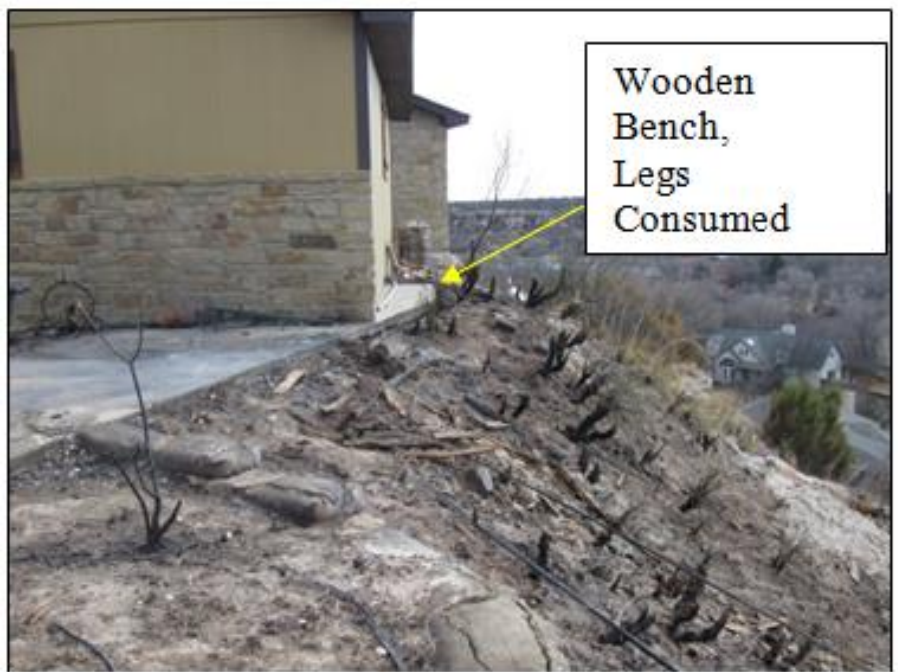

Figure 56 Damaged wooden bench and burned and unburned vegetation on west side of 100 Camino Alto, NIST photo. low exposure on this side of the building with the burning of the wooden bench likely caused by a low intensity ground fire. As discussed in section 9.4 above, the low exposure might have been a result of topographic configuration.

A partially destroyed wood fence was also recorded at 114 Bayshore Drive as shown in Figure 57. As can be seen in Figure 57, the heat from the burning fence caused the vinyl soffit to

melt. There was, however, no scorching or burning to the underlying wood part of the soffit. There were extensive defensive actions in this area and it is unknown if the burning fence was extinguished by first responders or extinguished without manual intervention. As can be seen in Figure 57, the burning fence also caused scorching of the brick siding.

\subsection{Vegetative Element Ignition Mechanisms}

Untreated vegetation in areas behind 140 to 154 Port-O-Call Drive was a hazard, which first responders defended against, into the early morning hours of February 28. Fire spread from these occluded wildlands to Buffalo grass and then to vegetated hedge rows as shown in Figure 48 and Figure 58. This vegetation helped spread the fire to 105 Port-0-Call Drive. This fire spread from vegetation ignited the secondary structure described above at 105 Port-O-Call Drive.

The destroyed home at 102 Port-O-Call Drive is thought to have spread embers to Buffalo grass at 113 Bayrock Circle as shown in Figure 48. This Buffalo grass was specifically described as extinguished by first responders. The burned Buffalo grass in the interior area described above and shown in

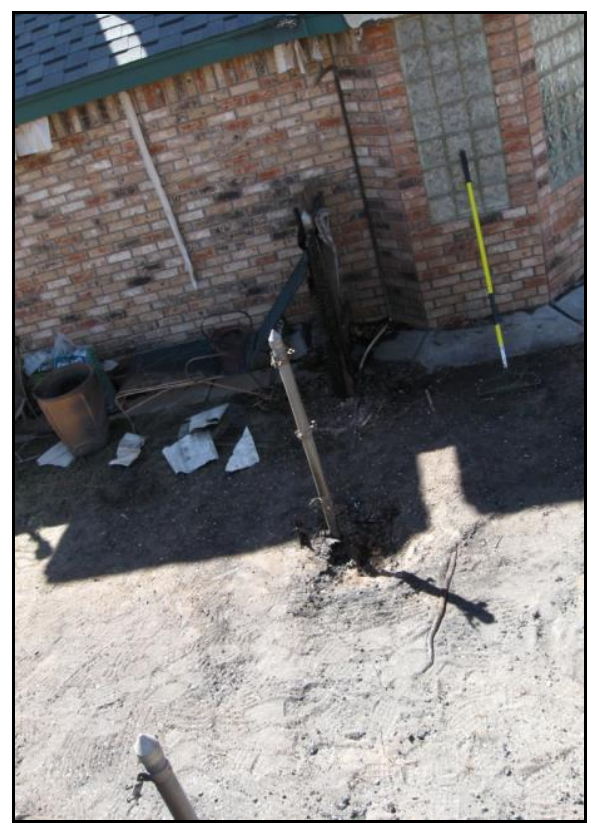

Figure 57 Partially destroyed wood fence, which caused scorching to brick siding and melting of vinyl soffit, NIST photo.

Figure 58, again appeared to correspond to areas with less photosynthetically active vegetation as shown in pre-fire infrared imagery displayed in false color in Figure 59. 
The greyer areas both in the interior portion of Port-O-Call Drive and other locations burned while redder areas, likely corresponding to vegetation treatments (water and/or nutrients), did not burn.

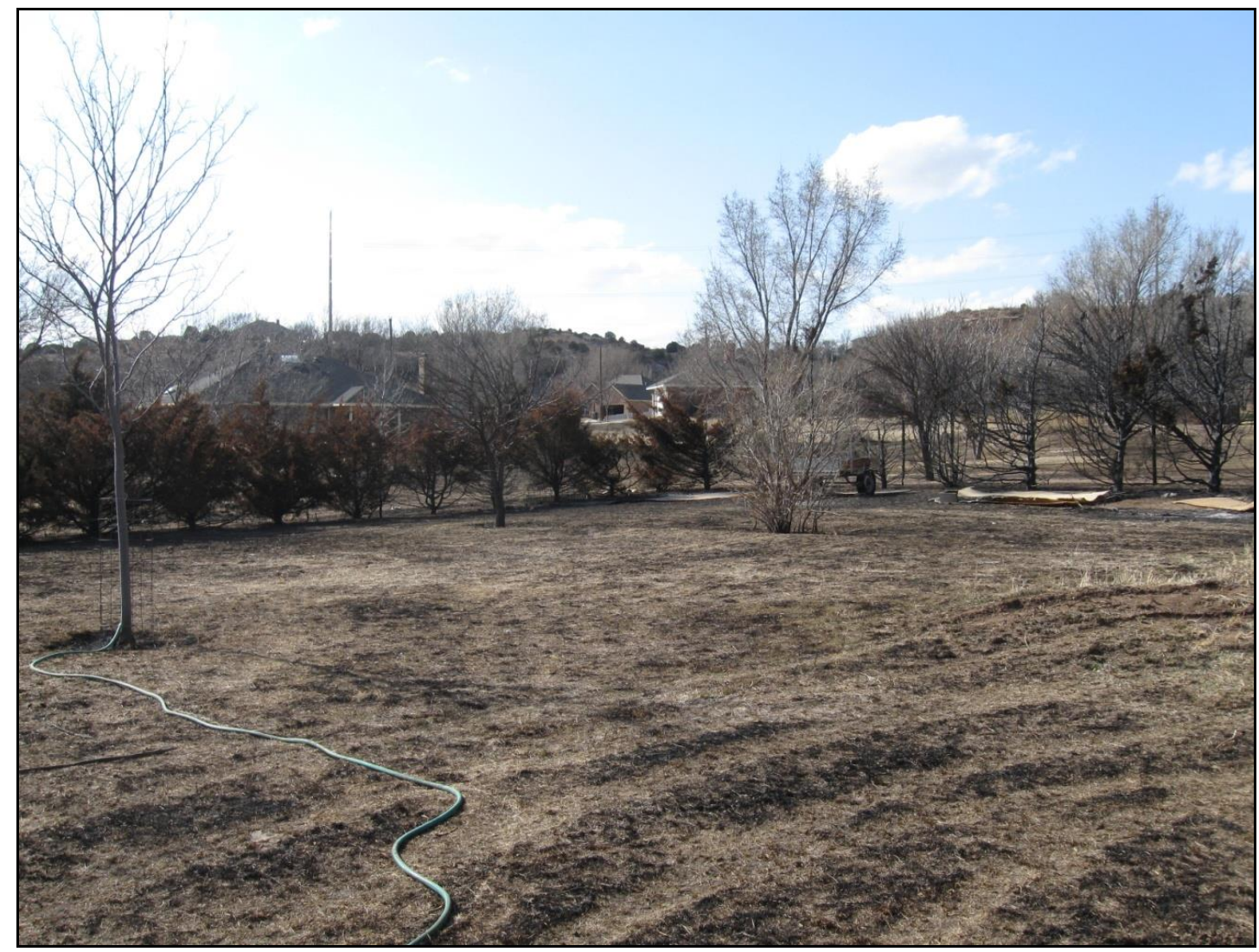

Figure 58 Burnt hedgerow and Buffalo grass that facilitated fire spread to destroyed secondary structure at 105 Port-O-Call Drive, NIST photo. 


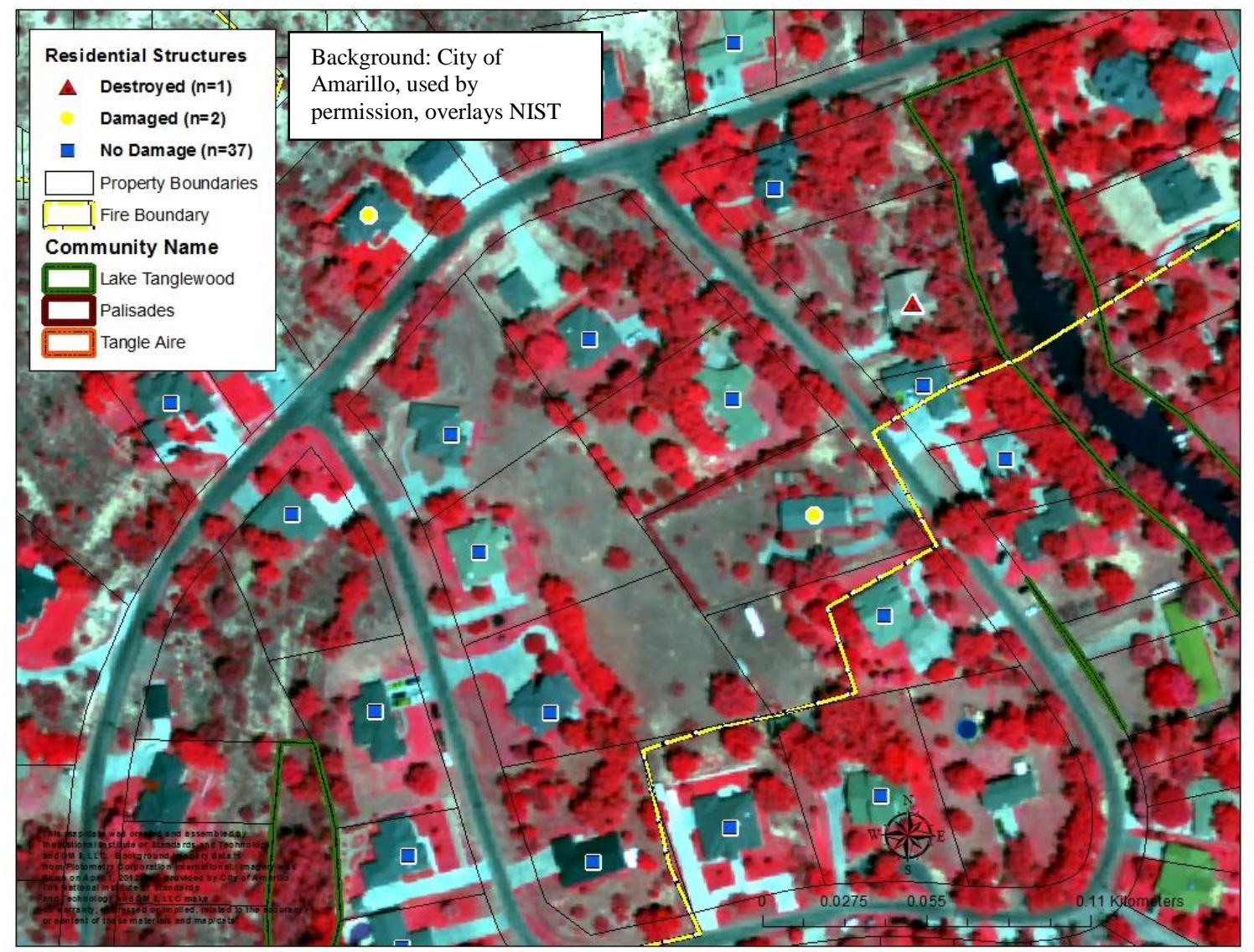

Figure 59 Pre-fire false color imagery showing redder areas that did not burn along with brown to black areas that did burn. In some locations the fire perimeter ended where these red, photosynthetically active, areas began and interior, red, photosynthetically active areas did not burn.

\subsection{South Lake Tanglewood}

This section begins with a tabulation of the damage and destruction to structural elements in the South Lake Tanglewood Community. Additionally, fire direction generalized from field observations of directional scorching are presented. Fire timeline information portrayed is derived from radio logs and the Amarillo Sheriff Helicopter flight.

This section also discusses fire behavior in the South Lake Tanglewood Community. Defensive actions conducted in the community along with defensive action structure categorizations are also described. Topographic characteristics are mapped and discussed. Finally, identified structural and vegetative element ignition mechanisms are detailed.

\subsection{Damage Assessment, Fire Direction and Fire Timeline}

Figure 61 shows damage to structural elements from the Tanglewood Fire within the South Lake Tanglewood Community. There were two damaged residential structures, one 
destroyed residential structure, and 12 residential structures with no damage. There was numerous damage to and destruction of combustible and linear features. A breakdown of damage to detached combustible features is shown in Table 20. Damage and destruction to linear features by length is shown in Table 21 .

Figure 62 shows fire direction in the South Lake Tanglewood Community. Little is known about the behavior of the wildland fire in this area. The wildland fire front appeared to reach the wildlands behind 200 South Shore Drive sometime after 15:30. However, it is not known precisely when the wildland fire front reached the wildlands behind 122 to 140 South Shore Drive, but these areas were already burnt by 18:18, during the Amarillo Sheriff Helicopter flight. A ground image at 17:14 shows the wildlands around 4 Canyon Circle already burnt. Nonetheless, fire behavior in these wildlands continued into the night (February 27 to February 28), as described by first responders. Exact fire direction in these wildlands was difficult to determine in the field.

There was only one location where the fire jumped South Shore Drive, which was on the west side of 109 South Shore Drive, as shown in Figure 62, though other embers might have jumped South Shore Drive and been suppressed by first responders before any ignitions could occur. The time of this fire jump is not known, illustrating one of multiple gaps in the fire timeline. The destroyed secondary structure was shown as igniting the one destroyed residential structure at 136 South Shore Drive at 18:16 during the Amarillo Sheriff Helicopter flight when the secondary structure was fully involved. There was a pile of unknown combustibles at 109 South Shore that was shown as fully involved during this flight also. Finally, a railroad tie retaining wall at 140 South Shore Drive was also shown as fully involved at 18:16.

Table 20 Damage and destruction to detached combustibles in South Lake Tanglewood Community.

\begin{tabular}{|l|c|c|}
\hline \multicolumn{1}{|c|}{ Combustible Feature } & Number Damaged & Number Destroyed \\
\hline Railroad Tie Retaining Wall & 0 & 1 \\
\hline Deck & 1 & 0 \\
\hline Hot Tub & 0 & 1 \\
\hline Secondary Structures & 1 & 1 \\
\hline Pergola/Gazebo & 1 & 0 \\
\hline Playground Equipment & 2 & 7 \\
\hline Boats & 0 & 3 \\
\hline Lawn Furniture & 0 & 1 \\
\hline Trailers & 5 & 0 \\
\hline Grills & 2 & 0 \\
\hline Dustbin & 1 & 0 \\
\hline HVAC System & 1 & 0 \\
\hline Electrical Utilities & 1 & 0 \\
\hline Planters & 1 & 0 \\
\hline Dog House & 1 & 0 \\
\hline Unknown Combustible & 0 & 1 \\
\hline Propane Tank & 1 & 0 \\
\hline
\end{tabular}




\subsection{Defensive Action Categorizations}

Figure 63 shows locations of identified defensive actions along with the resulting categorization of structures as to a defended category. First responders extinguished wood fences, railroad tie retaining walls, secondary structures, hot spots in the wildlands, residential grasses and various debris piles. Railroad tie retaining walls and secondary structures directly adjacent to wildlands were defended numerous times by different first responder teams due to multiple re-ignitions. There was a railroad tie retaining wall around treated vegetation at 140 South Shore Drive that was explicitly identified as being defended many times. The log home at 140 South Shore Drive was also explicitly identified as being defended, and it is assumed the home was defended against ember spread from the railroad ties. Finally, 212 South Shore Drive was explicitly identified as having water sprayed on it.

Table 21 Damage and destruction to linear features in South Lake Tanglewood Community.

\begin{tabular}{|l|c|c|}
\hline \multicolumn{1}{|c|}{ Linear Feature } & Meters Damaged & Meters Destroyed \\
\hline Fence & $18.6(61 \mathrm{ft})$ & $19.8(65 \mathrm{ft})$ \\
\hline Retaining Wall & $286.6(940 \mathrm{ft})$ & $15.9(52 \mathrm{ft})$ \\
\hline
\end{tabular}

There was residential grass around 200 South Shore Drive that was explicitly identified as being defended. The fire that destroyed the home at 136 South Shore Drive was contained by first responders. Destroyed features at 151 South Shore Drive were not explicitly identified as defended but it is possible the fire spread in this location was stopped by first responders. Extinguishment of vegetation along the east side of South Shore Drive also appeared to stop fire spread to 113 South Shore Drive and adjacent locations. Table 22 identifies damaged and destroyed linear and combustible features by identified defensive actions.

Table 22 Damage and destruction to features in South Lake Tanglewood Community categorized by identified defensive actions.

\begin{tabular}{|l|c|c|}
\hline \multicolumn{1}{|c|}{ Feature } & $\begin{array}{c}\text { Number } \\
\text { Damaged/Destroyed }\end{array}$ & $\begin{array}{c}\text { Number Identified as } \\
\text { Defended }\end{array}$ \\
\hline Linear Feature & 24 & 7 \\
\hline Detached Combustible Features & 23 & 2 \\
\hline
\end{tabular}

\subsection{Topographic Information}

Figure 64 displays radar derived percent slope for the South Lake Tanglewood Community. Figure 65 portrays radar derived aspect for the South Lake Tanglewood Community. As with the Southern Palisades Community the fire appeared to enter some sections of the South Lake Tanglewood Community in areas lacking cliffs. The damaged secondary structure at 200 South Shore Drive appeared to be a result of direct flame contact from burning vegetation, and the topography shown in Figure 64 displays an area between 160 and 200 South Shore Drive of moderate slopes. This area had continuous burned vegetation from the plateau right to the secondary structure. Vegetation in the steeper areas (i.e., cliffs) directly behind 160 and 212 South Shore Drive was not burned. 
It was more difficult in other locations in South Lake Tanglewood to identify paths of fire spread from the plateau into the canyons. There were areas of moderate slopes above 136 South Shore Drive where the fire might have traveled. These areas of moderate slopes might have resulted in ignition of the secondary structure at 136 South Shore Drive, which was directly adjacent to burned wildlands. These moderately sloped areas might also have resulted in burning of the railroad tie retaining walls at 140 South Shore Drive. It is possible, however, that fire traveled through wildlands along South Shore Drive, having entered the canyon in the eastern most canyon described in Section 7.2. The available data for this location lacks the resolution necessary to determine the exact fire spread paths.

\subsection{Structural and Vegetative Element Ignition Mechanisms}

The majority of structure ignition mechanisms found in the South Lake Tanglewood Community have been described above. Additionally, a wood pergola at 151 South Shore Drive had the roof ignited, as shown in Figure 60. This pergola was $12.5 \mathrm{~m}(41 \mathrm{ft})$ away from the closest burned feature, which was wildland vegetation. A small retaining wall and telephone poles also ignited at 151 South Shore Drive, with the closest burning feature being $11.5 \mathrm{~m}(38 \mathrm{ft})$ away. The source of ignition of the above features had to have been embers due to unburned features all around and a road between these features and other burned features. However, the embers could have come from another feature farther away than the distances listed above. Embers also caused melting of planters, a dog house and a trampoline at 128 South Shore Drive. The melting of these features did not appear to cause any significant flaming or radiant heat.

As with other areas described above, the burning of residential grass in the South Lake Tanglewood Community appeared to coincide with areas that were not as red in infrared imagery, displayed as a false color composite compared to other areas that did not burn.

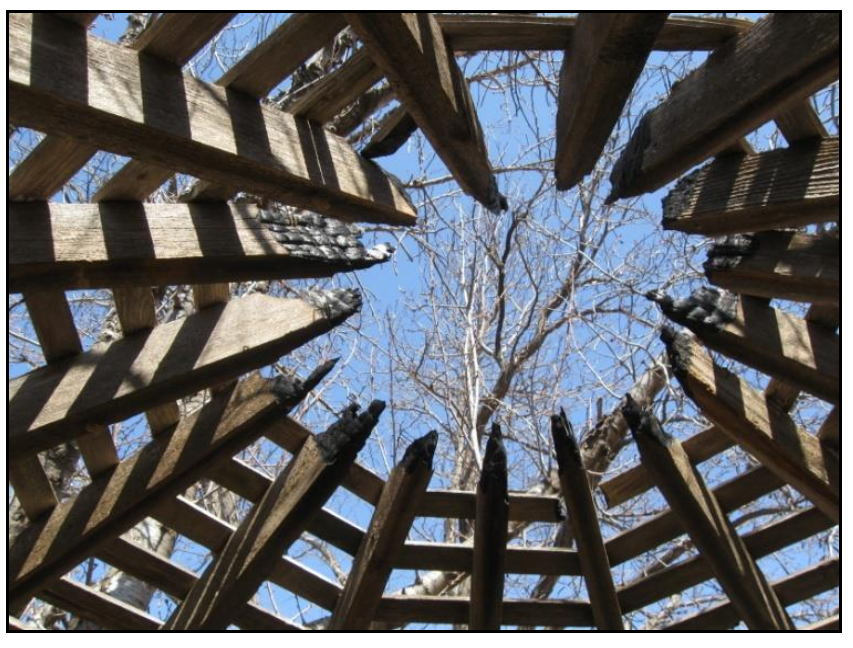

Figure 60 Damaged pergola roof ignited by embers, NIST photo.
This might be due to vegetation treatment. Many of the homes on the lake side of South Shore Drive, which did not have any burned features, appeared bright red in prefire imagery. It should, however, be noted that the exact extent of all defensive actions along South Shore Drive have not been quantified and some embers might have been suppressed by first responders before ignitions could occur. 


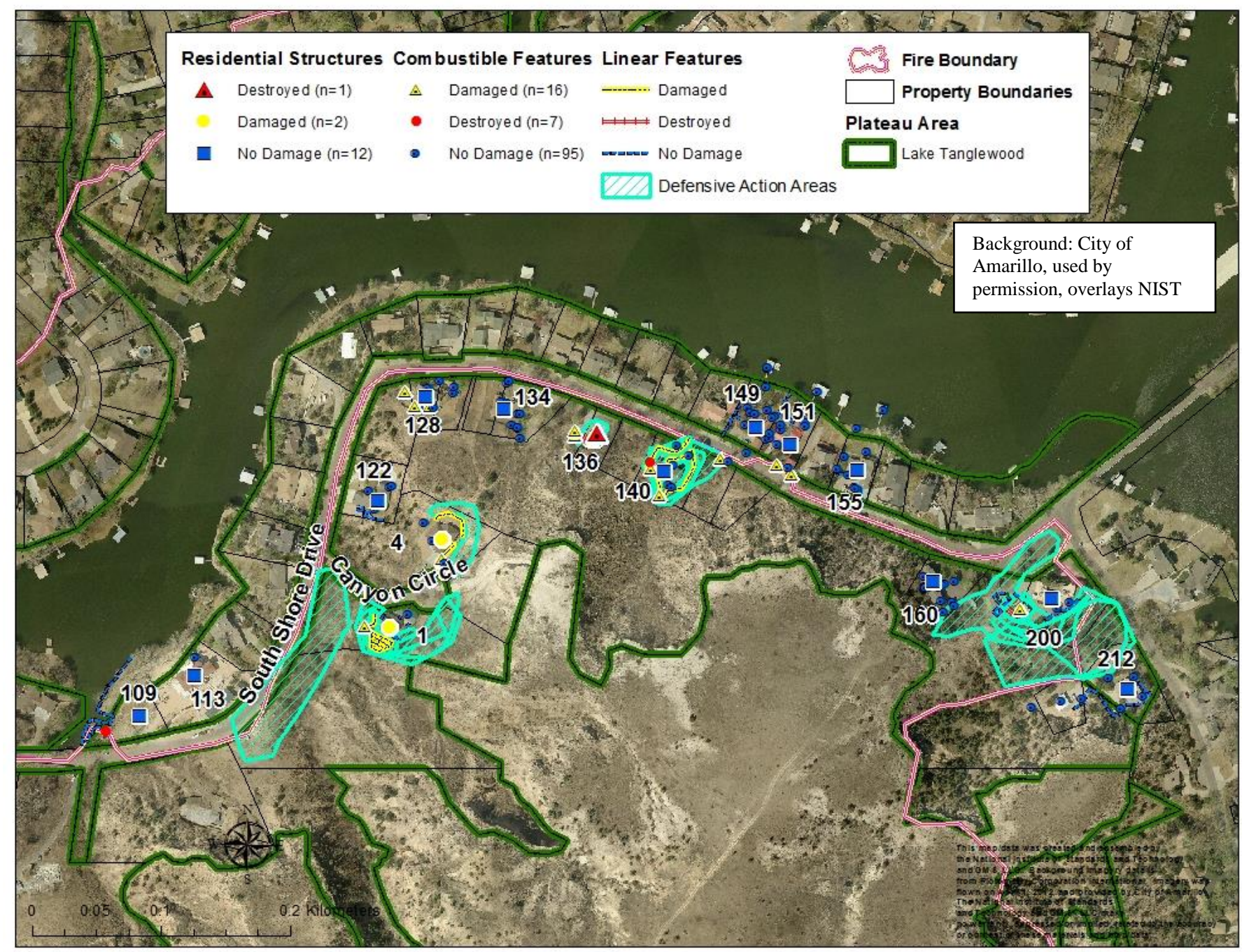

Figure 61 Damage to structural elements in the South Lake Tanglewood Community. 


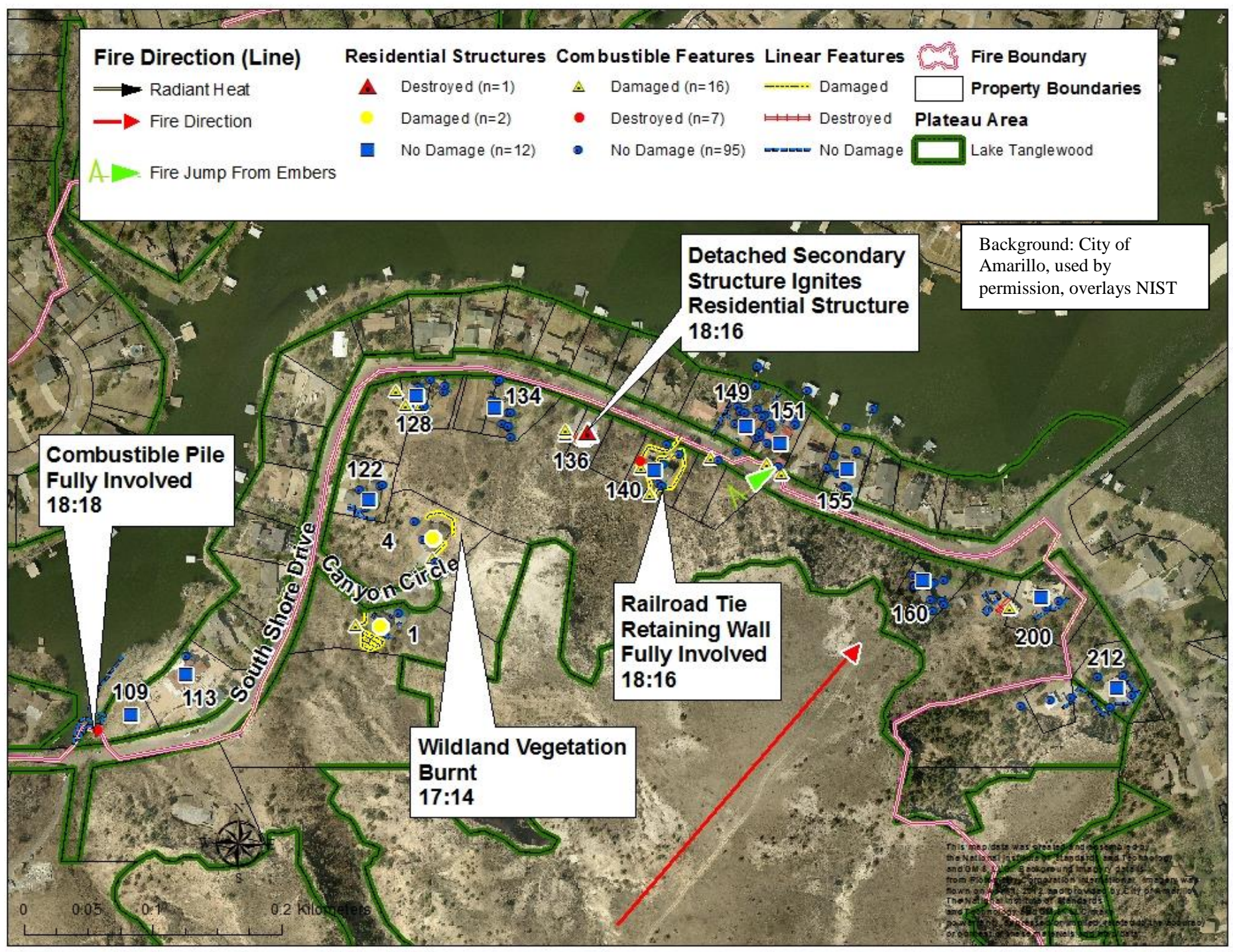

Figure 62 Fire direction and fire timeline in South Lake Tanglewood Community. 


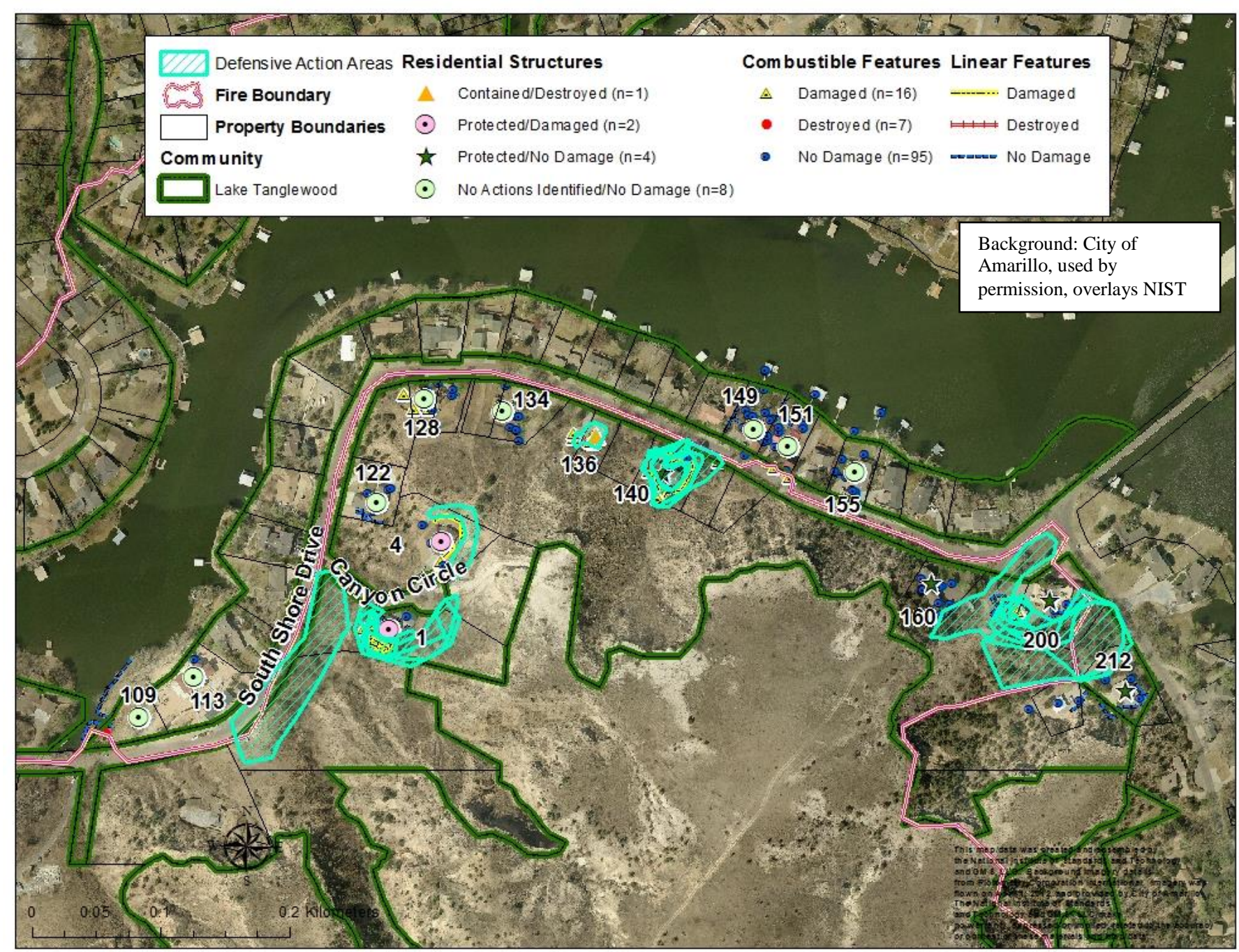

Figure 63 Defensive action locations and primary structure categorizations in South Lake Tanglewood Community. 


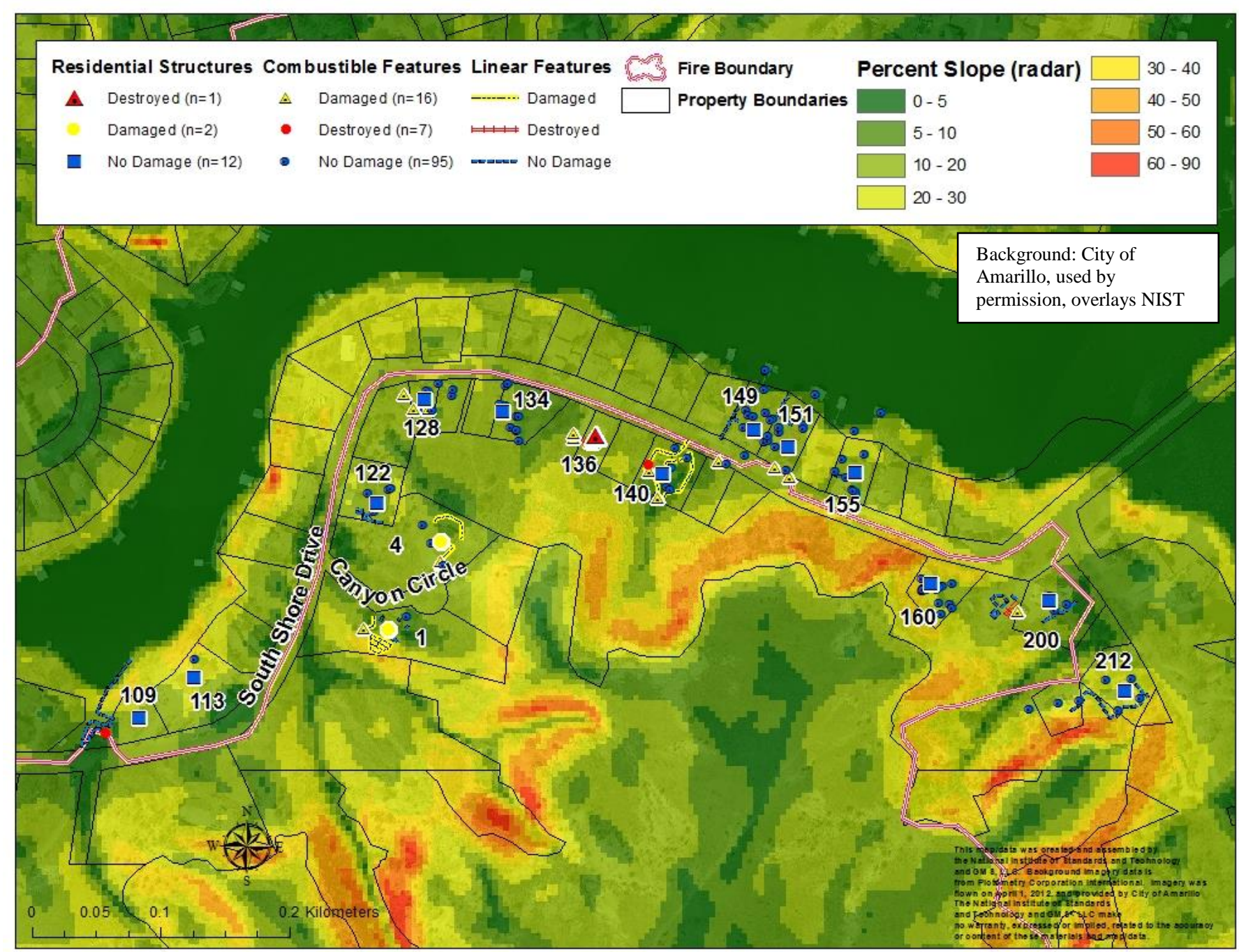

Figure 64 Radar derived percent slope in South Lake Tanglewood Community. 


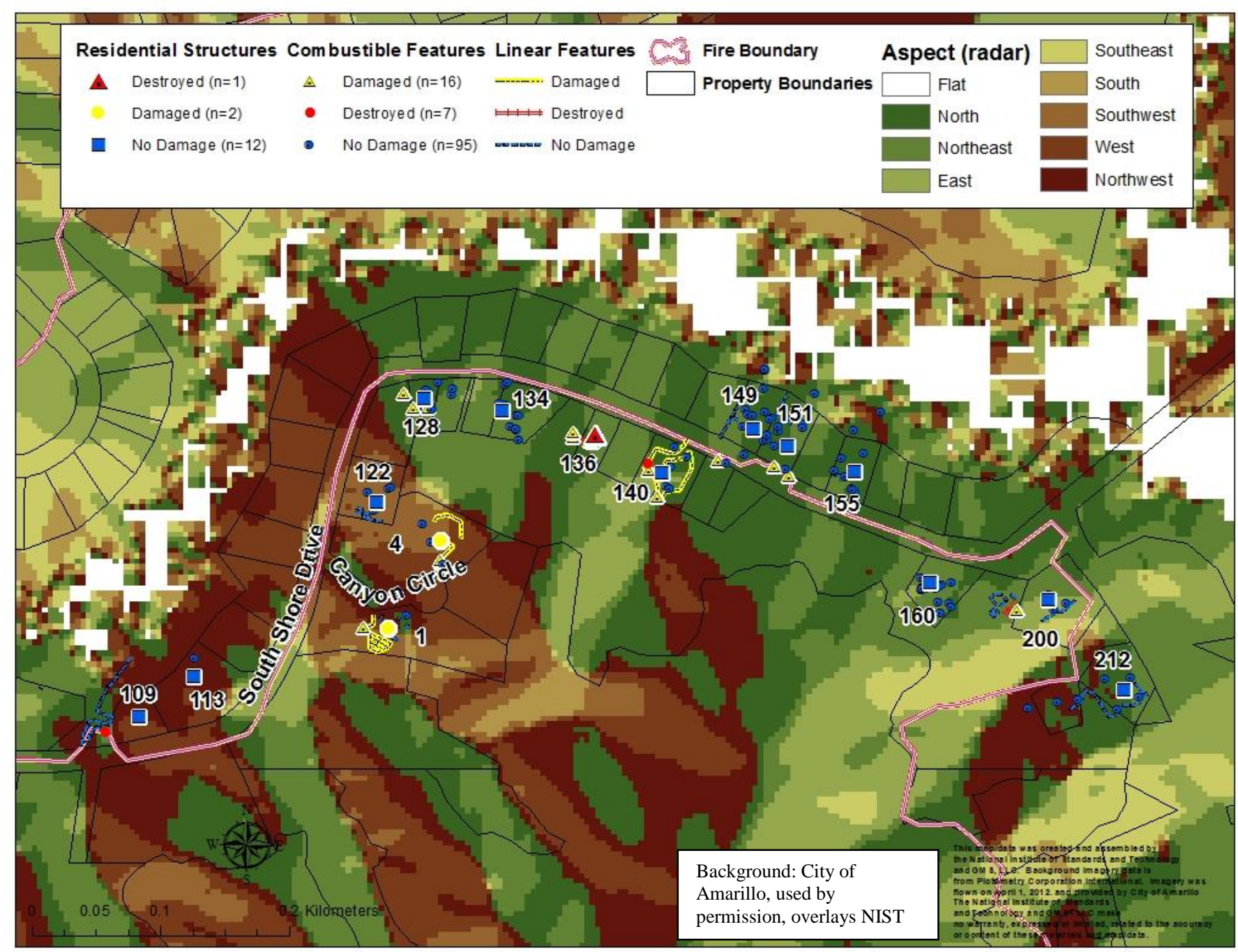

Figure 65 Radar derived aspect in South Lake Tanglewood Community. 


\subsection{Southeast Lake Tanglewood}

This section begins with a tabulation of the damage and destruction to structural elements in the Southeastern Lake Tanglewood Community. Additionally, fire direction generalized from field observations of directional scorching are presented. Fire timeline information portrayed is derived from the Amarillo Sheriff Helicopter flight. Defensive actions conducted in the community along with defensive action structure categorizations are also described. Topographic characteristics are mapped and discussed.

\subsection{Damage Assessment, Fire Direction and Fire Timeline}

Figure 66 shows damage to structural elements from the Tanglewood Fire within the Southeast Lake Tanglewood Community. No residential structures were damaged or destroyed in this area. Damage and destruction did occur to some detached combustibles and linear features as shown in Table 23. Damage and destruction to linear features by length is shown in Table 24. The exact time of when most of the detached combustibles burned is not known. Figure 67 shows fire direction in the Southeast Lake Tanglewood Community. The fire jumped the circular driveway at 310 South Shore Drive in two locations. As listed in Figure 67, the fire in the wildlands moved through the area sometime prior to $18: 21$ on February 27.

Table 23 Damage and destruction to detached combustibles in Southeast Lake Tanglewood.

\begin{tabular}{|l|c|c|}
\hline \multicolumn{1}{|c|}{ Combustible Feature } & Number Damaged & Number Destroyed \\
\hline Short Fence & 1 & 0 \\
\hline Short Retaining Wall & 1 & 0 \\
\hline Brush Piles & 0 & 2 \\
\hline Trailer & 1 & 0 \\
\hline Mailbox & 1 & 0 \\
\hline
\end{tabular}

Table 24 Damage and destruction to linear features in Southeast Lake Tanglewood Community.

\begin{tabular}{|c|c|c|}
\hline Linear Feature & Meters Damaged & Meters Destroyed \\
\hline Retaining Wall & $41(134 \mathrm{ft})$ & 0 \\
\hline
\end{tabular}

\subsection{Defensive Action Categorization}

Figure 68 shows the locations of identified defensive actions along with the resulting categorization of structures as to a defended category. First responders extinguished railroad tie retaining walls, landscape borders, grass vegetation by South Shore Drive and also suppressed burning wildland vegetation to the west of the residential structures. The damaged combustibles by 310 South Shore Drive were not explicitly identified as defended, but the scorching of these features was minor and suppression of nearby burning vegetation by first responders might have alleviated some of the damage to these features. Table 25 identifies damaged and destroyed linear and combustible features by identified defensive actions. 
Table 25 Damage and destruction to features in Southeast Lake Tanglewood Community categorized by identified defensive actions.

\begin{tabular}{|l|c|c|}
\hline \multicolumn{1}{|c|}{ Feature } & $\begin{array}{c}\text { Number } \\
\text { Damaged/Destroyed }\end{array}$ & $\begin{array}{c}\text { Number Identified } \\
\text { as Defended }\end{array}$ \\
\hline Linear Feature & 9 & 2 \\
\hline Detached Combustible Features & 8 & 0 \\
\hline
\end{tabular}

\subsection{Topographic Information}

Figure 69 displays radar derived percent slope for the Southeast Lake Tanglewood Community. Figure 70 portrays radar derived aspect for the Southeast Lake Tanglewood Community. As with other areas described above fire behavior was more heavily concentrated on one side of the canyon than the other side. It was more difficult to discern the precise area where the fire traveled from the plateau to the canyon in this area. Nonetheless, steep areas with cliffs have burned vegetation up to the cliffs on the plateau side with green vegetation on the canyon side of the community not being burned.

The residential structure at 314 South Shore Drive was also terraced above the surrounding wildlands. The terraced area, typically extending less than $20 \mathrm{~m}$ from the structure, consisted of treated residential grass, which did not burn except in one small location directly adjacent to the wildlands. The terracing as with 400 Casino Drive, might have helped direct fire behavior away from the house. As with other locations, however, it is unknown the exact role first responders played in preventing ignitions of the residential grasses on the terraced portion of 314 South Shore Drive.

\subsection{Structural and Vegetative Element Ignition Mechanisms.}

Other than the information shown in Table 23 and Table 24, not much is known about structural element ignition mechanisms in this area of the fire. Other than what is listed in section 11.3 above, not much is known about vegetative element ignition mechanisms in this area of the fire. 


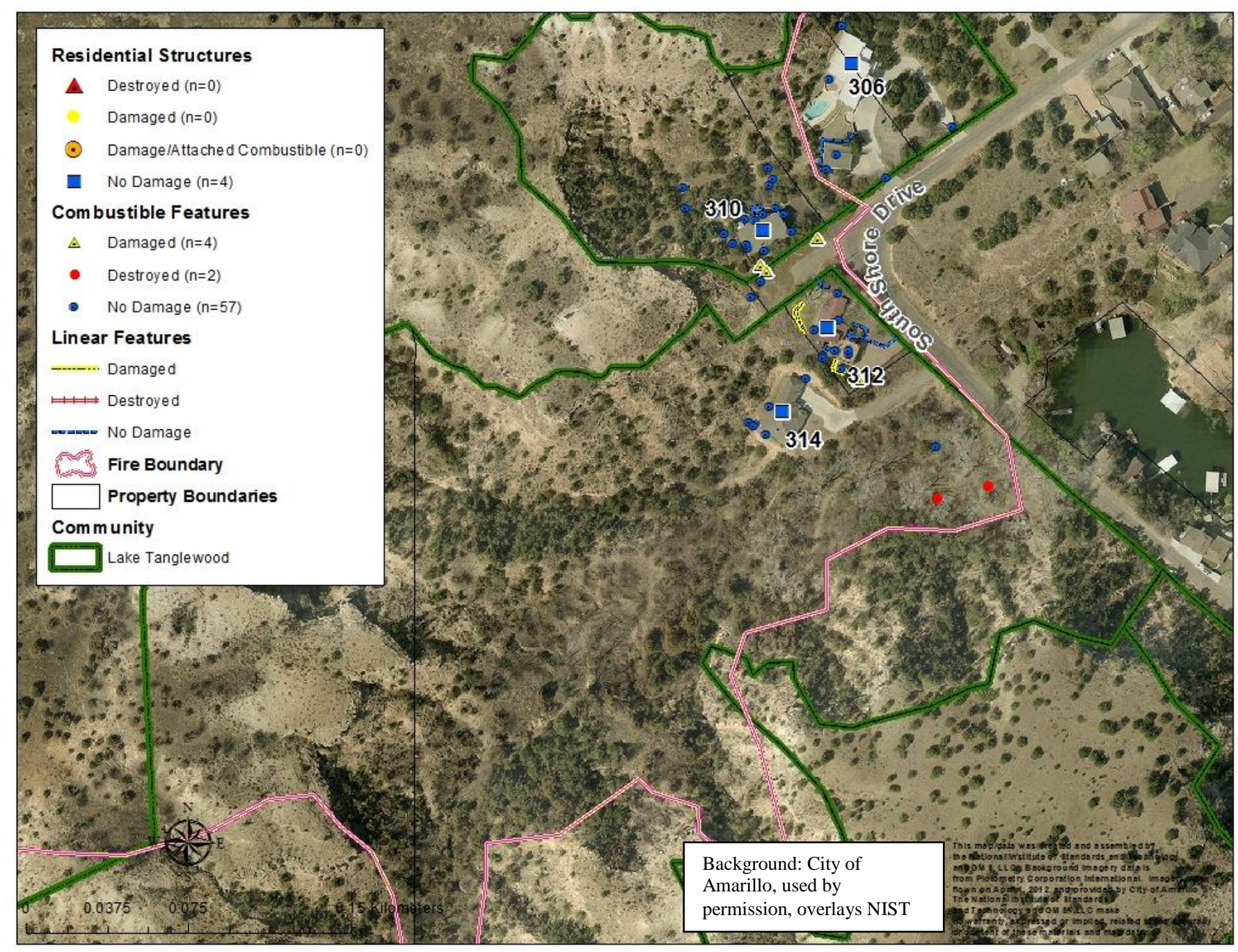

Figure 66 Damage to structural elements in the Southeast Lake Tanglewood Community. 


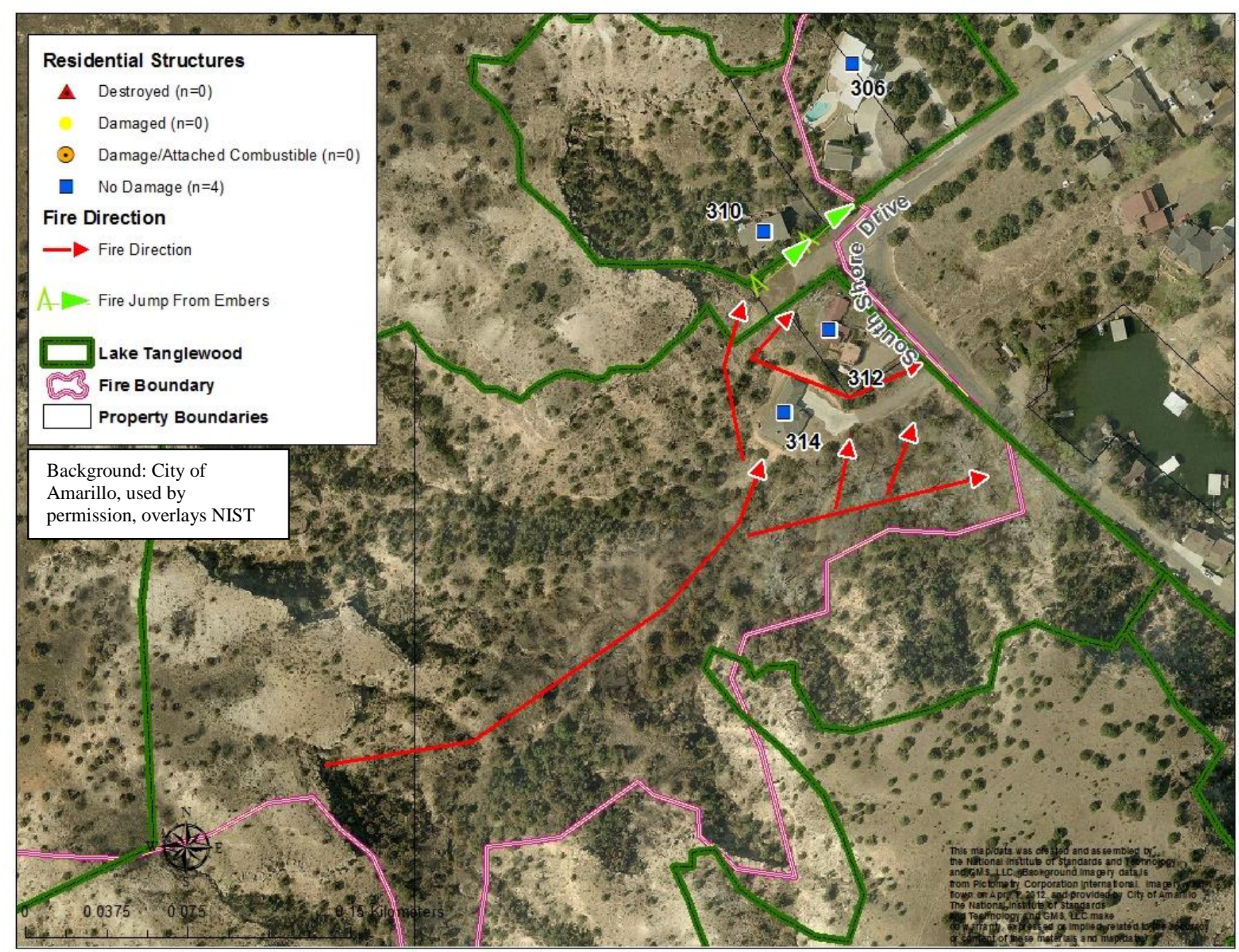

Figure 67 Fire direction in Southeast Lake Tanglewood Community. The main fire front moved through area by 18:21 on 2/27/2011 based on Amarillo Sheriff Helicopter flight. 


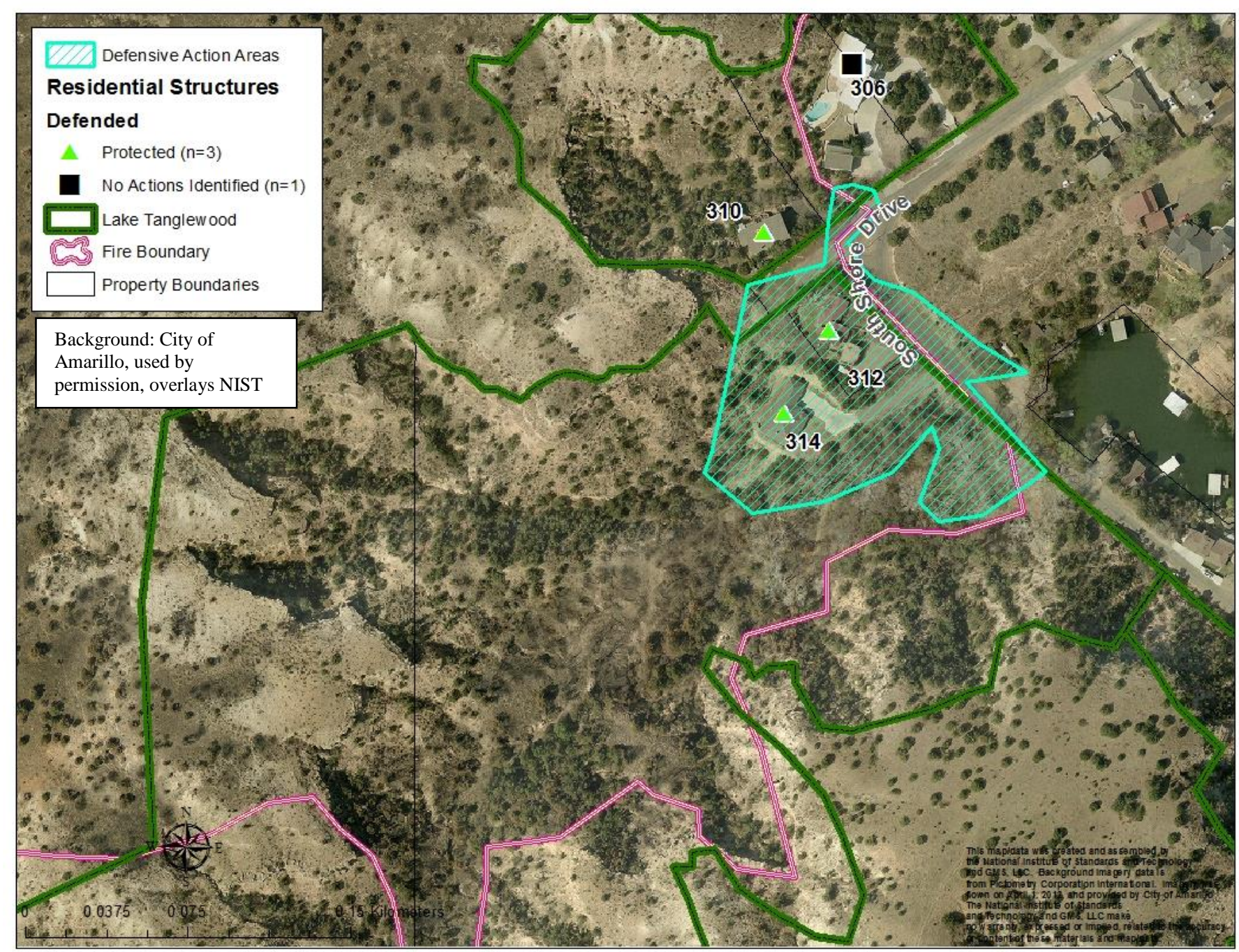

Figure 68 Southeast Lake Tanglewood Community defensive action locations and primary structure categorizations. 


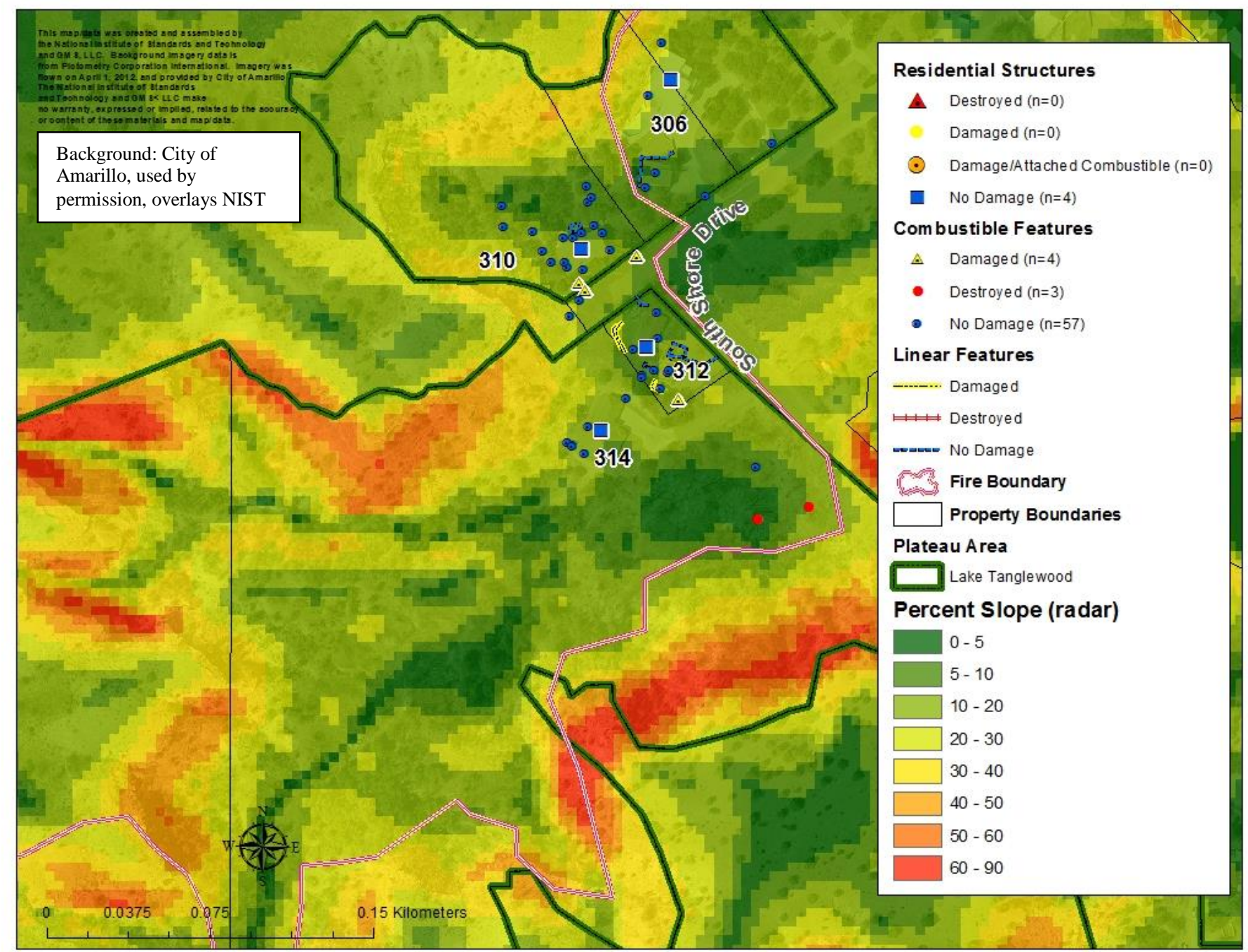

Figure 69 Radar derived percent slope in Southeast Lake Tanglewood Community. 


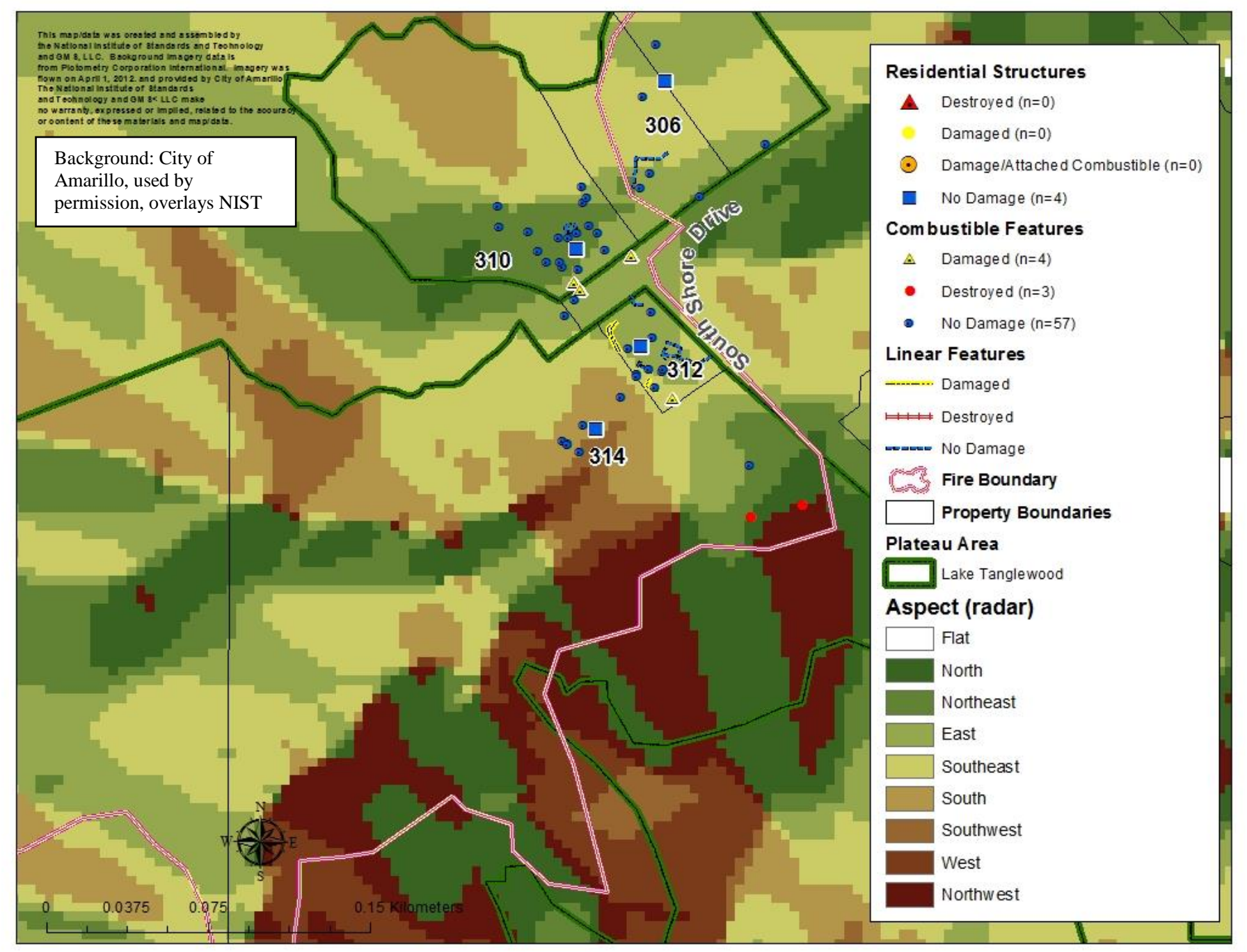

Figure 70 Radar derived aspect in Southeast Lake Tanglewood Community. 


\subsection{WUI Assessment Methodology and Science}

WUI Assessment Methodology and Science are in their infancy. This study represents the first attempt at characterizing the entire fire disturbance continuum ${ }^{1}$ in a post-fire environment. Although an original objective was to characterize all aspects of the fire disturbance, this study was not successful because the data was limited in resolution and completeness. This section addresses successes as well as shortcomings involved with assessing various aspects of the fire disturbance continuum. Additionally, possible improvements for future WUI assessments are listed. Recommendations for specific improvements to the NIST WUI 2 Data Collection System are listed in Appendix G.

\subsection{Pre-fire Hazard Mitigation Guidance and Assessment}

Appendix $\mathrm{H}$ shows one field form from a pre-fire assessment of the Tanglewood Fire area, which occurred on some unknown date prior to the Tanglewood Fire. The data was not in electronic format, nor complete for the entire community, and could not be used in this assessment. However, if collected properly, pre-fire WUI assessment data might be used to assess the appropriateness of the respective WUI mitigation guidance under consideration, in context of a WUI post-fire environment. Pre-fire mapping of the WUI provides the possibility of adaptive management regarding current WUI mitigation guidance. Collection of pre-fire conditions and assessment of these conditions in a postfire environment would allow WUI mitigation guidance to be improved and enhanced.

Nonetheless, the form presented in Appendix H highlights the need for a paradigm shift regarding WUI mitigation guidance. Most WUI mitigation guidance is presented to users in the form of weighted assessments. Each attribute collected has a specific weight assigned to it with the cumulative weighted attributes representing a total score for the property being assessed. These weighted WUI assessment methods have the possibility of presenting the homeowner with a false sense of security and preparation. There are no science-based WUI mitigation methods which take into account the spatial relationship amongst and between all WUI features, and rate WUI mitigation actions accordingly. Although distance to features is often considered, linear distance does not necessarily capture the full exposure from a dangerous topographic feature that has consequences for a structure's susceptibility to destruction from wildland fire. The interaction must include the spatial configuration of that topographic feature in relation to the structure, fuels and the wind. Some topographic features are not always dangerous in context of a WUI fire, such as cliffs or terraced platforms, which might serve to protect a structure in certain spatial configurations as described above. However, these features might direct fire to other structures or properties.

WUI mitigation guidance, presented in the form of weighted attributes, could result in homeowners working towards achievement of low scores for some treatments while leaving other more relevant attributes alone. Take for example 334 Cactus Drive, described above. This home had many features that would have resulted in low weighted scores in many WUI Mitigation models. The home had a metal roof, siding was largely brick (with some minor wood) and there was treatment $9 \mathrm{~m}(30 \mathrm{ft})$ around the structure. However, the Tanglewood Fire highlighted the vulnerability of combustible secondary 
structures, which were contained by first responders, close to the residential structure. This single attribute, which is not accounted for in many WUI Mitigation guidance (i.e., secondary structures and spatial relationship to residential structure), could have been ignored and still resulted in an "acceptable" score for the property, leaving the homeowner blissfully unaware of the potential hazard on their property.

A better approach, given the current understanding of the WUI and wildland fire, would be to identify hazards and not weight particular attributes. As WUI fire science progresses to a better understanding of the spatial relationships among WUI features, the framework ${ }^{5}$ can be coupled with implementation, using the concepts of Geodesign ${ }^{15}$, might result in more effective WUI mitigation advice than what currently exists. In the interim, mapping of existing hazards in WUI communities without the use of unfounded weighted attributes would provide a means of identification for homeowners and first responders of existing hazards (manmade and natural), thereby providing potential for removal of hazards by homeowners and land managers, and recognition by first responders during fires.

\subsection{Pre-Fire and Post-Fire Landscaping Characteristics}

This study did not focus on assessment of landscaping characteristics. Information was collected during the post-fire assessment on irrigation conditions and continuous fuels in various treatment zones around residential structures. While collecting vegetative data, a number of technical issues were identified. Five examples are provided here, while improvements to the WUI 2 data collection method are listed in Appendix G.

1. The data collection system asked if, for each treatment zone, irrigation was present. Some data collectors interpreted this to assess if irrigation was present during the fire. Additionally, because vegetation was in senescence, it was difficult to determine irrigation conditions at the time of data collection.

2. Assessing landscaping characteristics on properties that had burned vegetation can lead to a bias assessment of landscaping characteristics.

3. Information was collected on burned vegetation, but again, there was difficulty with consistent interpretation by data collectors.

4. The delineation of burned vegetation in the field by data collectors varied greatly due to problems with provided definitions and guidance.

5. There was no assessment of conditions present in the wildlands.

Assessment of landscaping characteristics, residential or wildland, in context of a postfire assessment requires having details on these characteristics in a pre-fire environment. These details should be collected at a sufficient temporal resolution (every one to two years, though this might be site dependent) to result in relevant conditions at the time of the fire being portrayed. Nonetheless, post-fire vegetation information also needs to be collected.

Field data collection of burned vegetation is a key component of post-fire assessments. This field data collection, however, must be coupled with timely acquisition of aerial imagery of sufficient spatial resolution, and focus on detailed ground imaging. The postfire imagery provided by the City of Amarillo was essential to this assessment, but the temporal resolution after the fire (i.e., 30 days) resulted in some burned vegetation being 
difficult to identify. For example, Figure 71A shows an image of burned vegetation right after the fire, while Figure 71B shows an image of the same area from the City of Amarillo provided post-fire imagery. As can be seen, the black marks, which clearly identify the burned area in the imagery right after the fire (Figure 71A), are not present in the aerial imagery taken a month later (Figure 71B).

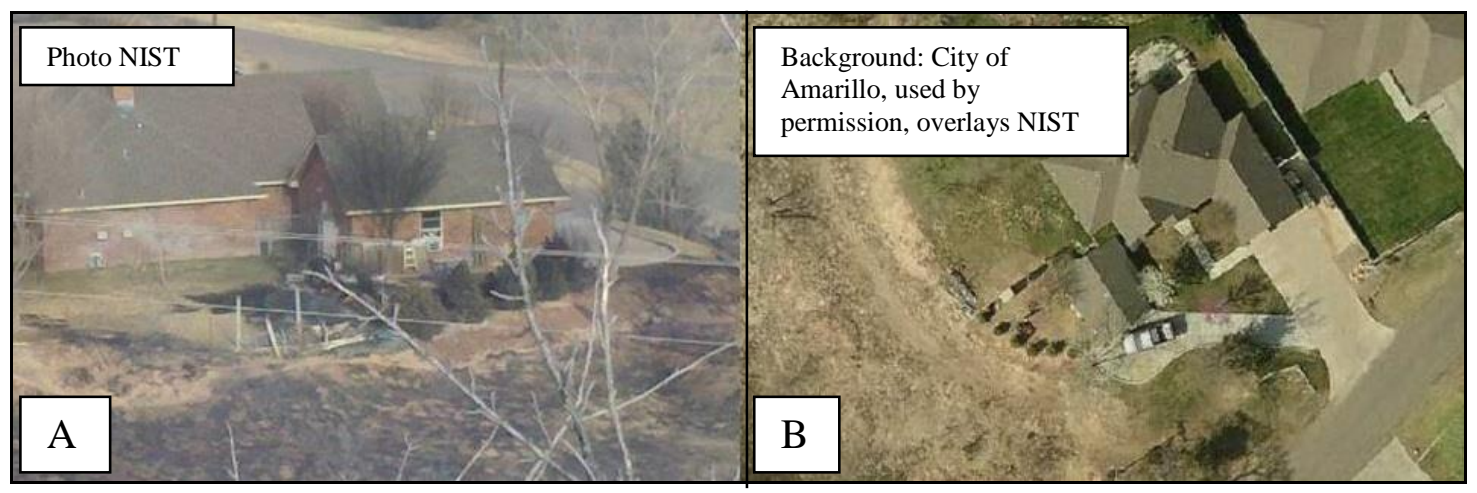

Figure 71 A: Image of burned vegetation right after the main fire front moved through the area. B: Aerial image of same area acquired one month after fire, lacking clear black demarcation of burned area.

Remote sensing, combined with field assessments, presents the best means to obtain prefire and post-fire vegetation information, as aerial imagery and LiDAR lacks the ability to identify understory conditions for both pre-fire and post-fire conditions. Advances in remote sensing have resulted in the timely acquisition of high spatial resolution imagery for most locations. This study site did have four-band imagery acquired in 2009.

Additionally, post-fire response imagery acquired to assess response of vegetation can help to provide additional important information. For example, Google Earth Imagery acquired a year after the fire was used to help identify locations where the fire did, and did not, enter canyons based on vegetation green up.

Aerial imagery, however, does lack the ability to identify understory conditions (even LiDAR data will vary in its ability to identify understory conditions) for both pre-fire and post-fire conditions. Consequently, homeowners living in the WUI should be encouraged to photograph their landscapes in the same manner they are encouraged to photograph their personal belongings. Technologies such as Photosynth ${ }^{\mathrm{TM}}$, and structure from motion, might provide potential for detailed pre-fire imaging of WUI understory conditions. Pre-fire WUI mitigation advice should also involve ground sampling of wildlands in close proximity to residential structures using established plot based techniques such as the Forest Inventory and Analysis National Program, the Fire Effects Monitoring and Inventory Protocol, or some other appropriate protocol. Homeowners should also be careful of listing these images publicly as they can be used for nefarious purposes by others.

Post-fire field data collection of burned vegetation should focus on imaging the burned vegetation on the ground with collection of very simple attribute information about directional scorching, scorch heights, white ash accumulation, char depth, and possibly other factors. Collection of this information should not be limited to residential areas and should continue into wildlands. A post-fire data collection methodology to estimate vegetative fuel consumption is needed. This ground information should be coupled with 
timely acquisition of aerial and ground imagery. Studies need to be conducted to determine degradation of information with increased time of acquisition after the fire in regards to aerial imagery.

The collection of post fire vegetation data from residential parcels, together with remote sensing for both pre and post fire documentation, has provided significant insights on improving future WUI vegetative data collection. Additionally, the collected information provided valuable insights, as described in Sections 5 through 11, in evaluating fire behavior around many structures within the fire perimeter.

\subsection{Building Characteristics}

A focus of the data collection effort utilized for this study was on the assessment of building characteristics. Out of the 183 structures documented in this case study, 35 homes were destroyed, and 13 were damaged. An unprecedented amount of structural elements were collected in the field and updated in the office using pre-fire and post-fire remote sensing. This included association of images of many of these structural elements to spatial locations, resulting in a unique spatial database in the WUI. Additionally, collection of this detailed structure information allowed for identification of numerous ignition mechanisms as detailed above. It should, however, be noted that analysis is confined to those structural treatments for which information exists prior to the fire. This information typically only exists, as was the case in this study, in local tax assessor's databases. Analyzing the response of destroyed structural elements is extremely difficult without the necessary pre-fire construction information, and prone to errors.

The data collected during this deployment, together with existing pre-fire information, was used to qualitatively evaluate individual structural response. When this was accomplished, it was done in context with known local exposure conditions and defensive actions. It was determined that damaged structures were preferable for analysis compared to destroyed structures, as building materials identification was more reliably achieved.

It should be noted, however, that even when pre-fire data exists, there are additional technical issues that need to be resolved before explicit statements about building material response can be made. For example, the destruction of a home with a wood roof does not mean the wood roof was the cause of the destruction. A wood deck, nearby secondary structure, or other factor might have ultimately contributed to the destruction. Without eyewitness accounts of the destruction, it is basically impossible to determine.

Nonetheless, in certain circumstances, analysis of certain building treatments might be possible, particularly in regards to identifying areas where current WUI mitigation advice is wrong (e.g. wood roofs are the major structural attribute problem in the WUI). This analysis, however, would still require, prior to the destruction by fire, knowledge of the building treatments. As mentioned above, this information would typically be obtained from local tax assessors. This highlights the need, in some locations, for expanded data collection in WUI areas prior to the fire regarding a plethora of building treatments including secondary structure information, attached combustibles, window treatments and other factors. Collection of this type of information varies greatly across the United 
States. A summary of some of the data collected is listed in Appendix F. The data presented is for attributes that were determined/known for many of the destroyed homes.

In the context of post-fire assessments, while it is important to document all the damage occurring in the area, characterization of all the structural elements is an onerous and unnecessary task when extensive pre-fire data is available. In addition to focusing on documentation of damage and destruction to all structural attributes, post-fire assessments should focus on structural treatments that might provide pertinent information for the given study and for which pre-fire information exists. This would be incident dependent. Post-fire assessments can then collect subsets of the structural information for undamaged buildings to assess the accuracy of the pre-fire structure information being used for the respective study. This type of information, when used in combination with defensive actions and exposure information as part of a detailed timeline reconstruction, is necessary to assess building attributes response.

\subsection{Topographic Characteristics}

Unlike building and landscaping characteristics, topographic characteristics can be collected either pre-fire or post-fire, with most topographic characteristics not changing substantially over time. This study did attempt to assess topographic characteristics in the field. The use of radar data did help to provide consistent topographic information across the study area, however, the available radar data lacked the spatial resolution of the LiDAR data used successfully during the Witch/Guejito fire case study. ${ }^{9}$ A number of topographical data collection improvements were identified to improve the data quality for future studies. Recommended data collection improvements are listed in Appendix G.

The use of digital elevation models for the assessment of topography is superior to field data collection techniques, short of actual surveys, because it provides a more consistent interpretation. It is not known, however, the resolution at which topographic information is required. It is possible that the scale of fire behavior is dependent to some extent on the scale of topography, with micro-topographical features in the range of meters affecting fire behavior over the same distances. For example, at the Trails at Rancho Bernardo Community studied by Maranghides et al, ${ }^{9}$ topographic features were at a coarser scale (on the order of tens of meters) than those at the Tanglewood Canyon Communities. It is, therefore, likely that the radar data did not capture all pertinent topographic features in this study, which had consequences for understanding and/or characterizing fire behavior.

The Trails at Rancho Bernardo Community provided an opportunity to examine the required spatial resolution of topography for post-fire assessments because high resolution topographic data does exist. ${ }^{9}$ The same analyses conducted by Maranghides et $\mathrm{al}^{9}$ could be run with radar data and $10 \mathrm{~m}$ (33 ft) United States Geologic Survey (USGS) Digital Elevation Models (DEMs) and examine differences. This also highlights the need for validated physics based fire models capable of providing a better understanding of appropriate scales for assessing and analyzing WUI environments. 


\subsection{Defensive Actions and Fire Behavior}

Defensive actions play a critical role in reconstructing WUI fire events as the state of the post fire environment is directly tied to them. Table 26 contains specifics on the homes damaged with respect to location of damage and associated defensive actions. The data show that 11 damaged homes out of the 13 damaged homes had evidence of defensive actions and out of the 11 that were known to be defended, the defensive actions on 5 exactly match the damage that was recorded.

Table 26 Damaged structures with damage status and defensive action.

\begin{tabular}{|c|c|c|}
\hline Address & Damaged Status & Defended \\
\hline 450 Casino Drive & $\begin{array}{c}\text { Attached Carport (No } \\
\text { Damage to Main Building) }\end{array}$ & No Actions Identified \\
\hline 411 Roberts Drive & Deck and Siding & $\begin{array}{c}\text { Deck and Siding Identified as } \\
\text { Defended }\end{array}$ \\
\hline 585 Canyon Creek Drive & Stairs & Stairs Identified as Defended \\
\hline 144 Exmoor Road & $\begin{array}{c}\text { Deck (No Damage to Main } \\
\text { Building) }\end{array}$ & Deck Identified as Defended \\
\hline 475 Casino Drive & $\begin{array}{l}\text { Discoloration on House; } \\
\text { Damage to Attached Fence }\end{array}$ & $\begin{array}{c}\text { Not Specifically Identified as } \\
\text { Defended but Signs of Defensive } \\
\text { Actions }\end{array}$ \\
\hline 105 Port o Call Drive & Attached Deck and Fence & $\begin{array}{c}\text { Deck and Fence Identified as } \\
\text { Defended }\end{array}$ \\
\hline 102 Gary Drive & $\begin{array}{l}\text { Damage to Eave in Two } \\
\text { Separate Locations, Broken } \\
\text { Window, Scorching of Brick }\end{array}$ & Eave Damage Identified as Defended \\
\hline 114 Bayshore Drive & $\begin{array}{c}\text { Melted Eaves, Possibly } \\
\text { Broken Window,Scorched } \\
\text { Siding, Completely Destroyed } \\
\text { Fence and Deck } \\
\end{array}$ & $\begin{array}{l}\text { Defensive Actions Identified but } \\
\text { Fence and Deck Not Specifically } \\
\text { Identified and Completely } \\
\text { Combusted }\end{array}$ \\
\hline 1 Canyon Circle & Minor Scorching Damage & Property Identified as Defended \\
\hline 4 Canyon Circle & $\begin{array}{c}\text { Minor Window Damage; } \\
\text { Damage to Fence }\end{array}$ & Property Identified as Defended \\
\hline 400 Casino Drive & Melted Eave & $\begin{array}{c}\text { Eave Not Specifically Identified as } \\
\text { Defended }\end{array}$ \\
\hline $\begin{array}{l}124 \text { Saint Andrews } \\
\text { Road }\end{array}$ & Scorched Siding & Specifically Identified as Defended \\
\hline 140 Bayshore Drive & Scorched Siding & Specifically Identified as Defended \\
\hline
\end{tabular}

An analysis of the fire scene without full knowledge of defensive actions or the lack thereof can be very misleading, as demonstrated in Section 8.5. Additionally, defensive actions can provide critical insight into fire behavior, exposure and local weather conditions as well as interactions between these four different components of WUI fires.

In this incident, defensive action information was collected and evaluated for the first twelve hours after ignition. Out of the 183 structures in the study domain 82 (45\%) were identified as having been defended during the fire. Defensive actions information along with fire and weather observations, still images and video, enabled the event 
reconstruction. In evaluating the effectiveness and efficiency of the data collection part of the methodology, a number of possible improvements were identified and are listed in Appendix D.

In order to fully utilize defensive action information, it is necessary to have a better understanding of the timeline of the fire and when defensive actions occurred. In this incident, first responder time estimates were difficult to reconcile. This is logical as it is not the first responder's responsibility to know the precise time of when and where certain events occurred. Additionally, possibly due to the high stress environment of any WUI fire event, times might become distorted for first responders. Nonetheless, most first responder accounts did correspond to observed features on the ground or at worst, close by features observed on the ground, allowing for the identification of many defensive action locations though not always the exact times these actions occurred.

The solution to effectively capture the sequencing and timing of defensive actions resides in large part in technological solutions and the implementation of documentation protocols. Relatively recent technologies like automated vehicle location systems, mobile phones, global positioning systems (GPS) and imaging technologies like GoPro ${ }^{\mathrm{TM}}$, allow for recording of real time fire information to help better understand the fire timeline. More widespread adoption of these technologies could not only allow for better understanding of WUI events, but also provide valuable information to first responders to improve tactics and firefighting efficiency for both wildland and structural fires.

There appears to be a wide range of fire department guidance on how to handle images from incidents, with some departments being against collecting imagery while others supporting it in various ways. Real time images and video are critical event timeline reconstruction tools and in many cases provide the critical information needed to quantify fire behavior and structural response. There is a lack of clear guidance provided to first responders for documenting incidents in real time, as well as collecting, sorting and storing incident images and video.

Implementation of the above technologies with timely post-fire aerial and ground imagery would also help to understand fire behavior. To the extent practical, flights such as the Amarillo Sheriff Helicopter flight or the utilization of unmanned aerial systems (UAS) when regulations allow, can also provide valuable fire behavior information. Sensing of high intensity fire behavior, however, will always be difficult from the air and use of direct ground sensors would be preferable. This would be necessary not only for quantifying heat fluxes but also for the quantification of ember fluxes.

Quantification of heat fluxes has been demonstrated in a number of prescribed burns including the International Crown Fire Experiments, ${ }^{16}$ Pine Barren Research Burns ${ }^{17}$ and Bastrop Research Burns. ${ }^{18}$ Ember flux quantification research from wildland and residential fuels had been very limited, while a very limited of total ember exposure data has been collected. ${ }^{19}$ The Joint Fire Science Program is beginning to address this deficiency with the FY2015 Solicitation on embers research. ${ }^{20}$ 
The three NIST WUI case studies $9,10,11$ to date have been conducted at the Wildland Urban Interface $^{\mathrm{k}}$. The studies provide a very preliminary understanding of the key drivers of fire behavior and defensive actions. There have been no such studies at the intermix.

\subsection{Fire Weather}

Field indicators such as needle freeze and tree scorching were used as surrogates for fire behavior and local wind. While only a limited number of sensor locations provided quantitative weather data, post fire field observations together with first responder observations enabled a general understanding of the complexities of local weather particularly when coupled with the complex topography of the Tanglewood Complex

Fire. The multidirectional fire behavior indicators in Figure 38 illustrate the complexities of characterizing fire behavior without information of wind and a preliminary understanding of general event timeline. The almost contradicting fire behavior from field data illustrated in Figure 38 demonstrates that additional technical understanding is necessary to quantify wind flow through topographically complex communities and that the coupling of wind and fire behavior needs to be further characterized.

NIST is conducting work to characterize wind flow though topographically complex terrain. San Diego State University is conducting a long term wind flow study at the Trails community in Rancho Bernardo, California. ${ }^{21}$ This community, which was affected by the Witch and Guejito fires in 2007, is being instrumented to capture wind behavior in different wind conditions including during Santa Ana winds. The collected wind flow data together with the post-fire field data, will be used to improve the technical understanding of fire behavior through the community during the 2007 fires. Collecting wind data in complex communities across the Trails is the first step to improve the technical understanding of fire behavior through the community during the 2007 fires. Additionally, wind data from this community will be used to assess large domain fire behavior prediction models such as the USFS Wildland Fire Dynamics Simulator ${ }^{22}$ or the NIST Fire Dynamics Simulator. ${ }^{23}$

\subsection{Exposure Characterization}

The post-fire WUI environment poses significant challenges in qualifying fire and ember exposures. The post-fire scene represents the final product of the interactions between exposure, defensive actions and the response of fuels (vegetative or urban) to the actual exposure. The exposure itself is a function of fuels, topography and the local weather. To further complicate the scene, the exposure, defensive action and weather can vary with time. As described earlier in the report, at any one location there can be numerous fire fronts, wind shifts and multiple defensive actions all taking place at different times.

A detailed timeline reconstruction, along with detailed weather and defensive action information, together with pre-fire conditions, are all necessary to begin qualifying exposure. The complexities of collecting all the above mentioned data with sufficient temporal and spatial resolution make the quantification of exposure in the fire environment practically impossible. There is, however, great value in a qualitative

\footnotetext{
${ }^{\mathrm{k}}$ The report on the third NIST case study of the Waldo Fire is being finalized and has not yet been published.
} 
assessment of exposure, as this information can be used, to first order, to determine how the event developed, and which homes were exposed to fire and embers and which homes were not. The information collected can be used to assess hazard mitigation technology failures rather than to quantify a success, which in the absence of field instrumentation can be very misleading and possibly lead to a false sense of security by homeowners.

In a post-fire environment, it may be possible to say that given current building materials and construction, a given structure separation distance may not be sufficient to prevent structure to structure direct flame impingement under certain topographical and weather conditions. However, post-fire reconstructions may offer only limited value in providing the exact spacing necessary to prevent ignition of a specific construction material under specific conditions. This is due to the finite number of data points and more specifically, due to the frequent interventions of first responders which effect the effective exposure of the structure.

Detailed exposure characterization is best accomplished in a controlled environment in real scale. Using prescribed burns, data can be collected on both fire and ember exposures under low to moderate exposure conditions. This experimental work will need to be conducted in different categories of vegetative fuels ${ }^{5}$ and under different topographic and weather conditions. The information collected would then be used to further develop reliable fire behavior prediction models. These models or tools could then be used to predict heat and ember fluxes in more extreme conditions. This information could be augmented, once appropriate data collection methodologies are developed and tested, by collecting data from real fires both in the wildlands and the WUI.

Additionally, quantification of the pre-fire, during-fire and post-fire environment of prescribed burns might lead to the discovery of surrogates that might be used to provide a better understanding of exposure in both wildland and WUI environments. Several surrogates such as white ash accumulation, scorching, leaf and needle drop and others might provide valuable surrogates for post-fire exposure assessment.

\subsection{Technical Findings Summary}

The five primary findings are listed here:

1. Information collected from detailed post-fire case studies is more useful for assessing hazard mitigation technology failures than for quantifying successes (data collection and analysis methodologies).

2. Damaged structures provided more useful information compared to destroyed structures, as building materials and ignition location were more reliably identified (structure ignition and hazard mitigation).

3. Damaged structures, which were defended, in many cases did not show direct signs of defensive actions. Without the collection of defensive action data, the effectiveness of hazard treatments can be wrongly interpreted (defensive actions).

4. Remote sensing combined with field assessments presents the best means to obtain pre-fire and post-fire vegetation information (data collection and analysis methodologies). 
5. Mapping of existing hazards in WUI communities without the use of weighted attributes ${ }^{1}$ provides a means for identification of existing hazards (manmade and natural). This will provide potential for removal of hazards by homeowners and land managers, and recognition by first responders during fires (structure ignition and hazard mitigation).

The specific findings on structure ignition and hazard mitigation areas include:

1. Out of the 183 structures documented in this case study, 35 homes were destroyed, and 13 were damaged.

2. Secondary structures such as sheds, garages, etc., when ignited, generated a significant amount of embers, exposing primary residences under certain conditions to increased hazardous conditions.

3. Mapping of existing hazards in WUI communities without the use of weighted attributes provides a means of identification of existing hazards (manmade and natural), thereby providing potential for removal of hazards by homeowners and land managers, and recognition by first responders during fires.

4. Ember and fire generating combustibles, both detached and attached to residential structures, include fences, decks, railroad ties, mulch beds, attached stairs and piles of firewood.

5. Detached combustibles, in numerous cases, ignited prior to the primary structure and were then responsible for the ignition of the structure.

6. Damaged structures, which were defended, in many cases did not show direct signs of defensive actions. Without evidence and documentation of defensive action data, the effectiveness of hazard treatments can be wrongly interpreted.

7. The exposure from a fire burning up to or near a structure varied significantly across the incident. In some cases, a very low intensity fire reached the structure walls, while in other cases very severe fire exposure was experienced by the structure even without fuel reaching all the way to the structure walls.

The findings on defensive actions include:

8. Out of the 183 structures in the study, $82(45 \%)$ were identified through technical discussions as having been defended during the fire.

9. The lack of evidence of a defensive action around a particular structure or feature does not mean that a defensive action did not occur on that feature. This implies that due diligence in collecting data from first responders is necessary.

10. Same as technical finding \#6 (above).

11. Many features including fences and railroad ties were recorded as being defended multiple times by different first responders. This is consistent with the features' long lasting potential to generate flames and embers. These items increased the hazard to nearby unburned structures.

12. Relatively recent technologies such as AVL systems, mobile phones, GPS and imaging technologies allow for recording of real time fire information that could help better understand fire timeline information.

\footnotetext{
${ }^{1}$ Current WUI Fire hazard rating systems rely on very limited technical information to develop weighted ratings. Due to this limited technical information such weighed systems can provide erroneous assessments of actual hazards.
} 
The findings on exposure and fire behavior include:

13. Fire moved from the fire origin, in the vicinity of 501 Pinto Drive, and crossed Cactus Road into the wildlands to the east of Timber Creek Canyon (a linear distance of approximately $500 \mathrm{~m}$ (1640 ft.)) in about $30 \mathrm{~min}$ or less.

14. The post-fire scene represents the final product of the interactions between exposure, defensive actions and the response of fuels (vegetative or urban) to the actual received exposure. This was also identified in the Witch/Guejito case study.

15. Fire and ember exposure onto a target was a complex function of fuels, topography and the local weather. The interaction between topography and weather significantly affected local exposure conductions. Parcel aspect in combination with local prevailing winds sometimes had a significant impact on local exposure conditions.

16. The exposure, defensive actions, and weather vary with time. There were numerous fire fronts, wind shifts and multiple defensive actions all taking place at different times.

17. Fire burned more intensely along the leeward side of canyons and drainages.

18. Topographic features that significantly affected fire behavior were in many cases less than $40 \mathrm{~m}(130 \mathrm{ft})$ in length, such as terracing around a structure.

19. In numerous locations, steep slopes or cliffs appeared to stop fire spread in both the upward and downward directions.

20. Fire direction observations from the field were misleading without utilizing a detailed event timeline, as multiple fire fronts or changes in wind direction occurred during the fire incident.

The findings on data collection and analysis methodologies include:

21. Electronic data collection systems are essential in capturing the multidimensional data and interactions between topography, fuels, weather and defensive actions associated with WUI fires.

22. Same as technical finding \#14 (above).

23. Complexities of collecting field data with sufficient temporal and spatial resolution make the quantification of exposure in the post-fire environment difficult. There is, however, great value in a qualitative assessment of exposure as this information can be used, in first order, to determine how the event developed and which homes were exposed to significant fire and embers and which homes were not.

24. Information collected from detailed post-fire case studies is more useful for assessing hazard mitigation technology failures than for quantifying successes.

25 . There is a lack of clear guidance provided to first responders for documenting incidents in real time, as well as collecting, sorting and storing incident images and video.

26. Data collected on vegetation both for the wildlands and in the community were important to understand the fire behavior.

27. There is currently no established post-fire data collection methodology to estimate vegetative fuel consumption.

28. Remote sensing combined with field assessments presents the best means to obtain pre-fire and post-fire vegetation information, as aerial imagery and LiDAR lacks the ability to identify understory conditions for both pre-fire and post-fire conditions. 
29. Post fire data loss based on aerial imagery increased with time of acquisition after the fire.

30. Analysis of the effectiveness of structure treatments requires pre-fire data for comparison. This was also identified during the Witch/Guejito case study, NIST TN 1635.

31. Many structure treatments could confound the analysis/interpretation of structure performance during a WUI fire. For example, the destruction of a home with a wood roof does not mean the wood roof was the cause of the destruction. Without eyewitness accounts of the destruction, it is impossible to determine the ignition sequence.

32. Damaged structures provided more useful information compared to destroyed structures, as building materials and ignition location were more reliably identified.

33. There are no case studies similar to this one at the Wildland Urban Intermix, resulting in very limited understanding of how to effectively implement mitigation techniques in that environment.

34. Currently, there is a no validated physics based fire model capable of providing a better understanding of appropriate scales for assessing and analyzing WUI environments.

\subsection{Recommendations}

As a result of this study, the following are the five primary technical recommendations:

1. Adequate technologies need to be developed and deployed to document the event including first responder actions. - Technical finding \#12.

2. The coupling of wind and fire behavior needs to be better characterized, including the quantification of wind flow through topographically complex communities. This is necessary in order to quantify fire behavior at the WUI - Technical finding \#15.

3. Standardized electronic data collection systems need to be implemented to capture post-fire data - Technical finding \#21.

4. Clear guidance need to be developed for first responders to document incidents in real time, as well as collect, sort and store incident images and video - Technical finding \#25.

5. Pre-fire WUI mitigation advice needs to involve vegetative sampling of wildlands in close proximity to residential structures using standardized plot based techniques Technical finding \#26.

Additionally there are three recommendations that will improve community resilience to WUI fires by conducting specific research activities as well as data collection. These are:

1. Heat fluxes and ember fluxes from wildland and urban interface fuels need to be quantified in both wildfire and controlled environments - Technical finding \#3.

2. A methodology needs be developed to estimate vegetative fuel consumption in a postfire environment. Collection of this information should not be limited to residential areas and should continue into the wildlands - Technical finding \#27.

3. Case studies similar to this one need be conducted at the Wildland Urban Intermix Technical finding \#33. 


\subsection{Conclusions}

The Amarillo fires of 2011 was the first time the NIST WUI 1/WUI 2 field data collection methodology was utilized to investigate WUI fires. The method successfully documented the fire scene. A number of improvements have been identified as a result. These improvements will be implemented in future deployments.

The Tanglewood Complex post-fire data collection and analysis resulted in a number of technical findings, including seven on structure ignition and hazard mitigation, five on defensive actions, eight on exposure and fire behavior, and fourteen on data collection and analysis. The technical findings identified in this case study are applicable at the interface between the wildlands and urban areas. The data collection and analysis findings will also apply at the Wildland Urban Intermix. Additionally there are six general recommendations and two research recommendations that will improve community resilience to WUI fires.

A very preliminary and limited data analysis was conducted in Section 13 . This was due to limited resources as well as limited defensive action information and complex exposure conditions in many parts of the Tanglewood Complex Fire. These preliminary and limited findings indicate that additional analysis needs to be conducted in the future to assess the impact and contributions of different building attributes and topographical features such as aspect. Future WUI deployments should include case studies of both interface and intermix fires using the improved methodologies highlighted from the Amarillo fires documented and analyzed here. Deployments should be focused in locations/areas where there is reliable pre-fire data. Incidents with 100 to 400 destroyed homes represent a sizable data set that can yield important lessons learned. Entire incidents should be investigated, instead of a subset of a larger incident as, by looking at the entire incident, the entire response can be analyzed in context. Future case studies will continue to provide fire behavior, structural response/ignition vulnerabilities and defensive actions technical information that will continue to provide guidance for laboratory experiments, model development and large scale field research.

\subsection{Acknowledgments}

The Joint Fire Science Program, Grant \#11-1-3-29m is acknowledged for providing the half of the funding for this deployment, post-fire analysis and documentation. The Texas Forest Service and Coeur d'Alene Tribe are acknowledged for their assistance with data entry and data collection. The City of Amarillo and Potter-Randall County 911 are gratefully acknowledged for their extensive cooperation in providing vector and raster data for this analysis. The authors would also like to acknowledge the citizens of Timber Creek, Palisades, Tanglewood and Tangle Air and the first responders for their insights into the fire development and defensive actions taken. Additionally the authors would like to acknowledge Blaza Toman from NIST for conducting the statistical analysis presented in this report.

m JFSP 11-1-3-29, Evaluating the Effectiveness of Mitigations Activities in the Wildland Urban Interface. 


\section{Appendix A NIST TN1708 Preliminary Findings}


The following preliminary findings relate to the two specific objectives of the initial reconnaissance:

\section{Likely technical factors responsible for the damage, failure, and/or successful performance of buildings and/or infrastructure in the aftermath of the Amarillo fires}

- Extreme weather, in the form of severe wind and very low humidity, resulted in very rapid fire spread.

- Buffalo grass, even when mowed, carried fire on residential yards and in the wild.

- Statewide pre-deployment of firefighting resources using the Texas Intrastate Fire Mutual Aid System (TIFMAS) was effective in rapidly getting resources to the fires.

- Extensive defensive actions were identified in the Tanglewood Complex fire. The defensive actions will be factored into the evaluation of the response of structures to the WUI fire in the detailed technical report.

- Certain foundation constructions (pier and beam), as well as modular/mobile homes may exhibit certain ignition vulnerabilities.

- Pre-fire and post-fire aerial imagery, particularly oblique imagery such as that found on Microsoft ${ }^{\mathrm{TM}}$ Bing Maps, was found to be essential for efficient and accurate delineation of the total number of damaged/destroyed structures.

- The local wind direction and speed, and the topography, had a significant impact on fire behavior; however, limited weather observation equipment was located in the bottom of the canyon and along the creek beds.

Specific improvements to standards, codes, and practices as well as any further research and other appropriate actions based on study findings

- The multijurisdictional aspects of this event posed a significant challenge to the accurate documentation of the damage and performance of the buildings.

- In the absence of a national standardized data collection framework, the NISTdeveloped WUI 1 and WUI 2 systems enabled the documentation and analysis of structural loses from the Amarillo WUI fire.

- Collecting data from undamaged as well as from the damaged/destroyed structures provided for meaningful assessment of the data.

- There is no scale to characterize the severity of WUI events, like the scales used to rate tornadoes, hurricanes or earthquakes.

- Additional weather observational equipment in numerous locations in the bottom of the canyon and along the creek beds would significantly help NWS forecasters, and also help local fire officials understand the potential behavior of the fire. Additional Remote Automated Weather Stations (RAWS) or West Texas MesoNet stations would be extremely helpful in cases of wildfires in these areas. ${ }^{\text {n }}$

\footnotetext{
${ }^{\mathrm{n}}$ From NWS Amarillo Office, email communication, March 28, 2011.
} 
Appendix B Unassessed Building Characteristics 
The data contained in this appendix illustrate the limitations of not having reliable prefire building construction information specifically in identifying attributes of the destroyed homes. The data shows that for eave construction material, 25 out of 28 undetermined were destroyed homes. The same applies to eaves type where 24 out 25 unknowns were destroyed homes and gutters where 20 out the 22 undetermined were destroyed. The same issue associated with undetermined construction applies to the rest of the tables in this appendix.

Table 27 Eave Material across Residential Structures

\begin{tabular}{|r|r|r|r|r|r|}
\hline Eave Material & Totals & $\begin{array}{c}\text { Damage (Attached } \\
\text { Combustible) }\end{array}$ & Destroyed & Damage & No Damage \\
\hline Not Determined & 28 & 0 & 25 & 0 & 3 \\
\hline Cement Fiber & 6 & 0 & 0 & 0 & 6 \\
\hline Heavy Timber & 1 & 0 & 0 & 0 & 1 \\
\hline Light Timber & 98 & 3 & 3 & 7 & 85 \\
\hline Vinyl & 11 & 1 & 0 & 2 & 8 \\
\hline Metal & 13 & 0 & 0 & 0 & 13 \\
\hline Other & 15 & 0 & 4 & 0 & 11 \\
\hline Not Applicable & 11 & 0 & 3 & 0 & 8 \\
\hline
\end{tabular}

Table 28 Eave Type across Residential Structures

\begin{tabular}{|r|r|c|r|r|r|r|}
\hline \multicolumn{1}{|c|}{ Eaves } & Totals & $\begin{array}{c}\text { Damage (Attached } \\
\text { Combustible) }\end{array}$ & Destroyed & Damage & No Damage \\
\hline Not Determined & 25 & 0 & 24 & 0 & 1 \\
\hline Boxed & 123 & & 3 & 6 & 8 & 106 \\
\hline Exposed & 24 & 1 & 1 & 1 & 21 \\
\hline 99 & 11 & 0 & 4 & 0 & 7 \\
\hline
\end{tabular}

Table 29 Gutter Material across Residential Structures

\begin{tabular}{|r|r|r|r|r|r|}
\hline Gutter Material & Totals & $\begin{array}{c}\text { Damage (Attached } \\
\text { Combustible) }\end{array}$ & Destroyed & Damage & No Damage \\
\hline Not Determined & 22 & 0 & 20 & 0 & 2 \\
\hline Combustible & 7 & 0 & 1 & 0 & 6 \\
\hline Non- & 62 & 1 & 9 & 3 & 49 \\
\hline Combustible & & 32 & 5 & 6 & 78 \\
\hline Not Present & 92 & & 3 & & \\
\hline
\end{tabular}


Table 30 Roof and Gutter Debris across Residential Structures

\begin{tabular}{|r|r|r|r|r|r|}
\hline $\begin{array}{c}\text { Roof/Gutter } \\
\text { Debris }\end{array}$ & Totals & $\begin{array}{c}\text { Damage (Attached } \\
\text { Combustible) }\end{array}$ & Destroyed & Damage & $\begin{array}{c}\text { No } \\
\text { Damage }\end{array}$ \\
\hline Not Present & 102 & 3 & 2 & 4 & 93 \\
\hline Present & 14 & 0 & 1 & 1 & 12 \\
\hline Not Applicable & 28 & 1 & 1 & 4 & 22 \\
\hline Not Determined & 39 & 0 & 31 & 0 & 8 \\
\hline
\end{tabular}

Table 31 Shutter Material across Residential Structures

\begin{tabular}{|c|c|c|c|c|c|}
\hline Shutter Material & Totals & $\begin{array}{l}\text { Damage (Attached } \\
\text { Combustible) }\end{array}$ & Destroyed & Damage & $\begin{array}{c}\text { No } \\
\text { Damage }\end{array}$ \\
\hline Not Determined & 26 & 0 & 24 & 0 & 2 \\
\hline Combustible & 13 & 0 & 0 & 2 & 11 \\
\hline Not Combustible & 13 & 0 & 2 & 0 & 11 \\
\hline Not Present & 131 & 4 & 9 & 7 & 111 \\
\hline
\end{tabular}

Table 32 Window Frame Type across Residential Structures

\begin{tabular}{|r|r|r|r|r|r|}
\hline Window Frame & Totals & $\begin{array}{c}\text { Damage (Attached } \\
\text { Combustible) }\end{array}$ & Destroyed & Damage & $\begin{array}{c}\text { No } \\
\text { Damage }\end{array}$ \\
\hline Not Determined & 21 & 0 & 19 & 0 & 2 \\
\hline Wood & 20 & 1 & 4 & 1 & 14 \\
\hline Metal & 137 & 3 & 12 & 8 & 114 \\
\hline Vinyl & 4 & 0 & 0 & 0 & 4 \\
\hline Not Present & 1 & 0 & 0 & 0 & 1 \\
\hline
\end{tabular}

Table 33 Window Pane Type across Residential Structures

\begin{tabular}{|r|r|r|r|r|r|}
\hline Window Pane & Totals & $\begin{array}{c}\text { Damage (Attached } \\
\text { Combustible) }\end{array}$ & Destroyed & Damage & $\begin{array}{c}\text { No } \\
\text { Damage }\end{array}$ \\
\hline Not Determined & 17 & 0 & 15 & 0 & 2 \\
\hline Single & 60 & 1 & 12 & 1 & 46 \\
\hline Double & 103 & 3 & 6 & 8 & 86 \\
\hline Triple & 1 & 0 & 1 & 0 & \\
\hline Other & 1 & 0 & 1 & 0 & \\
\hline Not Present & 1 & 0 & 0 & 0 & 1 \\
\hline
\end{tabular}




\section{Appendix C Unconfirmed Defensive Actions}


The data in this appendix (Table 34) represent information that was either not independently verifiable (labeled here as anecdotal) or information that was generic in location and could not be linked to a specific parcel and attribute.

Table 34 Anecdotal Defensive Actions

\begin{tabular}{|c|c|}
\hline Defensive Action Comment & Editor Comments \\
\hline Engine 1 and Engine 2 came to assist 338 Cactus house on fire. & $\begin{array}{l}\text { Anecdotal and could not confirm } \\
\text { location of address. }\end{array}$ \\
\hline Left 338 Cactus and went to defend another unknown house. & Anecdotal \\
\hline Came back to unknown location in Timber Creek to do mop-up. & Unknown location \\
\hline Truck protecting structure at Audach Ranch. & Anecdotal \\
\hline Brush 2 RCFD defending structure on Rocky Point Road. & $\begin{array}{l}\text { Anecdotal and no fire occurred in } \\
\text { area. }\end{array}$ \\
\hline $\begin{array}{l}\text { Attack } 3 \text {, tanker } 1 \text {, unit 3, brush } 3 \text { all came to Rocky Point road from } \\
\text { Canyon Country Club fire; all worked until almost sundown. }\end{array}$ & Anecdotal and unknown location. \\
\hline Attack 2 and Brush 3 left to monitor and mop-up. & Anecdotal \\
\hline $\begin{array}{l}\text { Happy Tanker truck and RCFD Tanker showed up to Rocky Point } \\
\text { road for water. }\end{array}$ & Anecdotal \\
\hline 204 Rocky Point; homeowner defending too. & Anecdotal \\
\hline Attack 2 went to east side of 204 Rocky Point Road to Defend & Anecdotal \\
\hline Defensive Action Comment & Editor Comments \\
\hline A little more water on RR ties at 411 Roberts by Timber Creek FD. & Unknown location \\
\hline Ravine on polar, 20-30 civilians fighting fire with shovels. & Anecdotal \\
\hline $\begin{array}{l}215 \text { Quail Ridge - defended - Brooks home - sprinklers on. Brush } \\
\text { truck in backyard. Family worked fence line. }\end{array}$ & $\begin{array}{l}\text { Anecdotal and could not confirm } \\
\text { location of address. }\end{array}$ \\
\hline 209 Quail Ridge - homeowner stayed and defended. & Anecdotal \\
\hline Ordered to protect two unknown homes in Timber Creek & Unknown location \\
\hline Passed hill drive and saw 2 small brush rigs from PANTEX. & Anecdotal \\
\hline Stayed on south side of creek all night putting out hot spots. & $\begin{array}{l}\text { Anecdotal and no fire occurred in } \\
\text { area. }\end{array}$ \\
\hline Engine 1 and Engine 2 came to assist 338 Cactus house on fire. & Anecdotal and unknown location. \\
\hline Left 338 Cactus and went to defend another unknown house. & Anecdotal \\
\hline Came back to unknown location in Timber Creek to do mop-up. & Anecdotal \\
\hline Truck protecting structure at Audach Ranch. & Anecdotal \\
\hline Brush 2 RCFD defending structure on Rocky Point Road. & Anecdotal \\
\hline $\begin{array}{l}\text { Attack 3, tanker 1, unit 3, brush } 3 \text { all came to Rocky Point road from } \\
\text { Canyon Country Club fire; all worked until almost sundown. }\end{array}$ & Unknown location \\
\hline Attack 2 and Brush 3 left to monitor and mop-up. & Anecdotal \\
\hline $\begin{array}{l}\text { Happy Tanker truck and RCFD Tanker showed up to Rocky Point } \\
\text { road for water. }\end{array}$ & Unknown location \\
\hline 204 Rocky Point; homeowner defending too. & Unknown Palisades location \\
\hline Attack 2 went to east side of 204 Rocky Point Road to Defend & Unknown location \\
\hline A little more water on RR ties at 411 Roberts by Timber Creek FD. & Anecdotal \\
\hline Ravine on polar, 20-30 civilians fighting fire with shovels. & $\begin{array}{l}\text { Anecdotal and unknown specific } \\
\text { location. }\end{array}$ \\
\hline $\begin{array}{l}215 \text { Quail Ridge - defended - Brooks home - sprinklers on. Brush } \\
\text { truck in backyard. Brooks family worked fence line. }\end{array}$ & Anecdotal \\
\hline 209 Quail Ridge - homeowner stayed and defended. & Anecdotal \\
\hline Ordered to protect two unknown homes in Timber Creek & Anecdotal \\
\hline Passed hill drive and saw 2 small brush rigs from PANTEX. & Anecdotal \\
\hline Stayed on south side of creek all night putting out hot spots. & Unknown location \\
\hline
\end{tabular}


Appendix D Suggested Improvements to the NIST WUI Assessment Defensive Action Methodology 
Table 35 Issues and possible corrections with defensive action data collection methodology.

\begin{tabular}{|c|c|}
\hline Defensive Action Issue & Possible Correction \\
\hline $\begin{array}{l}\text { Many first responders had deleted images } \\
\text { taken during the event by the time the } \\
\text { discussion occurred. }\end{array}$ & $\begin{array}{l}\text { At the onset of first responder discussions with each } \\
\text { respective department, request that all images of the } \\
\text { incident be provided to researchers. Obtain images at the } \\
\text { discussion and have equipment to do this. }\end{array}$ \\
\hline $\begin{array}{l}\text { It was often difficult to determine which } \\
\text { resource (e.g. Type I Engine) went with } \\
\text { which first responder. }\end{array}$ & $\begin{array}{l}\text { At the onset of first responder discussions with each } \\
\text { respective department, request that a station roster } \\
\text { associating individuals with resources be provided. } \\
\text { Additionally, record the name, name of each staff, and } \\
\text { characteristics of the resource used by the responder. } \\
\text { Finally, when first responders change resources ensure this } \\
\text { is recorded in the notes, if portrayed. Nonetheless, this } \\
\text { situation appears to be common and would be difficult to } \\
\text { quantify. }\end{array}$ \\
\hline $\begin{array}{l}\text { Several first responders referenced images } \\
\text { that were not archived by data recorders. }\end{array}$ & $\begin{array}{l}\text { Store and archive data using the NIST standard directory } \\
\text { structure so that it can be retrieved by others using the data. } \\
\text { Ensure data collectors have appropriate hardware to transfer } \\
\text { photos from different devices. }\end{array}$ \\
\hline $\begin{array}{l}\text { Data recorders observed that more } \\
\text { experienced fire fighters were more } \\
\text { reliable in their recall of events compared } \\
\text { to less experienced members. }\end{array}$ & $\begin{array}{l}\text { At the onset of first responder discussions record the years } \\
\text { of experience of staff members and have discussions with } \\
\text { more senior staff members first. }\end{array}$ \\
\hline $\begin{array}{l}\text { Data sheets were not scanned until months } \\
\text { or sometimes years after the discussion. } \\
\text { Some notes were transcribed each night by } \\
\text { typing, but these did not contain all the } \\
\text { information present in the original notes } \\
\text { and had transcription errors. }\end{array}$ & $\begin{array}{c}\text { Ensure at a minimum that each night data sheets are } \\
\text { scanned or photographed, and archived appropriately. } \\
\text { Ensure that data recorders have hand writing that is legible. }\end{array}$ \\
\hline $\begin{array}{l}\text { For many defensive action notes it could } \\
\text { not be determined if the statement } \\
\text { represented a timeline observation, a } \\
\text { defensive action conducted by a third } \\
\text { party, or a defensive action conducted by } \\
\text { the respective first responder. }\end{array}$ & $\begin{array}{l}\text { Develop a nomenclature to clearly identify the type of } \\
\text { statement. }\end{array}$ \\
\hline $\begin{array}{l}\text { There was difficulty for some defensive } \\
\text { action statements in determining if the } \\
\text { defensive action represented a structure } \\
\text { protection action or a containment action. }\end{array}$ & $\begin{array}{l}\text { Develop a nomenclature to clearly identify the type of } \\
\text { defensive actions. }\end{array}$ \\
\hline Calibrate times for obtained images. & $\begin{array}{l}\text { At the time of collection of image, examine the imaging } \\
\text { device and determine the time offset if any. Make sure to } \\
\text { account for time changes. }\end{array}$ \\
\hline $\begin{array}{l}\text { Make an estimate in the field about } \\
\text { accuracy of time estimates }\end{array}$ & $\begin{array}{l}\text { Unless there is some other information to link time to first } \\
\text { responder estimates, it is unlikely time estimates will be } \\
\text { correct. Make sure the method to determine time is clearly } \\
\text { documented }\end{array}$ \\
\hline
\end{tabular}


Appendix E Aspect Transformations 
Slope and aspect might help to portray certain factors effecting fire behavior. The aspect calculations described here were necessary in order to derive the aspect for the different parcel within and around the fire perimeter. In order to average aspects within specified polygons, the aspect must be transformed to account for the measurement unit being in degrees. The aspect transformation performed required the following procedures:

1. Converting all flat aspect areas to no data values not included in subsequent procedures.

2. Converting the aspect grid in degrees to radians.

3. Calculating the sine and cosine of the aspect radians data set.

4. Summing the values of each sine and cosine aspect data set for each input polygon area.

5. Calculating the average aspect for each input polygon area using the equation below.

Average Polygon Aspect

$=\mathrm{FMOD}(360$

$+\operatorname{atan} 2\left(\sum\right.$ Polygon Sine Aspects, $\sum$ Polygon Cosine Aspects))

$\left.*\left(\frac{180}{\pi}\right), 360\right)$

where FMOD is equivalent to the $\mathrm{C}$ function to return the floating point remainder of $\mathrm{x}$ divided by $\mathrm{y}$ Atan2 returns $\operatorname{atan}(\mathrm{x} / \mathrm{y})$. 
Appendix F Tabulation of Incident Data and Discussion 
There were a total of 183 residential structures assessed in this study. Of these 183 residential structures, 124 where within the mapped fire perimeter and an additional 59 residential structures were outside the fire perimeter but had fire occurring within or close to the respective property boundary (i.e., parcel). This section presents building and topographic characteristics for these 183 structures.

Figure F1 displays damage status by building value ${ }^{15}, 16$. Figure F2 shows a bar graph displaying damage status by the year built. Table F1 lists damage status of residential structures by structure type.

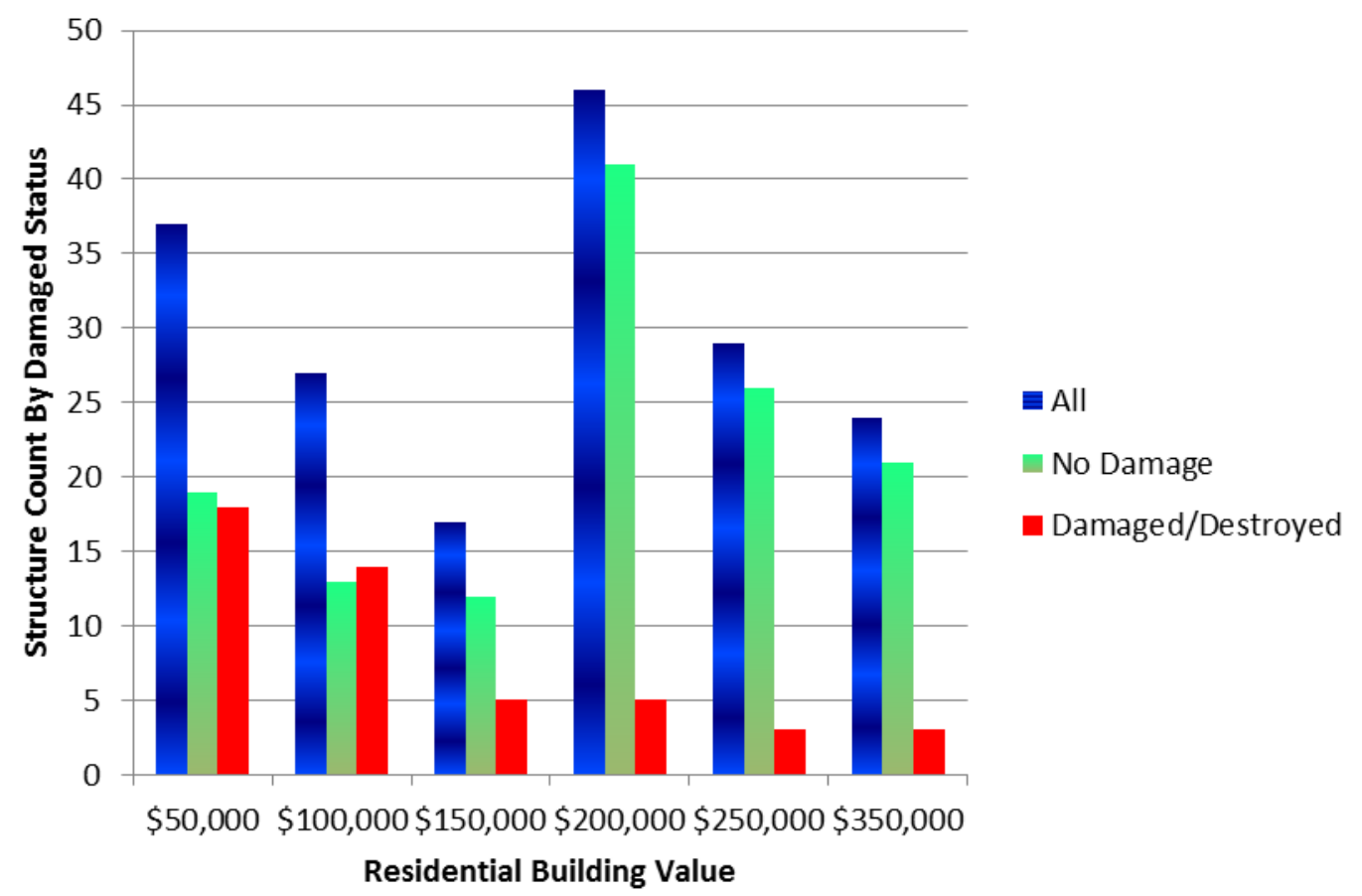

Figure 72 Residential structures by appraised building values and by damage status.

A more specific assessment of building materials is provided in 36 through 38 . These tables show damage status by roof type, exterior siding, foundation type and the presence of fireplaces (as assessed by chimney presence). Foundation type is presented as assessed in the field and as assessed by the Potter-Randall County Tax District in Tables 39 and 41 , respectively.

\footnotetext{
${ }^{15}$ Mobile homes, abandoned buildings, and miscellaneous buildings did not have a building value. These homes were placed in the $\$ 0$ - $\$ 50,000$ category.

${ }^{16}$ Potter and Randall County Tax Office, http://www.prad.org/
} 


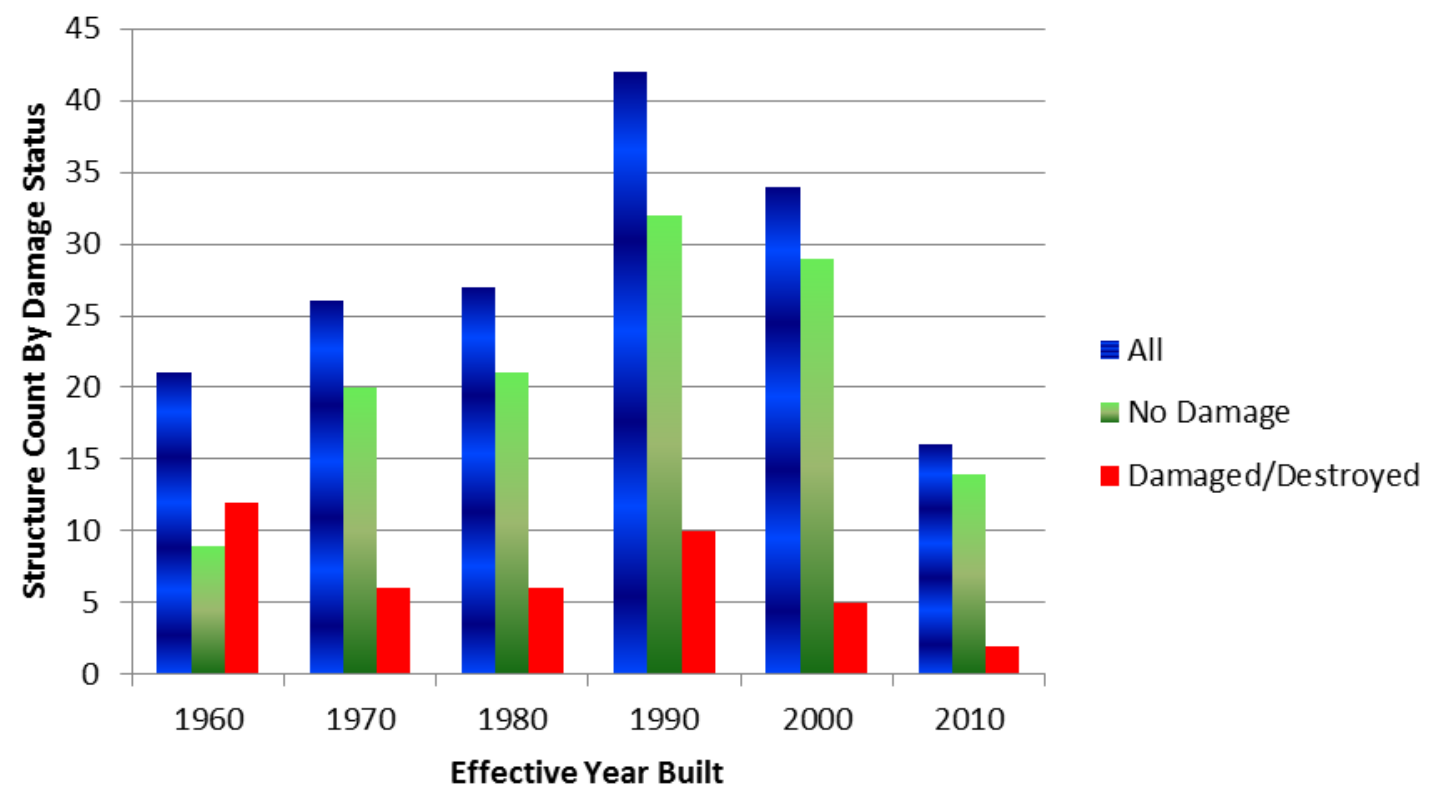

Figure 73 Residential structures by effective year built and by damage status.

Table 36 Damage status of residential structures by structure type.

\begin{tabular}{|l|c|c|c|}
\hline & No Damage & Damaged $^{17} /$ Destroyed & Total \\
\hline $1 \& 1 / 2$ Story Log Home & $0(0 \%)$ & $1(100 \%)$ & $\mathbf{1}$ \\
\hline $1 \& 1 / 2$ Story Residential & $20(80 \%)$ & $5(20 \%)$ & $\mathbf{2 5}$ \\
\hline One Story Residential & $94(76 \%)$ & $29(24 \%)$ & $\mathbf{1 2 3}$ \\
\hline Split Level Residential & $0(0 \%)$ & $3(100 \%)$ & $\mathbf{3}$ \\
\hline Two Story Log Home & $1(100 \%)$ & $0(0 \%)$ & $\mathbf{1}$ \\
\hline Two Story Residential & $13(72 \%)$ & $5(28 \%)$ & $\mathbf{1 8}$ \\
\hline Mobile Home & $6(55 \%)$ & $5(45 \%)$ & $\mathbf{1 1}$ \\
\hline Abandoned Building & $1(100 \%)$ & $0(0 \%)$ & $\mathbf{1}$ \\
\hline Total & $\mathbf{1 3 5}(\mathbf{7 4} \%)$ & $\mathbf{4 8}(\mathbf{2 6} \%)$ & $\mathbf{1 8 3}$ \\
\hline
\end{tabular}

Table 37 Damage status of residential structures by exterior type.

\begin{tabular}{|l|c|c|c|}
\hline & No Damage & Damaged/ Destroyed & Total \\
\hline Concrete Block & $7(88 \%)$ & $1(13 \%)$ & 8 \\
\hline Log & $1(100 \%)$ & $0(0 \%)$ & 1 \\
\hline Masonry Veneer & $89(89 \%)$ & $11(11 \%)$ & 100 \\
\hline Siding/Shingle/Metal & $16(41 \%)$ & $23(59 \%)$ & 39 \\
\hline Stone Veneer & $2(100 \%)$ & $0(0 \%)$ & 2 \\
\hline Stucco & $11(61 \%)$ & $7(39 \%)$ & 18 \\
\hline Not Determined (Mobile Home) & $9(64 \%)$ & $5(36 \%)$ & 14 \\
\hline $\begin{array}{l}\text { Not Determined (Abandoned } \\
\text { Building) }\end{array}$ & $1(100 \%)$ & $0(0 \%)$ & 1 \\
\hline Total & $\mathbf{1 3 5}(\mathbf{7 4} \%)$ & $\mathbf{4 8 ( 2 6 \% )}$ & $\mathbf{1 8 3}$ \\
\hline
\end{tabular}

\footnotetext{
${ }^{17}$ Damaged includes homes with damaged or destroyed attached combustibles. The damage category does not include detached combustible objects.
} 
Table 38 Damage status of residential structures by roof type.

\begin{tabular}{|l|c|c|c|}
\hline & No Damage & Damaged/ Destroyed & Total \\
\hline Asphalt Shingles & $92(76 \%)$ & $29(24 \%)$ & 34 \\
\hline Metal & $20(59 \%)$ & $14(41 \%)$ & 3 \\
\hline Spanish Tile & $3(100 \%)$ & $0(0 \%)$ & 7 \\
\hline Tar & $6(86 \%)$ & $1(14 \%)$ & 12 \\
\hline Wood & $9(75 \%)$ & $3(25 \%)$ & 4 \\
\hline Other & $4(100 \%)$ & $0(0 \%)$ & 2 \\
\hline Not Determined & $1(50 \%)$ & $1(50 \%)$ & \\
\hline $\begin{array}{l}\text { Concrete } \\
\text { Abandoned } \\
\text { Building) }\end{array}$ & $1(100 \%)$ & $0(0 \%)$ & $\mathbf{1 8 3}$ \\
\hline Total & $\mathbf{1 3 5}(\mathbf{7 4} \%)$ & $\mathbf{4 8}(\mathbf{2 6} \%)$ & \\
\hline
\end{tabular}

Table 39 Damage status of residential structures by foundation type (NIST/TFS).

\begin{tabular}{|l|c|c|c|}
\hline & No Damage & Damaged/ Destroyed & Total \\
\hline Slab & $119(82 \%)$ & $27(18 \%)$ & 146 \\
\hline Raised Open & $3(38 \%)$ & $5(63 \%)$ & 21 \\
\hline Raised Closed & $7(33 \%)$ & $14(67 \%)$ & 2 \\
\hline Not Applicable & $2(100 \%)$ & $0(0 \%)$ & 6 \\
\hline Not Determined & $4(67 \%)$ & $2(33 \%)$ & $\mathbf{1 8 3}$ \\
\hline Total & $\mathbf{1 3 5}(\mathbf{7 4} \%)$ & $\mathbf{4 8}(\mathbf{2 6} \%)$ & \\
\hline
\end{tabular}

Table 40 Damage status of residential structures by foundation type (Potter-Randall County).

\begin{tabular}{|l|c|c|c|}
\hline & No Damage & Damaged/ Destroyed & Total \\
\hline Slab & $109(79 \%)$ & $29(21 \%)$ & 138 \\
\hline Wood Subfloor & $17(55 \%)$ & $14(45 \%)$ & 31 \\
\hline Not Determined & $9(64 \%)$ & $5(36 \%)$ & 14 \\
\hline Total & $\mathbf{1 3 5}(\mathbf{7 4} \%)$ & $\mathbf{4 8}(\mathbf{2 6} \%)$ & $\mathbf{1 8 3}$ \\
\hline
\end{tabular}

Table 41 Damage status of residential structures by chimney presence.

\begin{tabular}{|l|c|c|c|}
\hline & No Damage & Damaged/ Destroyed & Total \\
\hline Chimney(s) Present & $102(84 \%)$ & $20(16 \%)$ & 122 \\
\hline No Chimney Present & $10(31 \%)$ & $22(69 \%)$ & 32 \\
\hline Not Determined & $23(79 \%)$ & $6(21 \%)$ & 29 \\
\hline Total & $\mathbf{1 3 5}(\mathbf{7 4} \%)$ & $\mathbf{4 8}(\mathbf{2 6} \%)$ & $\mathbf{1 8 3}$ \\
\hline
\end{tabular}

Average aspect ${ }^{18}$ in concentric buffers of $9.1 \mathrm{~m}(30 \mathrm{ft}), 30.5 \mathrm{~m}(100 \mathrm{ft}), 61.0 \mathrm{~m}(200 \mathrm{ft})$, $91.4 \mathrm{~m}(300 \mathrm{ft})$ around each building footprint are shown in Tables 42 through 45. Average percent slope for the same buffer distances are shown in Tables 46 through 49. These buffer distances were selected as they are frequently used in existing hazard mitigation guidance such as NFPA 1144: Standard for Reducing Structure Ignition Hazards from Wildland Fire ${ }^{10}$

\footnotetext{
${ }^{18}$ Average aspect over the entire buffer area.
} 
Table 42 Damage status of residential structures by mean aspect (5m ((16.4 ft)) radar derived) within $9.1 \mathrm{~m} \mathrm{(30} \mathrm{ft)}$ around the structure.

\begin{tabular}{|l|c|c|c|}
\hline & No Damage & Damaged/ Destroyed & Total \\
\hline North & $25(71 \%)$ & $10(29 \%)$ & 35 \\
\hline Northeast & $27(84 \%)$ & $5(16 \%)$ & 32 \\
\hline East & $14(78 \%)$ & $4(22 \%)$ & 18 \\
\hline Southeast & $17(68 \%)$ & $8(32 \%)$ & 25 \\
\hline South & $28(74 \%)$ & $10(26 \%)$ & 38 \\
\hline Southwest & $13(93 \%)$ & $1(7 \%)$ & 14 \\
\hline West & $4(50 \%)$ & $4(50 \%)$ & 8 \\
\hline Northwest & $7(54 \%)$ & $6(46 \%)$ & 13 \\
\hline Total & $\mathbf{1 3 5 ( 7 4 \% )}$ & $\mathbf{4 8 ( 2 6 \% )}$ & $\mathbf{1 8 3}$ \\
\hline
\end{tabular}

Table 43 Damage status of residential structures by mean aspect $(5 \mathrm{~m}((16.4 \mathrm{ft}))$ radar derived) within $30.5 \mathrm{~m}(100 \mathrm{ft})$ around the structure.

\begin{tabular}{|l|c|c|c|}
\hline & No Damage & Damaged/ Destroyed & Total \\
\hline North & $24(73 \%)$ & $9(27 \%)$ & 33 \\
\hline Northeast & $27(84 \%)$ & $5(16 \%)$ & 32 \\
\hline East & $20(80 \%)$ & $5(20 \%)$ & 25 \\
\hline Southeast & $17(65 \%)$ & $9(35 \%)$ & 26 \\
\hline South & $25(76 \%)$ & $8(24 \%)$ & 33 \\
\hline Southwest & $11(100 \%)$ & $0(0 \%)$ & 11 \\
\hline West & $5(56 \%)$ & $4(44 \%)$ & 9 \\
\hline Northwest & $6(43 \%)$ & $8(57 \%)$ & 14 \\
\hline Total & $\mathbf{1 3 5}(\mathbf{7 4} \%)$ & $\mathbf{4 8 ( 2 6 \% )}$ & $\mathbf{1 8 3}$ \\
\hline
\end{tabular}

Table 44 Damage status of residential structures by mean aspect (5m ((16.4 ft)) radar derived) within $61.0 \mathrm{~m}(200 \mathrm{ft})$ around the structure.

\begin{tabular}{|l|c|c|c|}
\hline & No Damage & Damaged/ Destroyed & Total \\
\hline North & $33(72 \%)$ & $13(28 \%)$ & 46 \\
\hline Northeast & $23(85 \%)$ & $4(15 \%)$ & 27 \\
\hline East & $19(66 \%)$ & $10(34 \%)$ & 29 \\
\hline Southeast & $15(68 \%)$ & $7(32 \%)$ & 22 \\
\hline South & $30(88 \%)$ & $4(12 \%)$ & 34 \\
\hline Southwest & $5(71 \%)$ & $2(29 \%)$ & 7 \\
\hline West & $5(83 \%)$ & $1(17 \%)$ & 6 \\
\hline Northwest & $5(42 \%)$ & $7(58 \%)$ & 12 \\
\hline Total & $\mathbf{1 3 5}(\mathbf{7 4} \%)$ & $\mathbf{4 8}(\mathbf{2 6} \%)$ & $\mathbf{1 8 3}$ \\
\hline
\end{tabular}


Table 45 Damage status of residential structures by mean aspect (5m ((16.4 ft)) radar derived) within $91.4 \mathrm{~m} \mathrm{(300} \mathrm{ft)} \mathrm{around} \mathrm{the} \mathrm{structure.}$

\begin{tabular}{|l|c|c|c|}
\hline & No Damage & Damaged/ Destroyed & Total \\
\hline North & $36(62 \%)$ & $22(38 \%)$ & 58 \\
\hline Northeast & $20(83 \%)$ & $4(17 \%)$ & 24 \\
\hline East & $15(75 \%)$ & $5(25 \%)$ & 20 \\
\hline Southeast & $17(81 \%)$ & $4(19 \%)$ & 21 \\
\hline South & $30(88 \%)$ & $4(12 \%)$ & 34 \\
\hline Southwest & $2(67 \%)$ & $1(33 \%)$ & 3 \\
\hline West & $4(67 \%)$ & $2(33 \%)$ & 6 \\
\hline Northwest & $11(65 \%)$ & $6(35 \%)$ & 17 \\
\hline Total & $\mathbf{1 3 5}(\mathbf{7 4} \%)$ & $\mathbf{4 8 ( 2 6 \% )}$ & $\mathbf{1 8 3}$ \\
\hline
\end{tabular}

Table 46 Damage status of residential structures by mean slope $(5 \mathrm{~m}((16.4 \mathrm{ft}))$ radar derived) within $9.1 \mathrm{~m} \mathrm{(30} \mathrm{ft)}$ around the structure.

\begin{tabular}{|l|c|c|c|}
\hline & No Damage & Damaged/ Destroyed & Total \\
\hline $0 \%-2.5 \%$ & $40(78 \%)$ & $11(22 \%)$ & 51 \\
\hline $2.5 \%-5 \%$ & $76(70 \%)$ & $33(30 \%)$ & 109 \\
\hline $5 \%-7.5 \%$ & $14(78 \%)$ & $4(22 \%)$ & 18 \\
\hline $7.5 \%-10 \%$ & $4(100 \%)$ & $0(0 \%)$ & 4 \\
\hline $10 \%-15 \%$ & $1(100 \%)$ & $0(0 \%)$ & 1 \\
\hline Total & $\mathbf{1 3 5}(\mathbf{7 4} \%)$ & $\mathbf{4 8}(\mathbf{2 6} \%)$ & $\mathbf{1 8 3}$ \\
\hline
\end{tabular}

Table 47 Damage status of residential structures by mean slope $(5 \mathrm{~m}((16.4 \mathrm{ft}))$ radar derived) within $30.5 \mathrm{~m}(100 \mathrm{ft})$ around the structure.

\begin{tabular}{|l|c|c|c|}
\hline & No Damage & Damaged/ Destroyed & Total \\
\hline $0 \%-2.5 \%$ & $57(77 \%)$ & $17(23 \%)$ & 74 \\
\hline $2.5 \%-5 \%$ & $59(68 \%)$ & $28(32 \%)$ & 87 \\
\hline $5 \%-7.5 \%$ & $14(82 \%)$ & $3(18 \%)$ & 17 \\
\hline $7.5 \%-10 \%$ & $3(100 \%)$ & $0(0 \%)$ & 3 \\
\hline $10 \%-15 \%$ & $2(100 \%)$ & $0(0 \%)$ & 2 \\
\hline Total & $\mathbf{1 3 5}(\mathbf{7 4} \%)$ & $\mathbf{4 8}(\mathbf{2 6} \%)$ & $\mathbf{1 8 3}$ \\
\hline
\end{tabular}

Table 48 Damage status of residential structures by mean slope $(5 \mathrm{~m}((16.4 \mathrm{ft}))$ radar derived) within $61.0 \mathrm{~m}(200 \mathrm{ft})$ around the structure.

\begin{tabular}{|l|c|c|c|}
\hline & No Damage & Damaged/ Destroyed & Total \\
\hline $0 \%-2.5 \%$ & $49(79 \%)$ & $13(21 \%)$ & 62 \\
\hline $2.5 \%-5 \%$ & $62(65 \%)$ & $33(35 \%)$ & 95 \\
\hline $5 \%-7.5 \%$ & $19(90 \%)$ & $2(10 \%)$ & 21 \\
\hline $7.5 \%-10 \%$ & $5(100 \%)$ & $0(0 \%)$ & 5 \\
\hline $10 \%-15 \%$ & $0(0 \%)$ & $0(0 \%)$ & 0 \\
\hline Total & $\mathbf{1 3 5}(\mathbf{7 4} \%)$ & $\mathbf{4 8}(\mathbf{2 6} \%)$ & $\mathbf{1 8 3}$ \\
\hline
\end{tabular}


Table 49 Damage status of residential structures by mean slope $(5 \mathrm{~m}((16.4 \mathrm{ft}))$ radar derived) within $91.4 \mathrm{~m} \mathrm{(300} \mathrm{ft)} \mathrm{around} \mathrm{the} \mathrm{structure.}$

\begin{tabular}{|l|c|c|c|}
\hline & No Damage & Damaged/ Destroyed & Total \\
\hline $0 \%-2.5 \%$ & $47(84 \%)$ & $9(16 \%)$ & 56 \\
\hline $2.5 \%-5 \%$ & $62(65 \%)$ & $33(35 \%)$ & 95 \\
\hline $5 \%-7.5 \%$ & $23(79 \%)$ & $6(21 \%)$ & 29 \\
\hline $7.5 \%-10 \%$ & $3(100 \%)$ & $0(0 \%)$ & 3 \\
\hline $10 \%-15 \%$ & $0(0 \%)$ & $0(0 \%)$ & 0 \\
\hline Total & $\mathbf{1 3 5}(\mathbf{7 4} \%)$ & $\mathbf{4 8}(\mathbf{2 6} \%)$ & $\mathbf{1 8 3}$ \\
\hline
\end{tabular}

\section{Data Discussion}

Understanding exposure, together with pre-fire information and defensive actions, are all essential in reconstructing the environment that affected buildings and detached combustibles in the WUI.

Exposure quantification, however, in the post fire environment is difficult without in-situ instrumentation during the fire ${ }^{19}$. There is, however, a significant amount of exposure qualification that can be accomplished by collecting field data, discussions with first responders, and video and still imagery. This exposure information can then be used to understand and interpret ignition response, defensive actions and overall fire behavior. Additional exposure characterization information can be found in Section 14.7

For the entire incident, the data in this Appendix represents individual attributes for which data was available for both destroyed and non-destroyed structures. The information presented in this Appendix does not factor in exposure and defensive actions as was recommended in Section 1. This is the result of limited exposure information and incomplete defensive action data. While the following analysis has limitation in terms of both exposure and defensive actions, there is however value, in looking at all the exposed population, not only the structures that were damaged or destroyed.

Field data collectors were instructed to assess properties where there was fire behavior within $30 \mathrm{~m}(100 \mathrm{ft})$ of the primary structure. Due to fire behavior information decaying with time, field data collectors did not always assess continuous properties and topographic conditions obscuring fire damaged or destroyed features. Consequently, the second field visit included additional properties on the edge of the fire, which might have been within $30 \mathrm{~m}(100 \mathrm{ft})$ of the fire, to ensure all possibly appropriate properties were assessed. Additionally, exposure conditions were observed to have varied greatly and one home that had fire behavior $15 \mathrm{~m}(50 \mathrm{ft}) \mathrm{up}$ wind from fire might have less exposure compared to another home $30 \mathrm{~m}$ (100 ft) downwind of fire behavior. Conversely, a home

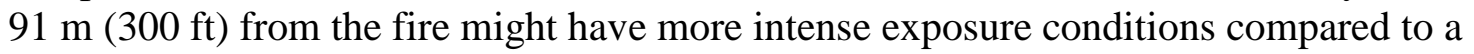
home $15 \mathrm{~m}$ (50 ft) away depending on wind, fuel and topographic conditions.

The above two factors, coupled with a low sample population, result in it being inappropriate to use the data as presented below to assess structure response. This is clearly illustrated in Table 38 portraying structure response by roof type. A statistical analysis using Fisher's Exact test of the data in Table F3 determined that there is a

${ }^{19}$ WUI mitigation effectiveness can reliably be assessed by utilizing in-situ instrumentation during wildfires or from control large scale experiments (prescribed burns). 
somewhat significant difference ( $\mathrm{p}$-value of 0.055 ) between the different types of roofing (metal versus asphalt or wood) when looking at the damaged/destroyed versus the notdamaged structures. Table 38 data show that metal roofs have a higher percentage of destroyed homes compared to other categories, with only one home not being determined. This, however, is accounted for by the fact that eight of these homes were mobile homes, where metal roofs are a common roof type. Other homes with metal roofs were in areas where fire spread might have been structure to structure fire spread. Some homes with metal roof had damage to other structural elements (e.g. eaves and broken windows).

The data presented above is presented as a first exploratory look at the data from which to subdivide into more appropriate populations for appropriate analysis of exposure and vulnerabilities using the data presented in this report, coupled with electronic spatial and tabular databases produced as part of this effort. The greatest hindrance from further assessment of the data would be lack of a good timeline for areas burned in the Palisades Communities and an inevitable low sample size. 
Appendix G Recommendations for Improvements to WUI 2 Data Collection System 
The WUI 2 Data Collection System implemented at the Tanglewood Fire collected a large amount of information that could not be used for analysis because consistent information did not exist for all homes (i.e., unless the building material was present in the tax assessor data) or because there was confusion in interpretation of attributes. Consequently, the overall data collection should be streamlined as follows:

1. Collection of structural information should be very limited, focusing on location of features, recording of damage condition and extensive photographic information.

2. Based on pre-fire building information available, it is recommended that accuracy assessments be conducted on sub-populations of homes not destroyed to confirm the validity of the data.

3. Topographic information should be obtained from high-resolution surveying or remote data sources. The required resolution is unknown and might be incident dependent. Nonetheless, some simple studies using information from the study of the Trails at Rancho Bernardo ${ }^{9,12}$ community might provide some insight into the impact of topographic resolution on the interpretation of fire behavior.

4. Post-fire WUI assessments require timely post-fire aerial imagery. Without high resolution post-fire imagery (e.g. less than $0.3 \mathrm{~m}((1 \mathrm{ft}))$ spatial resolution; further quantification is required) post-fire WUI assessments should not be conducted, as critical information on fire behavior and fuel consumption will not be available to provide context for the event reconstruction.

5. A plot based system should be developed for collection of post-fire vegetation information in the wildlands adjacent to the WUI. The post-fire imagery, along with pre-fire imagery, can be used to group the populations into subsets for appropriate sampling.

6. Collection of post-fire vegetation information in residential areas should be greatly simplified with a large emphasis on imaging of features. The onscreen digitizing of burned vegetation using pre-fire imagery did not result in a directly usable dataset in part due to varying skills in digitization as seen in Figure 74. In addition to varying degrees of digitizing expertise amongst data collectors, even an experienced digitizer often had errors such as flipping the orientation of burned vegetation, as shown in the figure below. The use of post-fire imagery as a base layer will aid in producing a more directly usable data set. However, being that data collectors are unlikely to be Geospatial professionals, it should be expected that the field data set will still require extensive post-processing.

7. Pre-fire information must also exist regarding vegetation. This requires, again, remote sensing data of adequate spatial, temporal and spectral resolution (i.e., less than $0.3 \mathrm{~m}(1 \mathrm{ft})$ horizontal resolution, acquired less than two years before incident, and having four bands of data including information in the nearinfrared).

8. Even the above information might not be enough for adequate characterization of the fire disturbance continuum without adequate ground images, particularly residential vegetation.

9. WUI communities should be encouraged to use an appropriate plot based sampling technique for recording information about adjacent wildlands in prefire conditions, the same way parcels are documented within the community. 


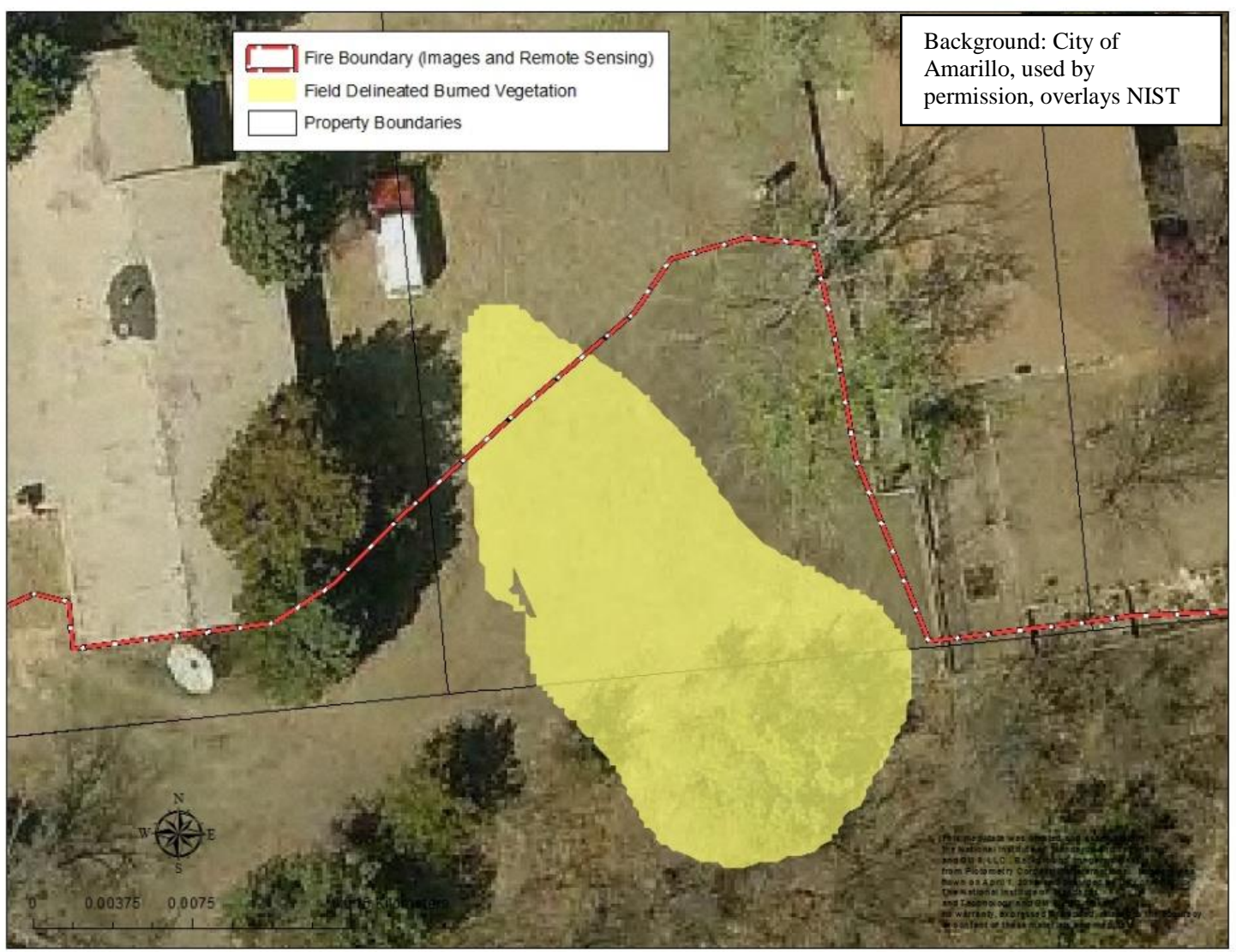

Figure 74 Erroneous field collected burn vegetation boundary

10. The focus of post-fire assessments should be on timely acquisition of burned vegetation data. The WUI 2 deployment at the Tanglewood Fire focused on documenting building material on destroyed homes first, so as not to lose information during building cleanup. However, very little information was able to be discerned about destroyed buildings. Additionally, this focus resulted in loss of information regarding burned vegetation on properties with nondestroyed structures but containing burned vegetation. The focus of WUI 2 postfire assessments, initially, should be on collection of burned vegetation information across the study area along with fire direction indicators.

11. Local authorities having jurisdiction (AHJ) should be the entities that conduct preliminary damage assessments because of their familiarity with the local environment. A new WUI 1 form should be developed that focuses on damage assessment only. Other simple assessments of building characteristics and vegetation require more in-depth study, as described above. This simple damage assessment can be incorporated into the WUI 2 assessments for efficiency.

12. All features collected should have extensive image documentation because, without documented images, quality assurance and quality control processes will be significantly hampered. However, images should be taken with efficiency in mind. The respective site should be photographed with the minimum number of images possible to capture the entire scene. Technologies such as Photosyth ${ }^{\mathrm{TM}}$ 
allow for simple creation of a 3D panoramic image. If logistics allow, these can simply be posted to Bing Maps or other such sites to facilitate detailed ground imaging of the entire scene.

13. Standard images should always be associated with the specific feature.

14. Post-fire assessments require adequate determination of the fire timeline. First responder discussions alone do not suffice to determine burn times of features. As described above, images and GPS locations are required to adequately recreate the fire timeline. 


\section{Appendix H Example of Pre-Fire WUI Mitigation Advice Form}

Implemented in Areas Affected by the Tanglewood Fire 
The field form in this Appendix is from a pre-fire assessment of the Tanglewood Fire area, which occurred on some unknown date prior to the Tanglewood Fire. The data was incomplete, not in electronic format, nor complete for the entire community, and could not be used in this assessment.

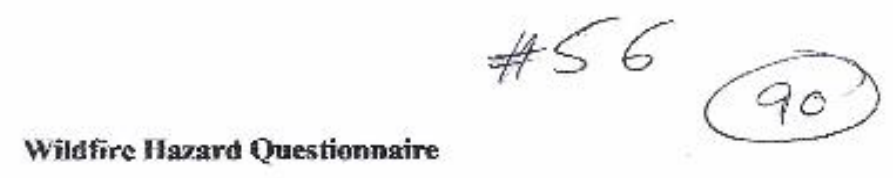

Field Surveyor's Nanie: Date of Surpey:

Subdivision Name: Subdivisiou Lot f: Strect Address: $330 C_{\text {an }}$ you Cued Structure Size Sq Ft:

Fire Protection District:

Latitude (decimal degrecs):

Photo Numbers:

L.ongitude (Jecinal degrees):

Dise Number:

Was survey completed ON or OFF site:

ROADS AND ACCESS:

1. Main Road Access for Eamergency Wildland Fire Apparatus:

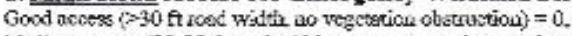

Methum necses (20-30 ft reed width, sparse vegetaticrn everbong) - 1 ,

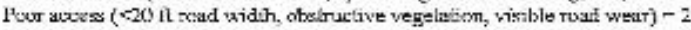

2. Secoudary Road to dhe Drivesury:

2 or more piimary wods $=0$.

i prisasty rin:e plus as nltecronte $=1$

1 Way an istel waik -2

3. Road width to the Driveras (hinelusive of vegetation clearance):

Geot 2-ARy rond grestis than $24 \mathrm{ft}$ wide $=0$

Nanuw 2-way issil hetweens $2 \pi-24 \pi$ wibe -

l-ray rood leas desin 20 if witle $=3$

4. Maximum Grale of lae Prituary Route to fle Driveway:

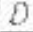

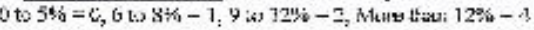

5. Read able Street Name

Ninked $-A$ ND - underatondable $=0$

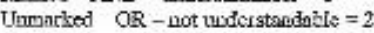

6. Visibie Identilication from the Road:

Nome $-A N D-$ rumber resdible $=0$

Nome - OR - sumbar readssle = I

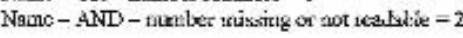

7. Drivenay Accessibilicy for lire squaratuz:

Gocd: 20 ft wide, no vegetstion olstruction, paved $=0$

Mrodiun: $11-19$ f. wide, some wcgetation obstruction, solid surface = 1

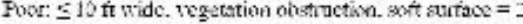


RHSPONSE AND WATER:

8. Fire Bepartment Resnonse Time:

Within 15 minules $-a$, Widiut 16 to 30 airndos -2

Moce thal 30 minutes $=1$, No organizcd $\mathrm{FD}=5$

9. Distance to closest Water IIVdrant:

Unable to deternine -2

Les:s thor 1000 teet - I

sare thor: 1000 feet $=2$

Flush valie (how towi-3

No hyidramis witrin 1 nuile $=4$

10. Distance to elasest Graft Source (ISU0 gallonx + ):

I hable los clelemernitie -2

On-3ite in easy access - 1

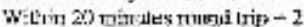

Wilhin /s nimites rourd trip -3

Nore thes 45 minutes scund trip $=4$

UTILITIKS:

11. Electaicity for the Subdivision:

All inderenuind -1 )

Abowe \& Beiow ground =

All Abow groond $=3$

12. Electricity to the Resifferse

All Ladergisiand $=0$

Above \& Beiow grouid =

Al Above grouma - 2

13. Prapane Cisa Location:

No propearc $=0$

Downinill for tocuse =

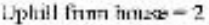

Les3 than soudalite to beterasine $=3$

DISTANCFS ANI FUELS:

14. Disfance to the closest Structure (oubbuilding, barns, etc): Mosc thas 2 Co feet $=0$

60 to 200 foct $=1$

$30 \mathrm{lc} \epsilon \mathrm{fect}^{2}=2$

less thing 30 ceet -3

15. Distance to closest Wildiand Fnets:

More thar 300 foct $=1$

100 to 300 fcot $=2$

30 to 1005000

lase ftam io fost $=4$
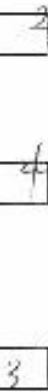
16. Fucl of predominant veretalian ON LOT:

No fuct $=0 \quad$ Evergrocd/prass =

Short eress $=1$

TnIl gross -2

Coust grass -4

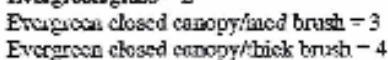

igint brust: $=2$

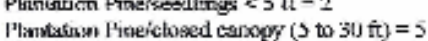

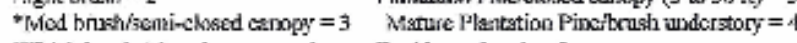

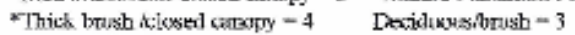

Decjidnoms /light brush or grass - 2

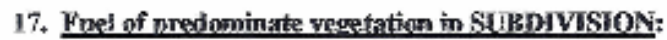

No fuel -0

Shor prose = I

Tall praiss -2 .

Cotikl itriss $n 4$

The imest. -2

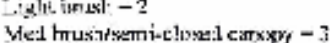

Thick bari intosel amove -4

Jecidusus s'ight brikh or smass - 2

\author{
Evergrown'gms - 2

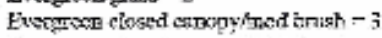

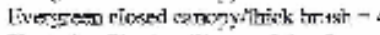

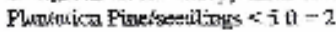

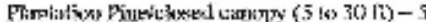

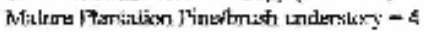

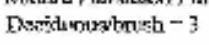

18. Combustible 3raterials:

Non sterod w site $=0$

Afore than 30 feet from bome $=0$

tess iham .70 lieet firm bome - ?

Under or aysinst the hasma -2

19. Burn Barrel:

No bum borrel co site $=0$

[jphill inm sr ievel wilh bore - I

Dowathill fiosu houm -2

\title{
TOPOGRAPHY
}

20. Predeminant Slane of the lat:

Less them $10 \%-1$

10 to $50 \%=2$

$31 \mathrm{tr} 45 \%=3$

Mure 11 sin $4.9 \%=4$

21. Predunnimunt Asypect af the Enat:

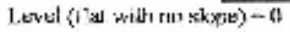

$\mathrm{NW}$ ks Nis (X)rth) - 1

NE to $S$ (East) $=2$

$\mathrm{SE}$ to $\mathrm{SW}$ (South) $=\hat{\mathrm{s}}$

SW to NW (Norh) $=4$

22. Distance of Home to Steep Slope:

More than 300 foct $=0$

100 to 300 feer $=1$

30 to 100 fext $=2$

Lcss than 30 foct $=3$

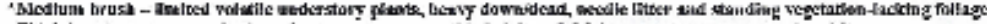

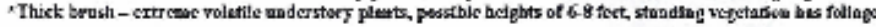


23. Bigtance to Natural Dangerves Feglure (canyens, chimineys, etc):

More tran 3 tho feet $=0$ )

IOO to $300 \mathrm{fcet}=1$

30 to 100 feet $=2$

Less them 30 ties -3

HOME:

24. Defensible Snace around the Fome:

Niore ther 200 fent -0

$100 \mathrm{\pi} 20 \mathrm{Coct}=1$

60 to 100 foct $=2$

30 to 60 feet -3

I exs Alars 3 [ [et, -4

25. Mfamfactored Howsing:

Nor 2 mirt

Skinity irsl widjtionil ncar - i

Skirting ONL Y $=2$

Nod Sirtet - 3

26. Vegetation Near or On the Roof:

More ther 15 foct frow roof $=0$

Less there 15 feex from roof = !

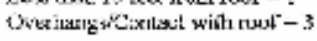

27. Vegetation near Chimaney:

Mure thum 15 fies from. cbimney CR No chimney -0

Less them 10 Sees fism chirm:ney -1

Contact with chimenc: $=3$

23. Ronting Naterist:

I Trahle is detemnite - I

Tile $=0$

Meral - 1

Cocmositaj Asplys: $=2$

Any lewit winh Deluis $=3$

Stable shingers $=4$

29. Siding Materigl (elosest to wildhand fucls):

Unable ks deicermiato - 1

Fill logs $=1$

Mascryyitricks -n

Fibengs sisocod abxat $=2$

Composinsinstalltike $=1$

Shuxe shinglesioesler -4

Wood of rolsin planting $=3$

30. Window type and Materisl:

Unable kı deienniata - 1

Therzial jarne $=2$

Temnete: plass pame - 1

Single gliss tarte $=7$ ivouhie pliss junte-2.

31. Bsicuny and Decha:

No huktuny ir tes:k -6

Enclncei rmiexpenth $=1$

Open nndersenth $=2$

32. Eaves and Overhanns:

Unable ks Leiemnizle - 1

finclskes imderten:ih h

No envestonerbnogs $=0$

Optes umitmmesth - ? 


\subsection{References}

${ }^{1}$ Jain, TB (2004) Confused Meaning for Common Fire Terminology Can Lead to Fuels Mismanagement. A New Framework is Needed to Clarify and Communicate the Concepts. Wildfire. July/August, 2004. http://leopold.wilderness.net/pubs/526.pdf

${ }^{2}$ Stein SM, Comas SJ, Menakis JP, Carr MA, Stewart SI, Cleveland H, Bramwell L, Radeloff VC (2013) Wildfire, Wildlands, and People: understanding and Preparing for Wildfire in the Wildland-Urban Interface. United States Department of Agriculture. Forest Service. Rocky Mountain Research Center, GTR RMRS-GTR-299. January, 2013.

${ }^{3}$ Jones J, Saginor A, Smith B (2012) 2011 Texas Wildfires Common Denominators of Home Destruction. Texas A\&M Forest Service. Accessed August 25, 2014. http://tfsweb.tamu.edu/uploadedFiles/FRP/New __Mitigation/Safety_Tips/2011\%20Texas\%20Wildfires.pdf

${ }^{4}$ Werth PA, Potter BE, Clements CB, Finney MA, Goodrick SL, Alexander ME, Cruz MG, Forthofer JA, McAllister SS (2011) Synthesis of Knowledge of Extreme Fire Behavior: Volume 1 for Fire Managers. United States Department of Agriculture. Forest Service. Pacific Northwest Research Station. General Technical Report PNWGTR-854. November, 2011.

${ }^{5}$ Maranghides A, Mell W (2012) Framework for Addressing the National WildlandUrban Interface Fire Problem - Determining Fire and Ember Exposure Zones Using a WUI Hazard Scale. NIST Technical Note 1748. Gaithersburg, MD: National Institute of Standards and Technology.

${ }^{6}$ Quarles S, Leschak P, Cowger R, Worley K, Brown R, Iskowitz C (2013) Lessons Learned from Waldo Canyon: Fire Adapted Communities Mitigation Assessment Team Findings. Insurance Institute for Business and Home Safety.

${ }^{7}$ Cohen JD, Stratton RD (2008) Home Destruction Examination Grass Valley Fire, Lake Arrowhead, CA. United States Department of Agriculture. R5-TP-026b. June 2008.

${ }^{8}$ Ridenour K, Rissel S, Powell W, Gray R, Fisher M, Sommerfeld J (2012) Bastrop Complex Wildfire Case Study: The Most Destructive Wildland Urban Interface Wildfire in Texas History. September 4, 2011. Texas Forest Service. 
${ }^{9}$ Maranghides A, McNamara D, Mell WE, Trook J, Toman B (2013) A Case Study of a Community Affected by the Witch and Guejito Fires: Report \#2: Evaluating the Effects of Hazard Mitigation Actions on Structure Ignitions. NIST Technical Note 1796. Gaithersburg, MD: National Institute of Standards and Technology. 99p.

${ }^{10}$ National Fire Protection Association, NFPA 1144: Standard for Reducing Structure Ignition Hazards from Wildland Fire, http://www.nfpa.org/codes-and$\underline{\text { standards/document-information-pages? } \operatorname{mode}=\operatorname{code} \& \operatorname{code}=1144}$

${ }^{11}$ Maranghides A, Mell W, Ridenour K, McNamara D (2011) Initial Reconnaissance of the 2011 Wildland-Urban Interface Fires in Amarillo, Texas, NIST Technical Note 1708. Gaithersburg, MD: National Institute of Standards and Technology.

${ }^{12}$ Maranghides A, Mell W (2009) A Case Study of a Community Affected by the Witch and Guejito Fires. NIST Technical Note 1635. Gaithersburg, MD: National Institute of Standards and Technology.

${ }^{13}$ Potter-Randall Appraisal District 2012 Parcel Information. http://www.prad.org/CamaDisplay.aspx? OutputMode=Input\&searchType=RealEstate\&p age $=$ FindByAddress Accessed 2012.

${ }^{14}$ Foote E, Liu J, Manzello SL (2011) Characterizing Firebrand Exposure During Wildland-Urban Interface Fires. Proceedings of the $12^{\text {th }}$ International Conference on Fire and Materials. San Francisco, February 1, 2011.

${ }^{15}$ Miller WR (2012) Introducing Geodesign: The Concept. Environmental Systems Research Institute. Accessed 7/31/2014. http://www.esri.com/library/whitepapers/pdfs/introducing-geodesign.pdf

${ }^{16}$ Alexander, M.E.; Stocks, B.J.; Wotton, B.M.; Flannigan, M.D.; Todd, J.B.; Butler, B.W.; Lanoville, R.A. 1998. The international crown fire modelling experiment: an overview and progress report. In: Proceedings of the second symposium on fire and forest meteorology; 1998 January 12-14; Phoenix, AZ. Boston, MA: American Meteorological Society; 20-23.

${ }^{17}$ Clark K.L., Skowronski, N., Hom J., Duveneck M., Pan Y., Tuyl S.V., Cole J., Patterson M. and Maurer S., Decision support tools to improve the effectiveness of hazardous fuel reduction treatments in the New Jersey Pine Barrens, International Journal of Wildland Fire 2009, 18, 268-277 
${ }^{18}$ A Technical Research Burn Conducted to Develop Field Methodologies for Wildfire Behavior Data Collection, Alexander Maranghides, Karen Jackson, William Mell, Bob Vihnanek, Bret Butler, Fletcher Miller, Rich Gray, Mike Hennig, Derek McNamara, Gene Robinson, NIST Technical Note, in preparation, 2015.

${ }^{19}$ Manzello S, Park SH, Cleary T, Development of rapidly deployable instrumentation packages for data acquisition in wildland-urban interface (WUI) fires, Fire Safety Journal, July 10, 2010.

${ }^{20}$ Joint Fire Science Program (2014) Open Funding Opportunity Notices. http://www.firescience.gov/JFSP_funding_announcements.cfm Accessed 10/25/2014.

${ }^{21}$ Miller, Fletcher, San Diego State University, Research Foundation, Measurements and Modeling of Wind Effects on Wildland Urban Interface Fires, NIST Fire Grant, Fiscal Year 2012. Ongoing Fire Grant - Report in Progress, 2015.

${ }^{22}$ http://www.fs.fed.us/pnw/fera/wfds/index.shtml

${ }^{23} \mathrm{http} / / /$ code.google.com/p/fds-smv/ 